COO-2250-5

MITNE-157

\title{
EVALUATION OF THE PARFAIT BLANKET CONCEPT FOR FAST BREEDER REACTORS
}

\author{
by \\ G. A. Ducat, M. J. Driscoll and N. E. Todreas \\ January 1974
}

Massachusetts Institute of Technology

Department of Nuclear Engineering

Cambridge, Massachusetts 02139

AEC Research and Development Report

UC-34 Physics

Contract AT(11-1)-2250

U.S. Atomic Energy Commission 


\section{DISCLAIMER}

This report was prepared as an account of work sponsored by an agency of the United States Government. Neither the United States Government nor any agency Thereof, nor any of their employees, makes any warranty, express or implied, or assumes any legal liability or responsibility for the accuracy, completeness, or usefulness of any information, apparatus, product, or process disclosed, or represents that its use would not infringe privately owned rights. Reference herein to any specific commercial product, process, or service by trade name, trademark, manufacturer, or otherwise does not necessarily constitute or imply its endorsement, recommendation, or favoring by the United States Government or any agency thereof. The views and opinions of authors expressed herein do not necessarily state or reflect those of the United States Government or any agency thereof. 


\section{DISCLAIMER}

Portions of this document may be illegible in electronic image products. Images are produced from the best available original document. 


\section{MASSACHUSETTS INSTITUTE OF TECHNOLOGY \\ DEPARTMENT OF NUCLEAR ENGINEERING \\ Cambridge, Massachusetts}

\section{EVALUATION OF THE PARFAIT BLANKET CONCEPT FOR FAST BREEDER REACTORS}

by

G.A. Ducat, M.J. Driscoll and N.E. Todreas

January, 1974

COO-22 50-5

MITNE-157

AEC Research and Development Report UC-34 Physics

Contract AT (11-1)-2250

U.S. Atomic Energy Commission

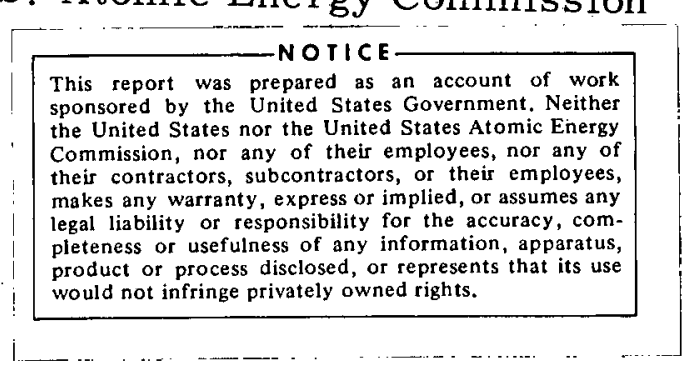


DISTRIBUTION

$$
\text { COO-2250-5 MITNE-157 }
$$

AEC Research and Development Contract

$$
\text { A T }(11-1)-2250
$$

UC-34 Physics

1-3. U.S. Atomic Energy Commission, Headquarters Division of Reactor Development and Technology Reactor Physics Branch

4,5. U.S. Atomic Energy Commission Cambridge Office

6. Dr. Paul Greebler, Manager

Nuclear Energy Division Breeder Reactor Department General Electric Company 310 DeGuigne Drive Sunnyvale, California 94086

7. Dr. Harry Morewitz, Manager

LMFBR Physics and Safety Projects Atomics International P.O. Box 309

Canoga Park, California 91305

8. Mr. Malcolm Dyos, Manager Nuclear Development, LMFBR Project Westinghouse Electric Corporation Advanced Reactors Division Waltz Mill Site P.O. Box 158 Madison, Pennsylvania 15663

9. Dr. Robert Avery, Director Reactor Physics Division Argonne National Laboratory 9700 South Cass Avenue Argonne, Illinois 60439

10. Dr. Charles A. Preskitt, Jr., Manager Atomic and Nuclear Department Gulf Radiation Technology P.O. Box 608 San Diego, California 92112 


\begin{abstract}
An evaluation of the neutronic, thermal-hydraulic, mechanical and economic characteristics of fast breeder reactor configurations containing an internal blanket has been performed. This design, called the parfait blanket concept, employs a layer of axial blanket fuel pellets at the core midplane in the fuel pins of the inner enrichment zone; otherwise, the design is the same as that of the conventional LMFBR's to which the parfait configuration was compared.

Two significant advantages were identified for the parfait blanket concept relative to the conventional design. First, the parfait configuration has a $25 \%$ smaller peak fast flux which reduces wrapper tube dilation by $37 \%$ and fuel element elongation by $29 \%$; and second, axial and radial flux flattening contribute to a $7.6 \%$ reduction in the peak fuel burnup. Both characteristics significantly diminish the problems of fuel and metal swelling.

Other advantages identified for a typical parfait design include: a $25 \%$ reduction in the burnup reactivity swing, which reduces control rod requirements; a $7 \%$ greater overpower operating margin; an increased breeding ratio, which offsets the disadvantage of a higher critical mass; and more favorable sodium voiding characteristics which counteract the disadvantage of an $8 \%$ smaller power Doppler coefficient. All other characteristics investigated were found to differ insignificantly or slightly favor the parfait design.
\end{abstract}




\section{ACKNOWLEDGMENTS}

The work described in this report was performed primarily by the principal author, G. A. Ducat, who has submitted substantially the same report in partial fulfillment of the requirements for the degree of Doctor of Philosophy at M.I.T.

Financial support from the U.S. Atomic Energy Commission under Contract AT (11-1)-2250 is gratefully acknowledged. The authors would also like to acknowledge the interest and assistance provided by Professor Arden L. Bement of M.I.T.

Computer calculations for this work were performed at the Laboratory of Nuclear Science and at the M.I. T. Information Process.ing Center. V.A. Miethe supplied assistance in communicating with the computers and Mrs. Mary Bosco very ably handled the typing of this manuscript. 
T:ABLE OF CONTENTS

Page:

Abstract

Acknowledgments

3

Table of Contents

List of Figures

List of Tables:

Chapter. 1. Introduction

$\begin{array}{lll}1.1 & \text { Foreword } & 18\end{array}$

$\begin{array}{lll}1.2 & \text { Previous Internal Blanket Studies } & 19\end{array}$

1.3. Objectives and Scope of this Work 23

1. 3. 1 Problem Statement: 23

1.3.2 Anticipated Design Advantages:
and Disadvantages:

1.3.3 Method of Evaluation: 25

1.. 3.4 Assumptions: and Constraints: 28

1:. 4: Reference Core Configuration $\quad 30$

1.. 5 Organization of the: Report: 32

Chapter: 2. Neutronics: $\quad \therefore \quad 36$

2. 1 Introduction $\quad: \quad 36$

2.2 Design Variable Considerations $\quad 38$

2.2 .1 Internal Blanket Thickness: $\quad 4.0$

2..2.2. Radial Extent: of the Internal Blanket 48

2.2.3 Internal: Blanket Enrichment 49

2.2.4 Flux and Power Profiles: $\quad 60$ 
Page

2. 3 Core Fuel Volume Fraction $\quad: \quad 61$

$\begin{array}{lll}2.4 \text { Reactivity Control Requirements } & 78\end{array}$

2.4.1 Burnup Reactivity Loss 78

2.4.2 Control Material Worth 79

2.4.3 Differential and Integral Control
Rod Worths

2.4.4 Effect of Control Rods on the Power
Profile

2.5 Alternate Core Configurations 99

$\begin{array}{ll}2.6 \text { Conclusions } & 101\end{array}$

Chapter 3. Core Engineering $\quad \because \quad 102$

3.1 Introduction $\quad \ldots 102$

$\begin{array}{lll}3.2 & \text { Thermal Analysis } & 103\end{array}$

3.2.1 Mixed-Mean Coolant Outlet Temperature 103

3.2.2 Material Temperature Profiles $\quad \cdots \quad 108$

3.2.3 Nominal Operating Margins … $\quad 115$

3.3 Material Considerations 119

3.3.1 Fuel Swelling $\quad 120$

3.3.2 Swelling in Type-316 Stainless Steel 122

3.4 Mechanical Design $\quad \cdots \quad 128$

3.4.1 Wrapper Tube Dilation $\quad 128$

3.4.2 Fuel Element Elongation 130

3.4.3 Axial Gradients $\quad 132$

3.5 Conclusions $\quad 136$ 
Page

$\begin{array}{ll}\text { Chapter 4. Safety Considerations } & 139\end{array}$

$\begin{array}{lll}4.1 & \text { Introduction } & 139\end{array}$

4.2 Delayed Neutron Fraction and Prompt Neutron Lifetime

4. 3 Sodium Density Reactivity Effects 141

4.3.1 Regionwise Sodium Void Reactivity 142

4. 3.2. Partial Sodium Density Reduction 151

4. 4 Doppler Coefficients 152

4.4.1 Isothermal Doppler Coefficient $\quad 154$

4.4.2 Power Coefficient of Reactivity 154

4. 5 Net Reactivity Effects from Startup to Full Power Operation

158

4.6 Fuel Movement Within the Reactor 160

4.7. Conclusions 164

Chapter 5. Feasibility and Economics $\quad 165$

5.1 Introduction $\quad 165$

5.2 Feasibility $\quad 165$

5.2.1 Fabrication $\quad 165$

5.2.2 Quality Assurance 171

5.2.3 Fuel Management Patterns 173

5.2 .4 Reprocessing $\quad 174$

5.3 Economics $\quad 175$

5.3.1 Definition of the Economic Environment $\quad 175$

5. 3.2 Equilibrium Fuel Cycle $\quad 175$

5. 3. 3 Physics of the Equilibrium Fuel Cycle 179 
Page

5.3.4 Fuel Cycle Cost Evaluation 184

5. 3.5 Case Studies $\quad 188$

5.4 Conclusions 203

Chapter 6. Summary and Conclusions $\quad 205$

6.1 Introduction 205

6.2 Neutronics 209

6.3 Core Engineering $\quad 221$

6. 4 Safety Considerations $\quad 227$

6.5 Feasibility and Economics 229

6.6 Conclusions and Recommendations 233

Appendix A. Cross Sections and Codes 236

A. 1 Cross Section Sets and Group Collapses . 236

A. 1.1 Cross Section Collapse to Four Groups : $\quad 236$

A. 1.2 FTR-200 Cross Section Set $\quad 236$

A. 2 Methods' Support and Verification $\quad 239$

$\begin{array}{ll}\text { A.2.1 Transport. Theory vs. Diffusion Theory } & \\ \text { Four Group Flux Predictions } & 239\end{array}$

A.2.2 Comparison and Critical Experiments $\quad 242$

A.2.3 One, Two and Four Group Burnup
Comparisons

A.2.4 Comparison of Twenty-Six Group and
Four Group Predictions

Appendix B. Other Parfait Blanket Configurations $\quad 250$

B. 1 Gas-Cooled Parfait Configuration 250

B. 2 Demonstration Plant LMFBR Parfait
Configuration 
Page

B. 3 Split-Parfait Blanket Configuration

253

B. 4 Carbide-Fueled Parfait Configuration

255

Appendix C. References

261 


\section{LIST OF FIGURES}

Fig. No.

$\underline{\text { Page }}$

1. 1 Four Early 1000-MWe LMFBR Core Configurations 20

1.2 The Parfait Blanket Concept 24

1. 3 Reference and Parfait Core Configurations _ 33

2. 1 Core Configurations for Evaluating the Effects of Internal Blanket Thickness

2.2 Parfait Performance Relative to the Reference Core as a Function of Internal Blanket Thickness

2. 3 Internal Blanket Conversion Efficiency as a Function of Internal Blanket Thickness

2.4 Radial Power Profiles in Two Parfait Systems Having a Single Core Fissile Enrichment

2.5 Fissile Plutonium Buildup in a $30-\mathrm{cm}$ Internal Blanket

2.6 Internal Blanket Zone Designations for Evaluating the Spatial Distribution of Plutonium Production

2. 7 Uranium-238 Capture Cross Section

2.8 Percent of Total System Power Generated in a $30-\mathrm{cm}$ Internal Blanket

2.9 Sources of Power in a 30- $\mathrm{cm}$ Internal Blanket

2.10 Total Flux Along Core Centerline for Reference Core and $30-\mathrm{cm}$ IB Parfait

2.11 Total Flux at Radial Position $=107.5 \mathrm{~cm}$ for Reference Core and $30-\mathrm{cm}$ IB Parfait

2.12, Group 1 Flux Along Core Centerline for Reference Core and $30-\mathrm{cm}$ IB Parfait

2.13 Group 1 Flux at Radial Position $=107.5 \mathrm{~cm}$ for

Reference Core and $30-\mathrm{cm}$ IB Parfait

2.14 Group 2 Flux Along Core Centerline for Reference Core and $30-\mathrm{cm}$ IB Parfait

2.15 Group 2 Flux at Radial Position $=107.5 \mathrm{~cm}$ for Reference Core and $30-\mathrm{cm}$ IB Parfait 
Fig. No.

$\underline{\text { Page }}$

2.16 Group 3 Flux Along Core Centerline for Reference Core and $30-\mathrm{cm}$ IB Parfait

2.17 Group 3 Flux at Radial Position $=107.5 \mathrm{~cm}$ for

Reference Core and $30-\mathrm{cm}$ IB Parfait

2.18 Group 4 Flux Along Core Centerline for Reference Core and $30-\mathrm{cm}$ IB Parfait

2.19 Group 4 Flux at Radial Position $=107.5 \mathrm{~cm}$ for Reference Core and $30-\mathrm{cm}$ IB Parfait

2.20 Total Flux at Core Midplane for Reference Core and $30-\mathrm{cm}$ IB Parfait

2.21 Total Flux at $32.24 \mathrm{~cm}$ Above Midplane for

Reference Core and $30-\mathrm{cm}$ IB Parfait

2.22 Power Density Along Core Centerline for Reference Core and $30-\mathrm{cm}$ IB Parfait

2.23 Power Density at Radial Position $=107.5 \mathrm{~cm}$ for Reference Core and 30-cm IB Parfait

2.24 Performance Sensitivity to Fuel Volume Percent in Core

2.25 Core Fissile Inventory as a Function of Fuel Volume Percent in Core

2.26 Effective Reactivity Addition per Unit of Fissile Bred in a $30-\mathrm{cm}$ Internal Blanket

2.27 Discrete Control Rod Simulation

2.28 Control Rod Arrangement in Demonstration Size LMFBR Core

2.29 Reference Core Differential Control Rod Worth Curve

2. 30 Parfait Core (30-cm IB) Differential Control Rod Worth Curve.

2.31 Reference Core Normalized $\phi \phi^{*}$

2.32 Parfait Core (30-cm IB) Normalized $\phi \phi^{\text {*k }}$

2.33 Reference Core Central Control Rod Integral

Worth Curve 
Fig. No.

Page

2. 34 Parfait Core (30-cm IB) Cèntral Control Rod Integral Worth Curve.

2. 35 Control Curtain Configuration

2. 36 Reference Core Centerline Flux as a Function of Control Curtain Insertion

2.37 Reference Core Total Flux at Radial Position = $117.5 \mathrm{~cm}$ as a Function of Control Curtain Insertion

2. 38 Parfait Core Centerline Total Flux as a Function of Control Curtain Insertion

2. 39 Parfait Core Total Flux at Radial Position $=117.5 \mathrm{~cm}$ as a Function of Control Curtain Insertion

2.40 Flux Profile Surrounding a Control Rod in a Sea of Fue1

3.1 Reference Core Axially Integrated Power per Unit Core Cross Sectional Area

3.2 Parfait Configuration Axially Integrated Power per Unit Core Cross Sectional Area

3. 3 Center Assembly Coolant Temperature Profile

3.4 Center Assembly Clad Outer Surface Temperature Profile

3. 5 Center Assembly Clad Inner Surface Temperature Profile

3.6 Center Assembly Fuel Outer Surface Temperature Profile

3. 7 Center Assembly Fuel Centerline Temperature Profile

3.8 Procedure for Calculating Overpower Operating Margin 116

3.9 Results of Operating Margin Analysis

3.10 OLYMPUS-II Code Fuel Swelling Model

3.11 Empirically Determined Factor to Adjust Burnup Dependence of OLYMPUS-II Fuel Swelling Model 
Fig. No.

$\underline{\text { Page }}$

3. 12 Swelling of $20 \%$ Cold-Worked Type-316 Stainless Steel

124

3.13 EOC Elongation of Wrapper Tube Walls Due to Swelling

125

3.14 EOC Dilation of Wrapper Tubes Due to Swelling

125

3.15 Fast Neutron Fluence, Required Test Time and Program Objectives

3.16 EOC Wrapper Tube Dilation Due to Swelling

3.17. EOC Wrapper Tube Elongation Due to Swelling

3.18 Axial Temperature Profile Along Fuel Centerline at the Power Discontinuity Interface

3.19 Axial Temperature Profile at Fuel Outer Surface at the Power Discontinuity Interface

3.20 Axial Temperature Profile in the Clad at the Power Discontinuity Interface

4. 1 Sodium Density as a Function of Temperature

4.2 Definition of the Reactor Regions Used in the Sodium Void Analysis

4.3 Normalized $\phi \phi^{*}$ vs. $\mathrm{R}$ at the Core Midplane 161

4.4 Normalized $\phi \phi^{*}$ vs. $R$ at $Z=27.3 \mathrm{~cm}$ Above Midplane 162

4.5 Normalized $\phi \phi^{*}$ vs. $R$ at $Z=42.08 \mathrm{~cm}$ Above Midplane 163

5. 1 Internal Components of the Inner Core Zone Fuel Pins of the Reference and Parfait Designs

5.2 Process Flow Chart for the Fabrication of BWR Fuel 168

5.3 Gamma Scan of an FFTF Fuel Pin with Various Combinations of Plutonium Enrichment

5.4 Material and Cash Flows for an Equilibrium Fuel Cycle

5. 5 Unpoisoned System Multiplication Factor During the Equilibrium Cycle

5.6 Multiplication Factor for a System Poisoned Uniformly, with the Time-Averaged Boron Concentration of the Equilibrium Cycle 
Fig. No.

$\underline{\text { Page }}$

5. 7 Equilibrium Fuel Cycle Costs as a Function of Internal Blanket Thickness for Three Variations in Fabrication Charges

5. 8. Equilibrium Fuel Cycle Costs as a Function of Internal Blanket Thickness for an Effective Cost of Money of $8.0 \% / \mathrm{yr}$ and $9.25 \% / \mathrm{yr}$

5.9 Fuel Cycle Costs as a Function of Internal Blanket Thickness with Fabrication Charges for All Cores Normalized to the Reference Core with $30 \mathrm{v} / \mathrm{o}$ Fuel in Core

5. 10 Fuel Cycle Costs as a Function of Fuel Volume Percent with Fabrication Charges for All Cores Normalized to the Reference Core with $30 \mathrm{v} / \mathrm{o}$ Fuel in the Core

6. 1 The Parfait Blanket Concept

6.2 Core Configurations for Evaluating the Effects of Internal Blanket Thickness

6. 3 Parfait Performance Relative to the Reference Core as a Function of Internal Blanket Thickness

6.4 Total Flux. Along Core Centerline for Reference Core and $30-\mathrm{cm}$ IB Parfait

6. 5 Total Flux at Core Midplane for Reference Core and 30-cm IB Parfait

6.6 Performance Sensitivity to Fuel Volume Percent in Core

6. 7 EOC Wrapper Tube Dilation Due to Swelling

6.8 EOC Wrapper Tube Elongation Due to Swelling

6.9 Fuel Cycle Costs as a Function of Fuel Volume Percent (Fabrication Charges for All Cores Normalized to the Reference Core with $30 \mathrm{v} / \mathrm{o}$ Fuel in Core)

A. 1 26-Group Neutron Spectrum In Core

A. 2 Four-Group Neutron Spectrum In Core

A. 3 Transport Theory.vs. Diffusion Theory, Group Fluxes 1 and 2 
Fig. No.

Page

A. 4 Transport Theory vs. Diffusion Theory, Group Fluxes 3 and 4

A. 5 ZPPR-2 Critical Experiment Idealized Geometry

A. 6 One-, Two- and Four-Group Burnup Behavior, $\mathrm{k}_{\text {eff }} \mathrm{vs.} \mathrm{Time}$

A. 7 One-, Two- and Four-Group Burnup Behavior, Breeding Ratio vs. Time

B. 1 Conventional and Split-Parfait Configurations 
LIST OF TABLES

Table No.

Page

1.1 Qualitative Comparison of Core Configurations

1.2 Uncertainties in Nuclear Design Parameters

1.3 Assumptions and Constraints Imposed on the Parfait Blanket Concept for Comparison to the Reference Core

1. $4 \quad 1000-M_{e}$ LMFBR Core Characteristics

1. 5 Dimensional and Material Characteristics of the Reference and Parfait Systems

2. 1 Cross Section Group Collapse

2.2 Parfait System Performance as a Function of Internal Blanket Thickness

2.3 Parfait System Performance Relative to Reference Core as a Function of Internal Blanket Thickness

2.4 Spatial Distribution of Plutonium-239 Production in a 40-cm Internal Blanket

2.5 Mid-Equilibrium Cycle Power Fraction in Each Core Region

2.6 Comparative Worth of Identical Control Material Additions in the Reference and Parfait Cores

2. 7 Control Poison Effect on Breeding Ratio

3. 1 Time-Averaged Mixed-Mean Core Coolant Outlet Temperature

3.2 Reference and Parfait Configuration Fuel Element and Fuel Pin Characteristics

4.1 Comparison of the Effective Delayed Neutron Fraction and Prompt Neutron Lifetime

4.2 BOC Sodium Void Worth by Zone in the Reference and Parfait Reactors

4.3 EOC Sodium Void Worth in the Reference and Parfait Reactors 
Table No.

$\underline{\text { Page }}$

4. 4 BOC Sodium Void Worth With and Without Boron in the Core

4. 5 26-Group and Four-Group BOC Sodium Void Worth Predictions for the Reference and Parfait Systems

4.6 Reactivity Effect of Reducing the Reactor Sodium Density by $50 \%$

4. 7 Isothermal Doppler Coefficient Comparison

4.8 Doppler Constants for the Reference and Parfait Configurations

4.9 Power Coefficients of Reactivity

4.10 Reactivity Effects from Startup to Full Power Operation

5.1 Fuel Element Fabrication Cost Components 169

5.2 Standard Economic Environment $\quad 176$

5.3 Equilibrium Fuel Cycle Cost Contributions by Region 197

5.4 Percent of Equilibrium Fuel Cycle Cost by Item and by Region

6.1 Dimensional and Material Characteristics of the Reference and Parfait Systems

6.2 Neutron Energy Group Structure

6. 3 Parfait System Performance as a Function of Internal Blanket Thickness

6. 4 Comparison of Safety-Related Nuclear Parameters of the Reference and Parfait Configurations

6. 5 Equilibrium Fuel Cycle Cost Contributions by Region

6.6 Summary Evaluation of the 30-cm IB Parfait Blanket Configuration Relative to the Reference Reactor

A. 1 FTR Set No. 200 Energy Group Structure $\quad 239$

A. 2 ZPPR Assembly 2 (Loading 21) Region-Averaged Compositions 
Table No.

A. 3 Comparison with Critical Experiment 245

B. 1 Comparison of Gas-Cooled Reference and $30-\mathrm{cm}$ IB Parfait Configurations

B. 2 Comparison of Demonstration Plant LMFBR Reference and Parfait Configurations

B. 3 Comparison of Sodium Void Characteristics of the Conventional Parfait and the Split-Parfait Configurations

B. 4 Comparison of Uranium Carbide and Uranium Oxide

B. 5 Comparison of the Reference and Parfait Configurations Employing Carbide Fuel 


\section{Chapter 1}

\section{INTRODUCTION}

\subsection{FOREWORD}

The goal of the fast breeder reactor program, in this country and abroad, is to develop a source of low cost electric power for the future. By-products of a successful program and therefore further incentives for the development of this reactor type, include a means of protecting the investment in light water reactors against rising uranium ore costs, and a means of making efficient use of all uranium resources (E1).

The work reported here was carried out within the MIT Blanket Research Project, which is part of the AEC's Liquid Metal Cooled Fast Breeder Reactor (LMFBR) development program. The general scope of this project involves experimental and theoretical investigations of the characteristics of the blanket and reflector regions of large LMFBR's. This report describes the results of an evaluation of an advanced configuration called the parfait blanket concept. This concept retains the external axial and radial blankets of a conventional fast reactor, but also employs a disc-shaped internal blanket region inserted at the core midplane.

The consideration of internal blanket regions in fast reactor design is not a new concept, but earlier studies appear to have optimized a design for only one performance characteristic, and were carried out at a time when many of the difficult fast reactor design 
problems, such as swelling, were, as yet, not fully appreciated. Some of the previous major design efforts involving internal blankets are discussed in the following section. The remainder of this chapter is devoted to describing the scope of the present work and to outlining the guidelines for the evaluation performed. The chapter concludes with an outline of the remainder of the report.

\subsection{PREVIOUS INTERNAL BLANKET STUDIES}

The distribution of fissile and fertile material in a fast reactor core is used by reactor designers to achieve specific core characteristics. The core configurations of the 1000-MW $\mathrm{e}$ LMFBR Follow-On Studies (A1) conducted during the mid-1960's, reflect an overriding effort to minimize the positive sodium void coefficient. The reactor cores under consideration at that time, two of which include internal blanket regions, are sketched in Fig. 1.1. Each makes use of a "spoiled". geometry to increase leakage from the core. In its study, Westinghouse evaluated each of the different core configurations; and summarized its results as shown in Table 1.1 (H1).' Westinghouse selected a modular core design consisting of seven modules. In later evaluations, however, the number of modules was progressively reduced to four, then to three (S1), and finally the concept was abandoned along with all of the other configurations, except for the short cylindrical core employing zones of different plutonium enrichment to achieve radial power flattening.

The annular and modular core designs both made use of axiallyoriented, full-length internal blanket assemblies. Neutronically similar internal blankets were also considered in the study of the 


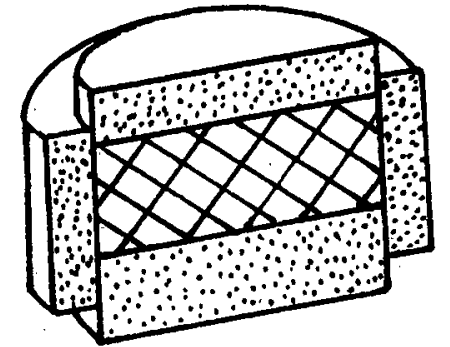

Short Cylindrical Core

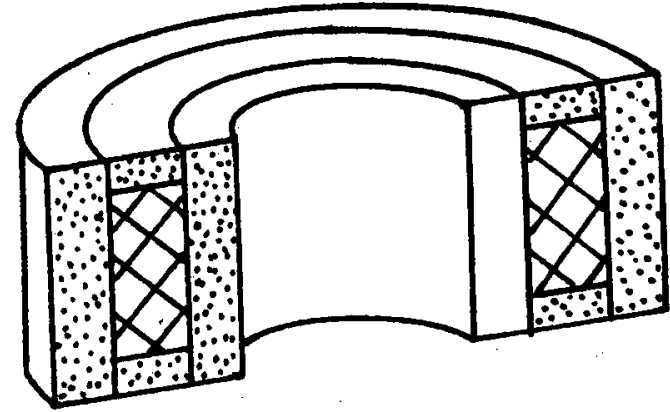

Annular Core

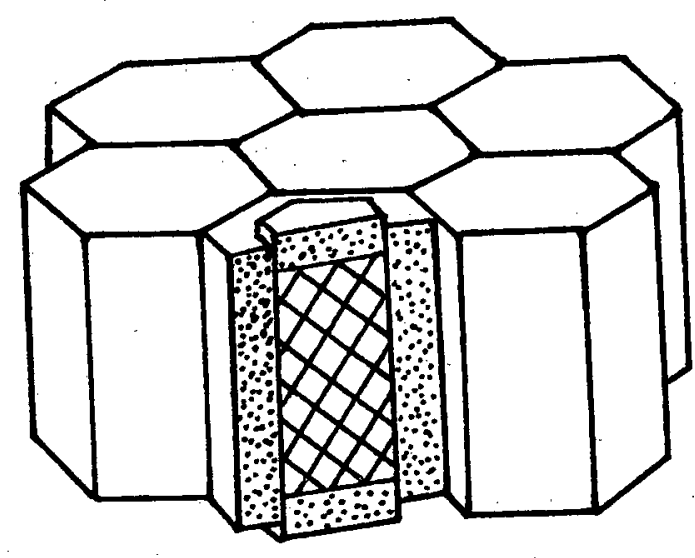

Modular Core
Pancake Core

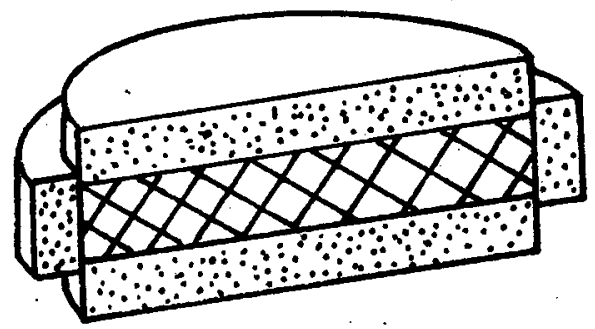

XX core Region

$[\because \because \because \vdots$ Blanket Region

Fig. 1.1 Four Early 1000-MWe LMFBR Core Configurations 
TABLE 1.1

Qualitative Comparis on of Core Configurations (H1)

\begin{tabular}{lllllll}
\hline Core Type & $\begin{array}{c}\text { Sodium } \\
\text { Void }\end{array}$ & $\begin{array}{c}\text { Breeding } \\
\text { Ratio }\end{array}$ & $\begin{array}{c}\text { Core } \\
\text { Inventory }\end{array}$ & $\begin{array}{c}\text { Control } \\
\text { Requirements }\end{array}$ & $\begin{array}{c}\text { Core Hot } \\
\text { Channel Factors }\end{array}$ & $\begin{array}{c}\text { Peak/Average } \\
\text { Burnup }\end{array}$ \\
\hline Cylinder, $1: 1$ & Bad & Good & Excellent & Excellent & Good & Bad \\
Pancake & Good & Good & Good & Good & Good & Good \\
Annular & Good & Excellent & Bad & Excellent & Excellent & Good \\
Modular Island & Good & Excellent & Good & Excellent & Excellent & Good \\
\hline
\end{tabular}


Ordered Bed Fast Reactor Concept (E2), and by the Japanese (E3). Larsen reported (L1) that a variation of the modular concept which included an axially-oriented internal blanket region at the center of each module exhibited substantially reduced reactivity requirements and an improved maximum to average core radial power ratio. Each of these concepts, however, has the disadvantage that the fulllength internal blanket assemblies experience large power swings during irradiation, and, if orificed for their end-of-life power generation rate, contribute a large penalty to the mixed mean coolant outlet temperature over much of the core life. In addition, the replacement of a fissile-loaded portion of the core by an absorbing blanket region requires an increase in the initial critical mass.

Other internal blanket configurations have also been considered. In addition to annular cores, the Russians have evaluated "infinite lattices of heterogeneously-arranged large fuel cassettes distributed in breeding zone material" for which a reduced reactivity requirement has been reported (L2).

Work was also done at both Argonne National Laboratory (L 3) and Westinghouse (H1) to evaluate multiple layers of horizontally-oriented core and blanket material regions for the purpose of minimizing the positive sodium void coefficient. And finally, a central blanket was included in Assembly 3 of the ZPR-III Facility experiments (L4).

In spite of the large number of internal blanket concepts which have been investigated in the past, none is currently the reference design for large fast power reactors. 


\subsection{OBJECTIVES AND SCOPE OF THIS STUDY}

\subsubsection{Problem Statement}

The purpose of this study was to evaluate the neutronic, thermalhydraulic, mechanical and economic characteristics of the advanced fast breeder reactor core and blanket configuration shown in Fig. 1.2. The configuration, called the parfait blanket concept; consists of a conventional short cylindrical core with a thin, horizontal layer of blanket material inserted at the core midplane and limited in radial extent to the inner core zone. The internal blanket region is an integral part of the core fuel assemblies, as are the upper and lower axial blanket regions, and is made up of standard axial blanket pellets.

\subsubsection{Anticipated Design Advantages and Disadvantages}

The reasons for pursuing the study of this concept were numerous. By inserting a region of blanket material in a position of relatively high flux, an increase in the breeding ratio of the system was anticipated. In addition, the preferential breeding of fissile material in the highworth central zone of the core was expected to reduce the burnup reactivity requirement of the configuration. This characteristic had been demonstrated in a previous study (G2) for a small, parfait-type configuration. Such an advantage would mean that fewer and/or lowerworth control rods would be required in the core, and the parasitic. losses of neutrons to control poisons would be reduced. It was also realized that in addition to the conventional functions served by blankets in fast reactors (as regions of fertile-to-fissile conversion and modest power production), the internal blanket region could be used to flatten 


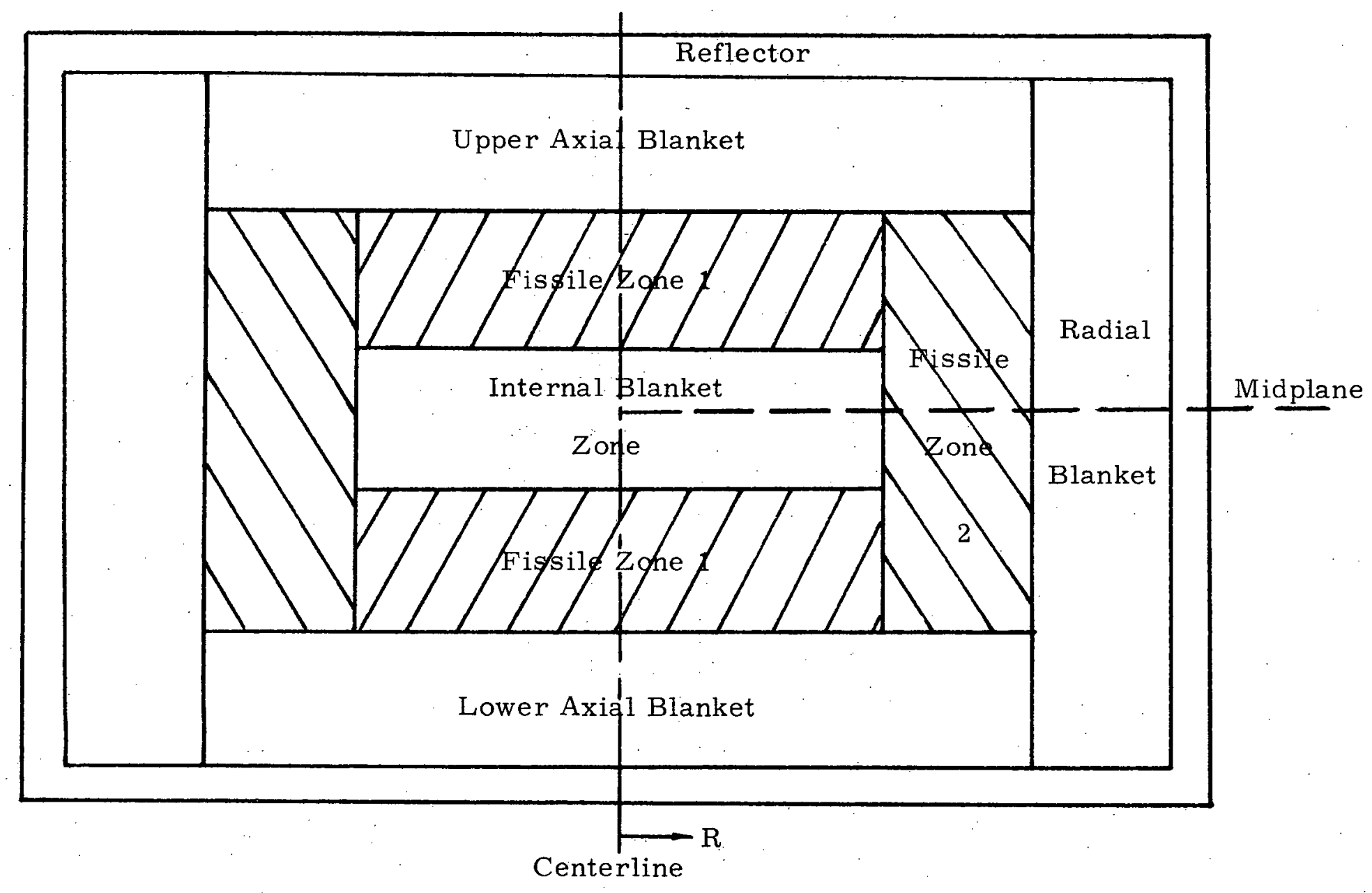

FIG. 1.2 The Parfait Blanket Concept 
the flux and power distribution in the plutonium-loaded zones of the coreparticularly in the axial direction, and to some degree, also in the radial direction. The flux and fluence, and therefore the swelling effects, would be reduced in the central region of the core, which is generally the most limiting location in terms of material damage. This characteristic would allow the parfait configuration to have a more compact core with a higher fuel volume fraction - an advantage which can significantly enhance core neutronic performance. The internal blanket region was also expected to help minimize the positive sodium void coefficient, as reported in the Westinghouse and ANL studies mentioned earlier.

Two primary disadvantages of the parfait concept were recognized from the outset. First, since the inner zone fuel assemblies include the internal blanket pellets and would be more complicated than a conventional fuel assembly, a fabrication penalty would be incurred. Second, since fissile material was initially removed from the high-worth central part of the core, the parfait concept would experience an initial fissile inventory penalty and an associated carrying charge penalty.

These and other characteristics of the parfait blanket concept were evaluated quantitatively and are discussed in this report.

\subsubsection{Method of Evaluation}

The product of this study is not, and was not intended to be a "standalone" fast reactor design effort. Instead, it is a comparative evaluation of the merits and demerits of the parfait blanket concept performed for the purpose of assessing the potential of this concept for application to large, fast breeder power reactors. In order to assess that potential, 
the focus of this study has been the equilibrium cycle performance of this concept relative to the performance of a conventional fast reactor configuration. The conventional core, or reference core as it is called, is described in Section 1.4. Every effort has been made to identify the major differences between the parfait and reference systems and to focus on a quantitative evaluation of those items of concern.' Some design considerations are discussed qualitatively and others, common to both reactor configurations and unaffected by the insertion of an internal blanket region into the core, have not been addressed.

The comparative evaluation technique was adopted for this study because of the large uncertainties which surround many fast reactor calculations. Table 1.2 (G1), which was extracted from an article describing the incentives for additional integral experiments, lists several important nuclear design parameters and the estimated precision in current predictions of these parameters. The magnitude of the uncertainties involved made it clear that the relative attractiveness of the parfait concept could only be evaluated by performing a series of internally consistent calculations employing the same methods and the same data (e.g., cross sections) for both reactor configurations. These parallel calculations could then be expected to yield results which would at least be correct in a relative sense. It is for this reason that the results discussed in the following chapters have often be presented as ratios or with particular emphasis on/magnitude of the differences between the two results. In addition, however, an effort was made whenever possible, to demonstrate that the results of the calculations were also reasonable in an absolute sense. 
TABLE 1.2

Uncertainties in Nuclear Design Parameters ${ }^{(a)}$ (G1)

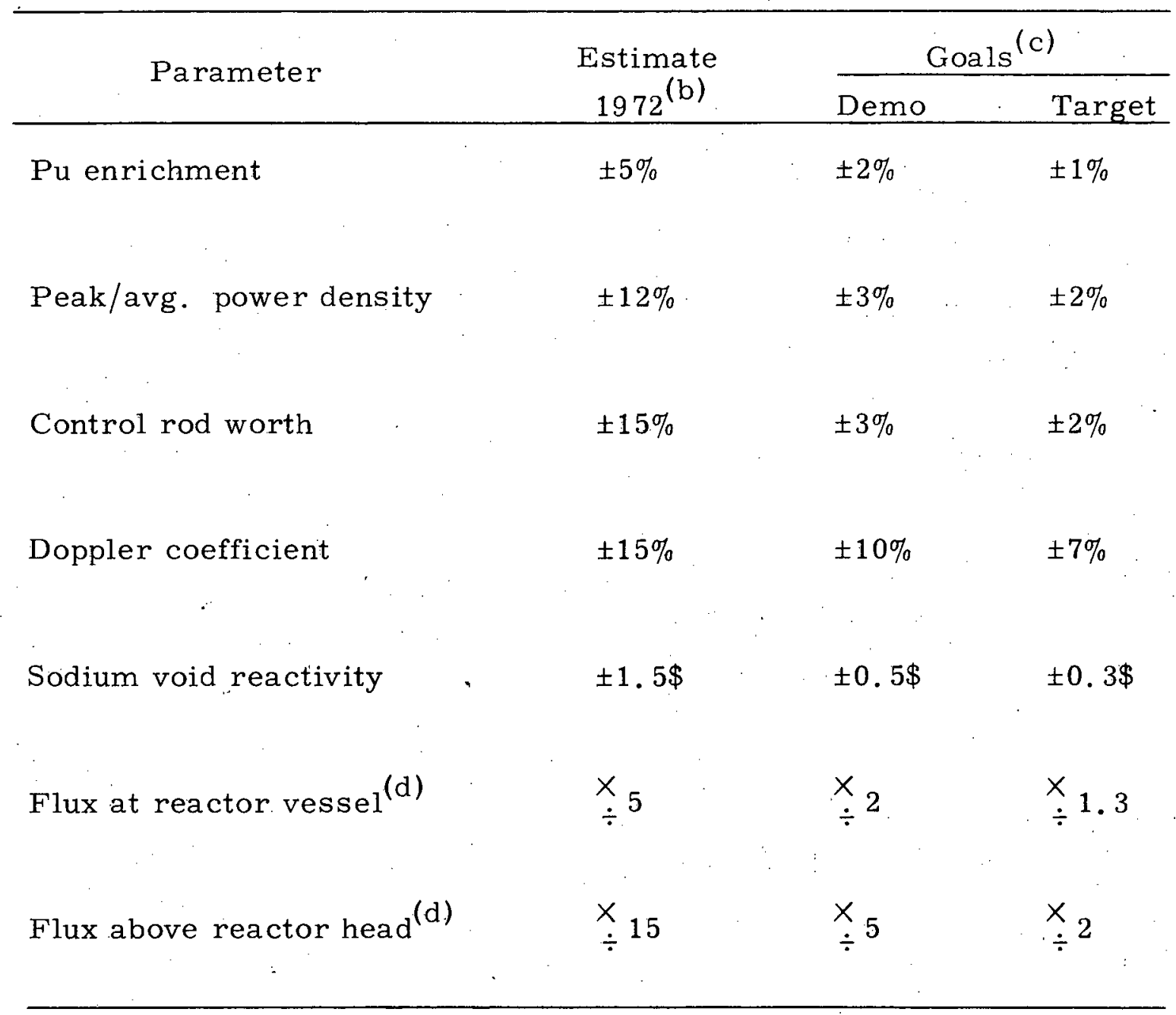

(a) Estimated one-sigma confidence levels.

(b) Without any additional mockup experiments or related nuclear development.

(c) Precision goals for the Demonstration Plant are those required at time of design freeze for the relevant component. For the target plant, the precision goals are required for the early-to-mid-1980 period.

(d) Uncertainties expressed as multiplicative rather than additive factors. For these cases the "two-sigma" confidence level value is estimated to be the square of the "one-sigma" value. 


\subsubsection{Assumptions and Constraints}

The assumptions and constraints imposed upon the parfait blanket concept to permit a meaningful comparison with the reference reactor are listed in Table 1.3. The comparative evaluation was performed so as to make use of the accumulated breeder reactor design experience to date, and to require no extrapolation of current technology. As such, the parfait concept may incorporate the results of on-going research to reduce design margins and improve basic nuclear data; to the same extent as the reference configuration. In addition, the imposed constraints contribute directly to the technical feasibility of the parfait concept.

The constraints and assumptions listed in Table 1.3 carry the consideration of practicality that has been a key concern throughout this work: By requiring that both cores have the same geometry, the same fuel assembly characteristics and the same total thermal power, the basic similarity between the two systems is guaranteed, which allows a meaningful comparison of the concepts. Furthermore, by requiring that the core volume inside the external blankets and the dimensions of the external blankets be the same, this evaluation isolates the effects caused by the internal blanket; and leaves open the possibility that the parfait concept may be considered as a reload core in a conventional reactor configuration. The maximum local power density of the configuration was required to be no greater than that of the reference design because of the important influence of this parameter on the fuel centerline temperature. It was also required that the arrangement of fuel assemblies in the parfait core be equally as simple as in the 
TABLE 1.3

Assumptions and Constraints Imposed Upon the

Parfait Blanket Concept for Comparison

to the Reference Core

1. Identical core volume inside external blankets

2. Identical external blanket dimensions

3. Same total thermal power from each configuration

4. Same maximum local power density limits

5. The use of only conventional core materials (i.e., mixed-oxide fuel, 316 SS structural material)

6. Core and blanket fuel assemblies having similar characteristics (i.e., hexagonal can dimensions, fuel pins per assembly; fuel pin radius, fuel-clad gap, clad thickness)

7. Fissile and fertile material distribution not significantly more difficult to fabricate than the reference core

8. An a rrangement of core fuel assemblies no more complicated than the reference core 
reference core. Because the reference core has only two types of fuel assemblies in the core (i.e., the inner and outer enrichment zones), the same constraint was imposed upon the parfait designs. In doing so, the internal blanket zone was limited in radial extent to the inner fissile-loaded zone. The parfait configuration then contains only two types of fuel assemblies - an inner core zone of one enrichment with an internal blanket, and outer fissile-loaded fuel assemblies similar to those of the reference core.

The above constraints were formulated to aid in the initial design of the parfait concept. Certain of these constraints were relaxed in the course of the evaluation for the purpose of improving a specific performance characteristic. In these cases, the relaxed constraints are clearly noted.

\subsection{REFERENCE CORE CONFIGURATION}

Since there are currently no firm designs for large fast breeder reactors, the reference configuration was selected from among the

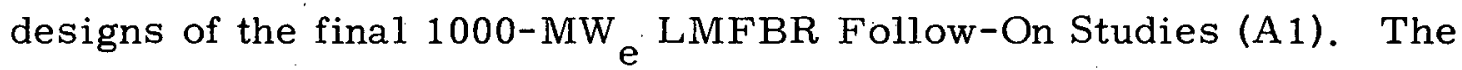
overall core characteristics of those designs are presented in Table 1.4. The first three designs, which employ cylindrical cores with oxide fuel, are characteristic of the designs being most seriously considered today. These designs, however, were initiated before the phenomenon of material swelling was fully appreciated, which accounts for the high fuel volume fractions in these cores. The current demonstration plant designs call for approximately 32 volume percent of fuel in the core. Therefore, the reference core configuration 
TABLE 1.4

$1000-M W_{e}$ LMFBR Core Characteristics

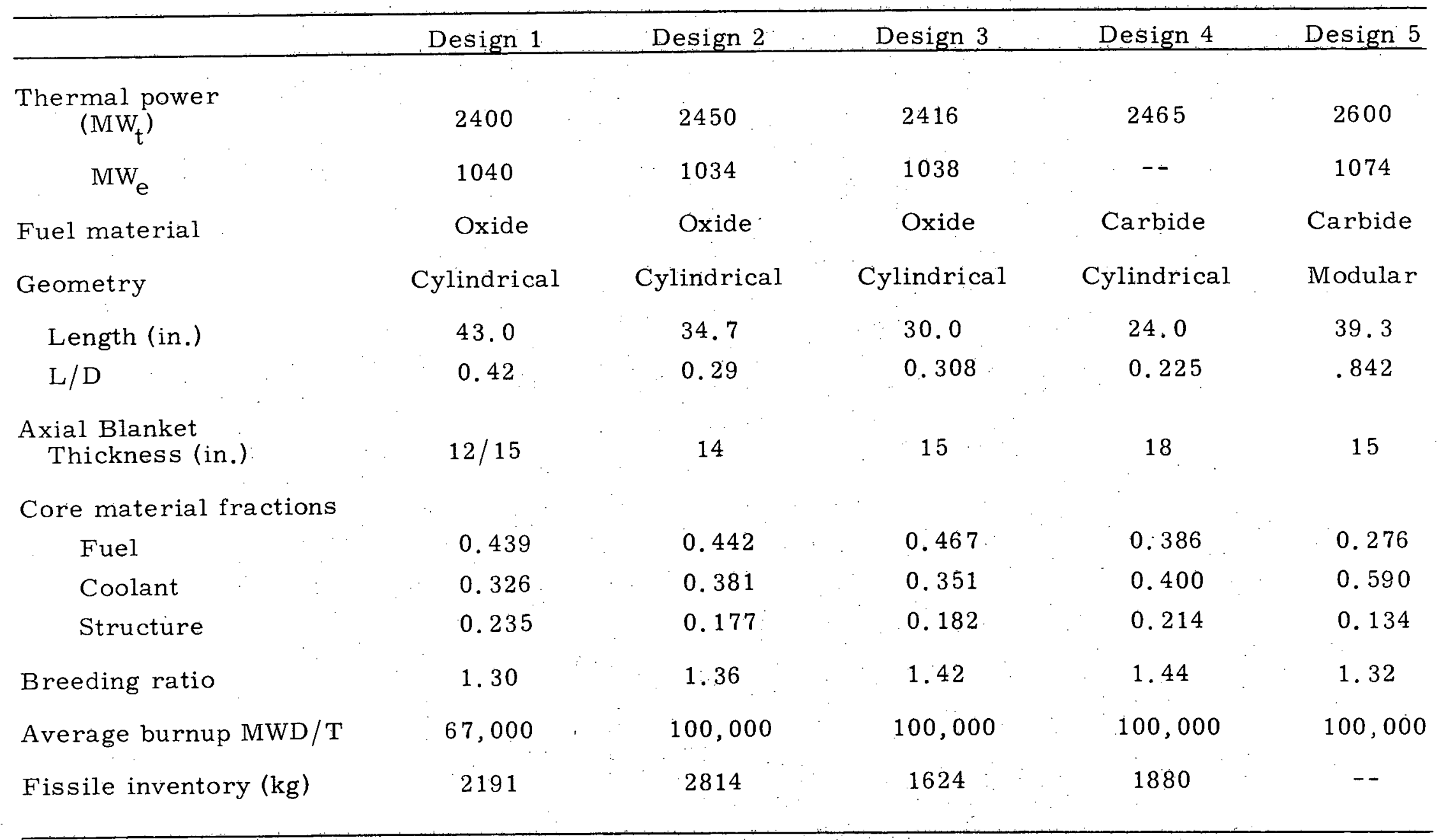


adopted for this study, while similar to the first design in Table 1.4, has material volume fractions in the core more in line with current estimates.

The reference and parfait core configurations used in this study are sketched in Fig. 1.3. The dimensional and material characteristics of these cores are given in Table 1.5. The only difference between the two configurations is that a portion of the fissile-loaded inner enrichment zone of the reference core has been replaced by an internal blanket zone in the parfait configuration.

\section{5 ORGANIZATION OF THE REPORT}

As noted above, the reactors which have been compared are identical in external appearance. They are, however, quite different neutronically because of the altered fissile and fertile material distribution.

Neutronic considerations are, therefore, discussed in Chapter 2. The burnup characteristics of the cores are compared as a function of the internal blanket dimensions, and flux and power profiles are presented. Reactivity control requirements are also determined.

Core engineering problems are addressed in Chapter 3. Thermalhydraulics, including core orificing and a calculation of the mixed-mean coolant outlet temperature are considered. The material temperature distributions and an analysis of the manner in which design limits are exceeded in overpower conditions are presented for both cores. Materials questions and the effects of axial and radial temperature and flux gradients on both designs a re compared on a relative basis.

Chapter 4 is devoted to a calculation of the major safety parameters including the isothermal Doppler coefficient, the power coefficient and the sodium void coefficient. 

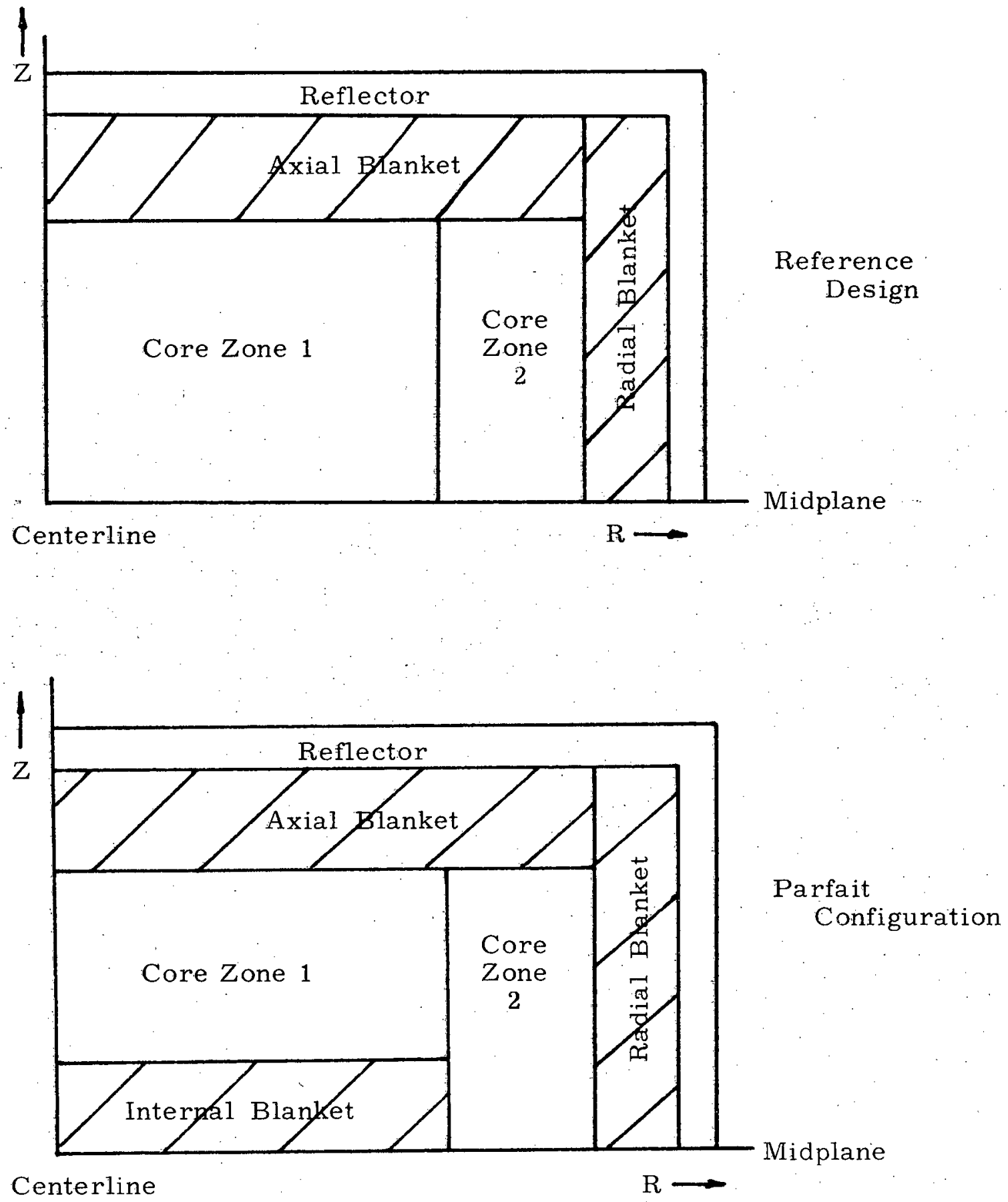

FIG. 1.3 Reference and Parfait Core Configurations (Upper Right Quadrant) 
TABLE 1.5 Dimensional and Material Characteristics of the Reference and Parfait Systems

\begin{tabular}{|c|c|c|c|c|}
\hline \multicolumn{4}{|r|}{ Reference } & Parfait \\
\hline \multicolumn{3}{|c|}{ Thermal power $\left(\mathrm{MW}_{\mathrm{t}}\right)$} & 2500 & 2500 \\
\hline \multicolumn{3}{|c|}{ Core volume $e^{*}$ (liters) } & 5780 & 5780 \\
\hline \multicolumn{3}{|l|}{ Core height $(\mathrm{cm})$} & 108.8 & 108.8 \\
\hline \multicolumn{3}{|l|}{ Core radius $(\mathrm{cm})$} & 130.0 & 130.0 \\
\hline \multicolumn{3}{|c|}{ Axial blanket thickness $(\mathrm{cm})$} & 38.1 & 38.1 \\
\hline \multicolumn{3}{|c|}{ Radial blanket thickness $(\mathrm{cm})$} & 28.4 & 28.4 \\
\hline \multicolumn{3}{|c|}{ Reflector thickness $(\mathrm{cm})$} & 14.2 & 14.2 \\
\hline & \multicolumn{4}{|c|}{ Region Compositions } \\
\hline & Core & Axial Blanket & Internal Blanket & Radial Blanket \\
\hline \multicolumn{4}{|l|}{ Fuel } & 0.50 \\
\hline Material & $\begin{array}{l}\text { Mixed } \\
\text { oxide }\end{array}$ & $\begin{array}{l}\text { Mixed oxide } \\
\text { (initially } \\
\text { depleted } \mathrm{UO}_{2} \text { ) }\end{array}$ & $\begin{array}{l}\text { Mixed oxide } \\
\text { (initially } \\
\text { depleted } \mathrm{UO}_{2} \text { ) }\end{array}$ & $\begin{array}{l}\text { Mixed oxide } \\
\text { (initially } \\
\text { depleted } \mathrm{UO}_{2} \text { ) }\end{array}$ \\
\hline Fraction of T.D. & 0.85 & 0.95 & 0.95 & 0.95 \\
\hline $\begin{array}{l}\text { Coolant } \\
\text { Volume fraction } \\
\text { Material }\end{array}$ & $\begin{array}{l}0.50 \\
\mathrm{Na}\end{array}$ & $\begin{array}{l}0.50 \\
\mathrm{Na}\end{array}$ & $\begin{array}{c}0.50 \\
\mathrm{Na}\end{array}$ & $\begin{array}{c}0.30 \\
\mathrm{Na}\end{array}$ \\
\hline $\begin{array}{l}\text { Structure } \\
\text { Volume fraction } \\
\text { Material }\end{array}$ & $\begin{array}{c}0.20 \\
316 \mathrm{SS}\end{array}$ & $\begin{array}{l}0.20 \\
31.6 \mathrm{SS}\end{array}$ & $\begin{array}{l}0.20 \\
316 \mathrm{SS}\end{array}$ & $\begin{array}{l}0.20 \\
316 \mathrm{SS}\end{array}$ \\
\hline \multicolumn{5}{|c|}{ Isotopic Compositions } \\
\hline \multicolumn{3}{|c|}{ Plutonium $^{* * * k}$} & \multicolumn{2}{|c|}{ Depleted U ranium } \\
\hline $\mathrm{Pu}-240$ & 0.22 & $U-2$ & & 0.0025 \\
\hline $\mathrm{Pu}-241$ & 0.12 & & & \\
\hline $\mathrm{Pu}-242$ & 0.03 & & & \\
\hline
\end{tabular}

\footnotetext{
* The core volume of the parfait design includes the internal blanket region. **WR discharge at $\sim 30,000 \mathrm{MWd} / \mathrm{T}$ (B1).
} 
The feasibility of the parfait concept is further discussed in Chapter 5, focusing on questions of fabrication and reprocessing. The equilibrium fuel cycle costs for both cores are also compared. Chapter 6 provides a brief summary of the work presented in this report and includes the overall conclusions and recommendations.

The main body of this report centers on the comparative evaluation of the two $1000-\mathrm{MW}_{\mathrm{e}}$ liquid metal cooled reactors defined in the previous section. The appendices include a brief consideration of a gas-cooled parfait concept and a smaller, demonstration size LMFBR. Material supporting the methods used in the calculations presented in this report is also included in the appendices. 
Chapter 2

NEUTRONICS

\subsection{INTRODUCTION}

It is the purpose of this chapter to describe the neutronic characteristics, excluding safety considerations, of the parfait blanket concept in comparison to the reference reactor. The primary tool used in this comparison was the two-dimensional, multigroup, fast reactor, diffusion theory burnup code $2 \mathrm{DB}$ (L5). It was used to determine flux and power profiles and to perform criticality calculations and burnup analyses. . The original cross section set used in this study was a twenty-six energy group set obtained by Brewer (B2) in 1970 from the Battelle Northwest Laboratory. It is essentially the Bondarenko set (B3) modified to conform to the American constant-lethargy-width group structure and corrected for resonance and spatial self-shielding by the 1DX code. To reduce computational costs, this twenty-six group cross section set was collapsed to four energy groups using the one-dimensional transport code, ANISN (E4). The group collapse structure employed in this study is shown in Table 2.1, and is similar to others which have appeared in the literature (F1, H2). The cross section collapsing procedure and the spectra over which the material cross sections were collapsed are given in Appendix A.1.1.

In order to gain assurance that the cross sections and the calculational methods would be adequate for the proposed calculations, a series of test calculations were performed which are more fully 
TABLE 2.1. Cross-Section Group Collapse

\begin{tabular}{|c|c|c|c|c|c|}
\hline Group & $\begin{array}{c}\text { Upper } \\
\text { Energy Limit }\end{array}$ & $\mathrm{x}_{\mathrm{g}}^{*}$ & Group & $\begin{array}{c}\text { Upper } \\
\text { Energy Limit }\end{array}$ & $x^{*}$ \\
\hline 1 & $10 \mathrm{MeV}$ & 0.0350 & 1 & $10 \mathrm{MeV}$ & 0.5894 \\
\hline 2 & 6.06 & 0.1214 & & & \\
\hline 3 & 3.68 & 0.2105 & & & \\
\hline 4 & 2.23 & 0.2220 & & & \\
\hline 5 & 1.35 & 0.1721 & 2 & 1.35 & 0.3948 \\
\hline 6 & 0.821 & 0.1102 & & & \\
\hline 7 & 0.498 & 0.0625 & & & \\
\hline 8 & 0.302 & 0.0330 & & & \\
\hline 9 & 0.183 & 0.0167 & & & \\
\hline 10 & 0.111 & 0.00823 & 3 & 0.111 & 0.0141 \\
\hline 11 & 0.0674 & 0.00398 & & & \\
\hline 12 & 0.0409 & 0.00191 & & & \\
\hline 13 & 0.0248 & $9.16 \times 10^{-4}$ & 4 & 0.0248 & 0.0017 \\
\hline 14 & 0.0150 & $4.31 \times 10^{-4}$ & & & \\
\hline 15 & $9.12 \mathrm{keV}$ & $2.06 \times 10^{-4}$ & & & \\
\hline 16 & 5.53 & $9.70 \times 10^{-5}$ & & & \\
\hline 17 & 3.35 & $4.60 \times 10^{-5}$ & & & \\
\hline 18 & 2.03 & $2.20 \times 10^{-5}$ & & & \\
\hline 19 & 1.23 & $1.00 \times 10^{-5}$ & & . & \\
\hline 20 & 0.749 & $5.00 \times 10^{-6}$ & & . & \\
\hline 21 & 0.454 & $2.00 \times 10^{-6}$ & & & \\
\hline 22 & 0.275 & $1.00 \times 10^{-8}$ & & & \\
\hline 23 & 0.167 & $1.00 \times 10^{-8}$ & & & \\
\hline 24 & 0.101 & 0 & & & \\
\hline 25 & 0.0614 & 0 & & & \\
\hline \multirow[t]{2}{*}{26} & 0.0373 & 0 & & & \\
\hline & 0.0226 & & & & \\
\hline
\end{tabular}

${ }^{*} x_{g} \equiv$ fraction of fission neutrons born into group $g$. 
described in Appendix A.2. Briefly, the results of those calculations were as follows:

1) Transport theory (ANISN) and diffusion theory (2DB) predictions of the group fluxes were found to be comparable to within about $2 \%$ throughout similar reactor systems.

2) $2 \mathrm{DB}$ and the four group cross section set described above were used to simulate a plutonium-fueled critical experiment. The calculational tools were found to be adequate for predicting $k$ eff and the fissile inventory requirements.

3) The burnup characteristics of calculations using one, two and four group cross sections were found to be very similar, but the different calculations led to widely varying $\mathrm{k}_{\text {eff }}$ and breeding ratio predictions for identical reactor systems. Based on the results of the present investigations and the evaluations of others (H3), no fewer than four groups were used in all further neutronic calculations.

4) A comparison between the results of burnup calculations employing 26 energy groups and four energy groups for both the reference and parfait reactors demonstrated very similar power profiles, burnup reactivity losses and breeding ratio predictions.

\subsection{DESIGN VARIABLE CONSIDERATIONS}

The choice of the reference reactor and the imposition of the assumptions and constraints listed in Table 1.3 precisely describe the parfait blanket configuration except for the characteristics of the 
internal blanket region. The design variables needed to define this region include the axial and radial extent of the internal blanket and its initial composition.

The axial extent or thickness of the internal blanket was treated as a continuously variable parameter because oxide pellets may be fabricated and assembled into any specified length. The radial extent, however, is a parameter which is only discontinuously variable. Because all of the fuel pins in any fuel assembly are required to be identical, the radial extent of the internal blanket may only correspond to the outer radius of a fuel assembly ring.

The primary limiting criterion used in defining the dimensions of the internal blanket was the local peak power density achieved in the remainder of the core. This parameter was used because of its strong influence on the temperature profile in the fuel, and, in particular, the maximum fuel centerline temperature.

It was discovered that extending the internal blanket region across the full radial extent of the active core caused the maximum power density in the parfait configuration to exceed that of the reference core for a wide range of internal blanket thicknesses; this result was a direct consequence of replacing too large a fraction of the high power density volume of the reference core with relatively low power density blanket material. A reduction in the volume of the internal blanket region was required to satisfy the limiting power density criterion. Therefore, in accord with the constraint that the parfait configuration be as simple as that of the reference core (i.e., each core comprised of only two types of fuel assemblies), the radial extent of the internal blanket was required 
to be the same as that of the inner enrichment zone.

\subsubsection{Internal Blanket Thickness}

The effects of varying the axial extent of the internal blanket were evaluated by comparing the cores shown in Fig. 2.1. Each core in the comparison was loaded with the required fissile material to achieve 300 full power days of operation, and the blanket regions of each core were loaded with a fissile content representative of that which would exist at the beginning of a cycle of equilibrium operation. The fissile enrichments in the inner and outer fuel zones were adjusted to obtain the minimum peak power density throughout the burnup cycle.

Parfait blanket configurations for internal blankets having thicknesses of up to $50 \mathrm{~cm}$ were compared to the reference core with respect to the key performance and design parameters shown in Table 2.2. These same parameters are compared to those of the reference core in Table 2. 3 , where the tabulated results are the ratio of the parameter for the parfait to that of the reference core; for example, the breeding ratio of the parfait concept relative to (divided by) the breeding ratio for the reference reactor. These relative results a re also plotted in Fig. 2.2.

These results, which a re illustrated in Fig. 2.2 confirm many of the anticipated effects of the internal blanket concept (Section 1.3.2) and quantify these effects with respect to the internal blanket thickness. Very briefly, these results are as follows: 

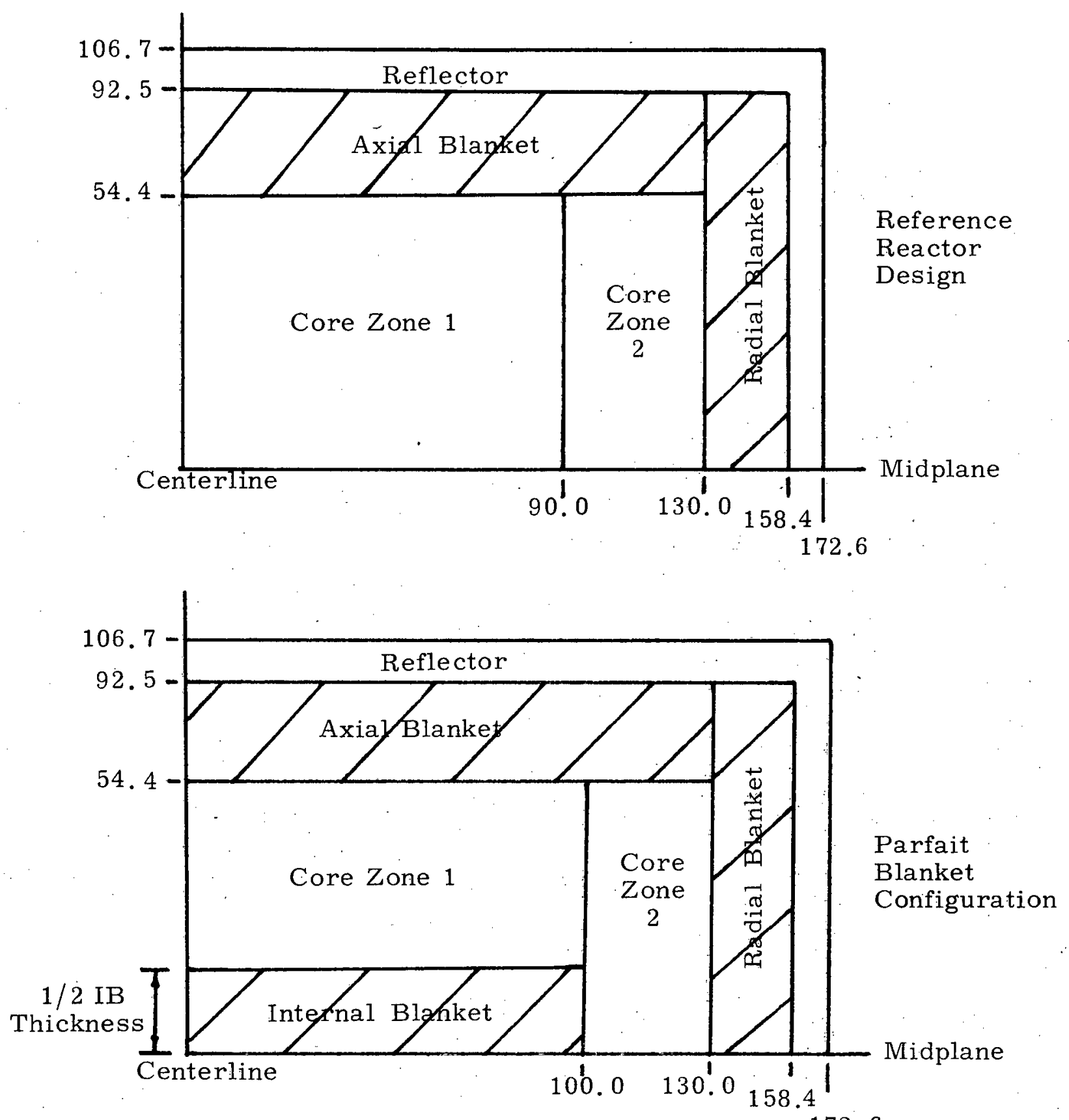

172.6

FIG. 2.1. Core Configurations for Evaluating the Effects of Internal Blanket Thickness 
TABLE 2.2. Parfait System Performance as a Function of Internal Blanket Thickness

\begin{tabular}{|c|c|c|c|c|c|c|c|c|}
\hline $\begin{array}{l}\text { Internal } \\
\text { Blanket } \\
\text { Thickness } \\
\text { (cm) }\end{array}$ & $\begin{array}{l}\text { Core } \\
\text { Fissile } \\
\text { Inventory } \\
\quad(\mathrm{kg})\end{array}$ & $\frac{\Delta \mathrm{k}}{300 \text { days }}$ & $\begin{array}{c}\mathrm{BR} \\
(\mathrm{BOC})\end{array}$ & $\begin{array}{l}\text { Peak } \\
\text { Power } \\
\text { Density } \\
(\text { BOC) } \\
(\mathrm{MW} / \ell)\end{array}$ & $\begin{array}{l}\text { Peak } \\
\text { Flux }\left(\times 10^{-16}\right) \\
(\mathrm{BOC}) \\
\left(\mathrm{n} / \mathrm{cm}^{2} \mathrm{sec}\right)\end{array}$ & $\begin{array}{l}\text { Peak } \\
\text { Power } \\
\text { Density } \\
(150 \text { days }) \\
(\mathrm{MW} / \ell)\end{array}$ & $\begin{array}{l}\text { Peak } \\
\text { Flux }\left(\times 10^{-16}\right) \\
(150 \text { days }) \\
\left(\mathrm{n} / \mathrm{cm}^{2} \mathrm{sec}\right)\end{array}$ & $\epsilon_{2} / \epsilon_{1}{ }^{*}$ \\
\hline 0 & 2065.02 & 0.052 & 1. 2291 & 0.600 & 0.929 & 0.573 & 0.946 & 1.327 \\
\hline 20 & *k* & 0.040 & 1. 2500 & 0.560 & 0.740 & 0,544 & 0.766 & 1. 216 \\
\hline 30 & 2146,12 & 0.040 & 1.2500 & 0.570 & 0.676 & 0.536 & 0.696 & 1.150 \\
\hline 40 & ** & 0.040 & 1.2500 & 0.573 & 0.626 & 0.537 & 0.648 & 1.074 \\
\hline 50 & 2187.30 & 0,044 & 1.2430 & 0.593 & 0.599 & 0.551 & 0.608 & 1.000 \\
\hline
\end{tabular}

(Outer zone enrichment)/(Inner zone enrichment).

***ailed calculations not performed. 
TABLE 2.3. Parfait System Performance Relative to Reference Core as a Function of Internal Blanket Thickness

\begin{tabular}{|c|c|c|c|c|c|c|c|c|}
\hline $\begin{array}{l}\text { Internal } \\
\text { Blanket } \\
\text { Thickness }\end{array}$ & $\begin{array}{l}\text { Core } \\
\text { Fissile } \\
\text { Inventory }\end{array}$ & $\Delta \mathrm{k} / \Delta \mathrm{t}$ & $\mathrm{BR}$ & $\begin{array}{l}\text { Peak } \\
\text { Power } \\
\text { Density } \\
\text { (BOC) }\end{array}$ & $\begin{array}{l}\text { Peak } \\
\text { Flux }\left(\times 10^{-16}\right) \\
(\text { BOC })\end{array}$ & $\begin{array}{l}\text { Peak } \\
\text { Power } \\
\text { Density } \\
\text { (150 days) }\end{array}$ & $\begin{array}{l}\text { Peak } \\
\text { Flux }\left(\times 10^{-16}\right) \\
(150 \text { days })\end{array}$ & $\epsilon_{2} / \epsilon_{1}{ }^{*}$ \\
\hline 0 & 1.0 & 1.0 & 1.0 & 1. 0 & 1.0 & 1.0 & 1.0 & 1.0 \\
\hline 20 & $* *$ & 0.755 & 1.02 & 0.933 & 0.796 & 0.95 & 0.810 & 0.917 \\
\hline 30 & 1.039 & 0.755 & 1.02 & 0.950 & 0.727 & 0.936 & 0.736 & 0.868 \\
\hline 40 & $* *$ & 0.755 & 1.02 & $\begin{array}{c}0.955 \\
-\end{array}$ & 0.675 & 0.931 & 0.685 & 0.812 \\
\hline 50 & 1.059 & 0.830 & 1. 012 & 0.996 & $\cdots \quad 0.645$ & 0.962 & 0.642 & 0.755 \\
\hline
\end{tabular}

* (Outer zone enrichment)/(Inner zone en richment).

* Detailed calculations not performed. 


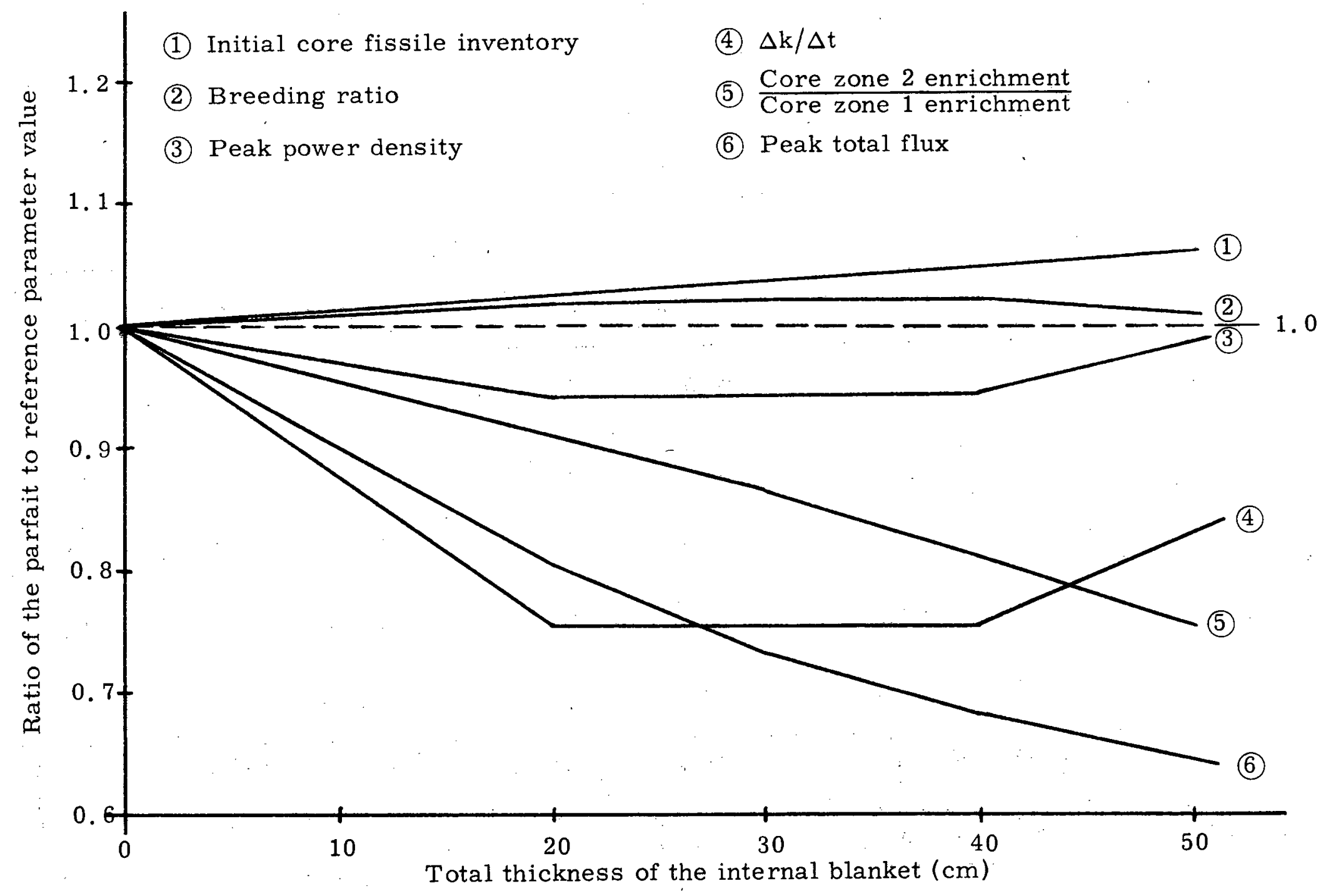

FIG. 2. 2. Parfait Performance Relative to Reference Core as a Function of Internal Blanket Thickness 
1) The initial fissile inventory was found to be a monotonically increasing function of the internal blanket thickness, a result of replacing the fissile material removed from the high-worth central portion of the core by a necessarily greater amount placed in the outer regions of the core.

2) The breeding ratio of the parfait design exhibits a small improvement over that of the reference core $(2 \%)$. This slight advantage appears to diminish somewhat for internal blanket thicknesses greater than forty centimeters. The reason for this behavior is in part explained by Fig. 2.3. This figure compares the fissile material yield in a given period of time per unit mass of fertile material loaded in the internal blanket for several internal blanket thicknesses. This parameter decreases because the material toward the center of the internal blanket becomes increasingly less efficient at breeding as the blanket is made thicker and the flux depression in the region becomes greater. In addition, the overall flux level throughout the reactor decreases with the increasing internal blanket thickness because of the greater beginning-of-cycle fissile loadings discussed in 1) above. Another consequence of the increased initial fissile inventory is that fertile-tofissile conversion in the active fuel volume of the core is reduced. All of these factors contribute to the reduced breeding ratio advantage noted for the thickest internal blanket regions.

3) A reduced peak power density was observed for the parfait configurations throughout the burnup cycle. This is a result of the axial and radial flux (and power) flattening produced in the fissile-loaded regions of the core by the internal blanket. In the $50-\mathrm{cm}$ internal blanket 


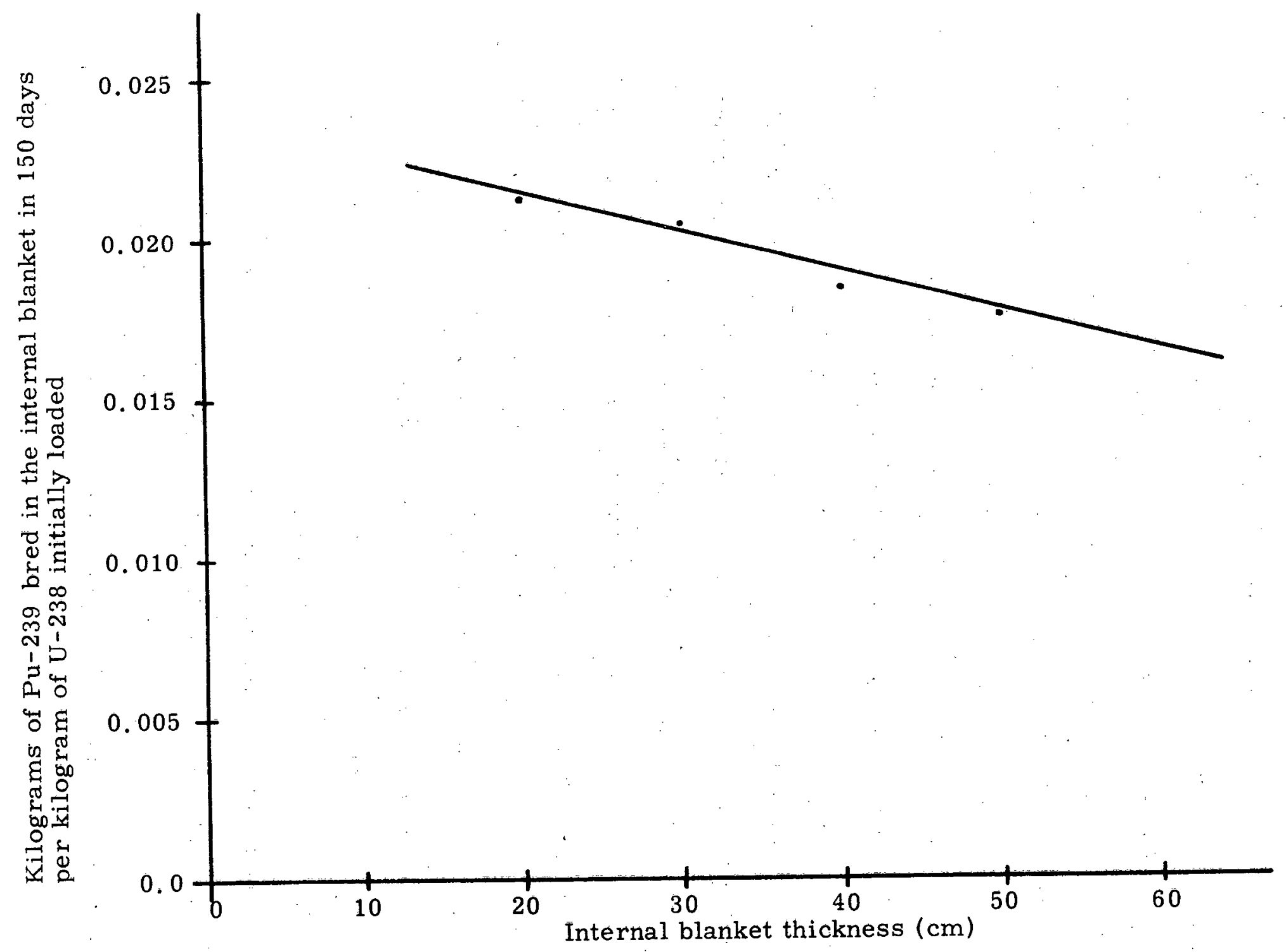

FIG. 2.3. Internal Blanket Conversion Efficiency as a Function of Internal Blanket Thickness 
case, this power flattening is so dramatic that even though $27 \%$ of the fissile loaded volume of the core is replaced by blanket material, the parfait configuration is able to generate as much power as the reference core while operating within the same power density limit. The flux and power profiles for certain parfait configurations a re plotted in Section 2.2.4.

4) A $25 \%$ reduction. in the burnup reactivity loss was achieved for the best parfait configuration. This characteristic is a consequence of the preferential breeding of fissile material: in the center of the core and results in the advantages of reduced control rod requirements and reduced losses of neutrons to control materials (Section 2.4). As with the effect on the breeding ratio, this advantage is also diminished for the thickest internal blankets.

5) The ratio of the fissile enrichment in the outer core zone to that of the inner core zone was found to decrease with increasing internal blanket thicknesses. As noted in Table 2.2; this ratio was 1.33 for the reference core and decreased to 1.0 for the parfait configuration having a 50-cm internal blanket. Thus, even though the advantages of an increased breeding ratio and a reduced burnup reactivity loss are slightly diminished by increasing the internal blanket thickness to $50 \mathrm{~cm}$, this case offers the possible economic advantage of having to fabricate fuel pellets of only one enrichment for the core. The economics of this and other configurations are discussed in Chapter 5.

6) The peak total flux in the core was found to decrease substantially with an increase in the internal blanket thickness. For a $30-\mathrm{cm}$ internal blanket, the peak flux was reduced by $27 \%$. 
Figure 2.2 also demonstrates that the attractive performance characteristics of the parfait configuration are not particularly sensitive to the internal blanket thickness. The advantage of an increased breeding ratio, a reduced peak power density and a reduced reactivity swing all exhibit broad maxima or minima. The core designer is thus afforded considerable flexibility to vary the internal blanket thickness to achieve a specific core characteristic without sacrificing overall system performance.

\subsubsection{Radial Extent of the Internal Blanket}

In the introduction to this section, the constraint was imposed that the internal blanket extend radially only as far as the inner core enrichment zone. Varying the radial extent of the internal blanket was, therefore, accompanied by moving the boundary between the inner and outer enrichment zones and altering the fissile enrichments in these zones - a procedure which has a substantial effect on the flux and power distribution in the core. The most favorable radially flattened power profiles for the parfait configuration were obtained when the inner core zone had roughly the same radial dimension as that in the reference core. A small advantage in radial flux flattening and in the breeding ratio were realized by extending the inner zone of the parfait configuration to $100 \mathrm{~cm}$ (as compared to $90 \mathrm{~cm}$ for the reference core), and this is the case which was presented in the previous discussion of the axial extent of the internal blanket.

Because the radial extent of the inner core zone is a characteristic of the reactor geometry which is determined by radial power flattening 
considerations and by the dimensions of the individual fuel assemblies, it is useful to note the design flexibility inherent in the parfait configuration. As a demonstration of this design flexibility, the following example shows how the two dimensional characteristics of the internal blanket - the axial extent and the radial - may be used together to achieve a specific design requirement. As noted in Section 2.2.1, the parfait configuration having an internal blanket thickness of $50 \mathrm{~cm}$ and a radial extent of $100 \mathrm{~cm}$ had the design characteristic of having just one fissile enrichment in both the inner and outer core zones. This configuration also displayed a very flat radial power profile. These same design characteristics were also achieved in a parfait configuration having an internal blanket thickness of $40 \mathrm{~cm}$ and a radial extent of $90 \mathrm{~cm}$. The radial power profiles for these cores in a plane $37 \mathrm{~cm}$ above the core midplane are plotted in Fig. 2.4.

\subsubsection{Internal Blanket Enrichment}

The rate at which fissile plutonium builds up in a "clean". internal blanket is illustrated in Fig. 2.5. In this case, a parfait configuration with a $30-\mathrm{cm}$ internal blanket made up of depleted uranium oxide was batch-loaded and burned up for 600 days. It is clear from the figure that plutonium builds up at a continually decreasing rate as the internal blanket is irradiated. This behavior is characteristic of a simple parent-daughter nuclear transmutation in which the daughter atom is also being consumed at a rate in proportion to its concentration. Thus, if the goal is to maximize the net yield of fissile material from the blanket, it is clear that the optimum internal blanket material is one which is initially depleted of fissile isotopes. 


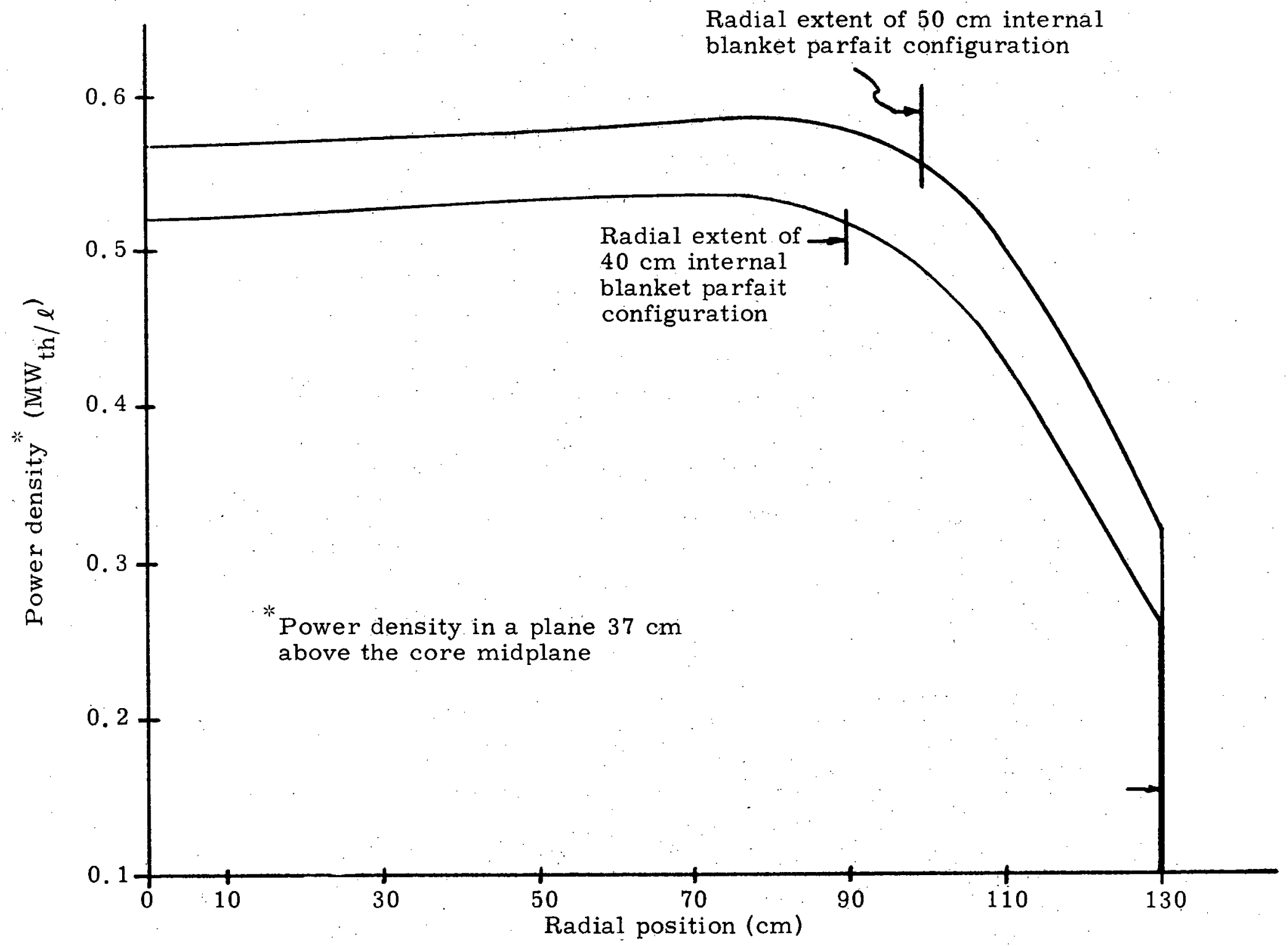

FIG. 2.4. Radial Power Profiles in Two Parfait Systems Having a Single Core Fissile Enrichment 


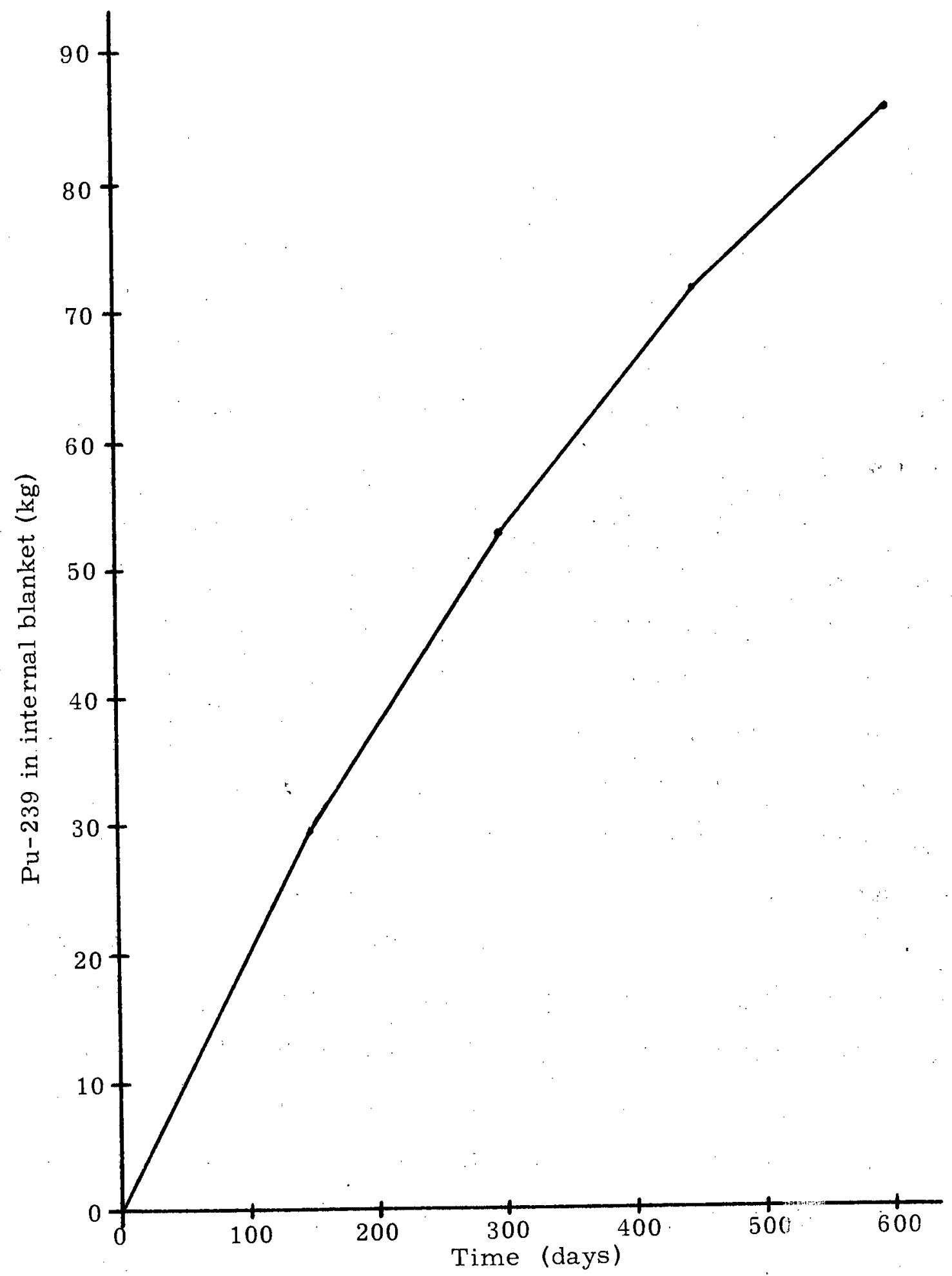

FIG. 2.5. Fissile Plutonium Buildup in a 30-cm Internal Blanket 
Another practical consideration relating to the initial enrichment of the internal blanket concerns fabrication. Any internal blanket pellet composition other than that loaded in the axial blankets makes the core more complicated, thereby causing the internal blanket to suffer an additional fabrication penalty. Thus, this practical fabrication consideration and the desire to maximize the fissile-material-yield from the internal blanket both contribute to the decision to use pellets in the internal blanket which are identical to the depleted uranium pellets of the axial blanket.

In addition to the overall rate of plutonium buildup in the internal blanket, the spatial variation of the plutonium production was evaluated and the results are presented in Table 2.4. For this evaluation, a parfait configuration with a $40-\mathrm{cm}$ internal blanket having a uniform initial composition and the detailed zoning shown in Fig. 2.6 was burned up in 50-day time steps to a total exposure of 200 days. As noted in the table, the spatial distribution of the plutonium production is remarkably uniform at the end of the burnup cycle. In zones one through five, for example, the local plutonium concentration was found to vary from the collective average by an average of less than $0.75 \%$ in spite of the fact that the total flux at the center of the internal blanket is reduced by $14 \%$ from the flux that exists at the blanket's upper edge. Two factors contribute to this spatial uniformity of plutonium production. First, as shown in Fig. 2.7, the uranium capture cross section increases monotonically with decreasing energy in the range of interest, thereby enhancing the $(n, \gamma)$ conversion reaction toward the center of the internal blanket where the low energy neutron flux is a maximum. 
TABLE 2.4. Spatial Distribution of Pu-239 Production in a 40-cm Internal Blanket (200 days)

\begin{tabular}{|c|c|c|c|c|c|}
\hline Zone & $\begin{array}{c}\text { Pu-239 } \\
\text { Content } \\
\left(\times 10^{+3}\right) \\
\left(\text { atoms } / \mathrm{cm}^{3}\right) \\
\end{array}$ & $\begin{array}{c}\text { Average Pu-239 } \\
\text { Content } \\
\left(\times 10^{+3}\right) \\
\left.\text { (atoms } / \mathrm{cm}^{3}\right) \\
\end{array}$ & $\begin{array}{l}\text { Percent } \\
\text { Variance } \\
\text { from } \\
\text { Average } \\
\end{array}$ & $\begin{array}{c}\text { Total Flux } \\
\left(\times 10^{15}\right) \\
\left(\text { neutrons } / \mathrm{cm}^{2} \mathrm{sec}\right)\end{array}$ & $\frac{\text { Average flux in zone }}{\text { Average flux at IB edge }}$ \\
\hline 1 & 0.1568 & & +0.37 & 4.0 & 0.86 \\
\hline 2 & 0.1571 & & +0.56 & 4.076 & \\
\hline 3 & 0.1572 & 0.1562 & +0.56 & 4.21 & 0.90 \\
\hline 4 & 0.1565 & & +0.18 & 4.40 & 0.95 \\
\hline 5 & 0.1535 & & -1.75 & 4.63 & 1.0 \\
\hline 6 & 0.1578 & & +1.5 & 4. 30 & 0.92 \\
\hline 7 & 0.1575 & & +1.3 & 4.36 & 0.93 \\
\hline 8 & 0.1568 & 0.1555 & +0.84 & 4.44 & 0.95 \\
\hline 9 & 0.1548 & & -0.44 & 4.55 & 0.97 \\
\hline 10 & 0.1505 & & -3.20 & 4.67 & 1.0 \\
\hline
\end{tabular}




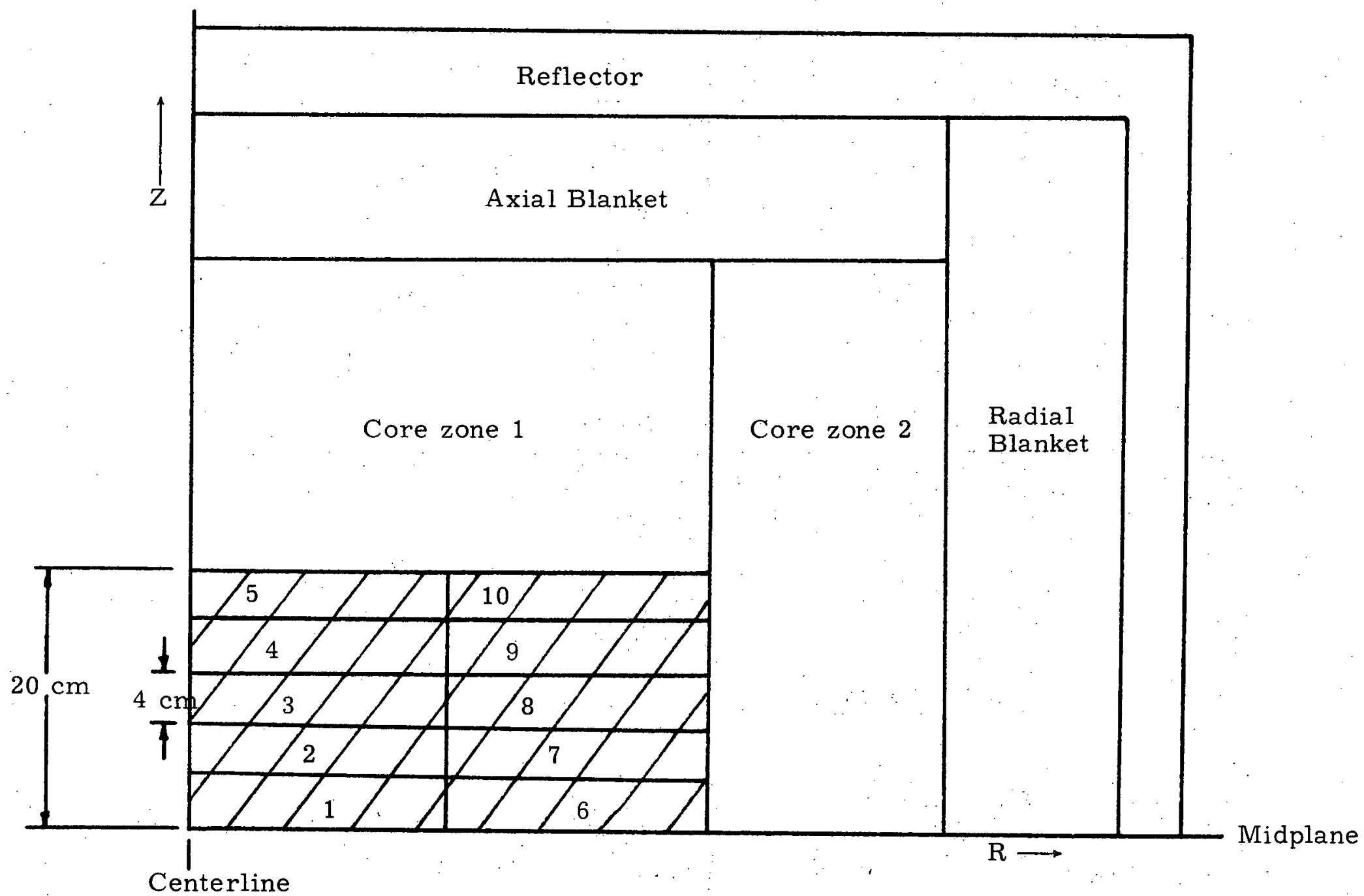

FIG. 2.6. Internal Blanket Zone Designations for Evaluating the Spatial Distribution of Plutonium Production 


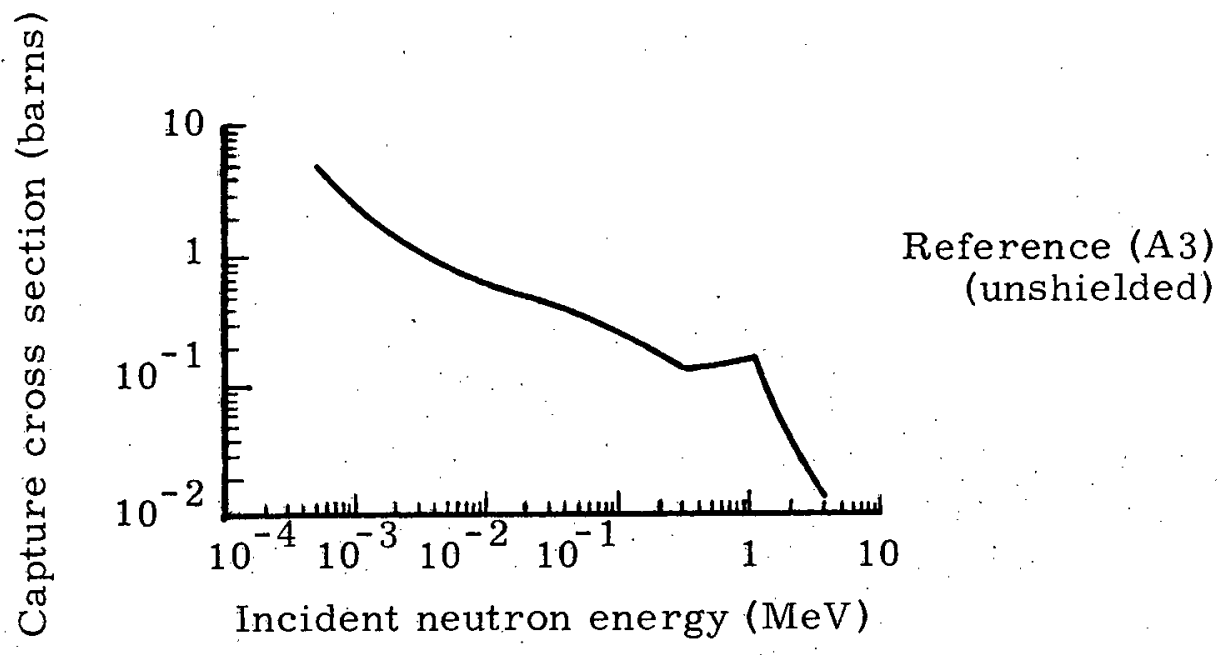

0
0
0
0
0
0
0
0
0
0
0
0
0
0
0
0
0
5
3
0
0
0
0

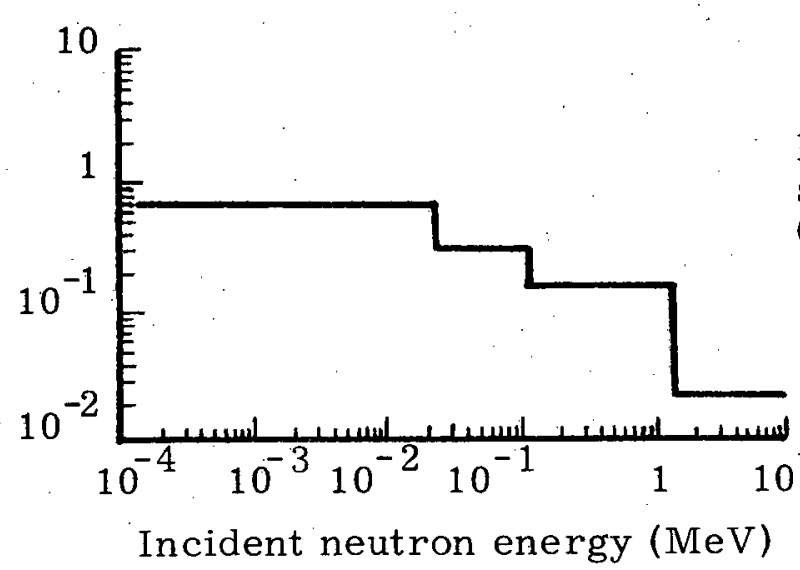

Four-group cross section representation (self-shielded)

FIG. 2.7. Uranium-238 Capture Cross Section 
(The spatially dependent group fluxes are plotted in the next section.) Second, the concentration-dependent consumption rate of fissile plutonium tends to drive the internal blanket toward a uniform fissile distribution.

The significant buildup of plutonium in the internal blanket as shown in Fig. 2.5 tends to harden the neutron energy spectrum in this region during irradiation. This characteristic of the neutron fluxes is also demonstrated in the next section... For the analyses presented in this report; however, blanket material cross sections (material cross sections collapsed over the neutron spectrum of a blanket region as discussed in Section A.1.1) were used throughout the burnup cycle because, in spite of the shift, the energy spectrum is still most characteristic of a blanket region. In order to evaluate qualitatively the effect of the spectrum shift in the internal blanket, a comparison was made between two calculations of a parfait configuration, one of which used blanket material cross sections for the internal blanket and the other using core material cross sections. The results demonstrated that the hardened spectrum in the internal blanket would contribute a small positive reactivity effect. The parfait configuration calculations of burnup reactivity loss presented in this report are, therefore, conservative with respect to this spectrum shift effect.

As its plutonium content increases, the internal blanket contributes an increasing fraction of the total power generated by the reactor system. The percentage of the total system power generated in the internal blanket is plotted in Fig. 2.8, and the fraction of that power 


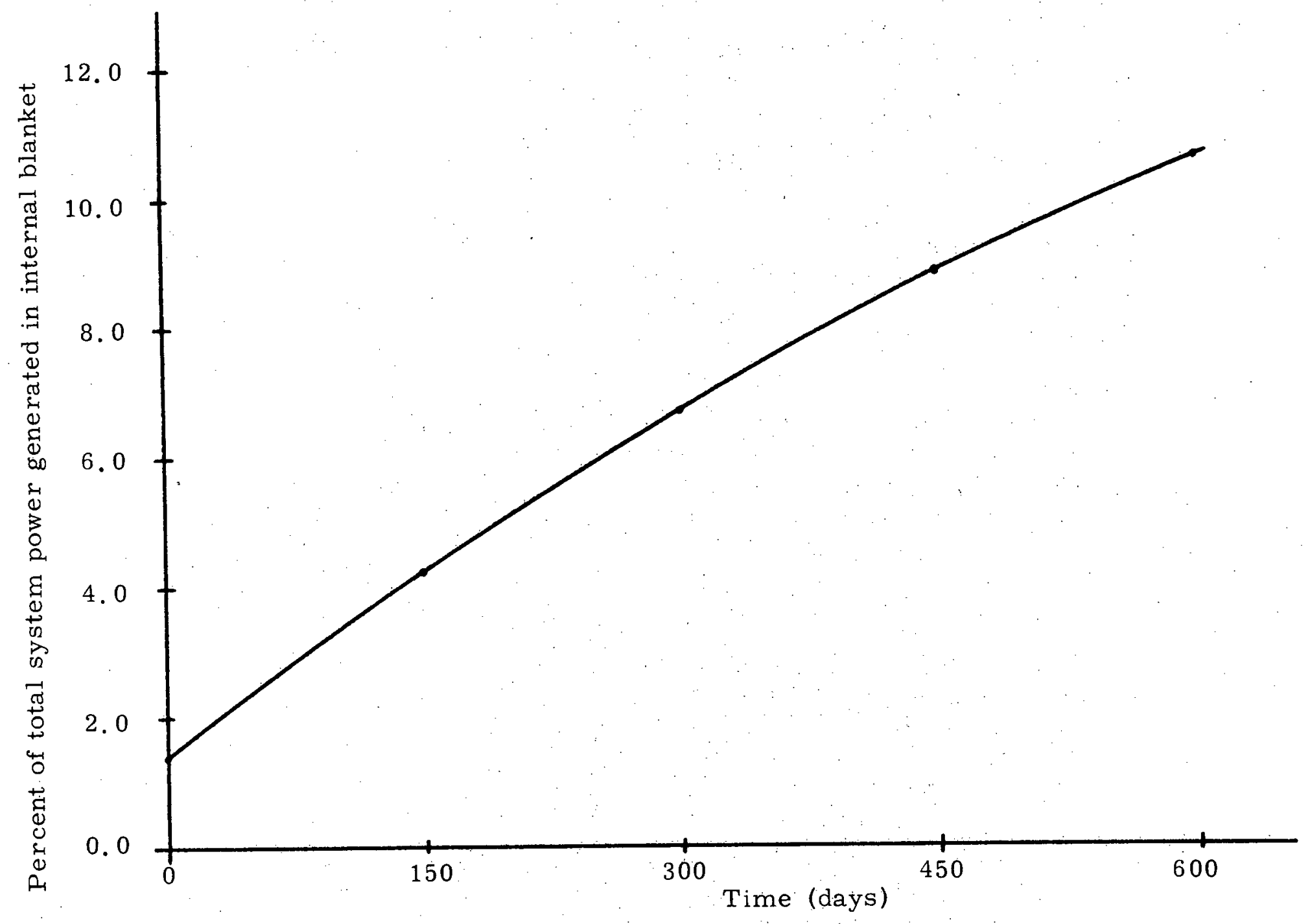

FIG. 2. 8. Percent of Total System Power Generated in a $30-\mathrm{cm}$ Internal Blanket 
attributable to the fertile isotopes ( $\mathrm{U}-238$ and $\mathrm{Pu}-240$ ), the bred fissile isotopes $(\mathrm{Pu}-239$ and $\mathrm{Pu}-241)$, and the residual fissile isotope (U-235) is plotted in Fig. 2.9. These curves were derived from the 600-day batch burnup of a parfait configuration having an initially clean $30-\mathrm{cm}$ internal blanket, and power generation was here assumed to arise only from the fission of heavy metal isotopes in the internal blanket. In an equilibrium cycle, for which one half of the core fuel assemblies are replaced every year, the internal blanket starts each cycle with an average plutonium concentration roughly equivalent to that which is built up in the batch burned internal blanket in 150 days. Therefore, : the power contribution from the internal blanket of a parfait configuration operating over a 300 -day equilibrium cycle is represented by the values plotted in Fig. 2.8 in the period from 150 to 450 days. Table 2.5 compares the fraction of the total reactor power generated in each major region of both the reference and parfait configurations at the middle of the equilibrium cycle.

TABLE 2.5

Mid-Equilibrium Cycle Power Fraction in Each Core Region

\begin{tabular}{lcc}
\hline & $\begin{array}{c}\text { Reference } \\
\text { Total Power }\end{array}$ & $\begin{array}{c}\text { Parfait } \\
\text { Total Power }\end{array}$ \\
\hline Internal blanket & - & 5.98 \\
Core zones & 90.55 & 82.64 \\
Axial blanket & 3.76 & 4.68 \\
Radial blanket & 5.69 & 6.70 \\
\hline
\end{tabular}




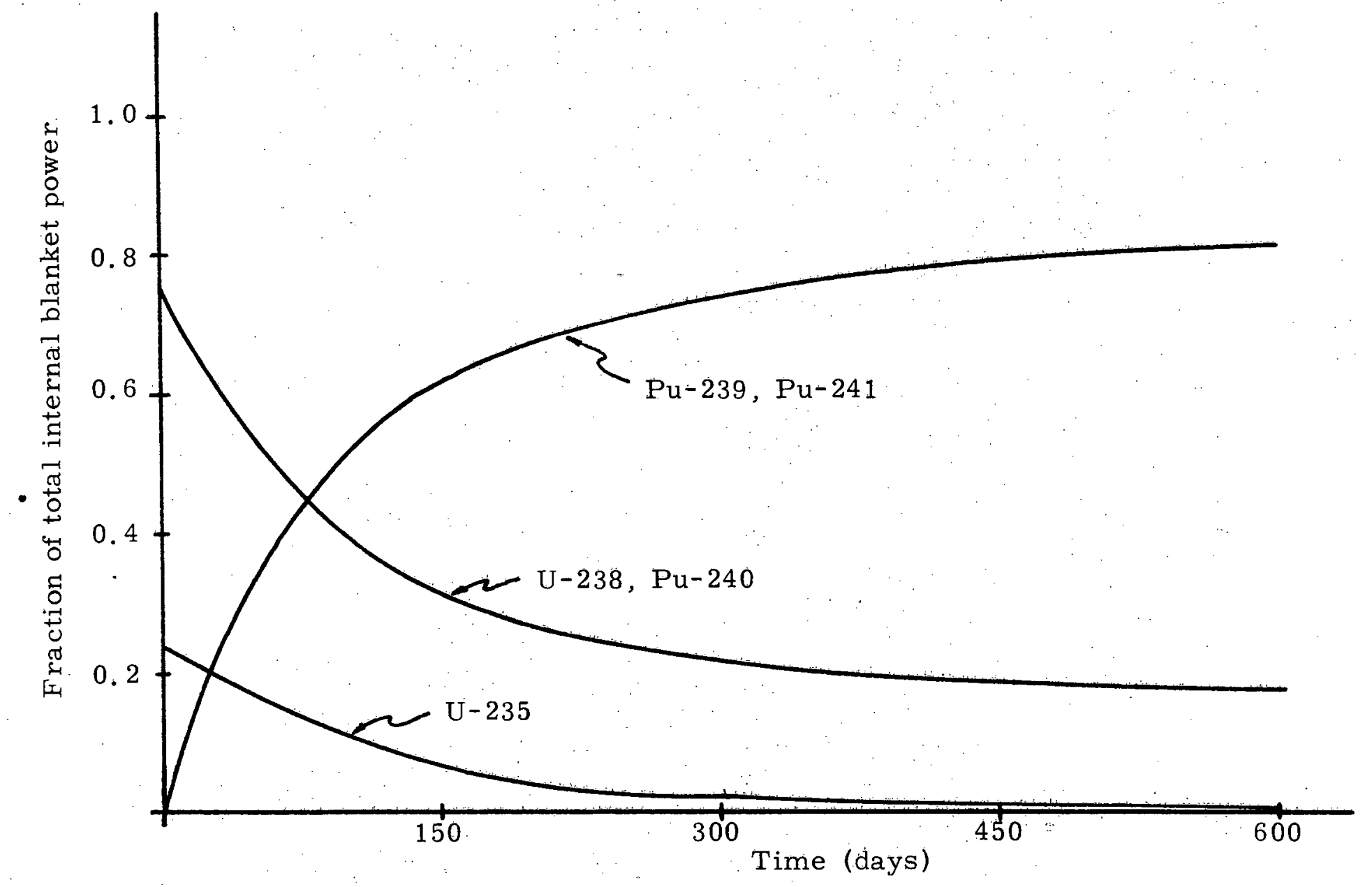

FIG. 2.9. Sources of Power in a $30-\mathrm{cm}$ Internal Blanket 


\subsubsection{Flux and Power Profiles}

The series of figures at the end of this section show the flux and power profiles in the reference core and in a parfait configuration having a $30-\mathrm{cm}$ internal blanket. The core geometries are the same as previously shown in Fig. 2.1. The axial plots were generated for two radial positions in the core: $r=0$ (the reactor centerline) and $r=$ $107.5 \mathrm{~cm}$ (a point roughly halfway through the outer core zone). The radial plots were generated at two planes in the reactor: at the core midplane and at an axial position $32.24 \mathrm{~cm}$ above the core midplane, roughly $17 \mathrm{~cm}$ above the top edge of the internal blanket. Those quantities which are plotted included the total flux, each of the group fluxes and the local power density. Each graph presents the data for the parfait and reference cores at both the beginning (BOC) and end (EOC) of a 300-day equilibrium burnup cycle. The general characteristics of these plots are as follows:

1) The internal blanket has a substantial influence on the flux shape in the core and this influence extends about $15 \mathrm{~cm}$ from the internal blanket's outer surface. Beyond this zone of influence, which corresponds to several neutron mean free paths, the flux profiles in the parfait configuration take on essentially the same shape as in the reference core. The neutron spectrum in the fissile-loaded zones of the parfait configuration is slightly harder than that of the reference core, and in the internal blanket the spectrum is quite similar to that of the external blanket regions.

2) As the parfait configuration burns up (and builds up a substantial inventory of fissile plutonium in the internal blanket), the 
flux shapes become progressively more similar to those of the reference core.

3) The peak total flux of the parfait configuration is substantially reduced at the center of the core - a location at which the peak flux of the reference core occurs.

\subsection{CORE FUEL VOLUME FRACTION}

The volume fraction of fuel in the core is a design parameter which was identified as having a significant impact upon the absolute performance and the relative performance of the reference and parfait designs. Figure 2. 24 illustrates this effect for two major performance characteristics, the breeding ratio and the burnup reactivity loss; and Fig. 2.25 illustrates the influence of the fuel volume fraction on the equilibrium core fissile inventory. This comparison was made for cores having equal volumes and equal reactivity-limited lifetimes. The other performance and design characteristics listed in Table 2.2 were relatively unaffected by the fuel volume fraction. In this comparison, the fuel volume fraction in the core was increased at the expense of the coolant volume fraction and vice versa. The structural component of the core was held constant at the base case level of 20 volume percent.

The effect of the fuel volume fraction variation is quite dramatic. The reference core, for example, displayed a $50 \%$ drop in the burnup reactivity loss and an increase of greater than $100 \%$ in the breeding gain (breeding ratio -1) for an increase in fuel volume from 27 percent to 33 percent. Throughout this range, the parfait configuration maintained an advantage over the reference core for both of these performance 


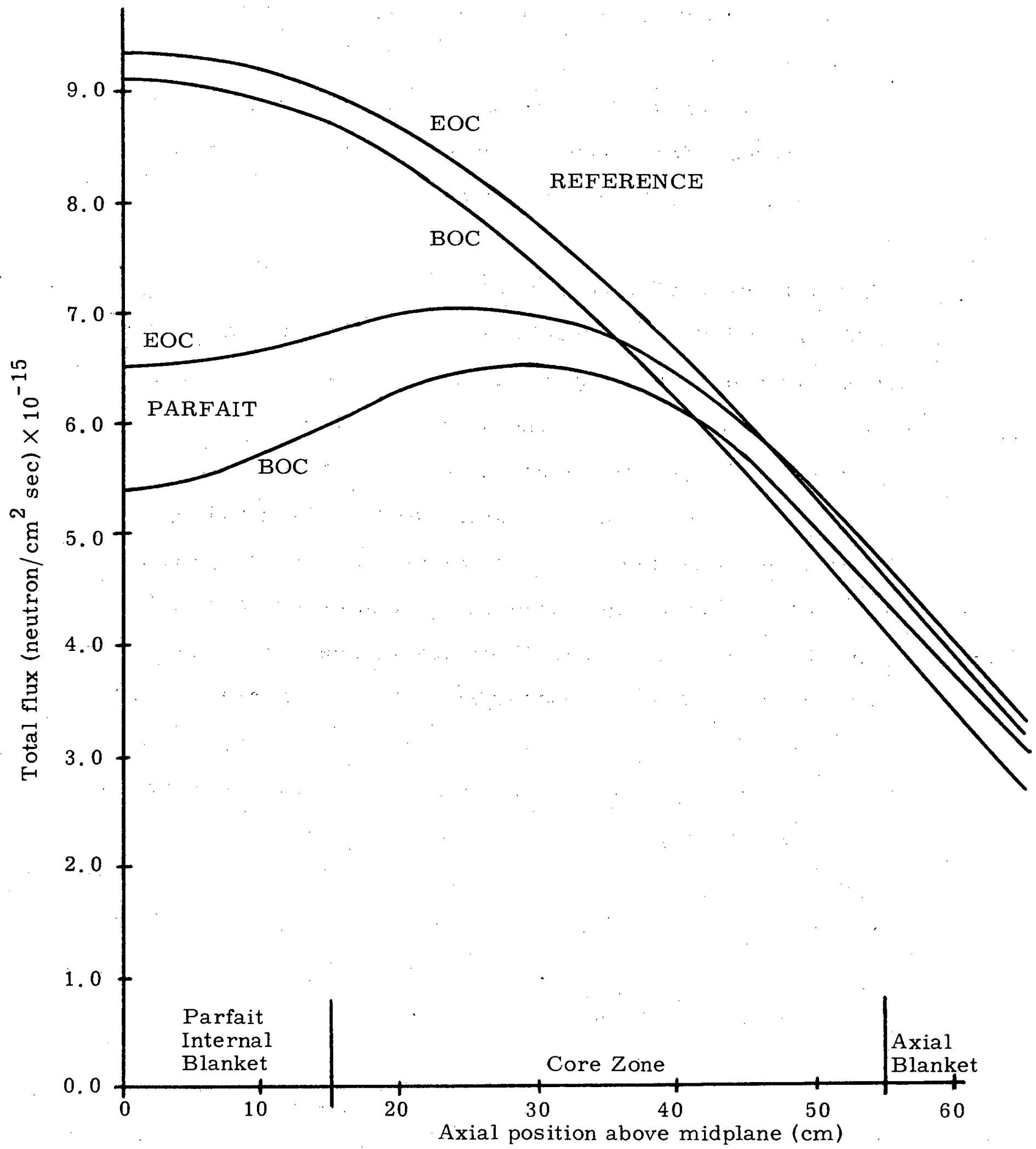

FIG. 2.10. Total Flux Along Core Centerline for Reference Core and $30-\mathrm{cm}$ Internal Blanket Parfait 


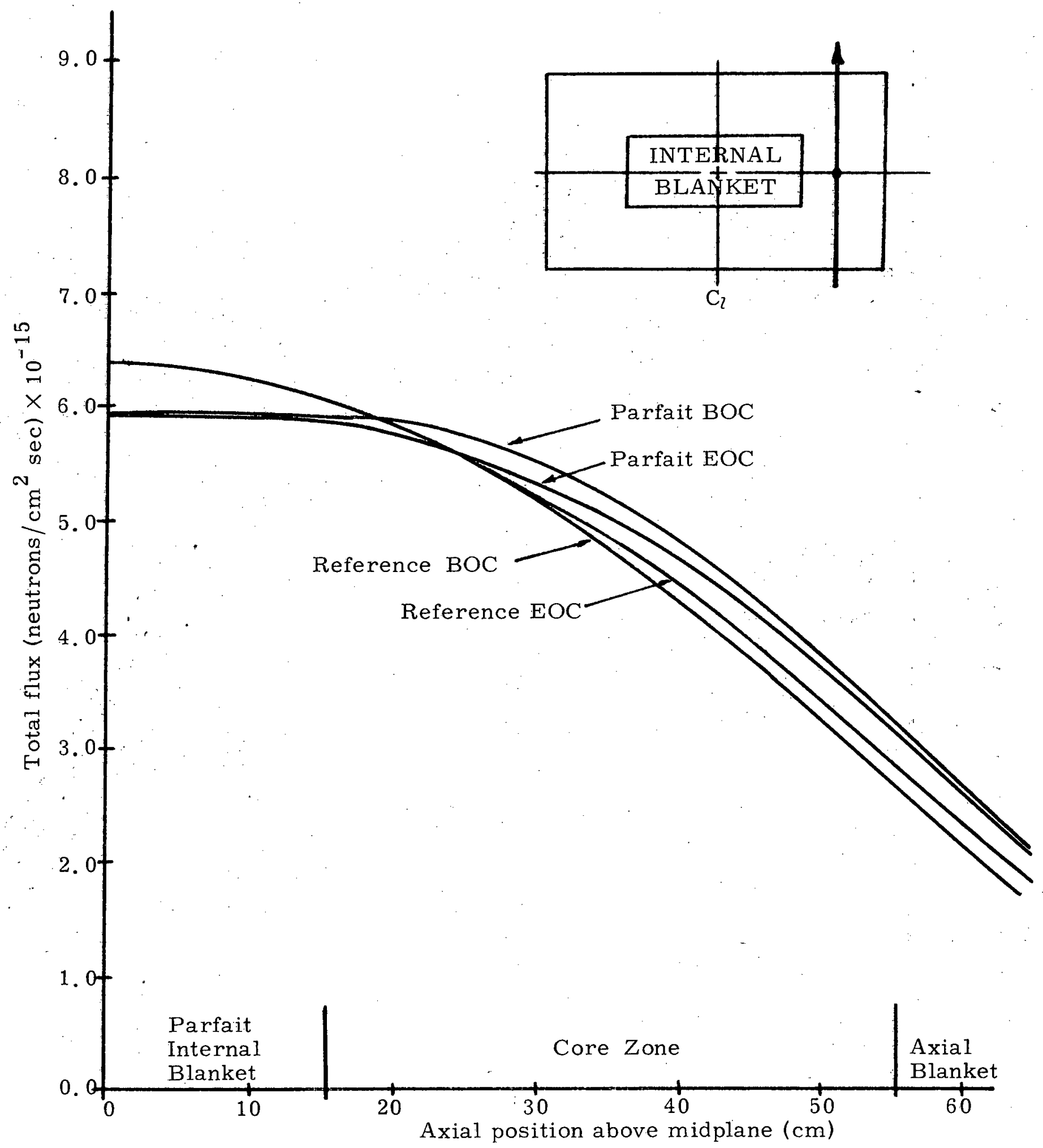

FIG. 2. 11. Total Flux at Radial Position $=107.5 \mathrm{~cm}$ for Reference Core and 30-cm IB Parfait 


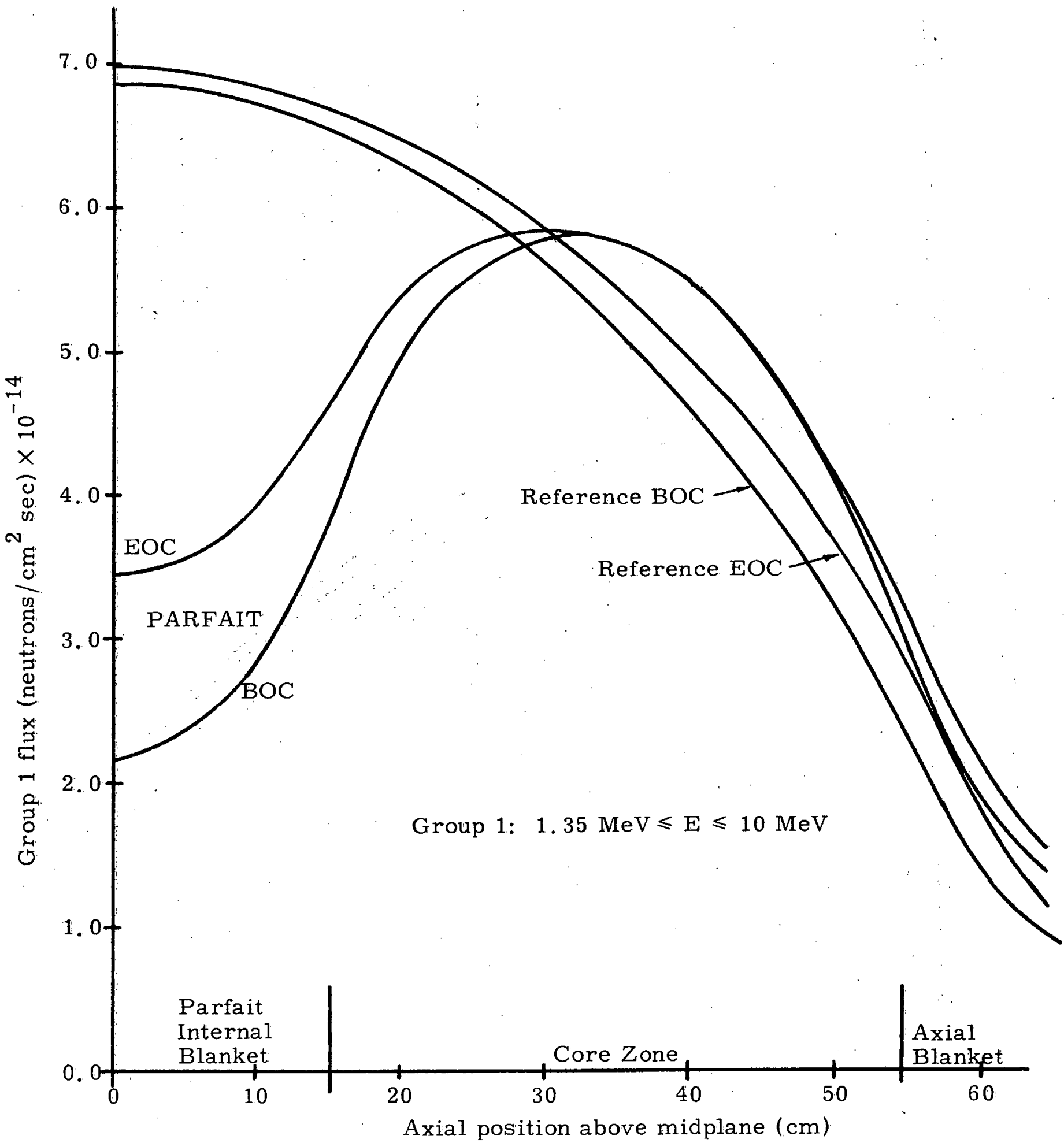

FIG. 2.12. Group 1 Flux Along Core Centerline for Reference Core and $30-\mathrm{cm}$ IB Parfait 


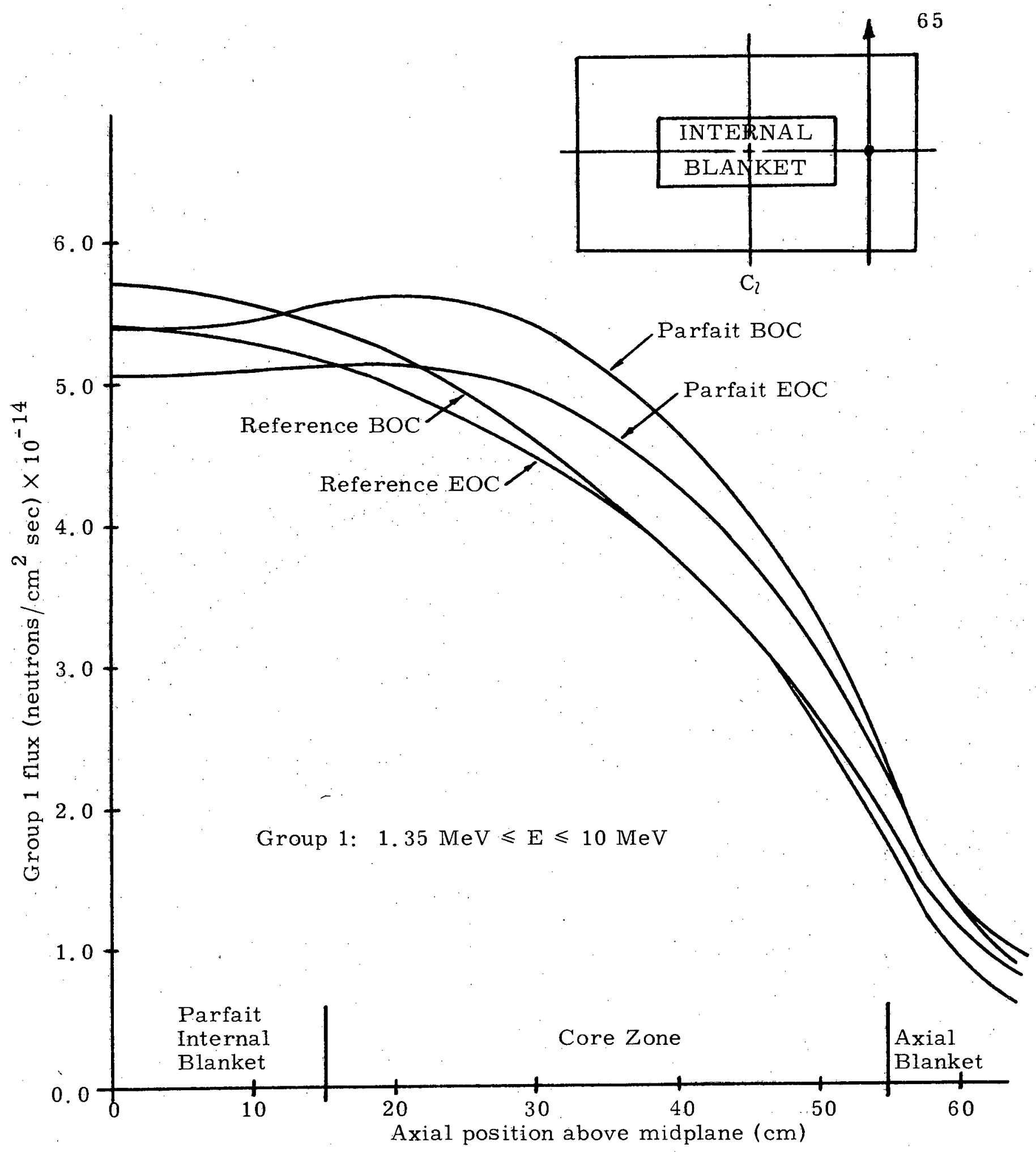

FIG. 2.13. Group 1 Flux at Radial Position $=107.5 \mathrm{~cm}$ for Reference Core and 30-cm Internal Blanket Parfait 


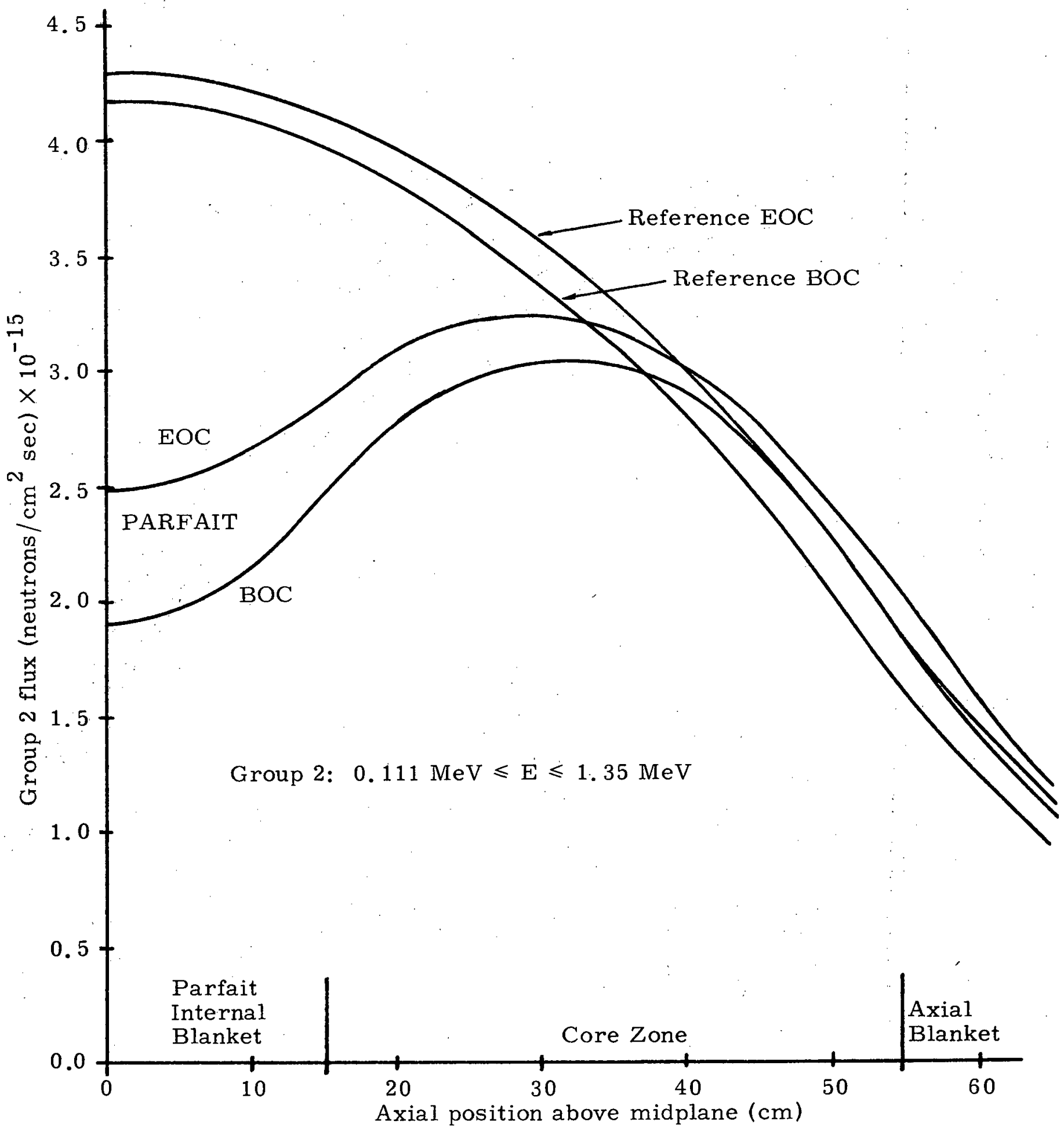

FIG. 2. 14. Group 2 Flux Along Core Centerline for Reference Core and $30-\mathrm{cm}$ Internal Blanket Parfait 


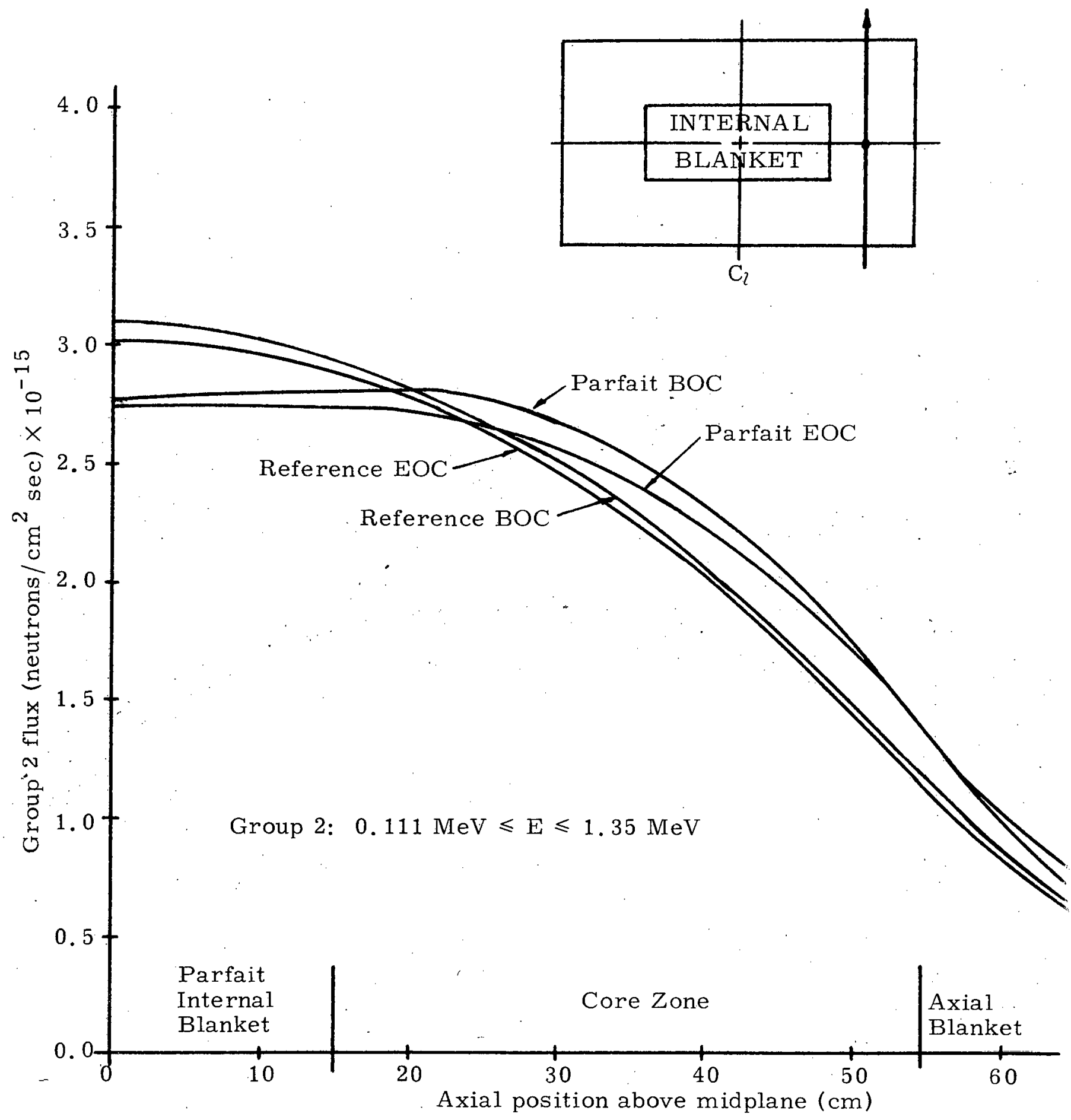

FIG. 2. 15. Group 2 Flux at Radial Position $=107.5 \mathrm{~cm}$ for Reference Core and 30-cm Internal Blanket Parfait 


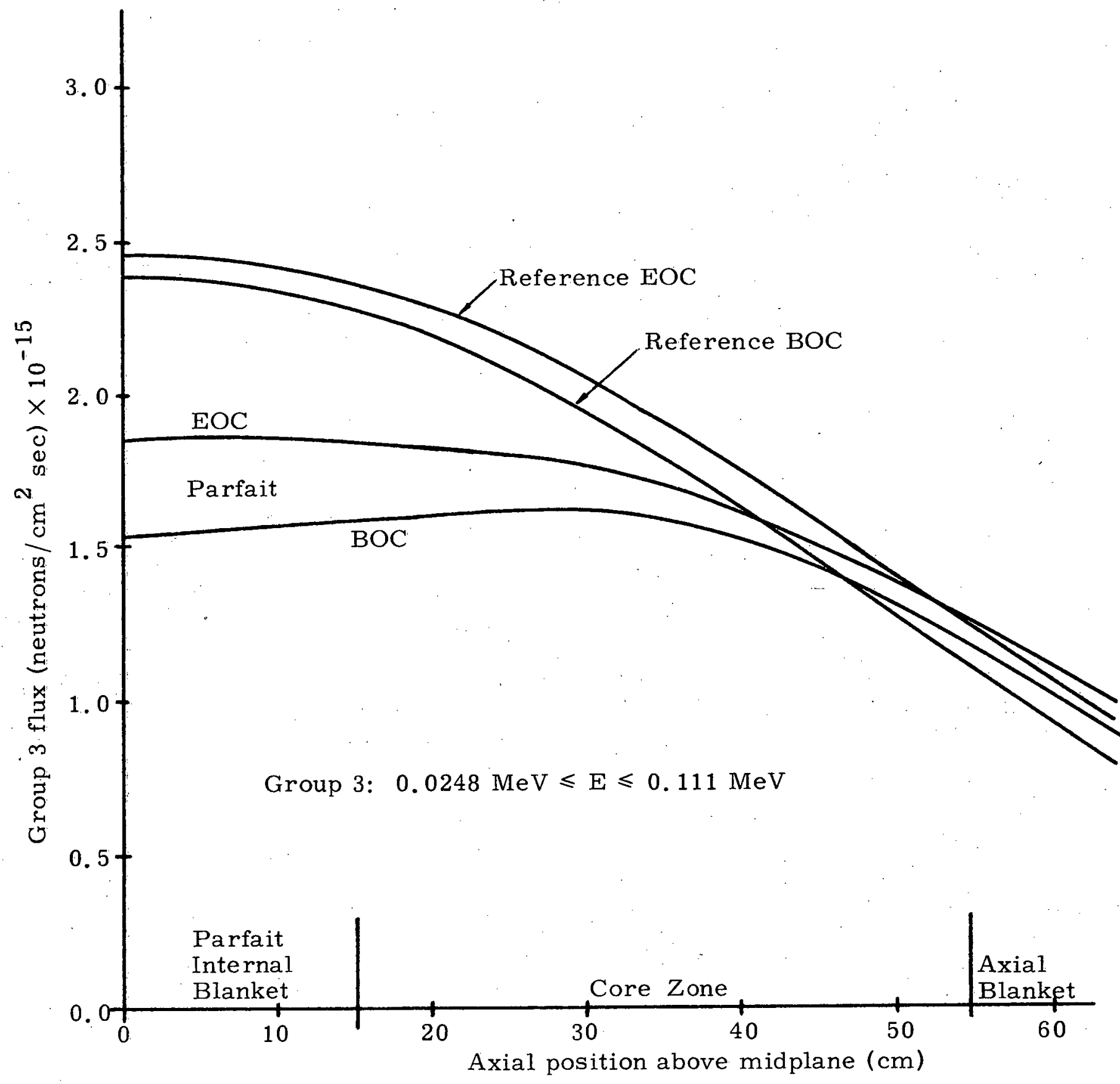

FIG. 2. 16. Group 3 Flux Along Core Centerline for Reference Core and $30-\mathrm{cm}$ IB Parfait 


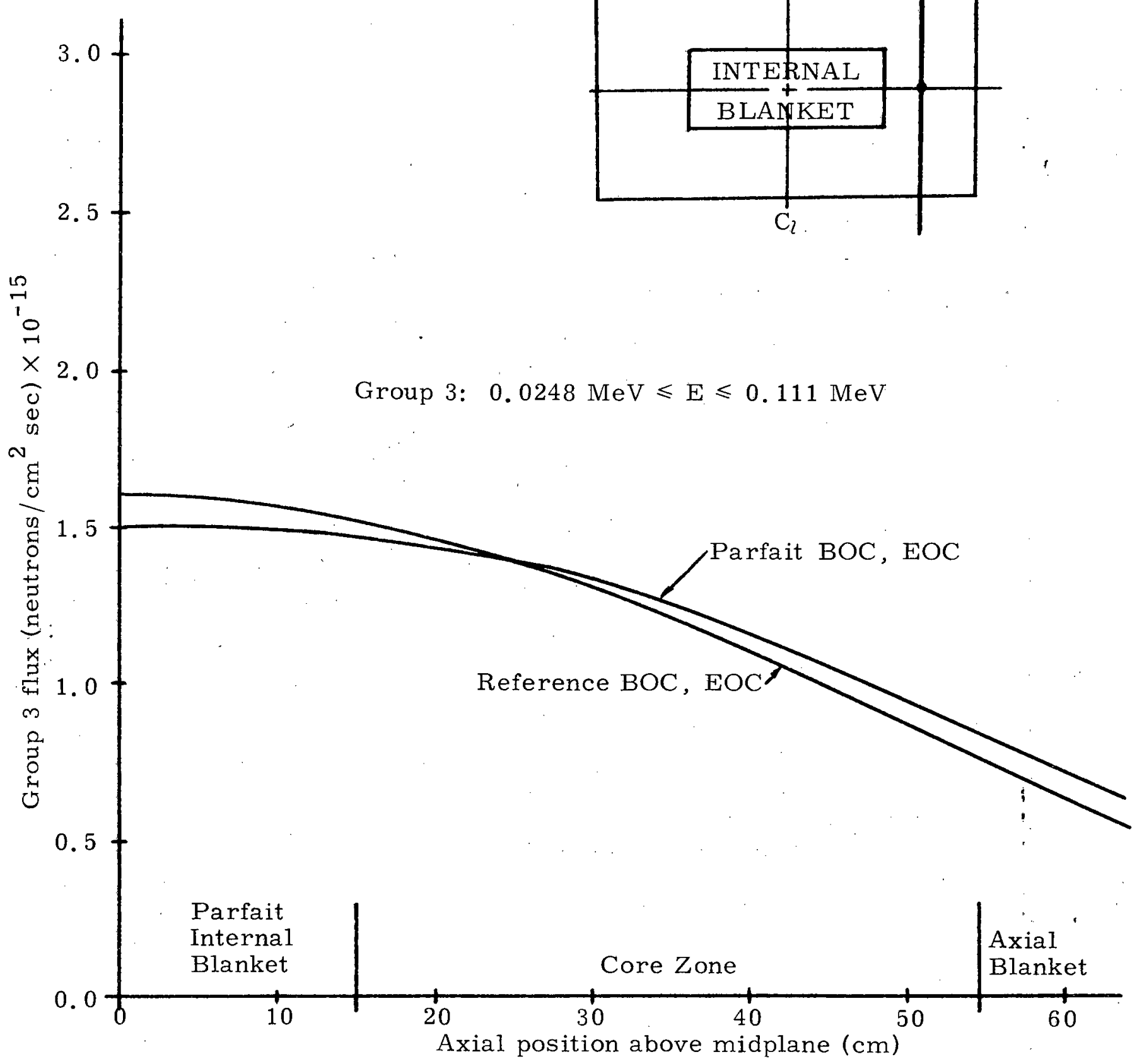

FIG. 2.17. Group 3 Flux at Radial Position $=107.5 \mathrm{~cm}$ for Reference Core and 30-cm IB Parfait 


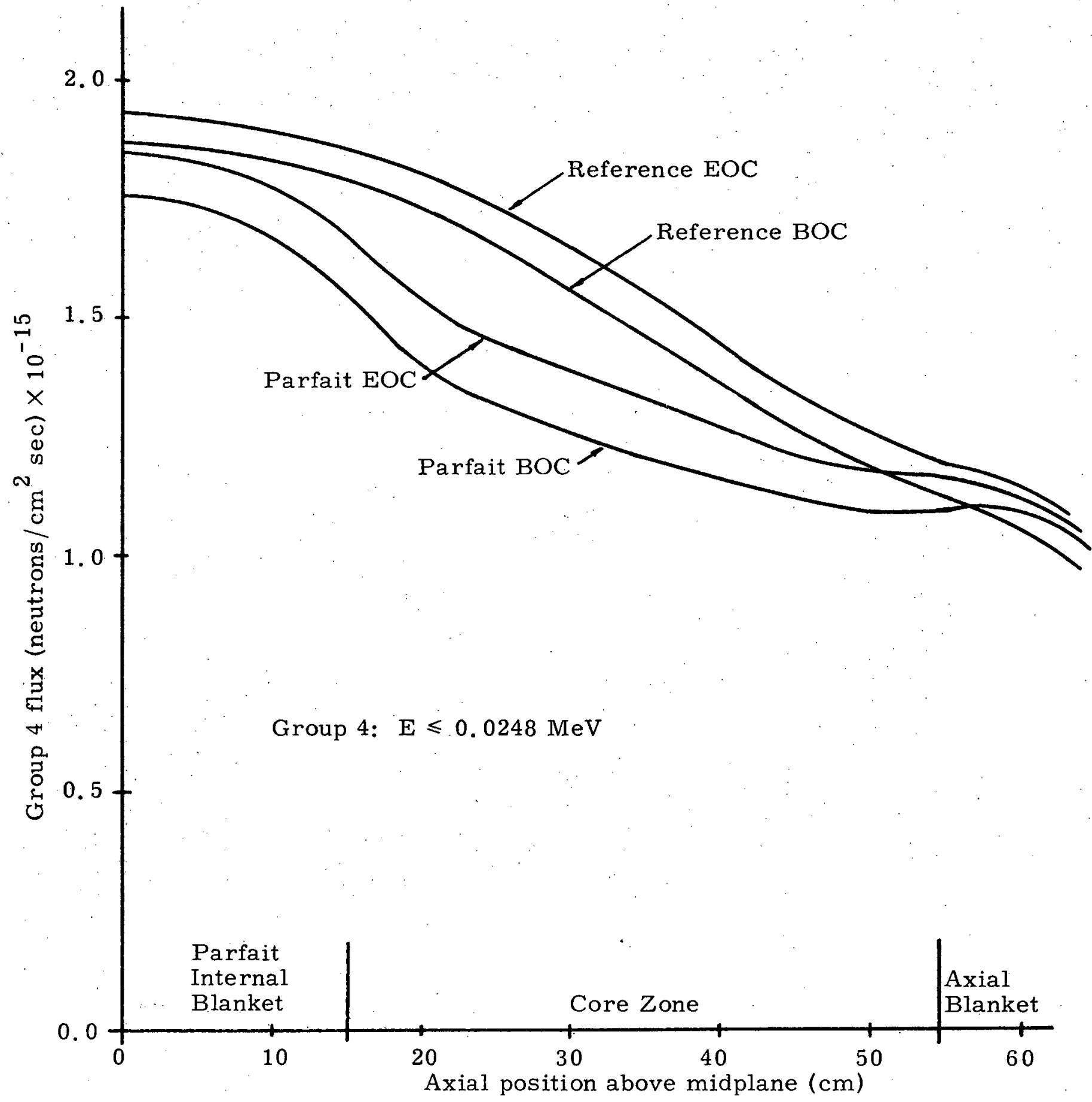

FIG. 2. 18. Group 4 Flux Along Core Centerline for Reference Core and 30-cm IB Parfait 


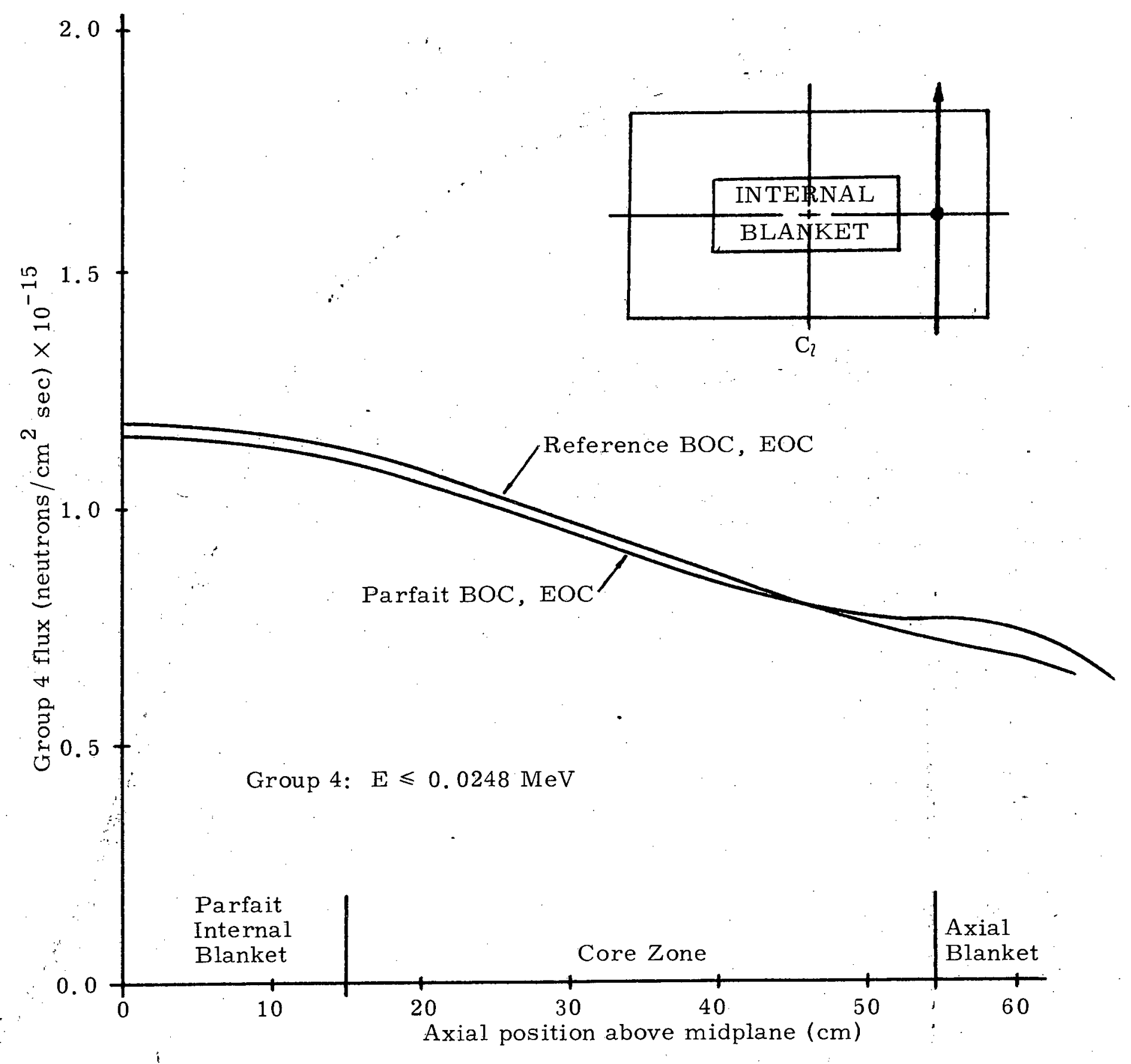

FIG. 2. 19. Group 4 Flux at Radial Position $=107.5 \mathrm{~cm}$ for Reference Core and $30-\mathrm{cm}$ IB Parfait 


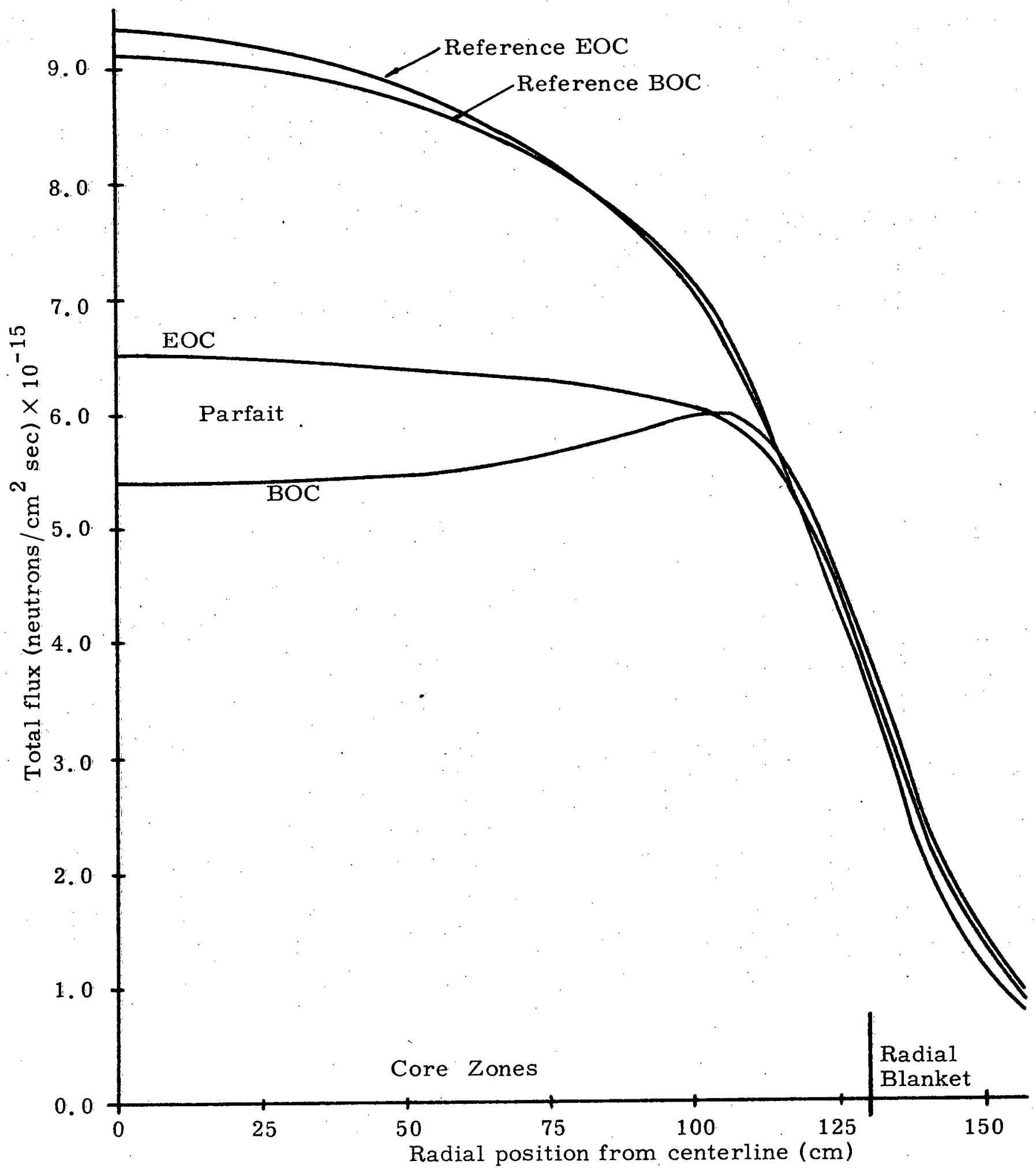

FIG. 2.20. Total Flux at Core Midplane for Reference Core and $30-\mathrm{cm}$ IB Parfait 


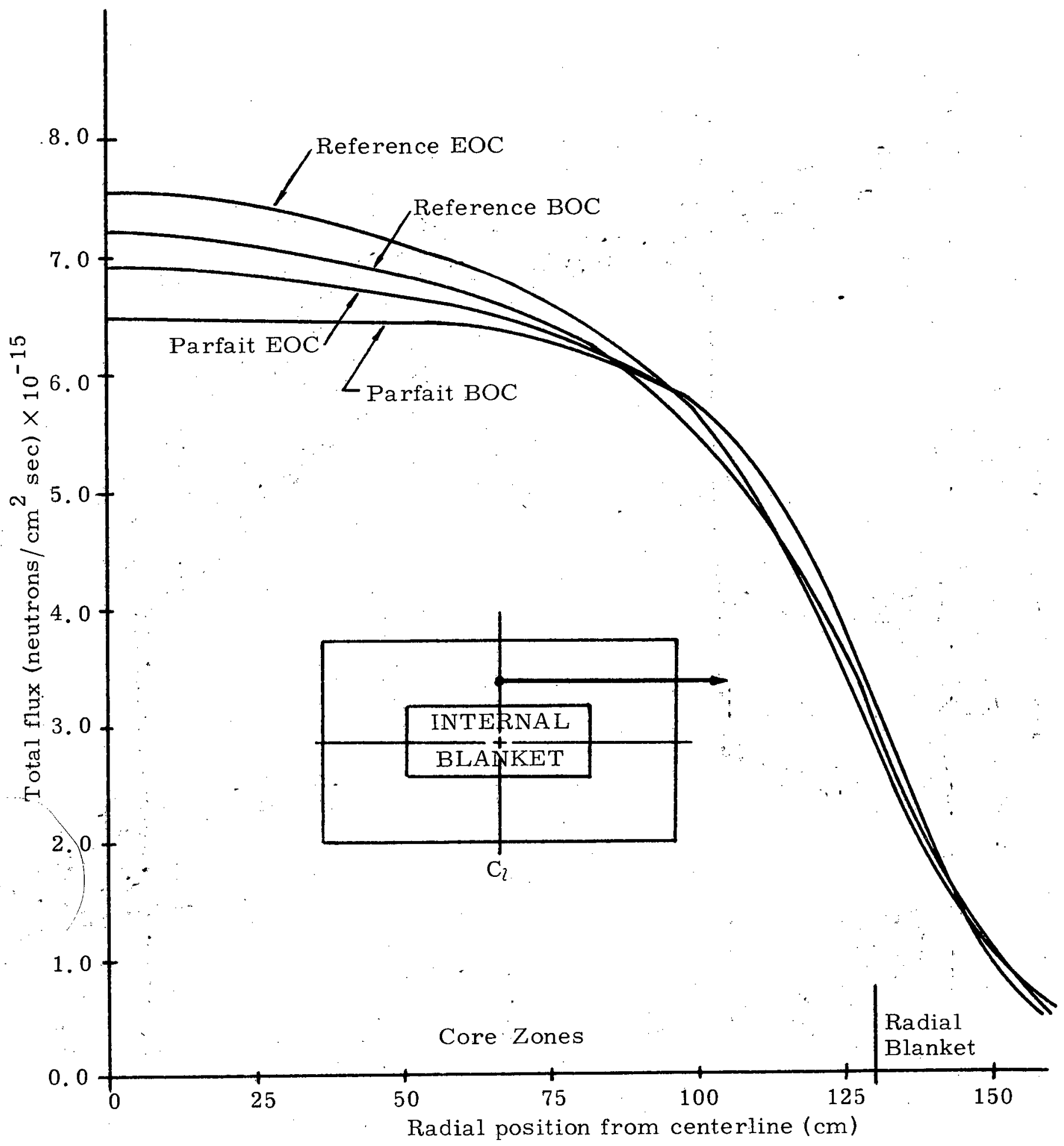

FIG. 2.21. Total Flux at $32.24 \mathrm{~cm}$ Above Midplane for Reference Core and 30-cm IB Parfait 


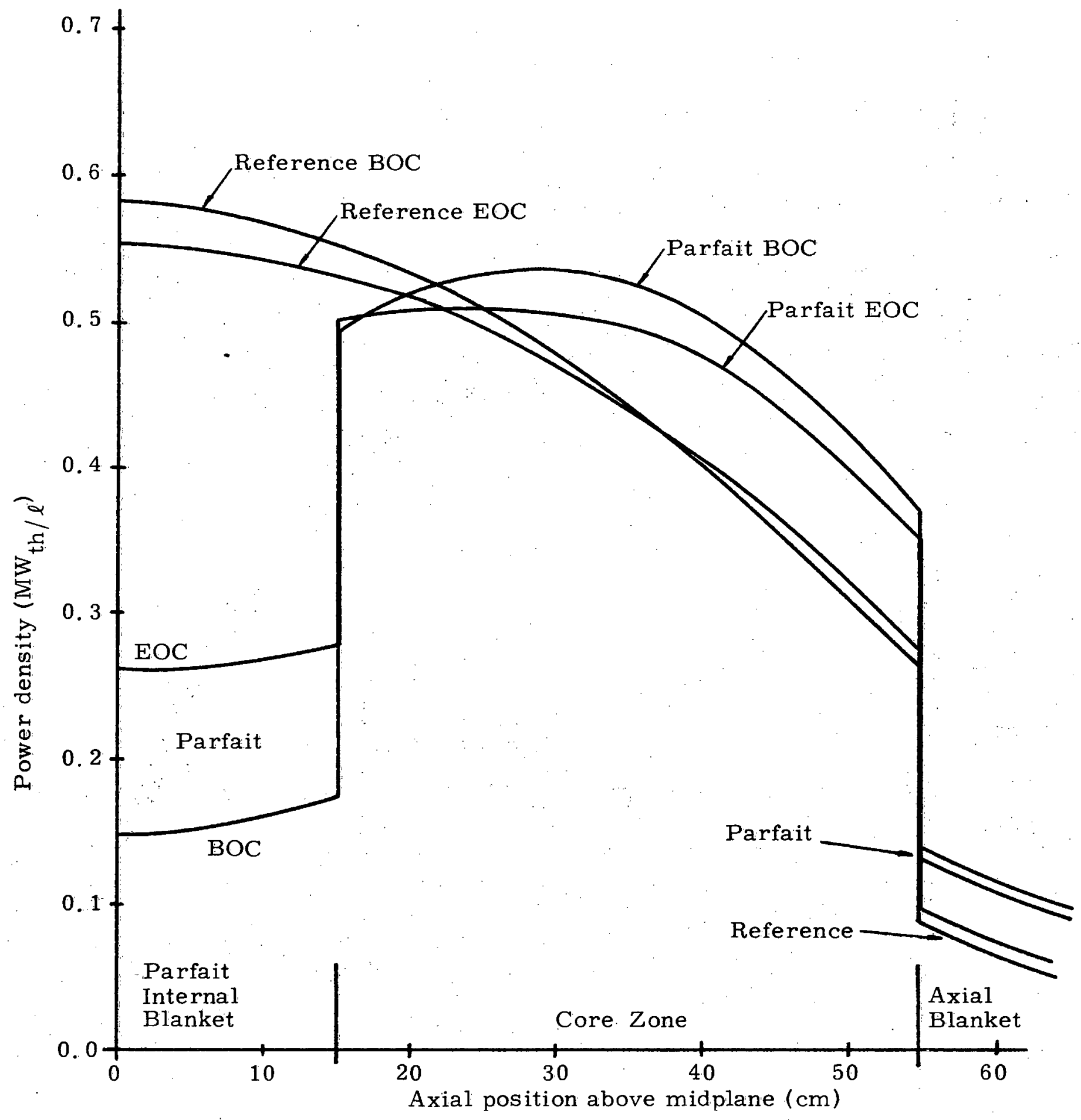

FIG. 2.22. Power Density Along Core Centerline for Reference Core and $30-\mathrm{cm}$ IB Parfait 


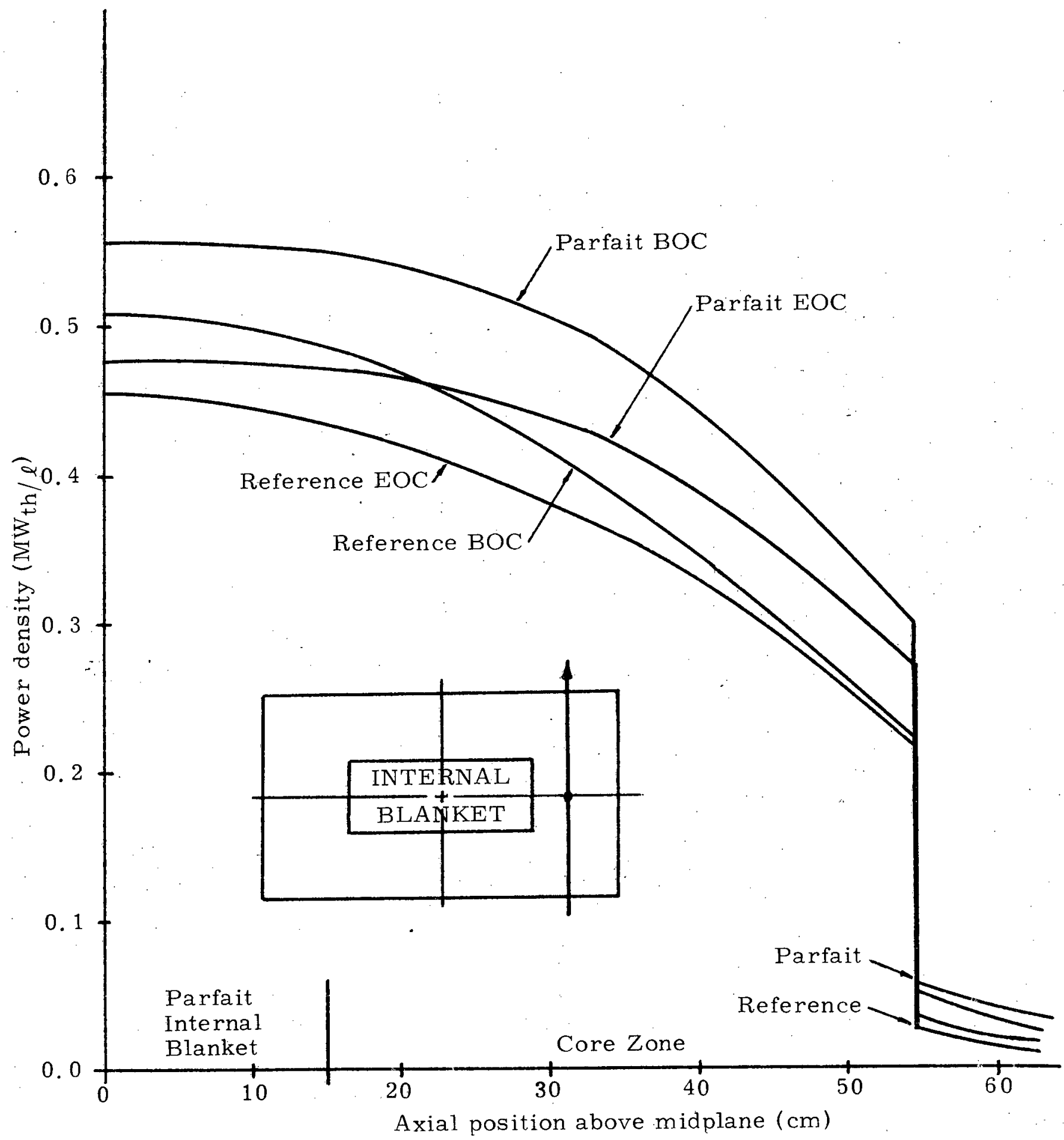

FIG. 2. 23. Power Density at Radial Position $=107.5 \mathrm{~cm}$ for Reference Core and $30-\mathrm{cm}$ IB Parfait 


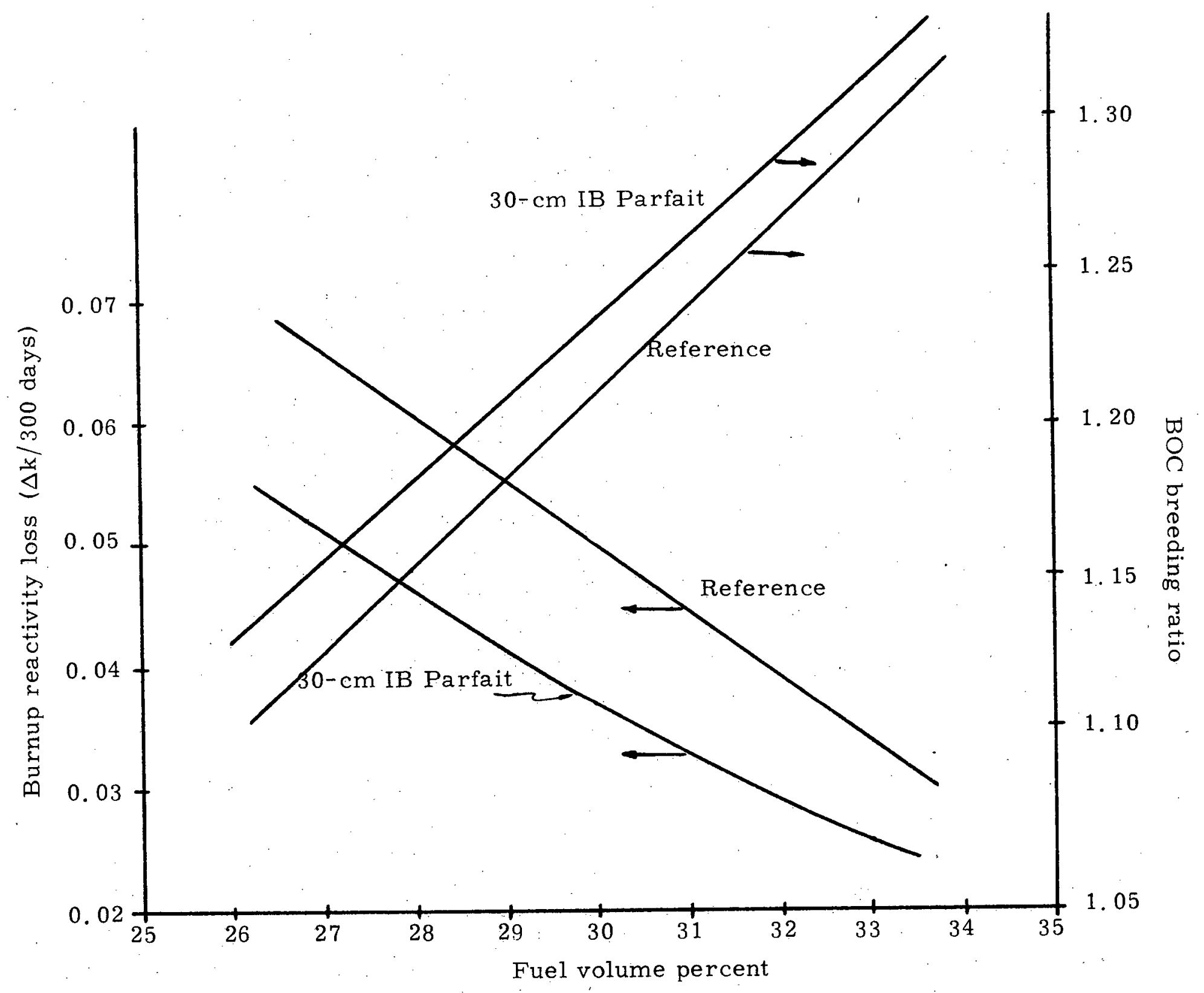

FIG. 2. 24. Performance Sensitivity to Fuel Volume Percent in Core 


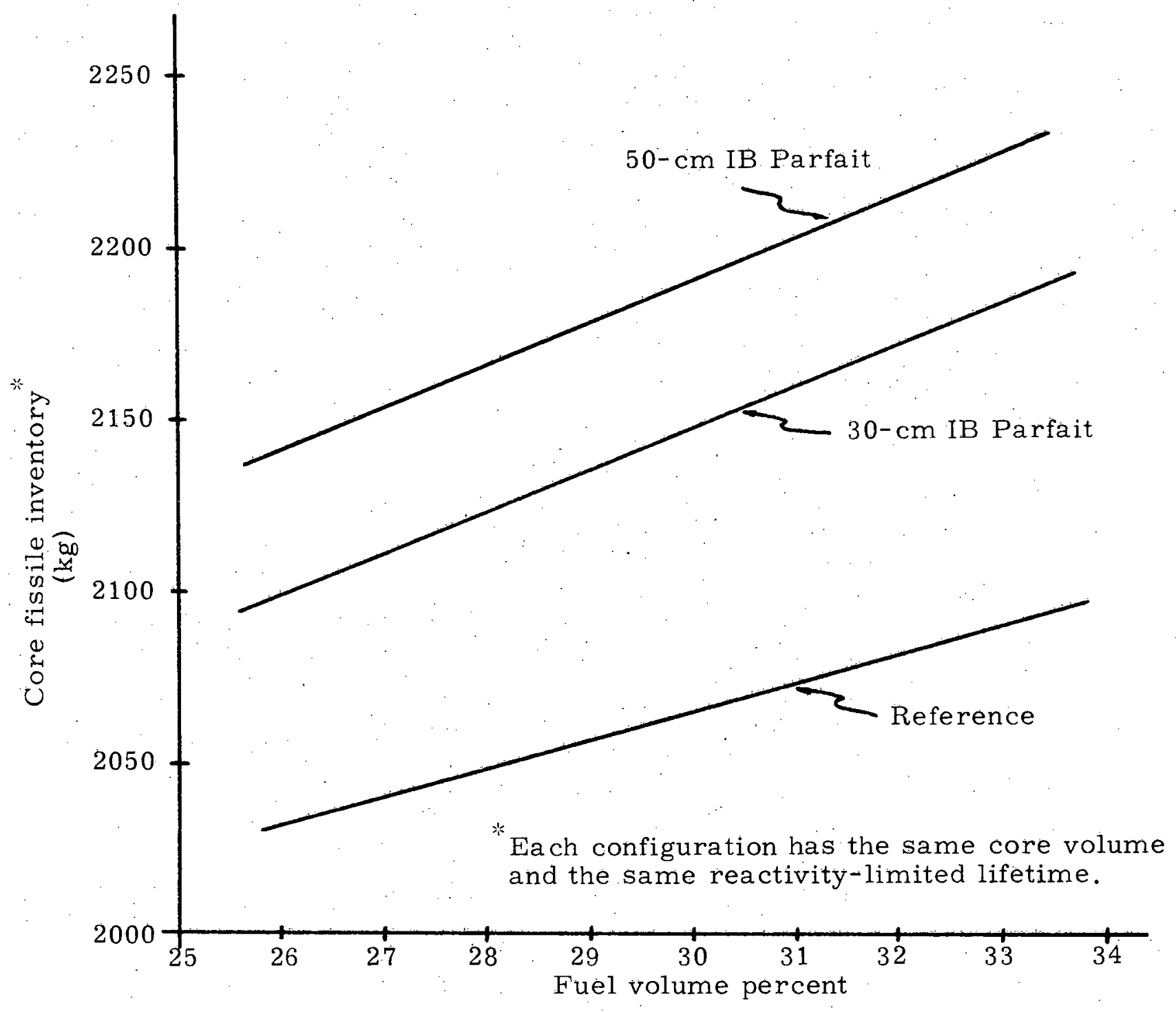

FIG. 2.25. Core Fissile Inventory as a Function of Fuel Volume Percent in Core 
parameters, but that advantage was slightly diminished at the higher fuel volume fractions. The increase in the equilibrium cycle fissile inventory for both the reference and parfait configurations is the result of adding additional neutron-absorbing fertile material to the cores. This increase in fissile inventory causes a reduction in the peak total fluxes in each configuration, but increases the carrying charges associated with fissile material purchases. The net effect of the enhanced performance characteristics and the increased inventory. charges on the fuel cycle economics will be evaluated as a function of core fuel volume fraction in Chapter 5 .

\subsection{REACTIVITY CONTROL REQUIREMENTS}

The $25 \%$ reduction in the burnup reactivity loss (Table 2.3 ) exhibited by the parfait configuration having a $30-\mathrm{cm}$ internal blanket represents a significant advantage for this concept. This advantage translates directly into a requirement for fewer and/or lower worth control rods in the core. In addition, the parasitic loss of neutrons to control poison is reduced.

\subsubsection{Burnup Reactivity Loss}

The primary reason for the reduced reactivity swing of the parfait configuration is preferential breeding of fissile material in the internal blanket. A previous figure, Fig. 2.5, illustrated the rate at which plutonium builds up in the internal blanket, but the net reactivity effect of the added plutonium is more involved than the simple addition of

fissile material to the core. As plutonium builds up in the internal blanket, the flux and adjoint flux depression in and a round the internal blanket is gradually reduced. The net effect is that the continuing 
buildup of plutonium in the region contributes additional worth to the fissile material already bred into the internal blanket and to the local core material. Another factor, though less significant than the above, is that during irradiation, uranium-238, a neutron-absorbing material, is effectively removed from the internal blanket as a. result of fast fissions and conversion to fissile isotopes. The net effect of all of these factors is illustrated in Fig. 2.26 where the effective reactivity addition per unit of fissile material bred in a $30-\mathrm{cm}$ internal blanket is plotted as a function of exposure. This curve was developed by making a series of snapshot $\mathrm{k}_{\text {eff }}$ calculations in which the composition of the internal blanket was changed to simulate progressive stages in its burnup; while the material composition throughout the rest of the reactor. remained unchanged. This sharply rising function illustrates that the effective worth of one kilogram of fissile material bred in the internal blanket at the end of a one-year equilibrium cycle is $24 \%$ greater than that of an equal fissile material gain at the beginning of the cycle.

\subsubsection{Control Material Worth}

Two types of calculations were performed using the $2 \mathrm{DB}$ code to evaluate the worth of control material in the reference and parfait cores. In the first calculation, the reactivity worth of a homogeneous smear of boron-10 in the core and axial blanket regions of the two configurations was evaluated. In the second calculation, discrete control rods were simulated as shown in Fig. 2.27, and the reactivity worths of equivalent localized boron concentrations were evaluated for both cores. The absolute and relative results of these calculations are tabulated in Table 2.6. 


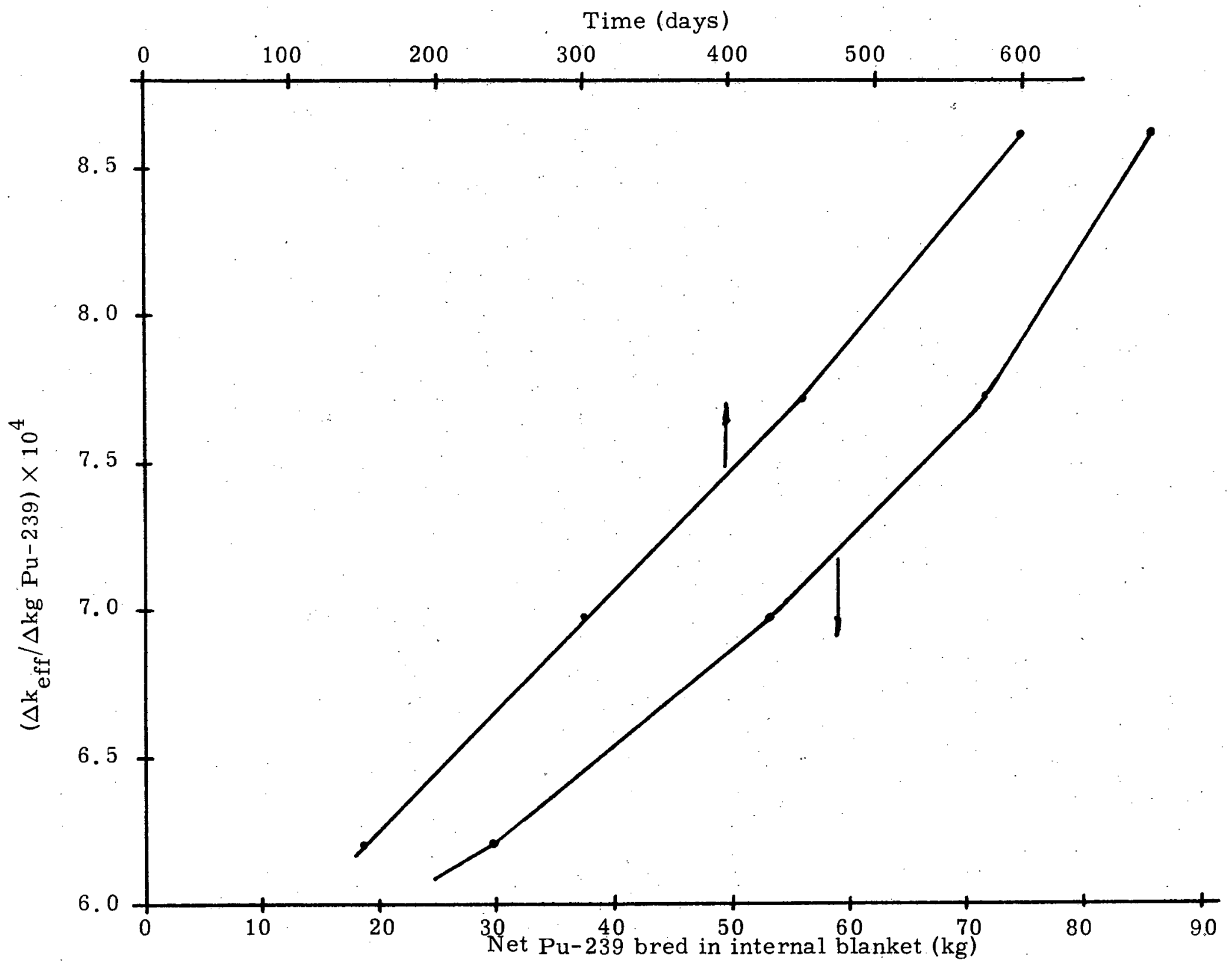

FIG. 2. 26. Effective Reactivity Addition per Unit of Fissile Bred in a $30-\mathrm{cm}$ 


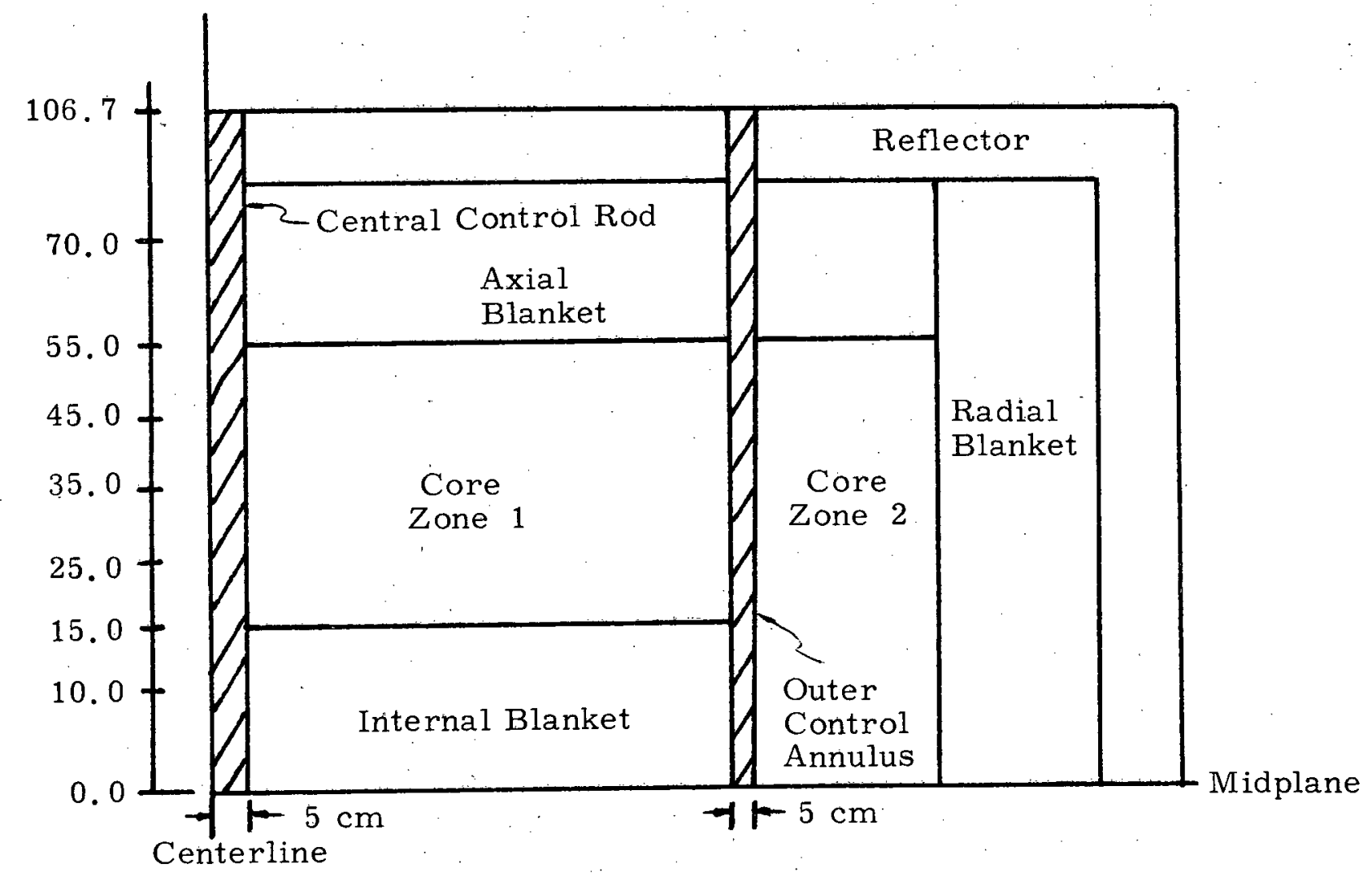

FIG. 2.27. Discrete Control Rod Simulation *Parfait concept with internal blanket as shown;
reference core without internal blanket region. 
TABLE 2.6

Comparative Worth of Identical Control Material

Additions in the Reference and Parfait Cores

\begin{tabular}{|c|c|c|c|}
\hline \multirow{2}{*}{$\begin{array}{l}\text { Control } \\
\text { Material } \\
\text { Addition }\end{array}$} & \multicolumn{2}{|r|}{$\% \Delta \mathrm{k}$} & Relative Results \\
\hline & Reference & $\mathrm{n}$ IB $\mathrm{Pa}$ & $\frac{\% \Delta \mathrm{k} \text { Parfait }}{\% \Delta \mathrm{k} \text { Reference }}$ \\
\hline
\end{tabular}

Homogeneous boron-10 concentration in core and axial blanket

4.33

4.23

0.977

$=1.0 \times 10^{-4}$

atoms/barn-cm

Centerline control rod

0.354

$0: 240$

0.680

Outer control annulus

4.71

4.84

1.025

The results obtained from the homogeneous poison calculation demonstrate that, on the average, control material has very nearly equal worth in both cores. The discrete rod calculations indicate that in the parfait configuration, the central control rod is worth substantially less ( $32 \%$ less) than in the reference core, while the rods at the interface between the inner and outer core zones simulated by the outer control annulus had a slightly greater worth. Since the majority of the control rods of a large fast reactor are likely to be located, as illustrated in Fig. 2.28, near the interface between the two core enrichment zones to reduce radial power peaking, the control systems for the reference and parfait configurations would appear substantially the

the same except that/parfait concept would require fewer burnup control 


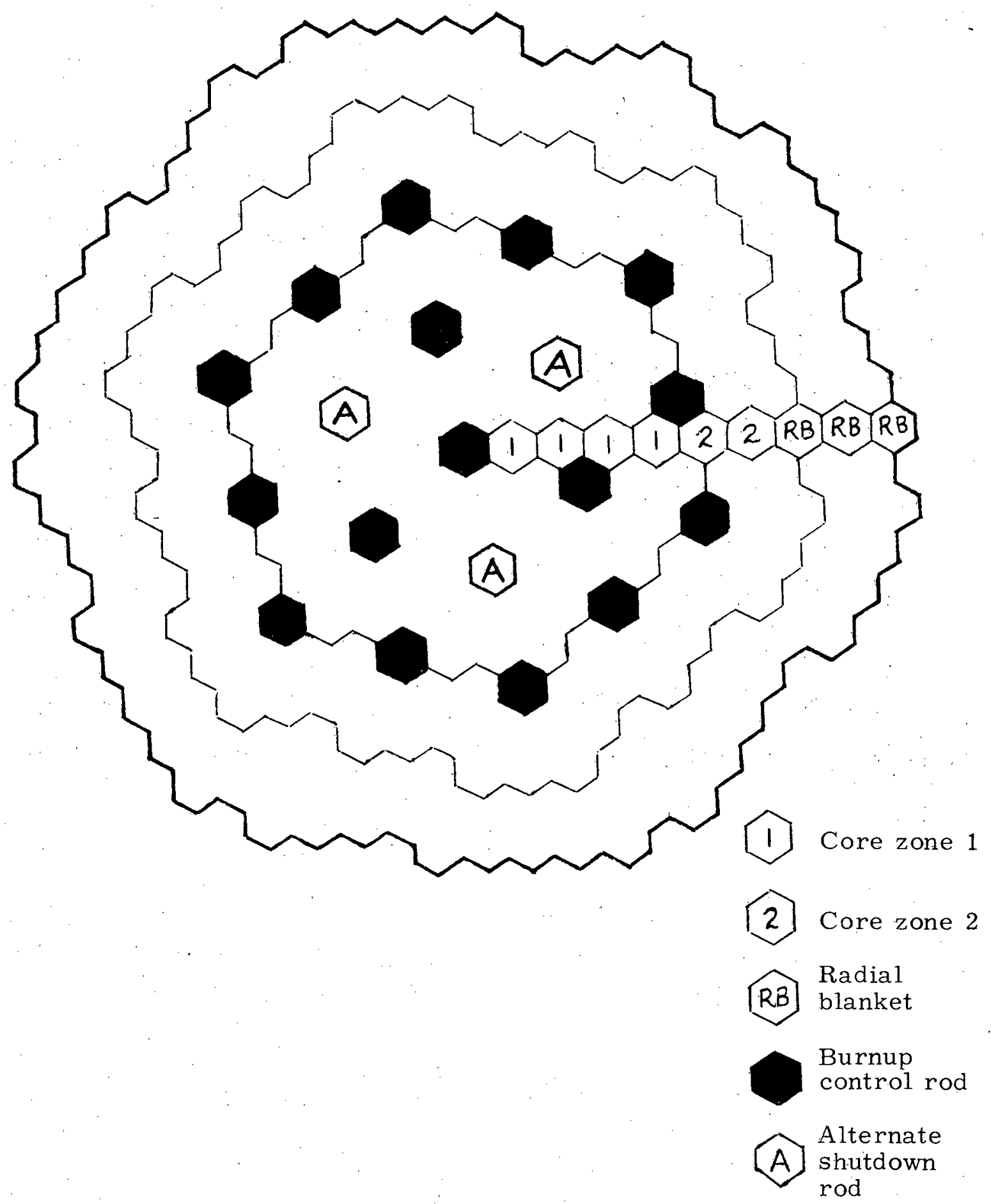

FIG. 2.28. Control Rod Arrangement in Demonstration Size LMFBR Core (P1). 
rods. To demonstrate the direct and indirect gains that result from this type of advantage, consider the core shown in Fig. 2.28. Of the 19 control rods in this core, 12 a re required to compensate for burnup losses. Since the parfait concept requires $25 \%$ less burnup compensation, three of those control rods could be removed and replaced with fuel assemblies. This addition of three extra fuel assemblies to the core would boost the core fuel volume fraction by $0.555 \%$, thus allowing the parfait concept a further reduction in the burnup swing as demonstrated by Fig. 2.24. This added fuel volume fraction would contribute to a further $5 \%$ reduction in the reactivity swing experienced by the parfait core. Although the absolute numbers presented in this brief example are highly dependent upon the exact core characteristics and a detailed analysis of the shim and safety control rod requirements, the principle is clearly demonstrated that the advantage of a reduced burnup reactivity swing realized as a requirement for fewer control rods in the core, may contribute to even further reductions in the reactivity control requirements.

The reduced reactivity swing gives the parfait core a substantial. advantage over the reference design which far exceeds the direct capital cost savings realized by merely reducing the number of expensive control rods, each of which may have total costs associated with it as high as $\$ 500,000$ (P2). A reduced number of control rods would tend to ease the difficult mechanical design problems in the region above the core and also diminish the net coolant by-pass flow through the control rods which tends to degrade the mixed-mean coolant outlet temperature. Another advantage of the parfait's reduced reactivity swing is that the time-averaged 
inventory of control poison in the core is reduced with the result that féwer neutrons are parasitically absorbed in control material. This effect was evaluated quantitatively by calculating the breeding ratio loss resulting from the addition of a homogeneous concentration of boron- 10 $\left(1.0 \times 10^{-4}\right.$ atoms/barn-cm) in the core and axial blanket regions of both reactors. This result was combined with the time-averaged concentration of control poison in each of the systems during the equilibrium cycle to arrive at a net control poison breeding ratio penalty. These results are given in Table 2.7. This table shows that the breeding ratio penalty for the parfait configuration is only $68 \%$ of that of the reference core. Because the control pois on breeding ratio penalty is relatively small, the net advantage of this effect is also small, but, nevertheless, in favor of the parfait configuration.

TABLE 2.7. Control Poison Effect on Breeding Ratio

\begin{tabular}{llcc}
\hline \multicolumn{1}{c}{ Quantity } & Reference & $\begin{array}{c}30-\mathrm{cm} \text { IB } \\
\text { Parfait }\end{array}$ & $\begin{array}{c}\text { Ratio } \\
\text { Parfait }\end{array}$ \\
\hline $\begin{array}{l}\text { Reference } \\
\text { addition of a homogene ous } \\
\text { boron- } 10 \text { concentration }\end{array}$ \\
$\begin{array}{l}1.0 \times 10^{-4} \text { atoms/barn-cm } \\
\text { Time-averaged boron-10 } \\
\begin{array}{l}\text { concentration during burnup } \\
\text { cycle (atoms/barn-cm) }\end{array}\end{array}$ & $0.583 \times 10^{-4}$ & $0.424 \times 10^{-4}$ & 0.726 \\
$\begin{array}{l}\text { Net control poison } \\
\text { breeding ratio loss }\end{array}$ & -0.0192 & -0.0181 & 0.943 \\
\hline
\end{tabular}




\subsubsection{Differential and Integral Control Rod Worths}

The total worths of control rods at the core centerline and at the interface between the inner and outer core enrichment zones were evaluated and the results were presented earlier in Table 2.6. Calculations were also performed to determine the differential worth of the centerline control rod by progressively adding control poison to the simulated central rod location in the finite intervals indicated along the Z-axis of Fig. 2.27. Figures 2.29 and 2.30 give the results of those calculations. In these figures, the fraction of the total control rod worth per centimeter of insertion is plotted for both the reference and parfait concepts. Superimposed on this plot of the differential rod worths is a normalized plot of the product of the total flux, $\phi$, and the total adjoint flux, $\phi^{*}$, along the core centerline: The differential rod worth profile may be seen to correlate quite well with perturbation theory predictions that the position dependent worth of a small absorber volume in the core adopts the same shape as the $\phi \phi^{*}$ function (L6). The method of using the product of the flux and adjoint flux to represent the shape of the differential rod worth curves was assumed to apply throughout the core and plots of this product function for the reference and parfait systems at two radial locations in the core at the beginning and end of an equilibrium burnup cycle are presented in Figs. 2. 31 and 2.32. Integral curves (BOC) of the worth of the central control rods for both cores are given in Figs. 2.33 and 2.34 . 


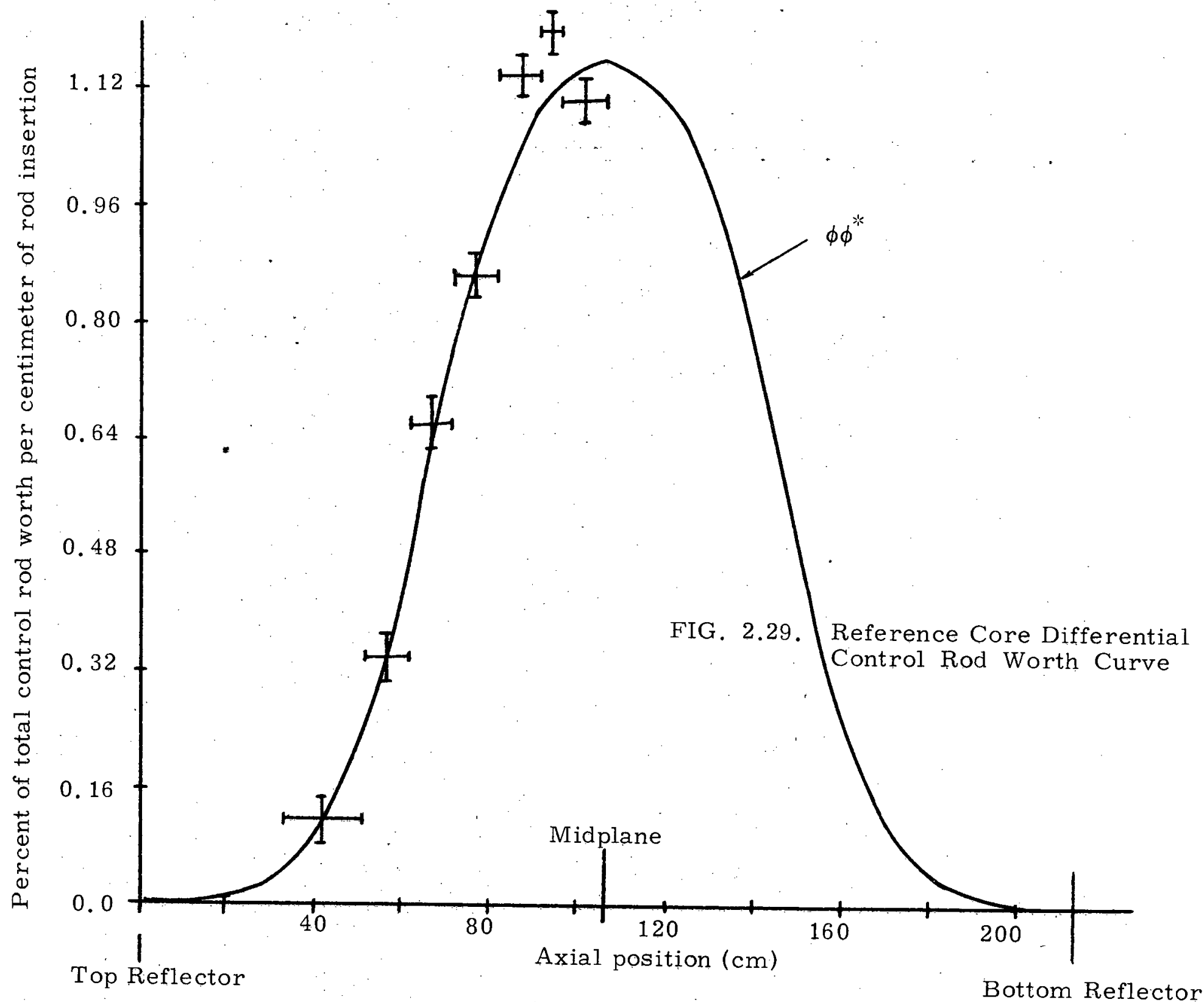




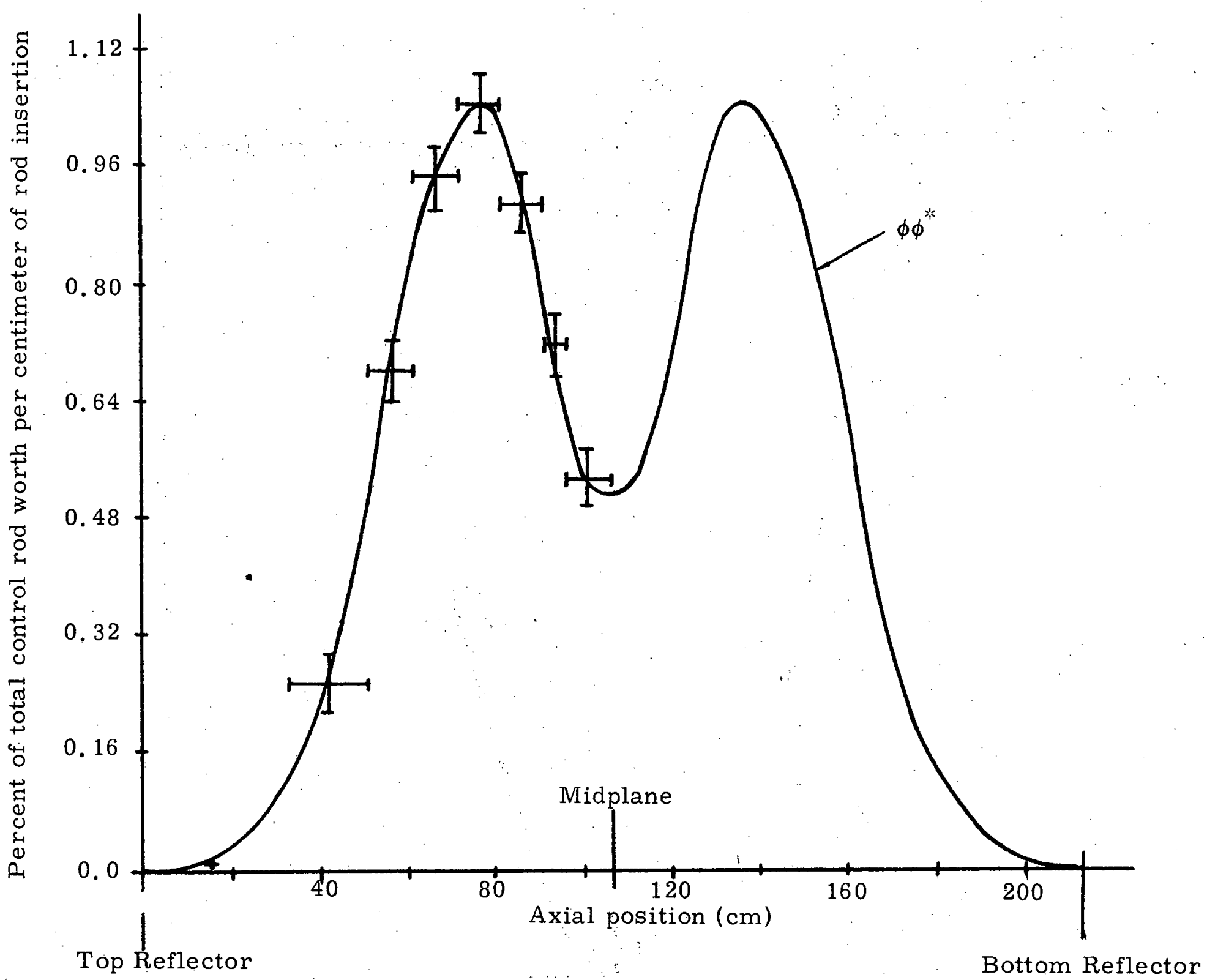

FIG. 2.30. Parfait Core (30-cm IB) Differential Control Rod Worth Curve 


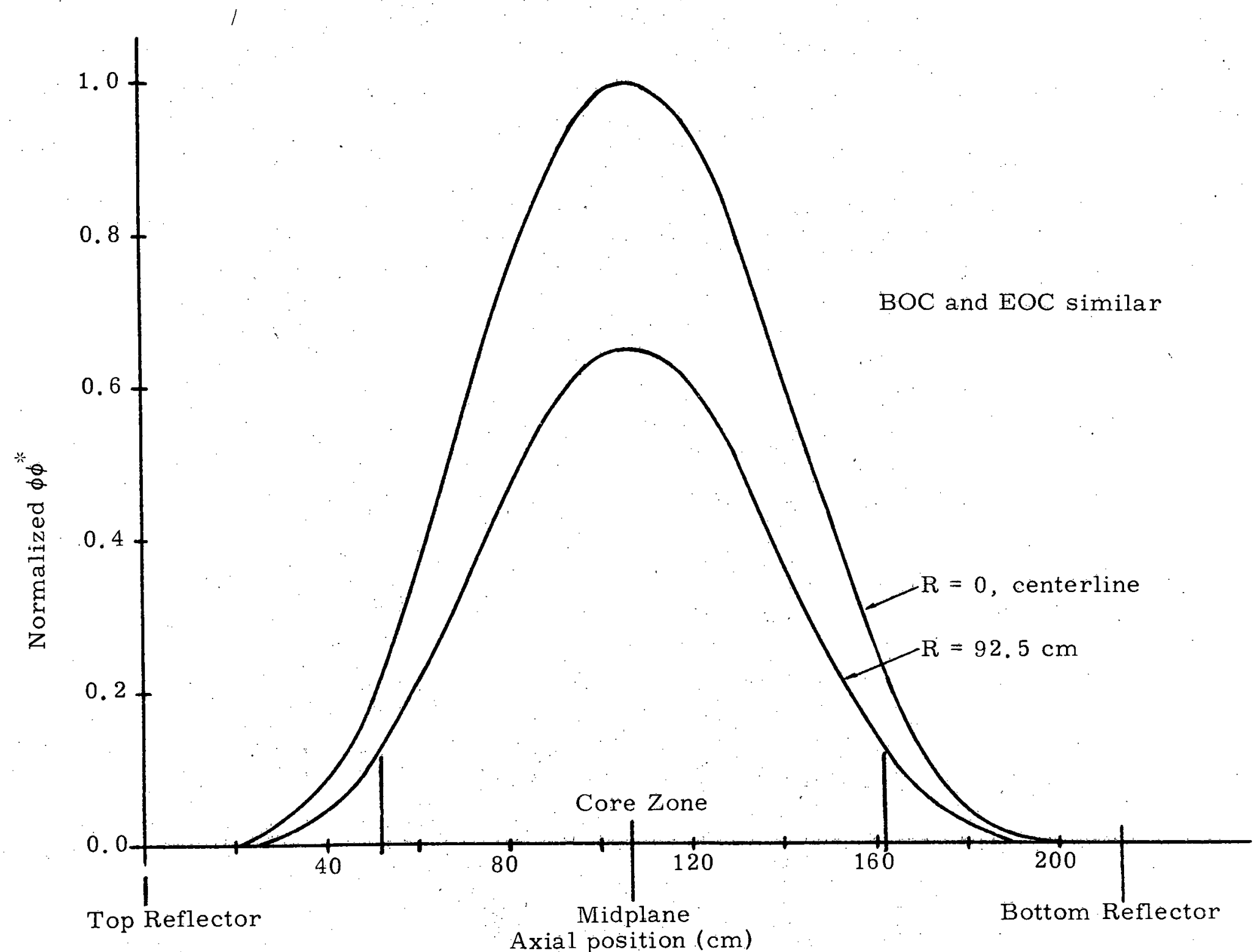

FIG. 2.31. Reference Core Normalized $\phi \phi^{*}$. (BOC, EOC; R $=0, \mathrm{R}=92.5 \mathrm{~cm}$ ) 


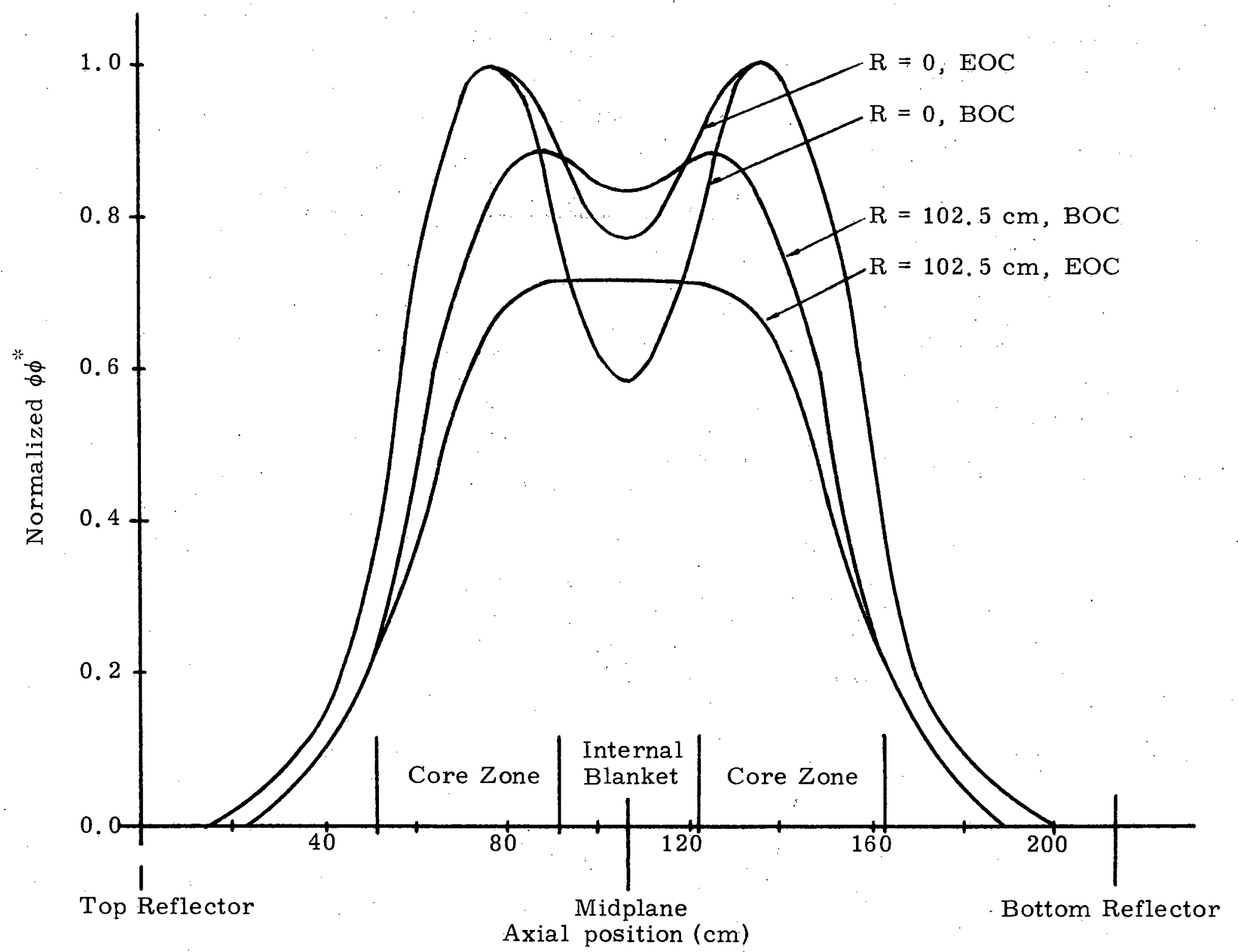

FIG. 2.32. Parfait Core (30-cm IB) Normalized $\phi \phi^{*}$. (BOC, EOC; $R=0, R=102.5 \mathrm{~cm}$ ) 


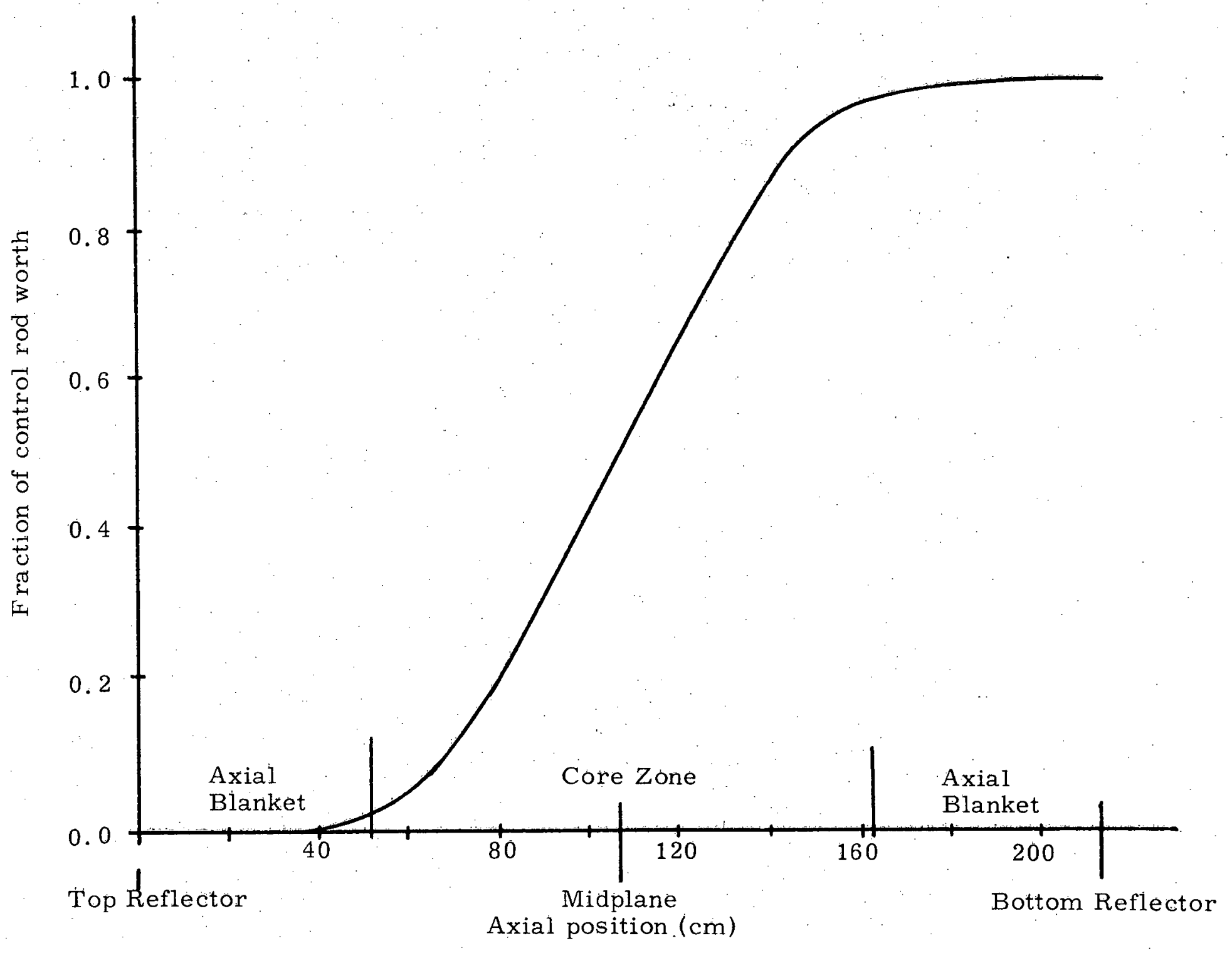

FIG. 2.33. Reference Core Central Control Rod Integral Worth Curve (BOC)

$\stackrel{\bullet}{\mapsto}$ 


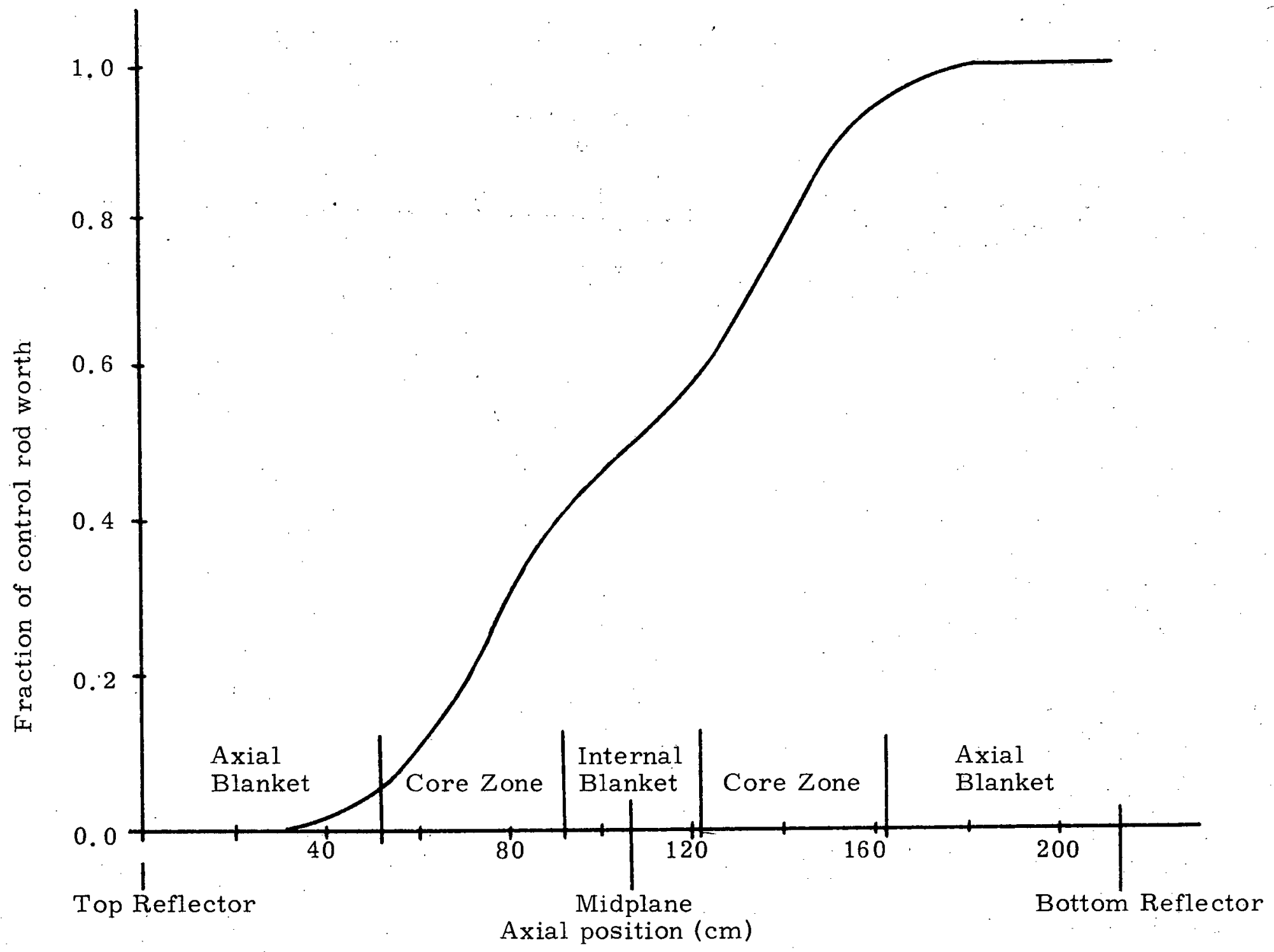

FIG. 2.34. Parfait Core (30-cm IB) Central Control Rod Integral Worth Curve 


\subsubsection{Effect of Control Rods on the Power Profile}

The effects of the axial location of the control rods on the power profile in each of the cores was evaluated by simulating the simultaneous withdrawal of the two control curtain annuli shown in Fig. 2. 35. The combined worth of the two control annuli was adjusted to be equal to the equilibrium cycle burnup reactivity loss for each reactor. The flux profiles in the cores were evaluated for the control rod banks in three different positions: fully inserted, withdrawn to a position corresponding to the bottom of the internal blanket (two-thirds inserted), and withdrawn to a position corresponding to the top of the internal blanket (one-third inserted). The negligible effect of the control rod bank location on the flux shape in the reference core is demonstrated in Figs. 2. 36 and 2.37, where the flux plot has been normalized to the flux along the core centerline $33 \mathrm{~cm}$ above the midplane. The effect of the control rod bank location in the parfait core is illustrated in Figs. 2. 38 and 2.39. These two flux profiles demonstrate that the control curtains and the internal blanket cause the flux to tilt axially, taking on a greater value toward the bottom of the core. According to these calculations, the magnitude of this flux tilt is such that the peak local power density in the lower core volume could, at times during the burnup cycle, be as much as $4.5 \%$ higher than that which would have been calculated had the effect of the control curtains been neglected. The magnitude of this calculated power shift could, however, be made significantly less in an operating reactor by employing appropriate control rod withdrawal patterns. In addition, simulating discrete control rods as a uniform control curtain accentuates the calculated power tilt. In fact, the 


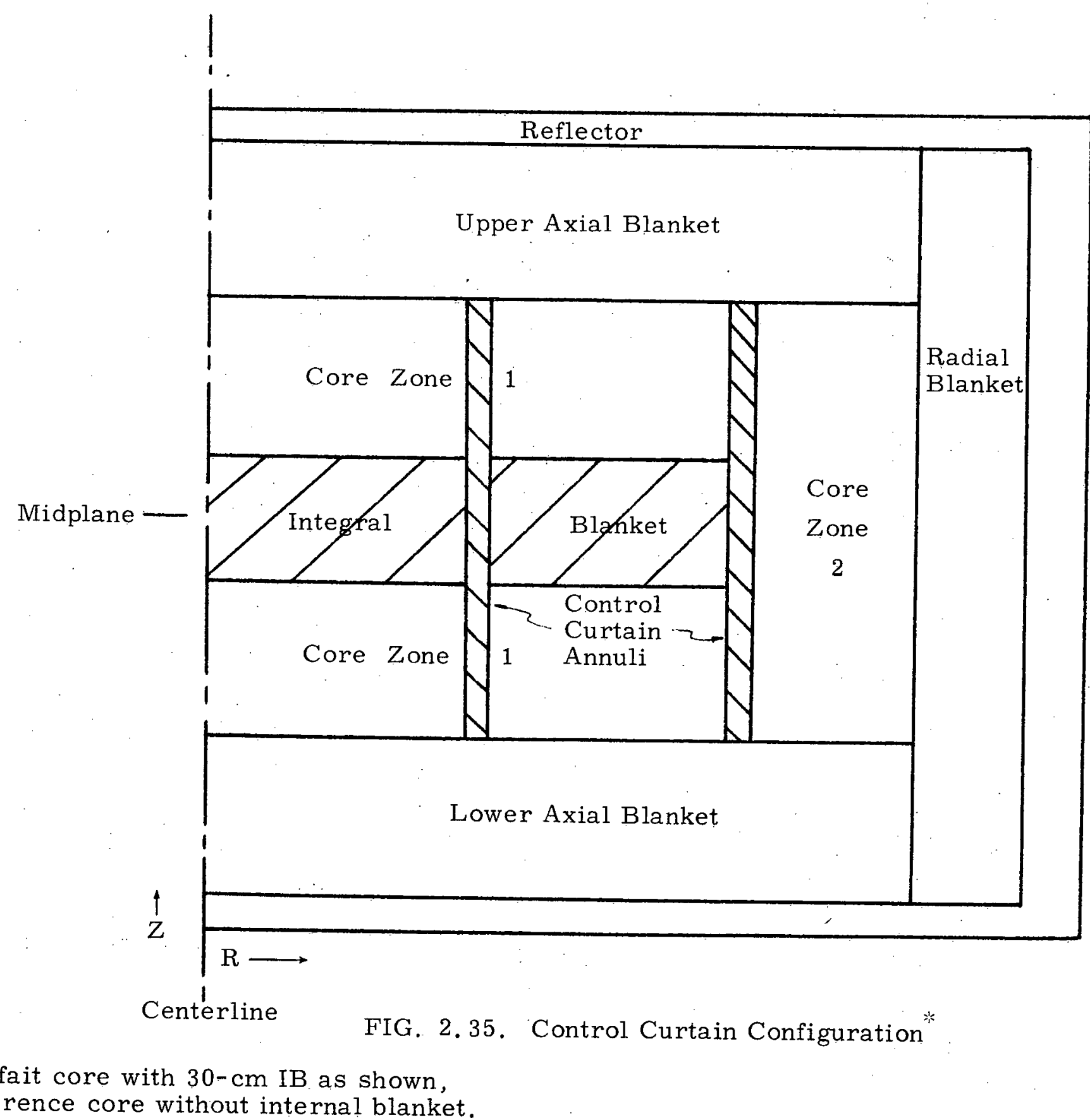




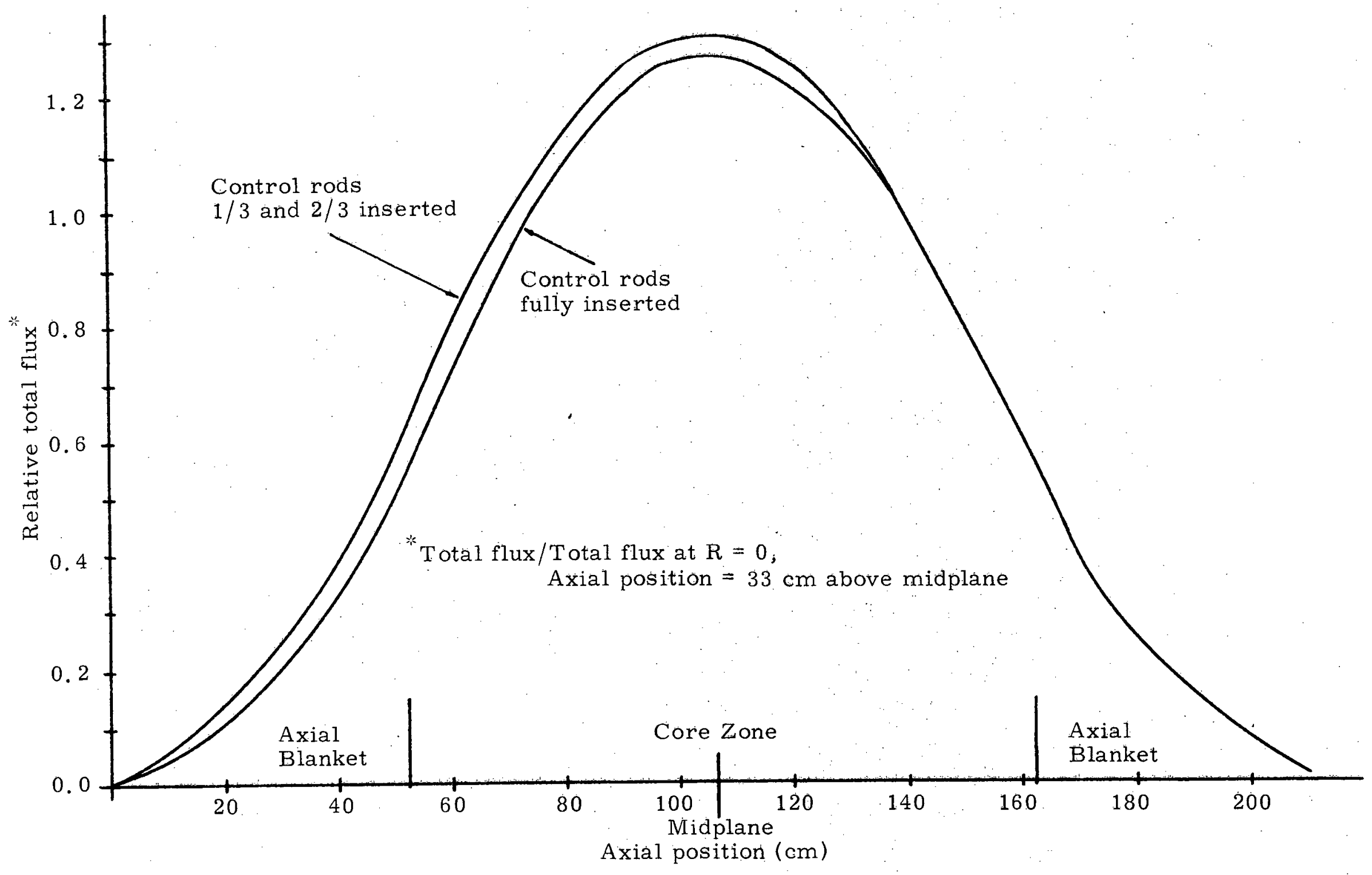

FIG. 2.36. Reference Core Centerline Flux as a Function of Control Curtain Insertion 


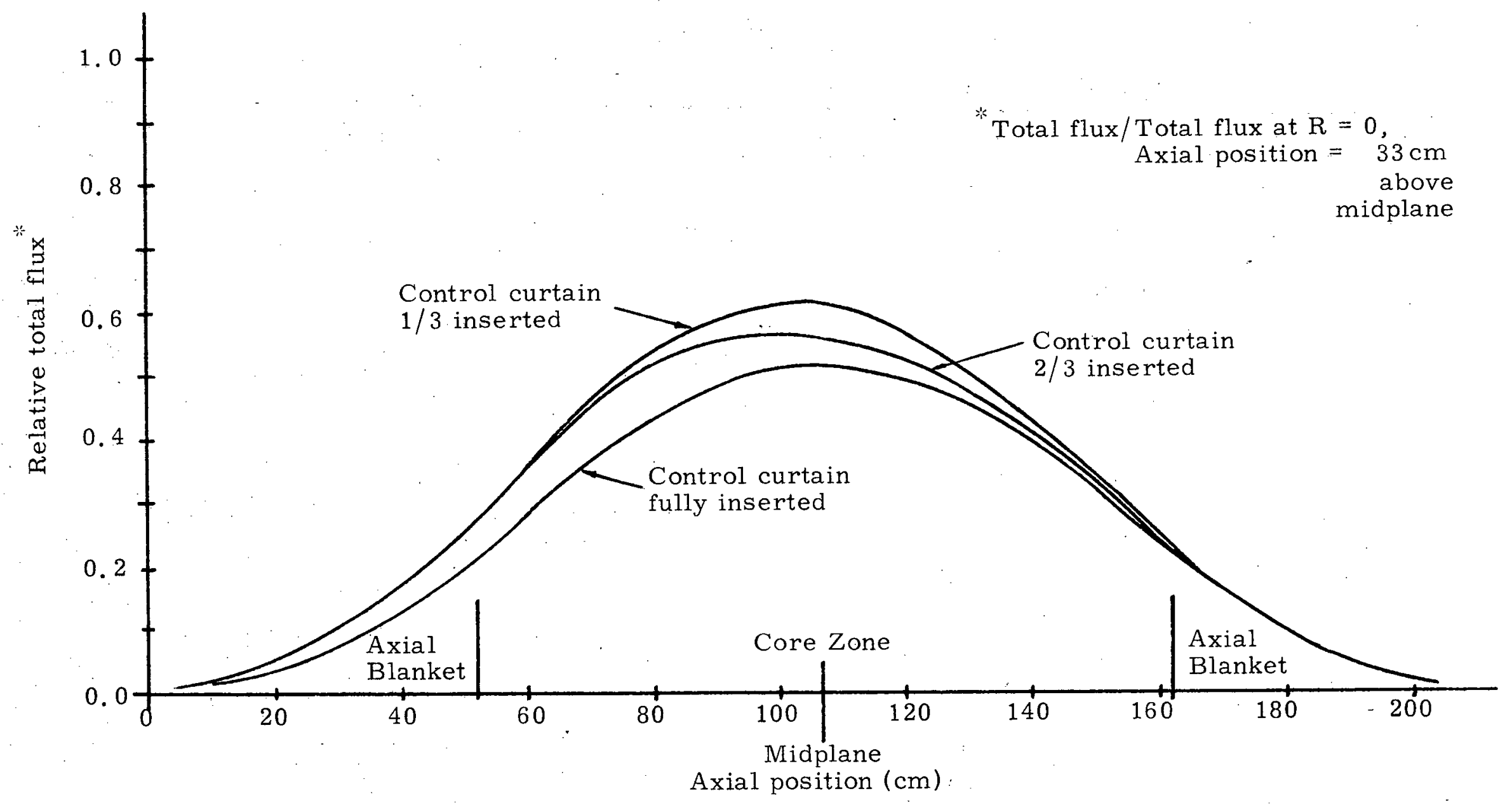

FIG. 2.37. Reference Core Total Flux at Radial Position $=117.5 \mathrm{~cm}$ as a Function of Control Curtain Insertion 


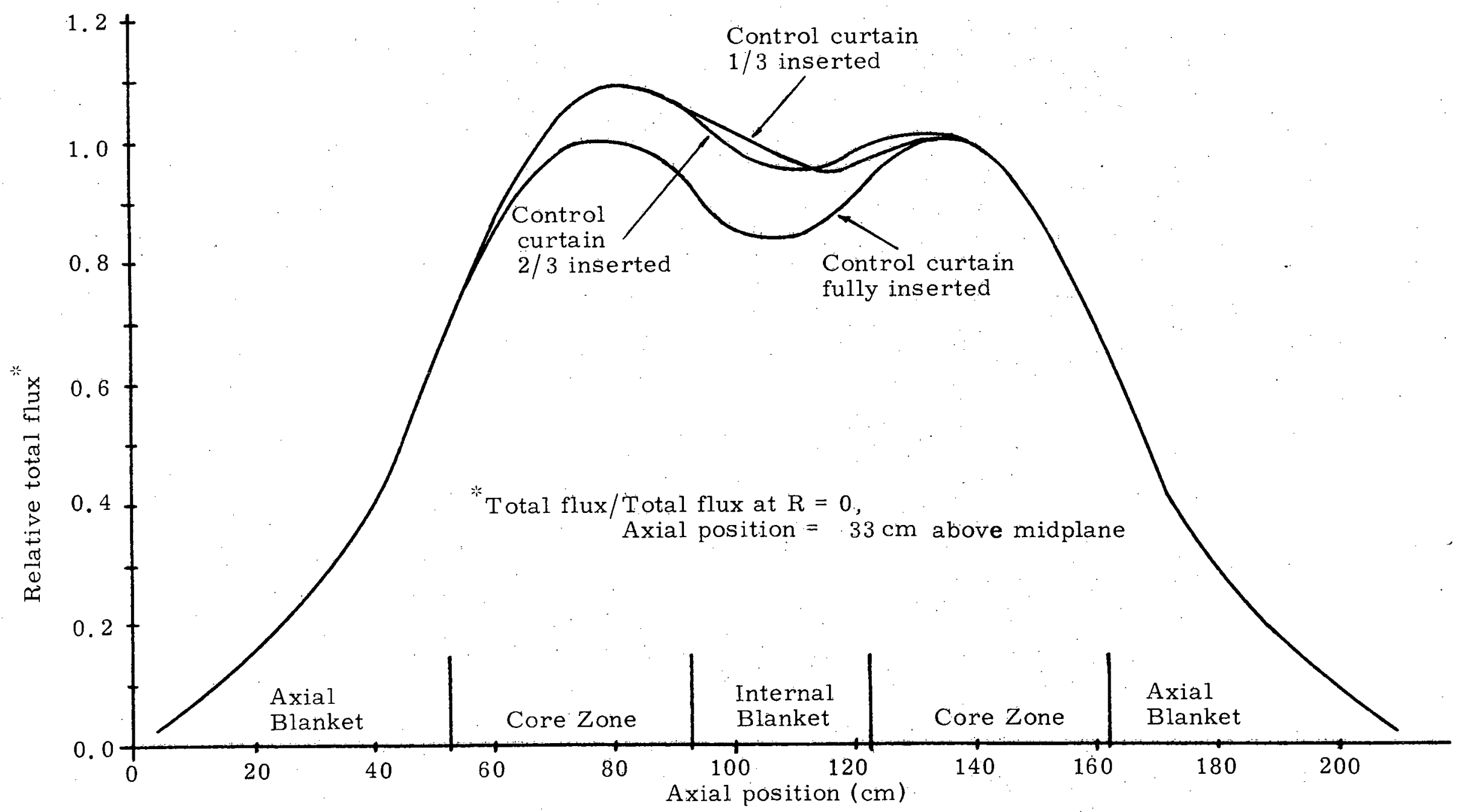

FIG. 2. 38. Parfait Core Centerline Total Flux as a Function of Control Curtain Insertion 


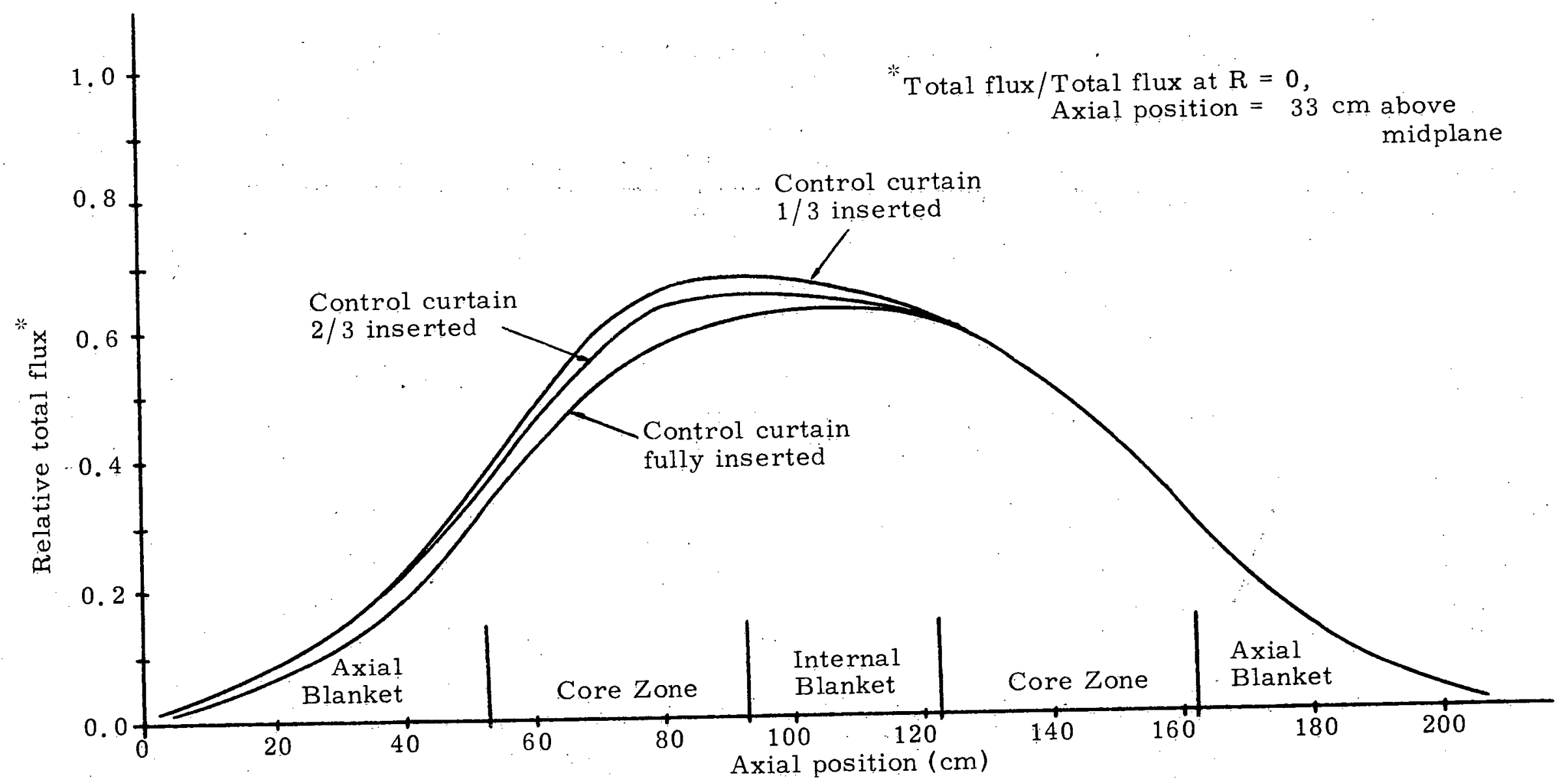

FIG. 2. 39. Parfait Core Total Flux at Radial Position $=117.5 \mathrm{~cm}$ as a Function of Control Curtain Insertion 
effects of an isolated control rod on the flux shape extend only about 5 or 10 centimeters, as illustrated in Fig. 2.40. (These results were derived from a one-dimensional, four-group transport theory calculation for a control rod immersed in a homogeneous fuel sea, and compare favorably with similar calculations which have been reported (J1).) Therefore, since control rods are generally separated by a distance several times this radius of influence, it is likely that simulating the control rods as control annuli tends to spatially screen the inner core zone more effectively than would individual rods. A more accurate estimate of the actual power tilts caused by the interaction of the control rods and the internal blanket could best be simulated by employing more elaborate calculational techniques including a threedimensional code in which each core assembly could be individually represented $(\mathrm{H} 4)$. It should also be noted that the calculated power tilt is well within the current estimated precision of power distribution calculations.

\section{5 ALTERNATE CORE CONFIGURATIONS}

The results presented in the preceeding sections have focused on the neutronic characteristics of the $1000-M_{e} L M F B R$ reference and parfait designs described in Section 1.4. Other calculations were performed which confirmed similar neutronic characteristics to those reported in this chapter for a $1000-\mathrm{MW}_{\mathrm{e}}$ gas-cooled fast reactor and a demonstration size LMFBR. The results of those calculations are discussed in Appendix B, Other Parfait Blanket Configurations. 


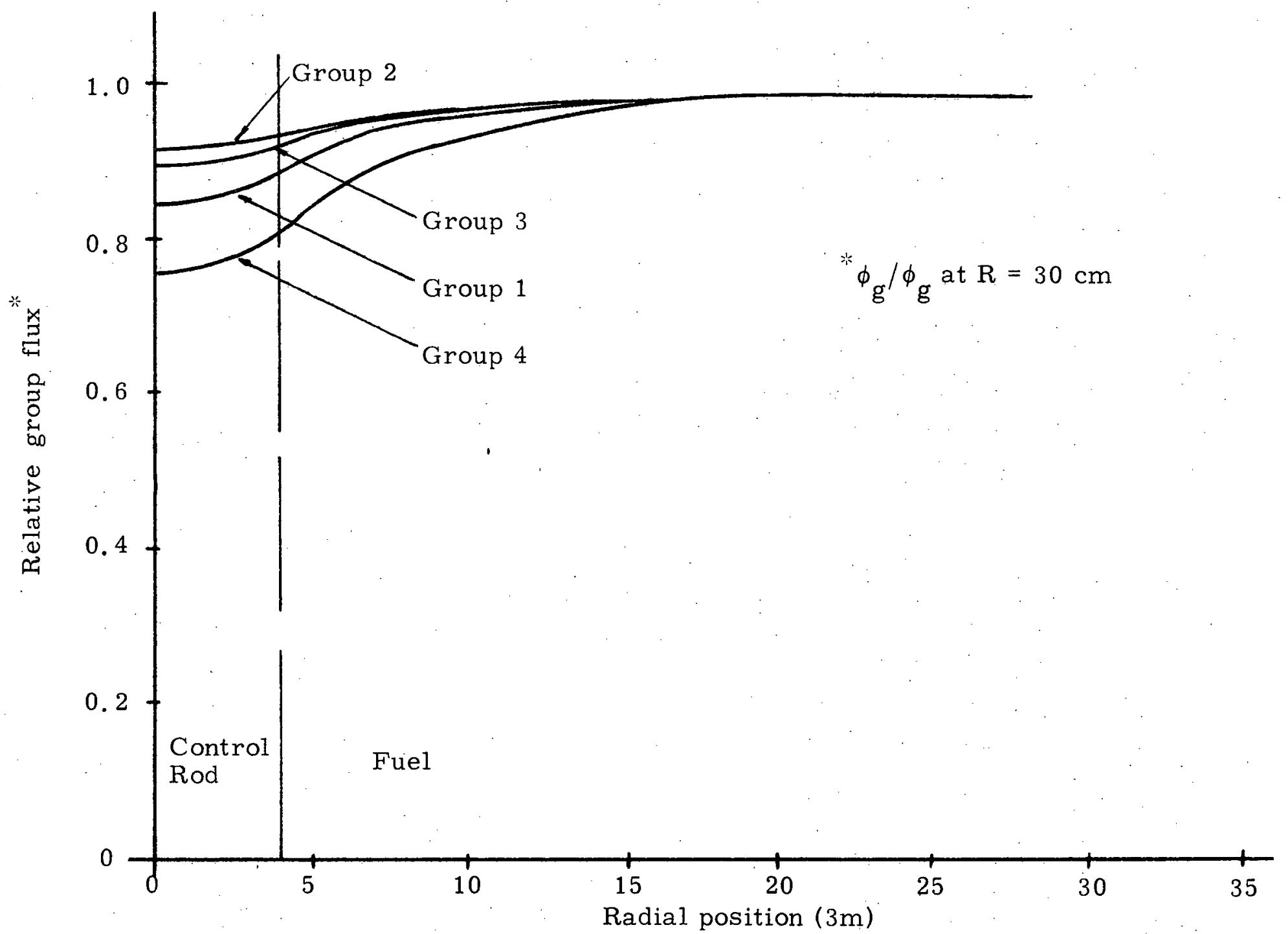

FIG. 2.40. Flux Profile Surrounding a Control Rod in a Sea of Fuel 


\subsection{CONCLUSIONS}

The neutronic characteristics evaluated in this chapter demonstrate a substantial advantage for the parfait configuration over the reference core design. Inserting an internal.blanket at the midplane of the core allows the parfait to achieve sufficient axial and radial flux and power flattening in the core zone such that, even though a substantial fraction of the high power density core fuel volume is replaced with much lower power density blanket material, the parfait core can generate the same total power as a reference core of the same external dimensions while operating within the same peak power density limit. The parfait configuration also demonstrates advantages over the reference core in terms of an increased breeding ratio, a substantially reduced peak flux in the core and a substantially reduced burnup reactivity swing. This latter advantage contributes to reduced control poison requirements for the core and reduced losses of neutrons to control poisons. An evaluation of the control systems required for both cores also demonstrated that the internal blanket introduces no unique control problems.

The only significant unfavorable neutronic characteristic identified for the parfait configuration was an increased initial fissile inventory in the core.

The flux and power distributions described in this chapter will be the focus of the next chapter which considers some of the engineering aspects of the parfait core design. Temperature profiles for the fuel, clad and coolant are developed and the behavior of the materials in the parfait core are considered. In particular, the implications of the reduced fluence and the reduced flux gradients in the inner zone of the core are discussed. 
Chapter 3

CORE ENGINEERING

\section{1. INTRODUCTION}

The neutronic characteristics of the parfait concept were described as a function of internal blanket thickness in the preceding chapter. The present chapter deals with a number of important engineering considerations. The parfait configuration evaluated in this chapter had an internal blanket thickness of 30 centimeters. This configuration was selected because, as illustrated in Fig. 2.2, it exhibited the most favorable performance characteristics identified for the parfait concept (an increased breeding ratio, a reduced peak power density and a reduced burnup reactivity swing), in addition to a significantly reduced peak total flux.

In the three major sections of this chapter, the reference and parfait systems are compared in the areas of thermal performance, materials' performance (fuel and metal swelling in particular), and the effect of the latter on core mechanical design. This chapter builds upon the flux and power profiles described in the previous chapter and, as with the previous calculations, it is the relative performance of the two systems which is of most interest in this evaluation. 


\subsection{THERMAL ANALYSIS}

\subsubsection{Mixed-Mean Coolant Outlet Temperature}

As illustrated in Fig. 2.22, the power distribution in the reference and parfait reactors is a function of both space and time. In particular, there is a dramatic increase in the power generation rate from each of the blanket regions during irradiation. In the analysis described here, the mixed-mean core coolant outlet temperature of both configurations has been calculated. The effect of the radial blanket was neglected since the radial blanket elements may be managed independently of the core and their coolant flow requirements are a strong function of position and irradiation history.

The power profiles for this analysis were generated using the $2 \mathrm{DB}$ code. Annular core regions were defined for each configuration to minimize the effects of the regionwise material homogenization following each burnup time step. Discrete fuel elements were simulated as annuli of fuel and blanket material. Material number densities were manipulated such that half of each of the core annuli simulated fresh fuel and the other half simulated fuel which had been irradiated for one cycle. The resulting beginning-of-cycle (BOC) and end-of-cycle (EOC) radial power profiles (axially-integrated power per unit core cross sectional area, $\mathrm{kw} / \mathrm{cm}^{2}$ ) for the two configurations are shown in Figs. 3.1 and 3.2. The mixed-mean core coolant outlet temperature was calculated for these power distributions assuming two different coolant orificing conditions. In one scheme, each of the fuel annuli was individually orificed to provide coolant flow such that the coolant outlet temperature from each of the fuel annuli was no greater than 


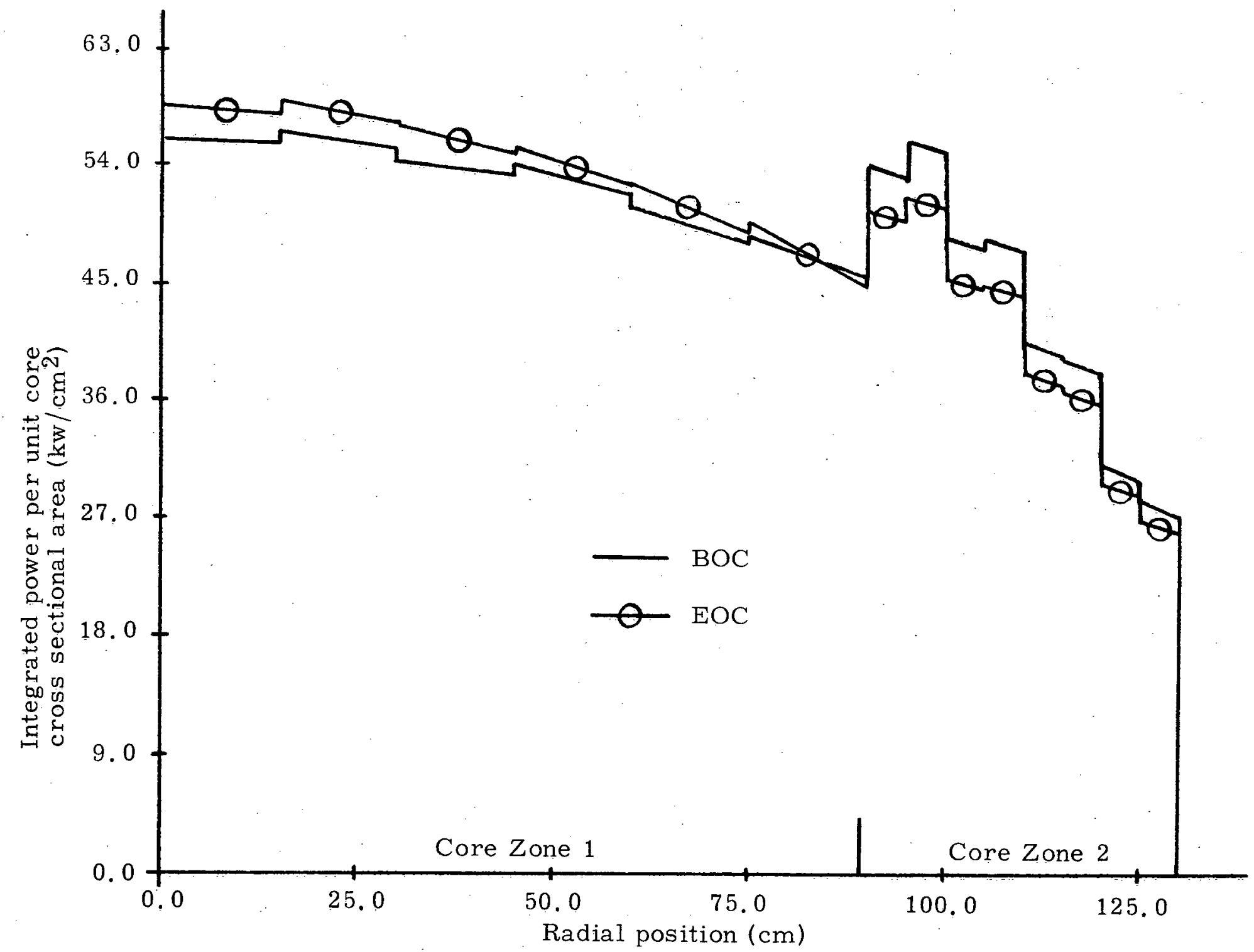

FIG. 3. 1. Reference Core Axially-Integrated Power Per Unit Core Cross Sectional Area 


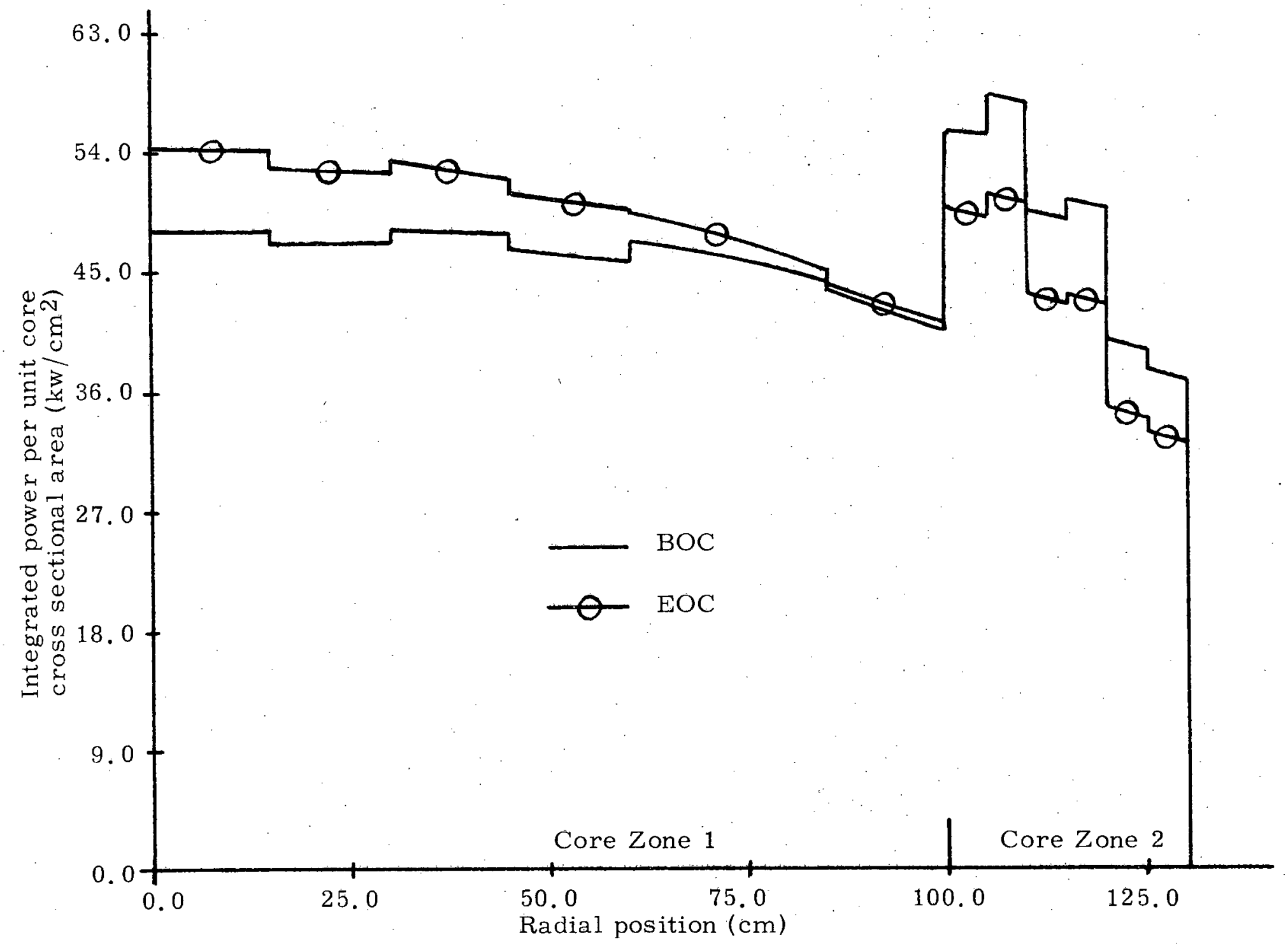

FIG. 3.2. Parfait Configuration Axially-Integrated Power Per Unit Core Cross Sectional Area 
$1050^{\circ} \mathrm{F}$ throughout the irradiation cycle. For the other set of orificing conditions, one coolant flow rate was specified for each of the two core zones such that the maximum coolant outlet temperature from any fuel annulus in a given zone was no greater than $1050^{\circ} \mathrm{F}$. In each case, the coolant inlet temperature was assumed to be $775^{\circ} \mathrm{F}$. A comparison of the time-averaged mixed-mean core coolant outlet temperature for the two configurations during the equilibrium cycle is given in Table 3.1 .

TABLE 3.1

Time-Averaged Mixed-Mean Core Coolant Outlet Temperature

\begin{tabular}{|c|c|c|c|}
\hline \multirow{2}{*}{ Orifice } & \multicolumn{2}{|c|}{$\begin{array}{c}\text { Mixed-Mean Core Outlet } \\
\text { Temperature, }{ }^{\circ} \mathrm{F}\end{array}$} & \multirow{2}{*}{$\begin{array}{c}\text { Parfait } \\
\text { Penalty } \\
{ }^{\circ} \mathrm{F}\end{array}$} \\
\hline & Reference & $30-\mathrm{cm}$ IB Parfait & \\
\hline $\begin{array}{c}\text { Individually orificed } \\
\text { fuel annuli }\end{array}$ & 1044.4 & 1038.8 & +5.6 \\
\hline Zone orificed & 996.6 & 999.0 & -2.4 \\
\hline
\end{tabular}

The parfait configuration suffers a larger BOC to EOC channel power variation, but the flatter radial power profile provides an offsetting effect and, as indicated in the table, both systems perform very similarly. If the mixed-mean core coolant outlet temperature for the two systems differed by as much as $5.6^{\circ} \mathrm{F}$ as indicated in Table 3.1 , the net thermal efficiency penalty for the parfait configuration would be small. The actual thermal efficiency for an LMFBR/Rankine power cycle operating between $1000^{\circ} \mathrm{F}$ and $80^{\circ} \mathrm{F}$ is about $62 \%$ of the Carnot efficiency for that system (B7). Using this model, it may be shown that the thermal efficiency is diminished by $0.016 \%$ per ${ }^{\circ} \mathrm{F}$ degradation 
in the mixed-mean outlet temperature. The total thermal efficiency penalty for the parfait configuration would, therefore, amount to less than $0.1 \%$. In fact, a realistic orificing scheme could be expected to produce results in the range between those for the two schemes shown in Table 3.1. In this case, the mixed-mean core coolant outlet temperatures for the two systems would be identical for all practical purposes.

The results described above a re conservative in that they do not include several system characteristics which would tend to degrade the mixed-mean coolant outlet temperature of the reference configuration more than that of the parfait configuration. As pointed out in the previous chapter, the parfait configuration would require fewer shim control rods than the reference core because of its reduced burnup reactivity swing. Since control rod positions represent a coolant by-pass across the core, the parfait configuration would suffer a smaller coolant temperature degradation than the reference core due to this effect. Another factor which would contribute a larger coolant temperature degradation in the reference core than in the parfait configuration is the by-pass flow in each fuel element resulting from a net increase in the flow area of each fuel element due to material swelling. As will be shown in a later section of this chapter, the fuel elements of the reference system suffer a greater change than those of the parfait configuration. Finally, as illustrated in Figs. 2.20 and 2.21, the radial power profile in the parfait configuration is significantly flatter than that in the reference core, especially in the inner enrichment zone. This characteristic contributes to a reduced peak-to- 
average pin power density ratio within an assembly for the parfait design. Therefore, if the coolant flow requirements for a given assembly are dictated by the peak pin in the assembly, then the parfait design suffers a smaller overcooling penalty due to radial power gradients within fuel assemblies of the inner core zone.

\subsubsection{Material Temperature Profiles}

Because many material characteristics exhibit a strong temperature dependence, an analysis was carried out to determine the temperature profiles in the materials which make up the cores of both configurations. The fuel assembly and fuel pin characteristics used in this analysis are displayed in Table 3.2. The inlet coolant temperature was $775^{\circ} \mathrm{F}$ and each of the fuel annuli was individually orificed to provide a peak coolant outlet temperature of $1050^{\circ} \mathrm{F}$. Using the BOC power profiles characteristic of the two configurations, the standard equations (E7) for heat conduction from a cylindrical fuel pin, and assuming a constant fuel conductivity, the axial temperature profiles illustrated in Figs. 3.3 through 3.7 were obtained. The temperature profiles for the coolant, the outer and inner clad surface, the outer fuel surface, and the fuel centerline are presented for the central fuel element of each configuration. The curves for the parfait configuration are typical of those for fuel elements containing an internal blanket region. The curves for the reference core are typical of those for fuel elements without an internal blanket - including the fuel elements in the outer enrichment zone of the parfait configuration. The altered power distribution in the fuel elements containing an internal blanket 
TABLE 3.2

Reference and Parfait Configuration Fuel Element and Fuel Pin Characteristics

Pins per subassembly

Hexagonal subassembly dimensions

5.5 across flats (in.)

Fuel pin radius (in.)

0.15

Fuel-clad gap thickness (in.)

0.0039

Clad thickness (in.)

0.0175

Fuel Conductivity (BTU/hr $\mathrm{ft}^{\circ} \mathrm{F}$ )

1.27

Gap conductance (BTU/hr $\mathrm{ft}^{2}{ }^{\circ} \mathrm{F}$ ) 1400

Clad conductivity (BTU/hr ft ${ }^{\circ} \mathrm{F}$ ). 12.6

Surface heat transfer coefficient (BTU/hr ft ${ }^{\circ} \mathrm{F}$ ) 


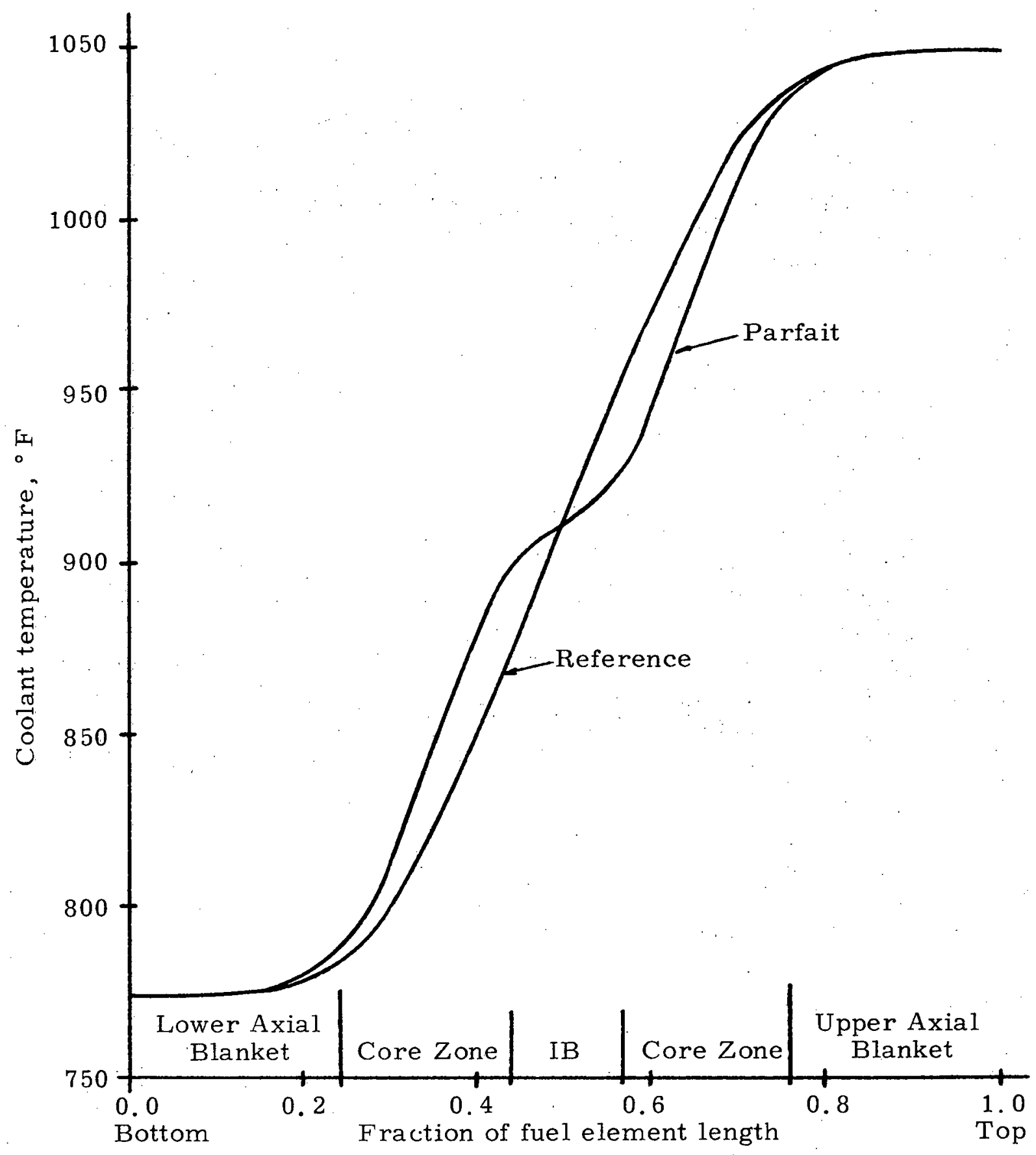

FIG. 3. 3. Center Assembly Coolant Temperature Profile 


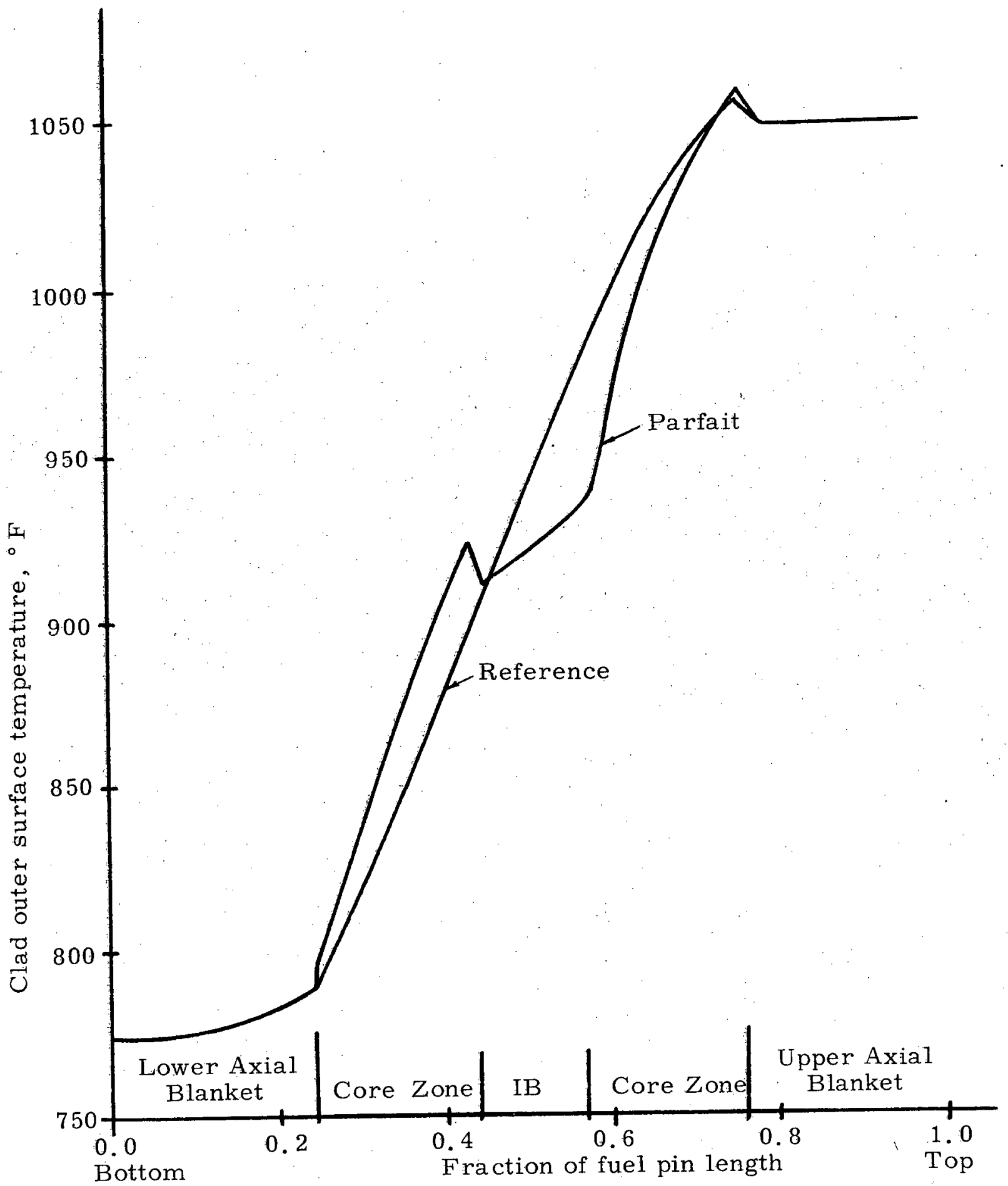

FIG. 3.4. Center Assembly Clad Outer Surface Temperature Profile 


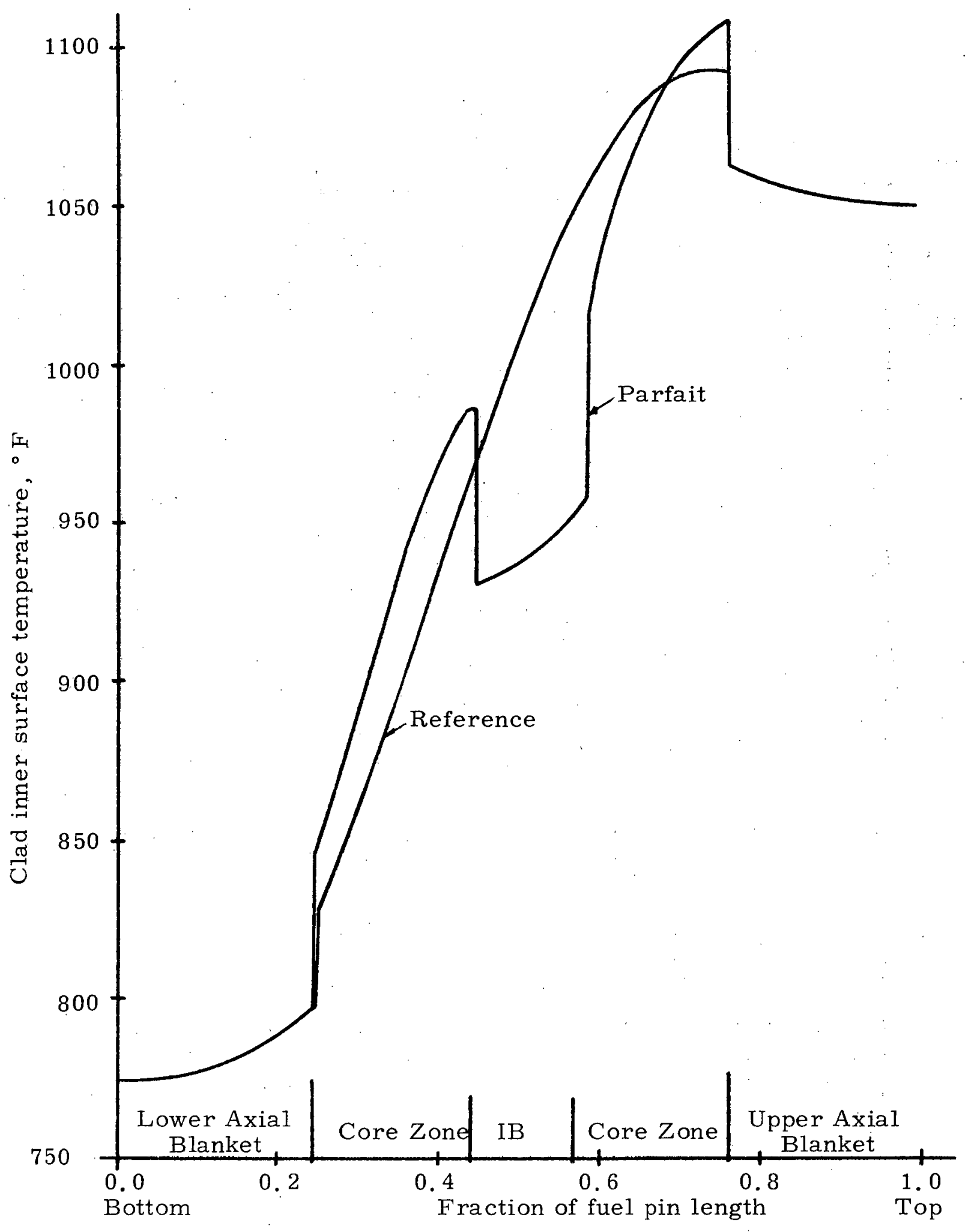

FIG. 3.5. Center Assembly Clad Inner Surface Temperature Profile 


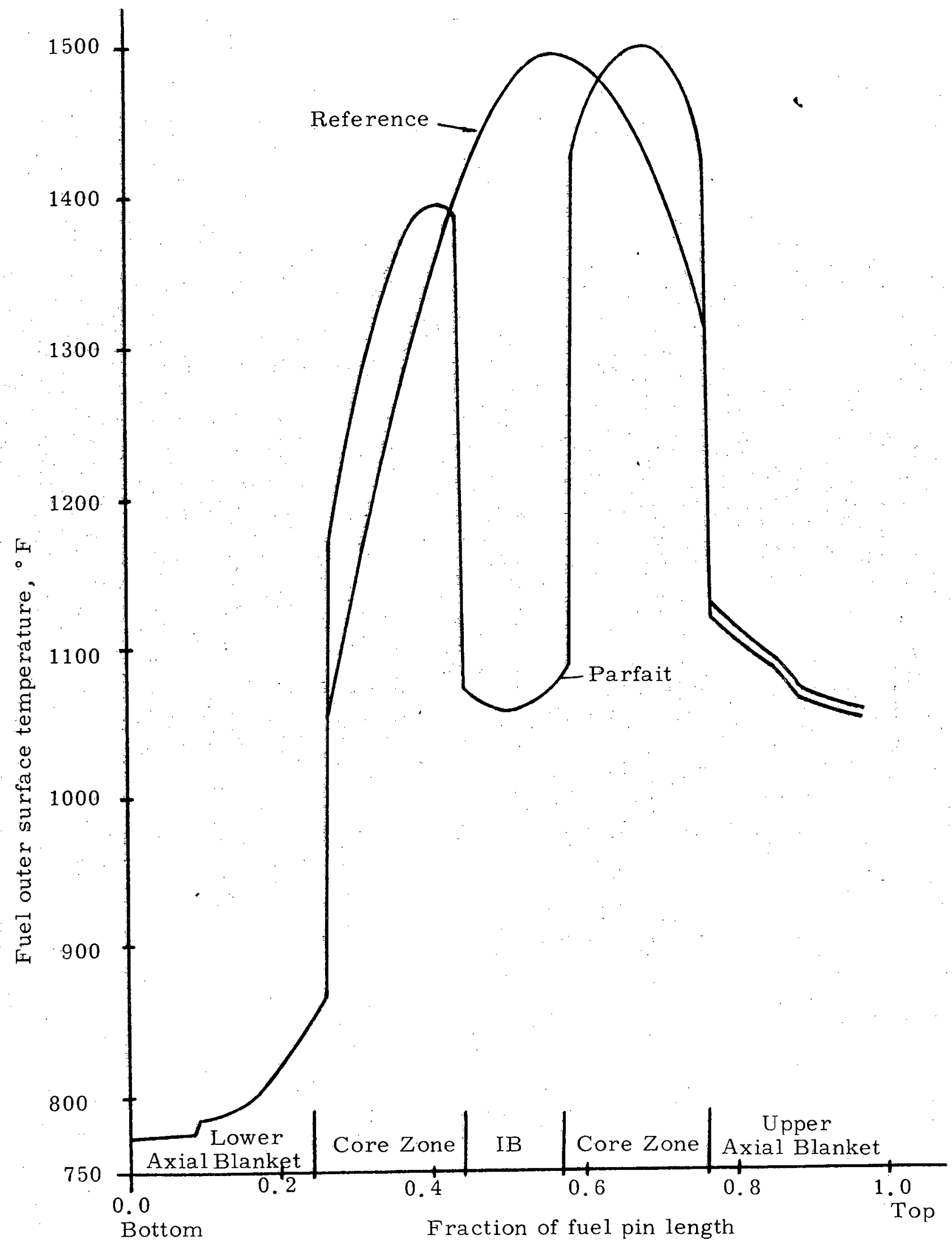

FIG. 3.6. Center Assembly Fuel Outer Surface Temperature Profile 


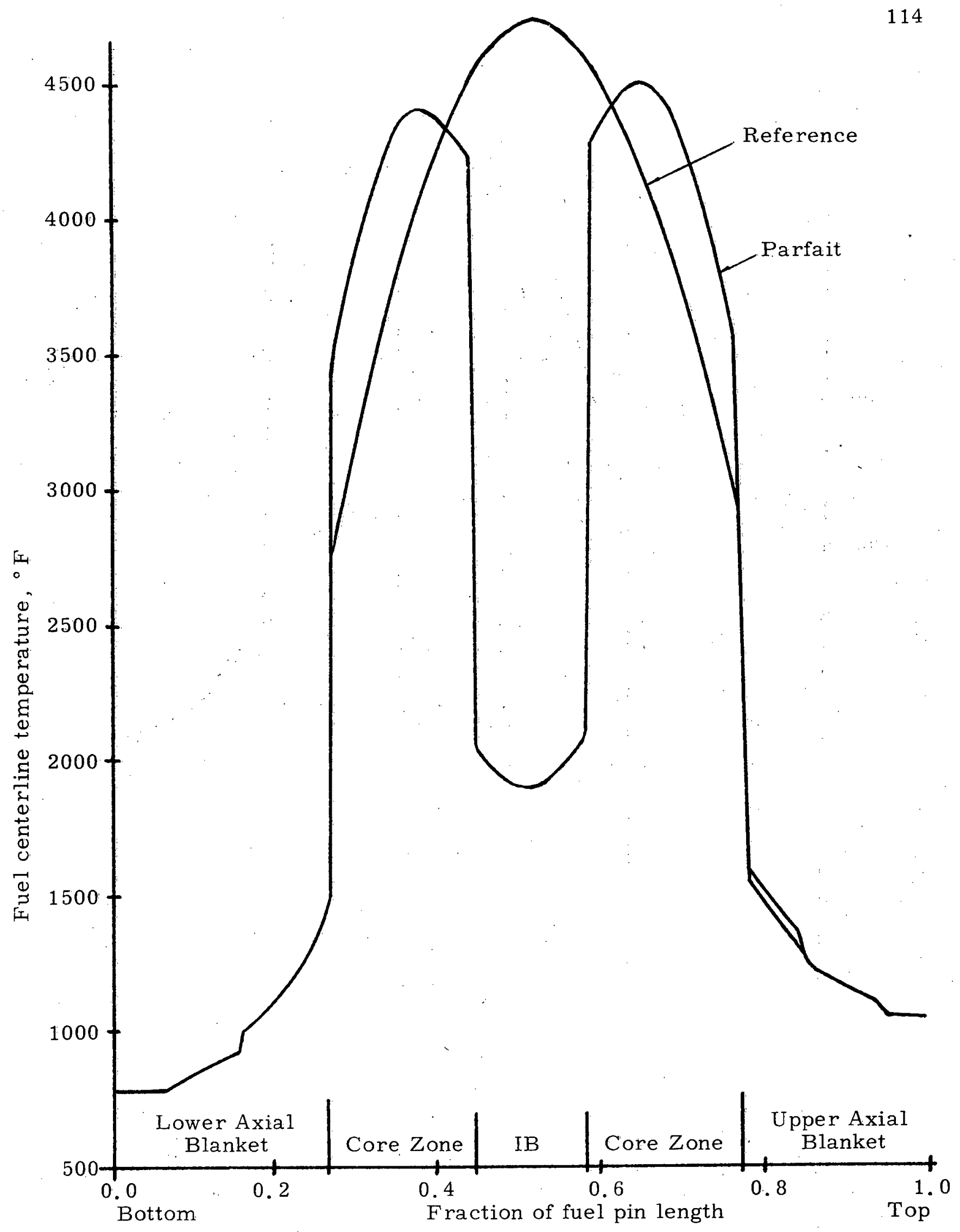

FIG. 3.7. Center Assembly Fuel Centerline Temperature Profile 
allows the fuel, the cladding material and the wrapper tube to run at a lower average temperature in the region of interest above the core midplane, even though the peak clad temperature is $17^{\circ} \mathrm{F}$ higher. The lower peak centerline fuel temperature of the $30-\mathrm{cm}$ IB parfait configuration is due to its reduced peak power density, as noted in Table 2.3.

\subsubsection{Operating Margins}

As indicated in Chapter 1 , the reference and parfait configurations have been compared on the basis of equal core volumes (including the internal blanket) and equal thermal power. The two configurations, however, operate at different peak power densities and are therefore not comparable in the margins each offers between normal operation and a transient overpower condition for which the hottest pins achieve centerline melting. This aspect of the parfait concept's capabilities relative to the reference system was assessed by comparing the fraction of the core volume of each configuration in which fuel centerline melting occurs as a function of an overpower factor. The procedure for performing this calculation is summarized in Fig. 3. 8. This calculation starts with the BOC power distribution calculated in $2 \mathrm{DB}$, from which the coolant requirements of each fuel annulus were calculated to yield a coolant outlet temperature of $1050^{\circ} \mathrm{F}$. The overpower factor was defined as the thermal power of the system relative to the nominal system power of $2500 \mathrm{MW}_{\mathrm{t}}$, and fuel centerline melting was determined based on the criteria given in Equation 3.1. 


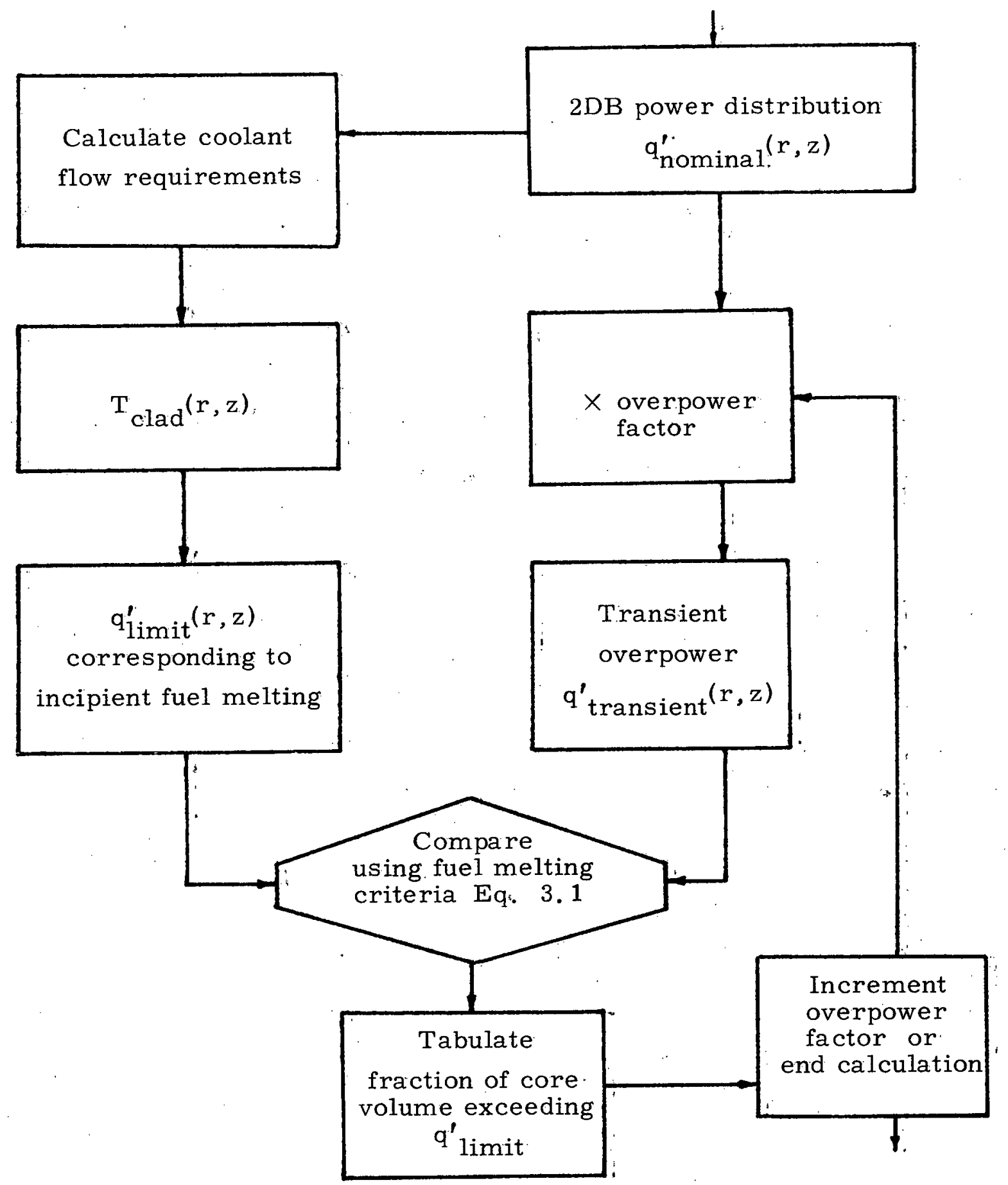

FIG. 3.8. Procedure for Calculating Overpower Operating Margin 
$\left(\mathrm{q}_{\text {nominal }}^{\prime}\right)\left(\begin{array}{c}\text { Overpower } \\ \text { factor }\end{array}\right) \begin{aligned} & \geqslant \mathrm{q}_{\text {limit }}^{\prime}: \text { Fuel centerline melting } \\ & <\mathrm{q}_{\text {limit: }}^{\prime} \text {. No fuel centerline melting }\end{aligned}$

The linear power limit corresponding to incipient fuel melting was defined as (C1):

$$
\mathrm{q}_{\text {limit }}^{\prime}(\mathrm{kw} / \mathrm{ft})=(18)\left[\frac{5000-\mathrm{T}_{\mathrm{clad}}(\mathrm{r}, \mathrm{z})}{5000-1060}\right]
$$

where $\mathrm{T}_{\text {clad }}(\mathrm{r}, \mathrm{z})$ is the local (inside diameter) clad temperature, ${ }^{\circ} \mathrm{F}$, as a function of position. The base limit of $18 \mathrm{kw} / \mathrm{ft}$ is an experimentally determined linear power rating corresponding to incipient melting for a fuel pin with a cold fuel-clad gap of 6.0 mils and for which the inside clad temperature is $1060^{\circ} \mathrm{F}$ (L7). The term in brackets accounts for the fact that the fuel centerline temperature depends upon the cladding temperature, which, in turn, is a function of position. The results for the reference and parfait configurations are displayed in Fig. 3.9. This figure illustrates that incipient fuel melting first occurs in the reference configuration for a $15 \%$ overpower condition. In the parfait configuration, fuel melting does not occur until $22 \%$ overpower is reached. For a $32 \%$ overpower condition, roughly $8 \%$ of the core volume of each configuration exceeds the linear power rating corresponding to incipient fuel melting. Since the current designs call for no fuel melting in a design overpower transient, the parfait configuration offers a $7 \%$ larger operating margin compared to the reference reactor. Or conversely, for equal operating margins, the parfait configuration is capable of generating $7 \%$ more power than the reference system. 


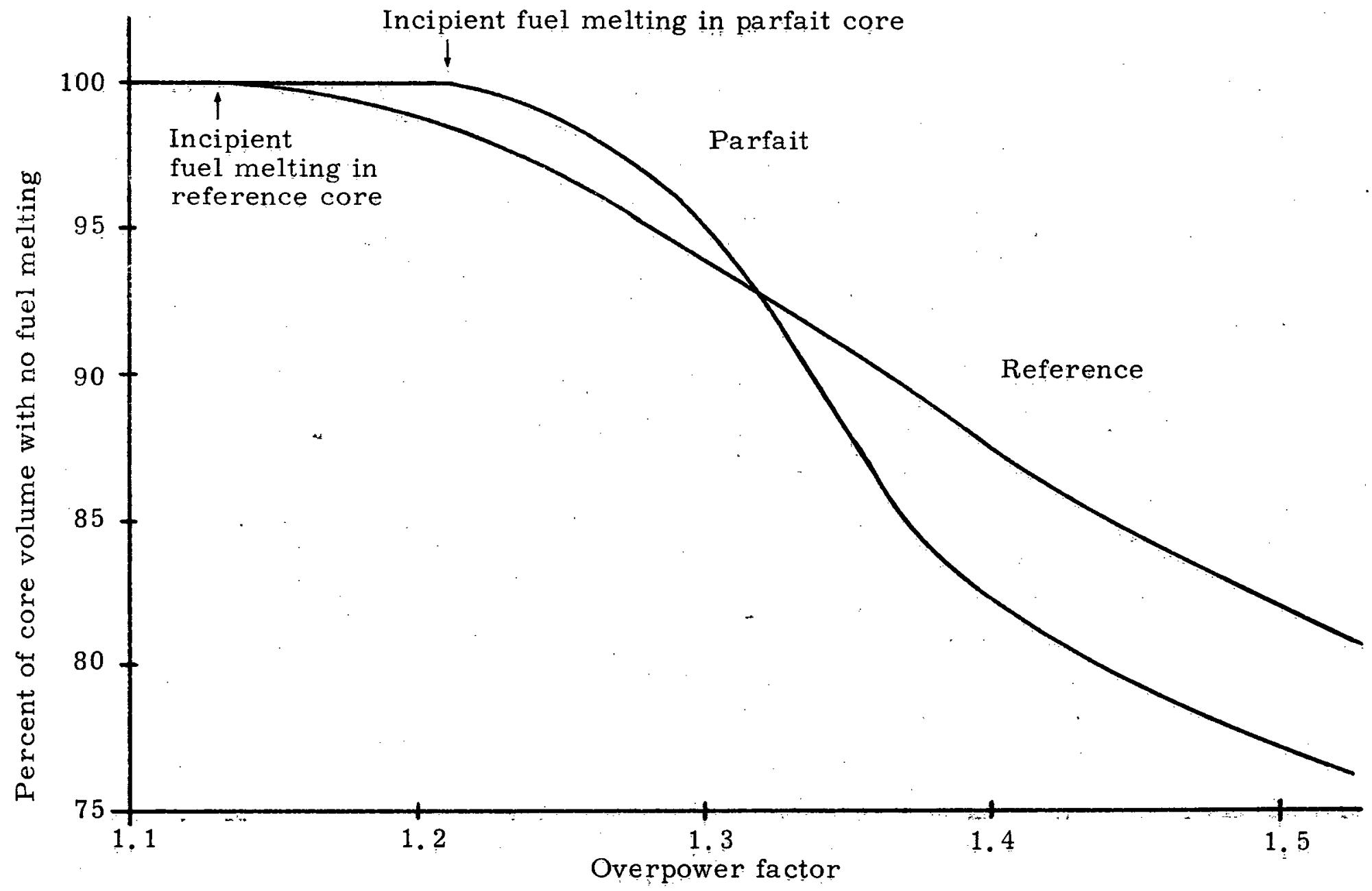

FIG. 3.9. Results of Operating Margin Analysis (BOC) 
The most significant factor contributing to this advantage for the parfait configuration is the axial and radial power flattening caused by the internal blanket region. The power flattening effect allows the parfait configuration to operate at a $5 \%$ lower peak power density than the reference reactor. (The flatter power distribution also explains why the parfait core exhibits a steeper profile than the reference core in Fig. 3.9 after the first position in its core reaches the limiting linear power rating.) Another factor contributing to the greater operating margin for the parfait configuration is the favorable coolant (and cladding) temperature profile described in the previous section. The coolant above the midplane in the central zone of the parfait configuration is at a lower temperature than in the reference reactor. This temperature profile characteristic contributes about $1 \%$ of the $7 \%$ higher operating margin enjoyed by the parfait configuration. Finally, the extra power generation in each of the blanket regions of the parfait configuration, due to higher fluxes and greater plutonium buildup in these regions, helps reduce the peak power density in the parfait configuration. Although insignificant at the beginning of a burnup cycle, this characteristic contributes to an even greater end-of-cycle operating margin for the parfait configuration than that indicated in Fig. 3.9.

\section{3. MATERIAL CONSIDERATIONS}

The materials in the cores of the reference and parfait configurations are the same; however, the environment to which they are exposed is significantly different in at least one respect. Although 
temperature is an important parameter influencing material behavior, it was shown in Section 3.2.2 that the material temperature profiles for the two configurations are quite similar. Therefore, the subsequent quantitative evaluation focuses on burnup as the primary factor influencing fuel behavior and on fast fluence ( $\mathrm{E}>0.1 \mathrm{MeV}$ ) as the primary factor influencing structural material behavior.

\subsubsection{Fuel Swelling}

Fuel swelling models such as the one developed for use in the OLYMPUS-II code include the effects of fuel restraint, fuel surface temperature and fuel burnup (B8). The fuel temperature and restraint dependence of that model are shown in Fig. 3.10. The burnup dependence is given by the lambda $(\lambda)$ factor shown in Fig. 3.11. When cladding restraint occurs, the fuel swelling rate is determined by the product of $\lambda$ and the fuel swelling rate given by Fig. 3.10. These curves clearly predict an accelerated rate of fuel swelling at the higher burnup levels. These curves have been normalized to one set of experimental results; however, other data support this same conclusion (C2).

The primary factor influencing fuel swelling in which there is a significant difference between the reference and parfait configurations is the peak burnup in the fuel. As discussed in Section 3.2.3, power flattening allows the parfait configuration to generate the same power as the reference configuration and yet operate at a $5 \%$ lower BOC power density. The local fuel burnup is, however, a function of not only power density, but also time. During irradiation, the combination 


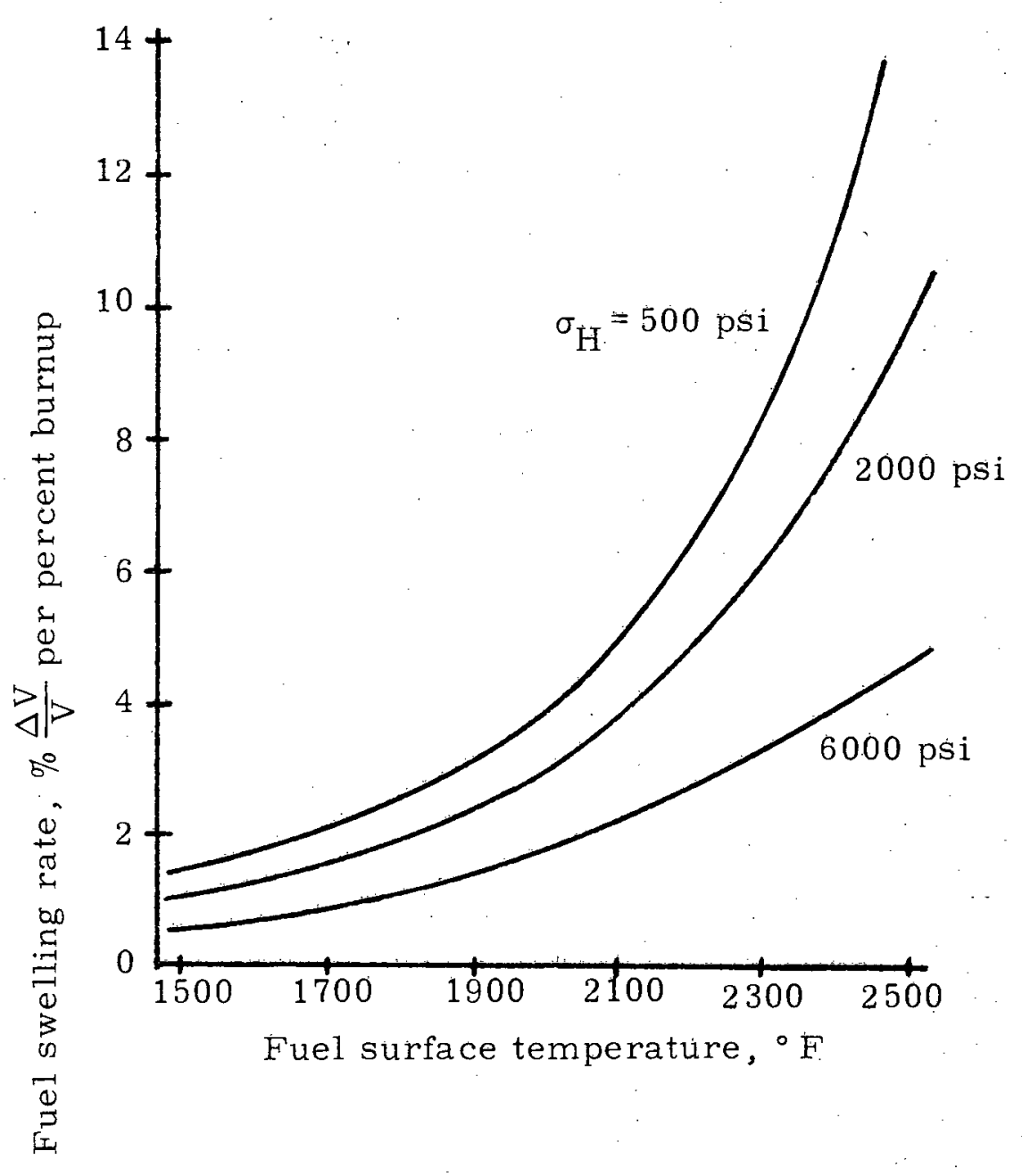

FIG. 3.10. OLYMPUS - II Code Fuel Swelling Model (B8)

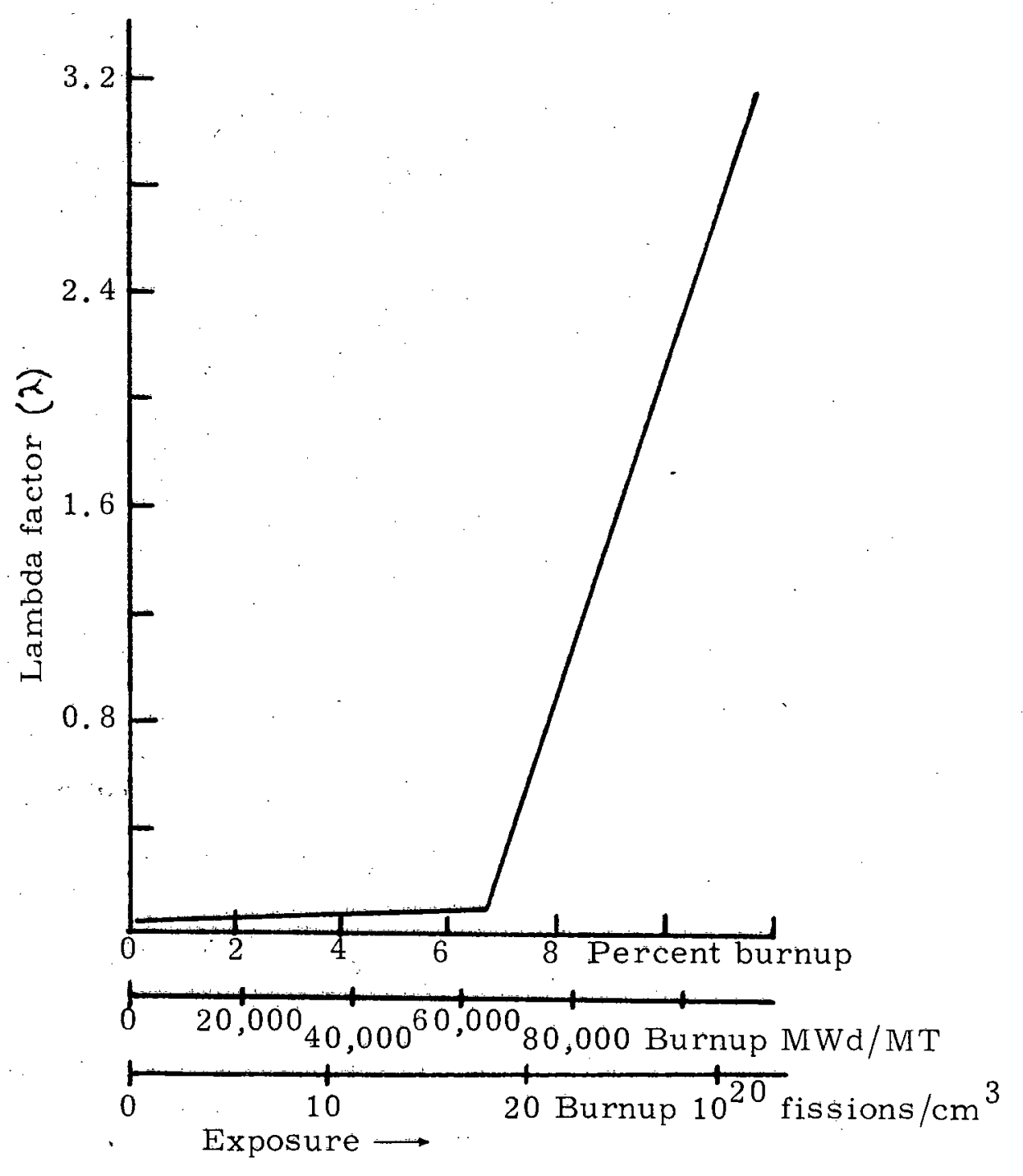

FIG. 3.11. Empirically Determined Factor to Adjust Burnup Dependence of OLYMPUS-II Fuel Swelling Model (B8) 
of the rapidbuildup of power in the internal blanket (which increases the difference between the maximum power densities in the two configurations) and the movement of the location of the peak power density in the core results in a net $7.6 \%$ smaller peak burnup in the parfait configuration. (The peak burnup in the parfait core may be further reduced compared to the reference core if the advantage of a reduced burnup reactivity swing allows several control rods to be replaced by fuel assemblies.) The reduced peak burnup in the parfait configuration means that fuel swelling and clad strain due to fuel swelling would be reduced. Since fuel swelling has been accommodated in fast reactor design by reducing the as-fabricated fuel density, the reduced fuel swelling in the parfait configuration may be viewed as a means of allowing an increase in the effective core fuel volume fraction. Alternatively, this characteristic could allow the parfait configuration the economic advantage of higher average fuel burnups.

\section{3.2. Swelling in Type-316 Stainless Stee1}

The effects of stainless steel swelling on the méchanical design of the reference and parfait cores of this study are described in the next section. As a necessary prelude, the present section reviews the results of a study evaluating the design, research and development implications of metal swelling in fast reactors $(H 7)$. The sample core used in reference $(\mathrm{H} 7)$ to provide quantitative results of the effects of metal swelling is the reactor design referred to as "Design $I^{\prime \prime}$ in Table 1.4 (Chapter 1). This configuration has the same geometry as that of the reference reactor of this study; however, the results are 
not directly applicable because of the different fluence levels in the cores, as will be discussed later in this section.

The primary structural material under consideration for use in fast reactors is $20 \%$ cold-worked, Type-316 stainless steel. A plot of its swelling characteristics as a function of temperature and fluence is shown in Fig. 3.12. The swelling correlation represented in this figure is dependent upon fast fluence (E $>0.1 \mathrm{MeV}$ ) raised to the 1.69 power.

Volumetric changes in the structural components of the core result in an overall growth in the size of the core and cause distortions in the fuel elements. For a core having the same dimensions as the reference reactor of this study and a peak fast flux of $3.77 \times 10^{15} \mathrm{n} / \mathrm{cm}^{2} \mathrm{sec}$ at the core center, the estimated core distortions due to metal swelling are displayed in Figs. 3.13 and 3.14. The residence time for core assemblies was two years and the residence time for radial blanket assemblies was five years. Figure 3.13 demonstrates that the core not only increases in length, but that radial flux and temperature gradients across the assemblies result in a different absolute growth for the opposite faces of the wrapper tube. This differential growth results in substantial fuel element bowing. Figure 3.14 demonstrates another source of radial distortions in the core, dilation of the wrapper tube. For this sample core, the combination of flux and temperature conditions resulting in the worst metal swelling occurs slightly above the core midplane. If no plastic flow of metal occurs, wrapper tube dilation could result in a $4.65-\mathrm{cm}$ increase in the core radius. In addition to increasing the difficulty of 


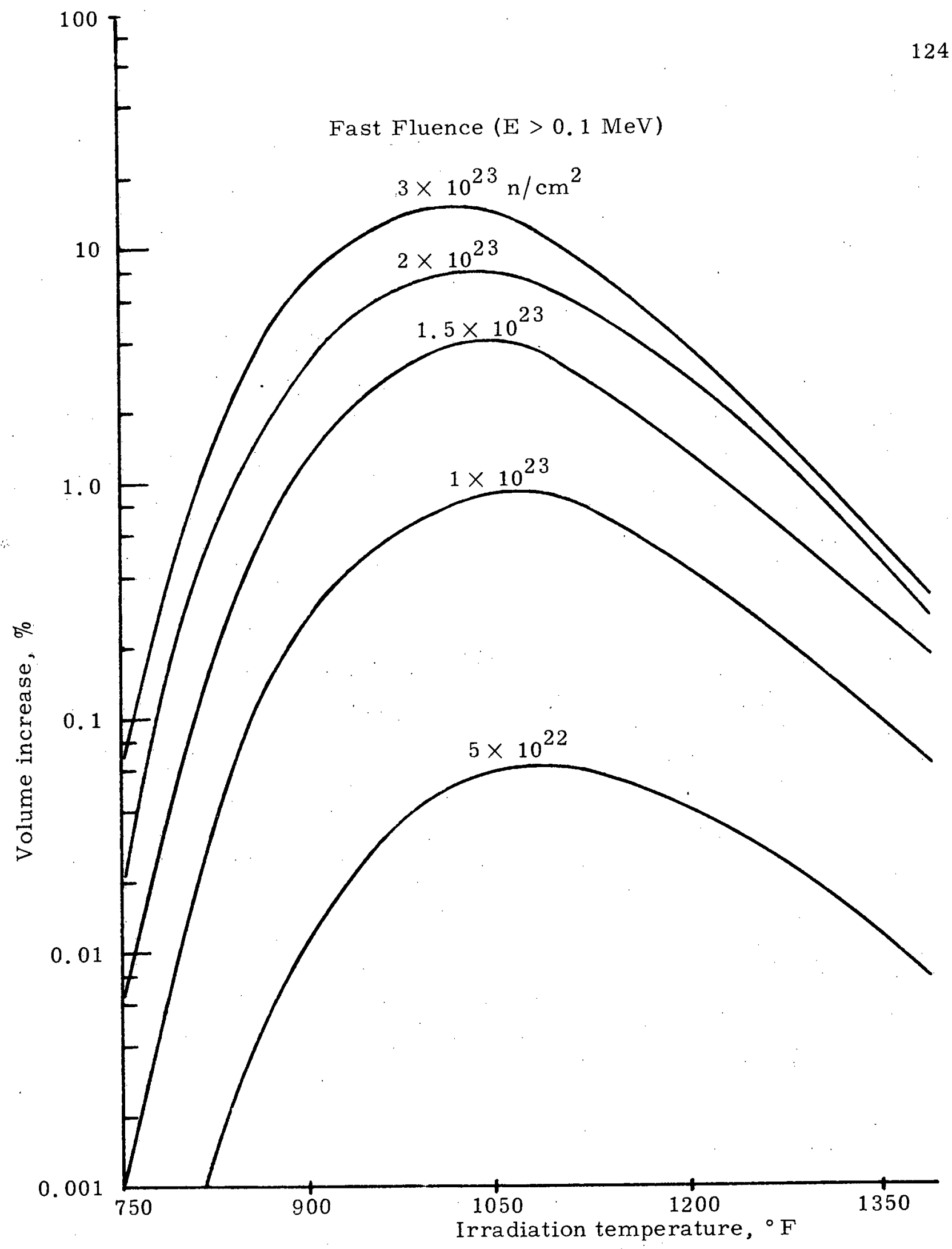

FIG. 3. 12. Swelling of $20 \%$ Cold-Worked

Type-316 Stainless Steel (G3) 


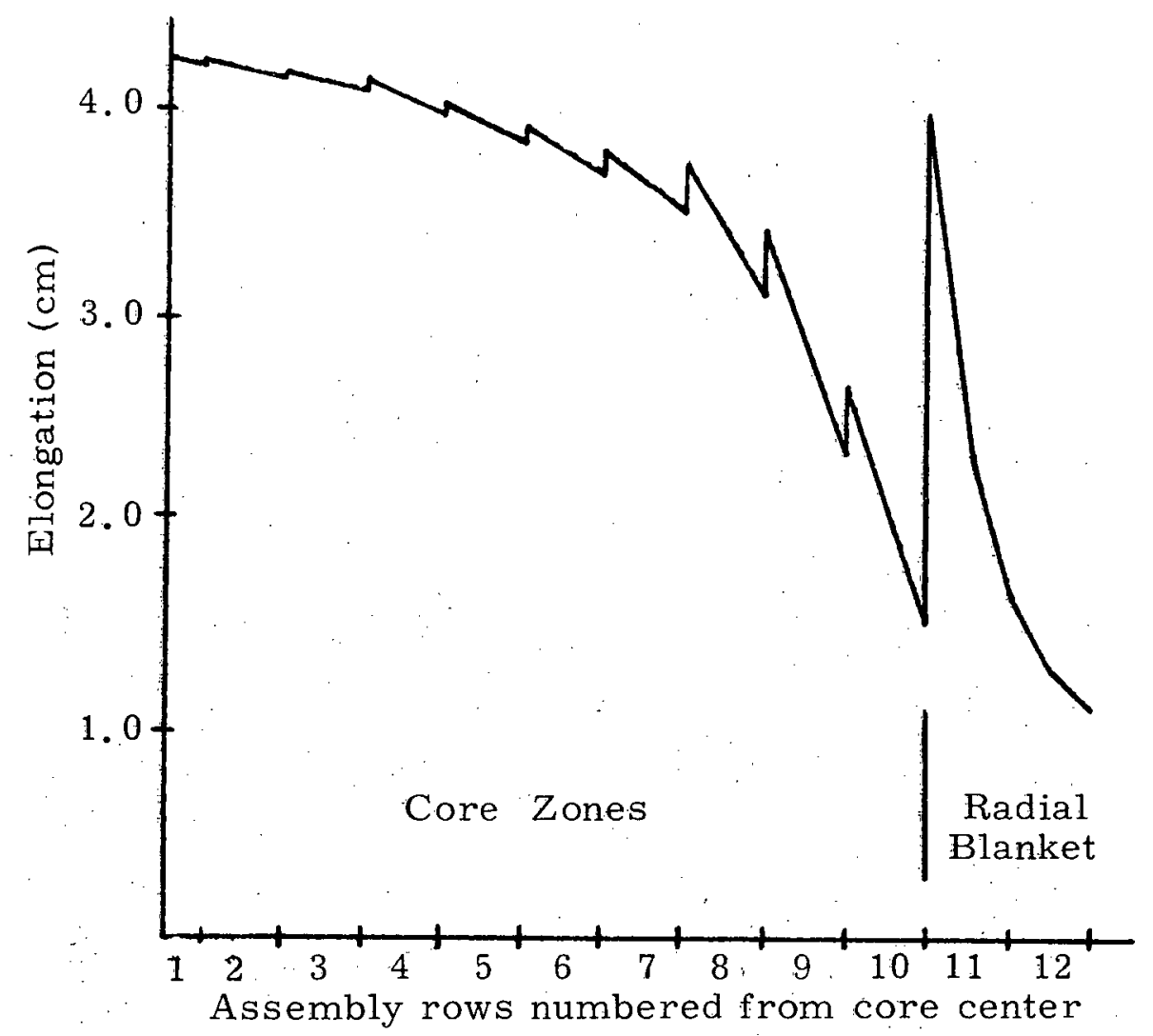

FIG. 3. 13. EOC Elongation of Wrapper Tube Walls Due to Swelling (H7)

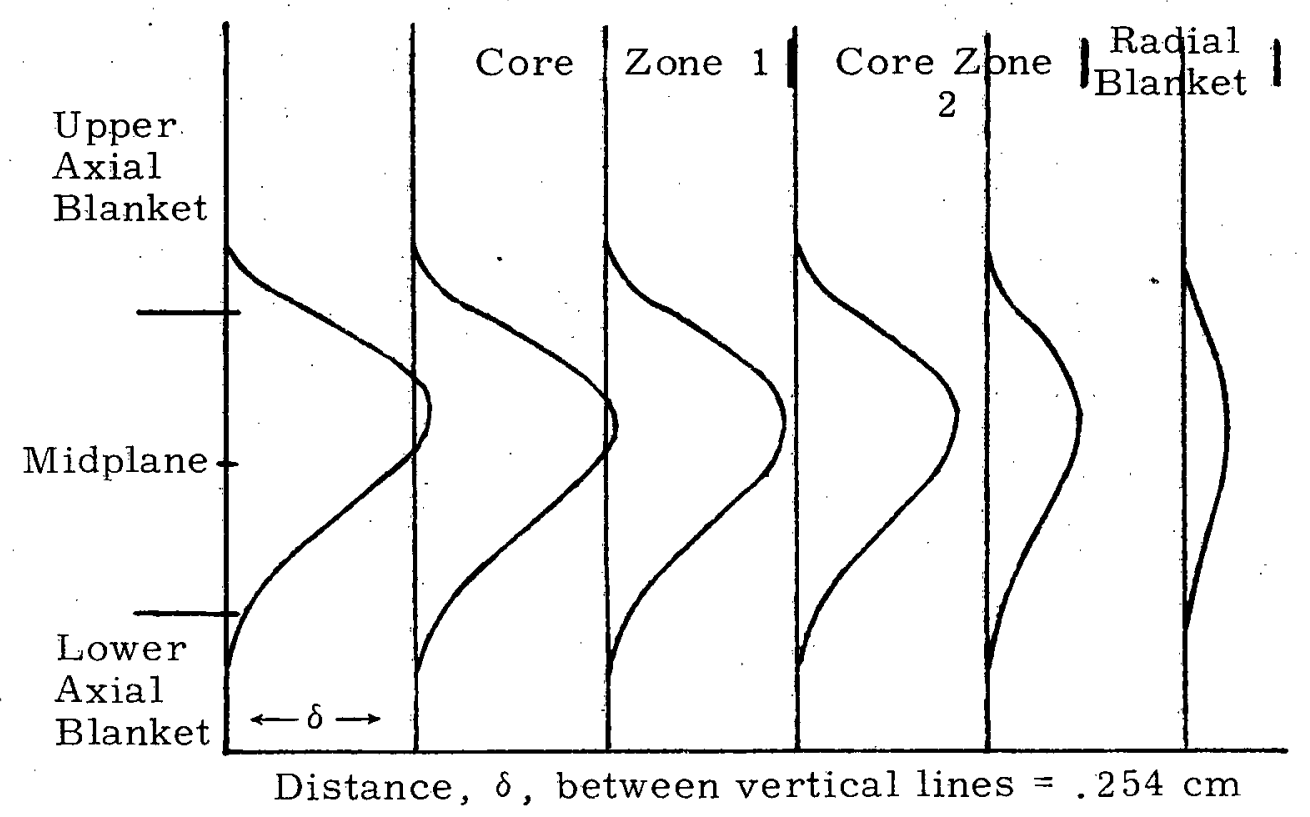

FIG. 3.14. EOC Dilation of Wrapper Tubes Due to Swelling (H7) 
blind fuel handling, and possibly causing misalignment of control rod guide tubes, unrestrained radial core expansion could cause a $3 \$$ loss of reactivity, and axial expansion an additional $2 \$$ loss.

The current fast reactor design philosophy has been to provide space in the core to accommodate metal swelling. This has resulted in cores with larger dimensions, lower fuel volume fractions (increased sodium-to-fuel-atom ratios), increased core fissile inventories and decreased breeding ratios. In addition to the economic penalties resulting from these neutronic characteristics, metal swelling has also increased the projected energy costs for LMFBR's because of greater design complexity (H 7). Still additional penalties may be incurred through lower reactor outlet temperatures.

The parfait configuration provides a means of reducing metal swelling and its associated penalties by reducing the peak fast fluence in the core. Figure 3.15 demonstrates that the reduced fast neutron fluence of the parfait concept would also allow extrapolation to a competitive LMFBR from a greater data base. The peak fast flux in the parfait configuration is $74.5 \%$ of that in the reference reactor. If, as indicated in Fig. 3.15, the approximate threshold for a competitive reference LMFBR is $2.0 \times 10^{23} \mathrm{n} / \mathrm{cm}^{2}$, a parfait configuration could be introduced which would have an expected peak fluence of $1.5 \times 10^{23} \mathrm{n} / \mathrm{cm}^{2}$, a fluence which will have been achieved in the FFTF driver fuel.

The peak fast neutron flux in the reference configuration of this study is greater than that used in reference (H7). This is primarily the result of employing a lower core fuel volume fraction for the 


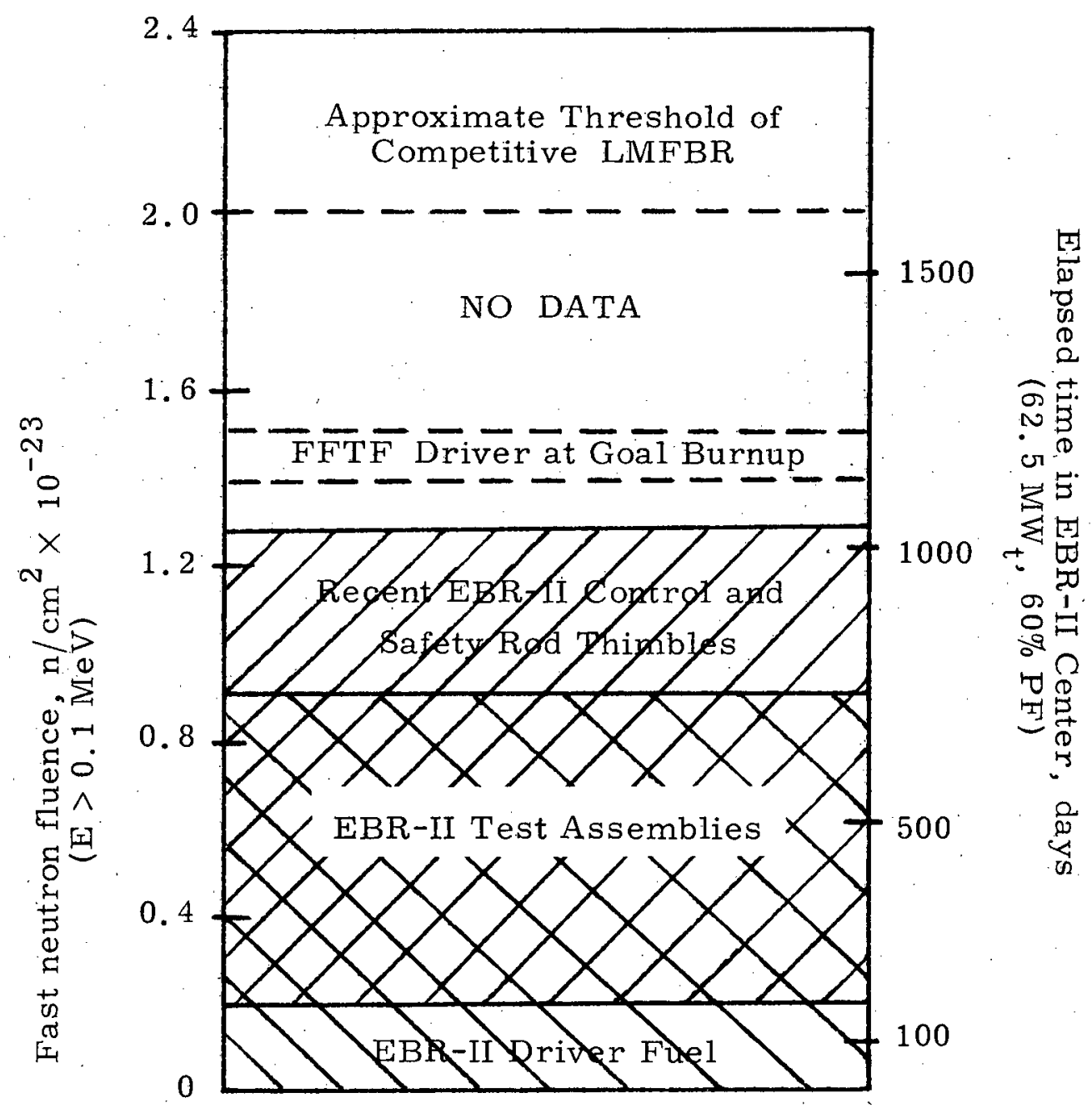

FIG. 3. 15. Fast Neutron Fluence, Required Test Time and Program Objectives (H7) 
reference and parfait reactors of this study. This change, which decreased the average fissile and fertile number densities in the core and hence $\Sigma_{f}$, forced an increase in the flux to maintain the same reactor power. The fluence-induced core distortions calculated in the next section for the reference reactor are, therefore, greater than those calculated in reference (H7).

\subsection{MECHANICAL DESIGN}

\subsubsection{Wrapper Tube Dilation}

The wrapper tube dilation in the reference and parfait configurations was assumed to be proportional to the local value of the fast fluence raised to the 1.69 power. The magnitude of the dilation was normalized to the value calculated at the core center for the sample configuration in Section 3.3.2. This analysis neglected the effect of temperature variations along the fuel element which, if included, would cause the peak dilation to occur above the core midplane. The lower coolant temperature above the midplane in the inner core zone would further reduce the peak wrapper tube dilation in the parfait configuration relative to the reference reactor. The results for the reference and parfait configurations are compared in Fig. 3.16. The maximum dilation of the wrapper tube in the parfait configuration is $37.5 \%$ smaller than in the reference configuration. The implications are that the parfait core can be made more compact and have a higher fuel volume fraction than the reference reactor. In addition, since the cross sectional area of the fuel assembly increases (by a maximum of about $6 \%$ in the reference configuration) as the wrapper tube dilates, the coolant by-pass 


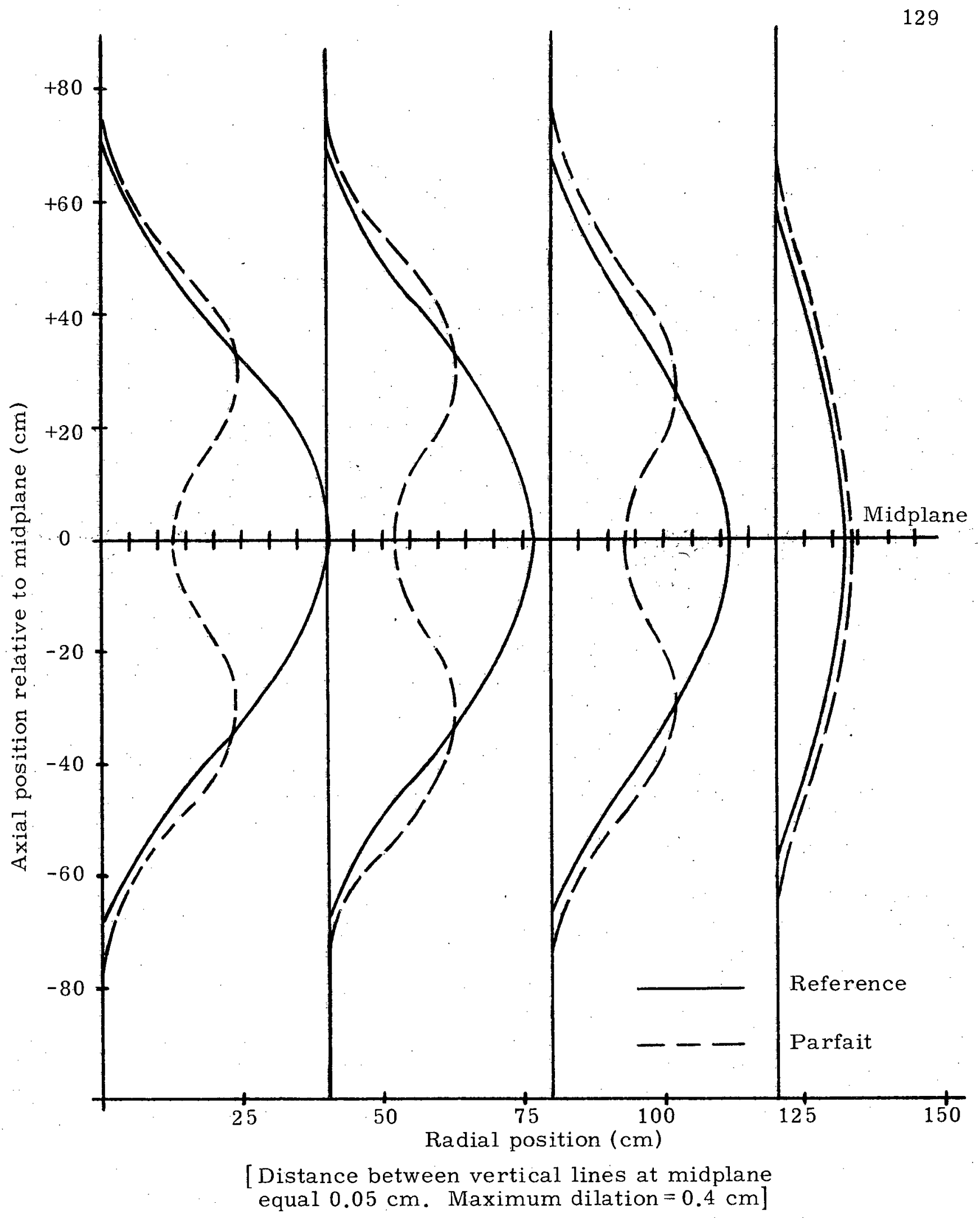

FIG. 3.16. EOC Wrapper Tube Dilation Due to Swelling 
flow within the assemblies of the parfait configuration is also less.

\subsubsection{Fuel Element Elongation}

As in the previous section, fuel element elongation in the reference and parfait configurations was assumed to be proportional to the fast fluence raised to the 1.69 power. The axially integrated, powerweighted fast fluence was determined as a function of radial position and the magnitude of the fuel element elongation was normalized to the value calculated along the core centerline for the reference configuration discussed in Section 3.3.2. The results for the reference and parfait configurations of this study are presented in Fig. 3.17. The residence time for the core fuel elements was two years and the residence time for the radial blanket elements was assumed to be four years. The original length of the fuel element, including the gas plenum, was $457 \mathrm{~cm}$. The maximum wrapper tube elongation of the reference reactor represents a growth of $1.5 \%$ as compared to $1.06 \%$ for the parfait configuration. Fuel element elongation may be readily accommodated in the design of a fast reactor, but differential growth between opposite faces of a fuel element results in fuel element bowing and is a much more severe problem. The greater the growth differential, the greater the free (unrestrained) bowing. Figure 3.17 demonstrates that within the inner core zone, the parfait configuration displays a significant advantage over the reference reactor in this respect. The analysis which produced these results neglected the effect of temperature differences between the opposite faces of the wrapper tube. These temperature differences arise from radial 


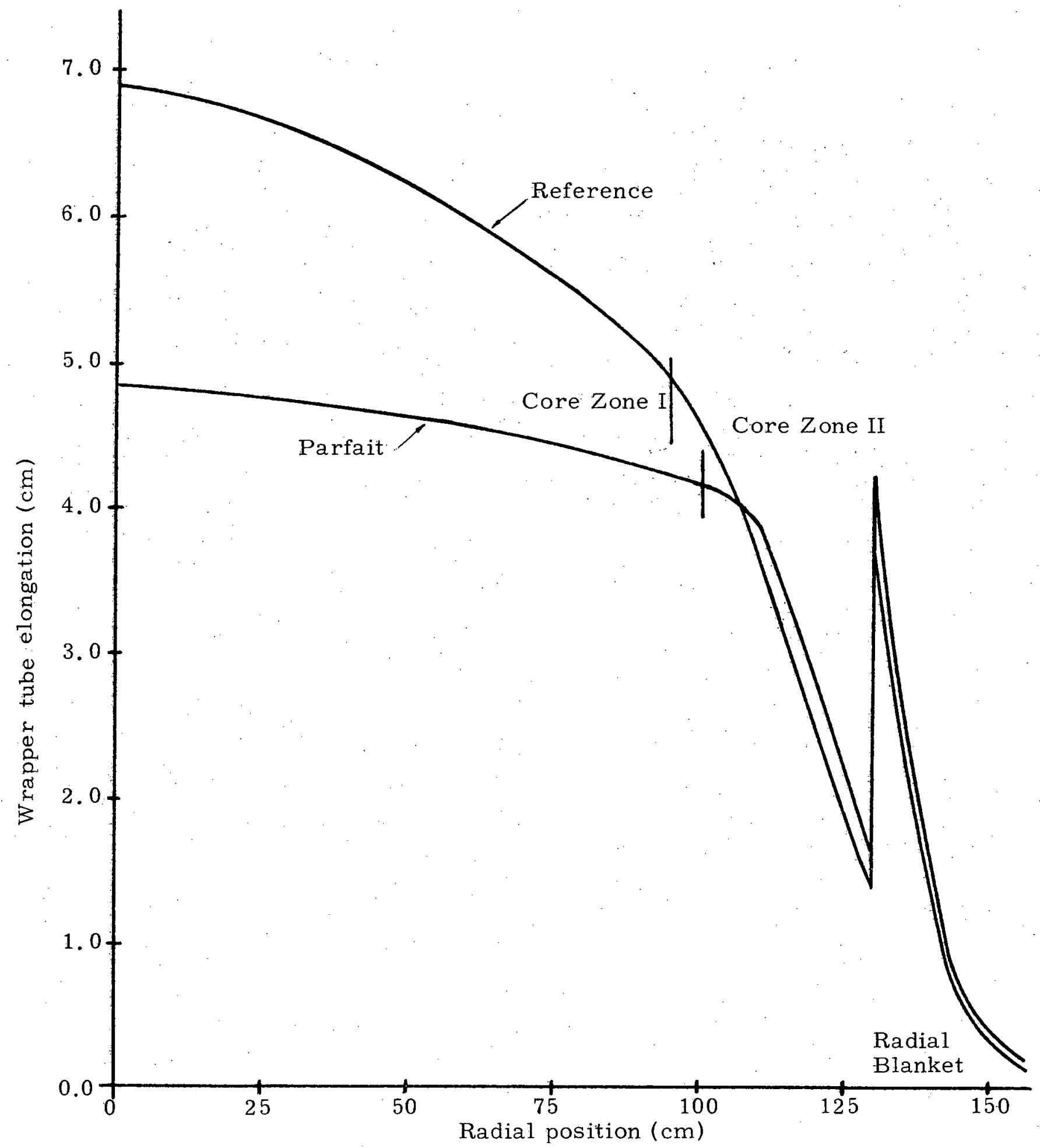

FIG. 3.17. EOC Wrapper Tube Elongation Due to Swelling 
power gradients in the core. Including their effect would impose a saw-tooth pattern on the curves in Fig. 3.17 similar to that in Fig. 3.13. Since the radial power gradient in the inner zone of the parfait configuration is less steep that in the reference reactor (Chapter 2, Figs. 2.20 and 2.21), including the effects of temperature differences would improve the relative advantage for the parfait configuration. The implication of this favorable performance characteristic is that fuel element distortions in the inner zone of the parfait configuration will be less severe than in the reference reactor, and the core restraint system will be subjected to smaller loads. In the outer core enrichment zone, the absolute and differential wrapper tube growth is comparable in both configurations.

\subsubsection{Axial Gradients}

Because the axis of symmetry for fuel pins, fuel elements and the core as a whole is oriented axially, axial flux, power and temperature gradients present far fewer mechanical design problems in fast reactor cores than do radial gradients. Nevertheless, one of the differences between the reference and parfait configurations is the introduction of a pair of power discontinuities into the core at the interface between the core zone and the internal blanket. This power discontinuity is similar to that in the reference reactor at the interface between the core and axial blanket. The axial temperature gradients in the fuel and clad due to these power discontinuities were evaluated using the three-dimensional heat conduction code, HEATIN2 (B9), and the results are presented in Figs. 3.18, 3.19, and 3.20. These figures 


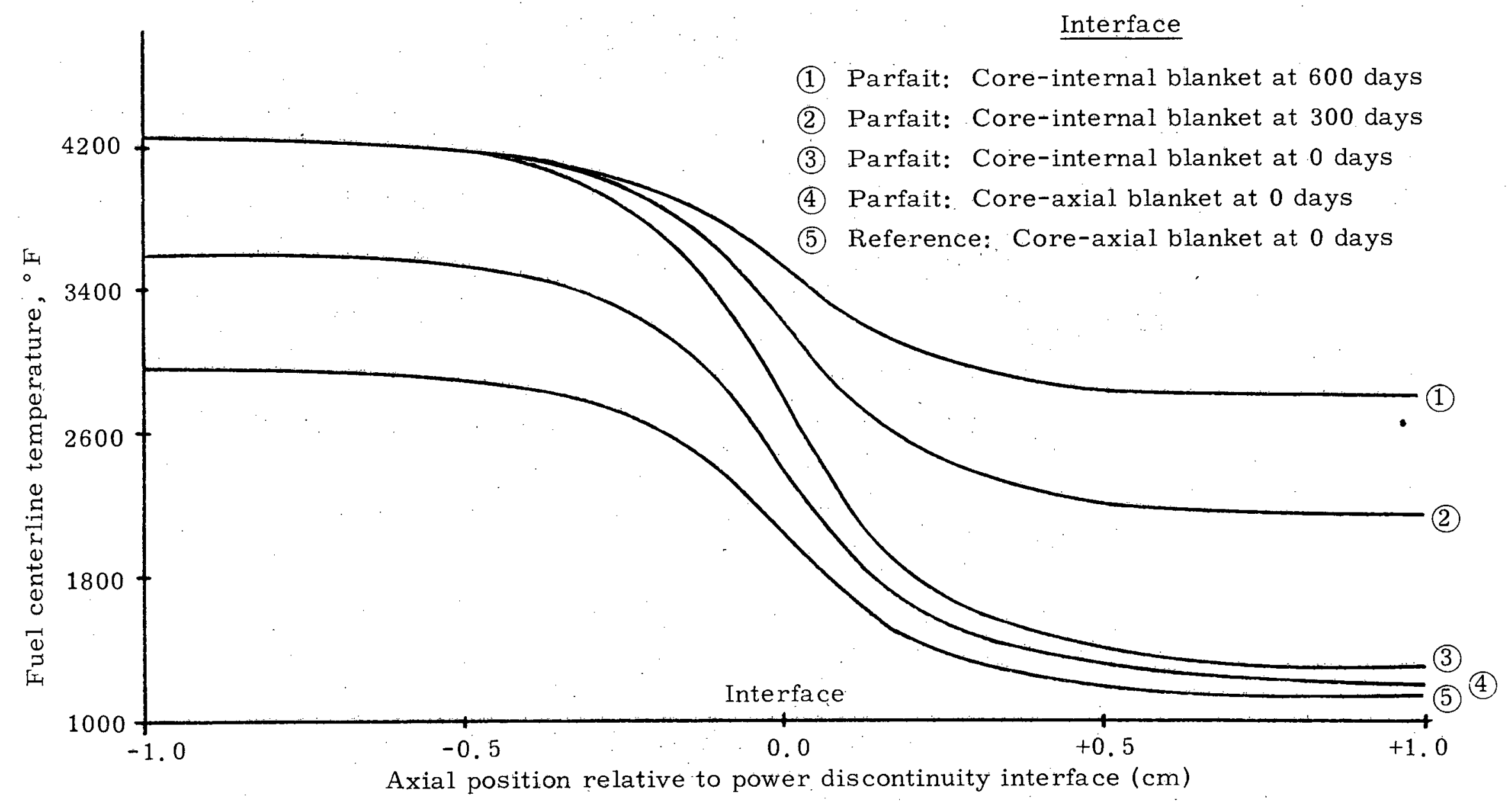

FIG. 3.18. Axial Temperature Profile Along Fuel Centerline at the Power Discontinuity Interface 


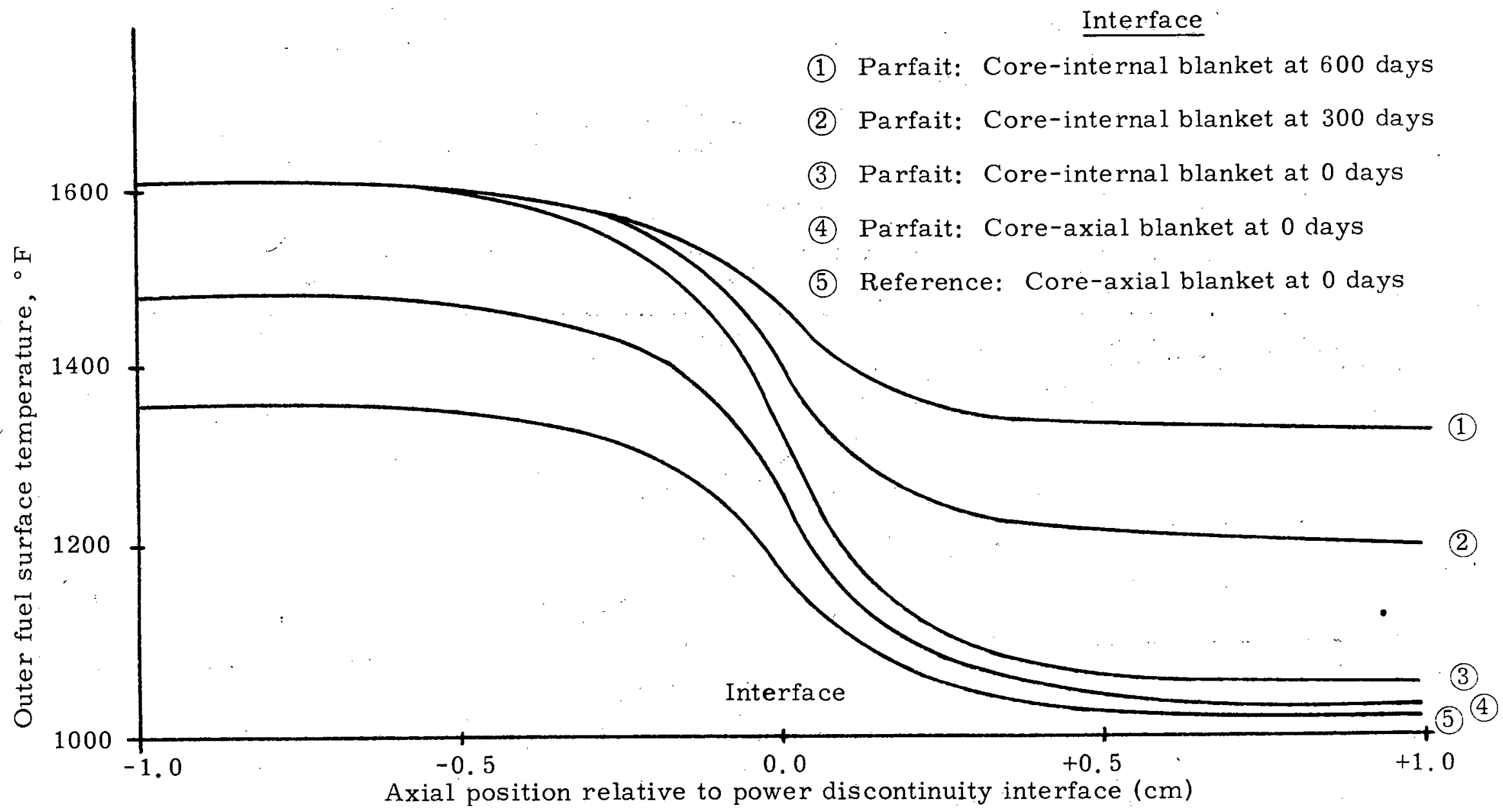

FIG. 3.19. Axial Temperature Profile at Fuel Outer Surface at the Power Discontinuity Interface 


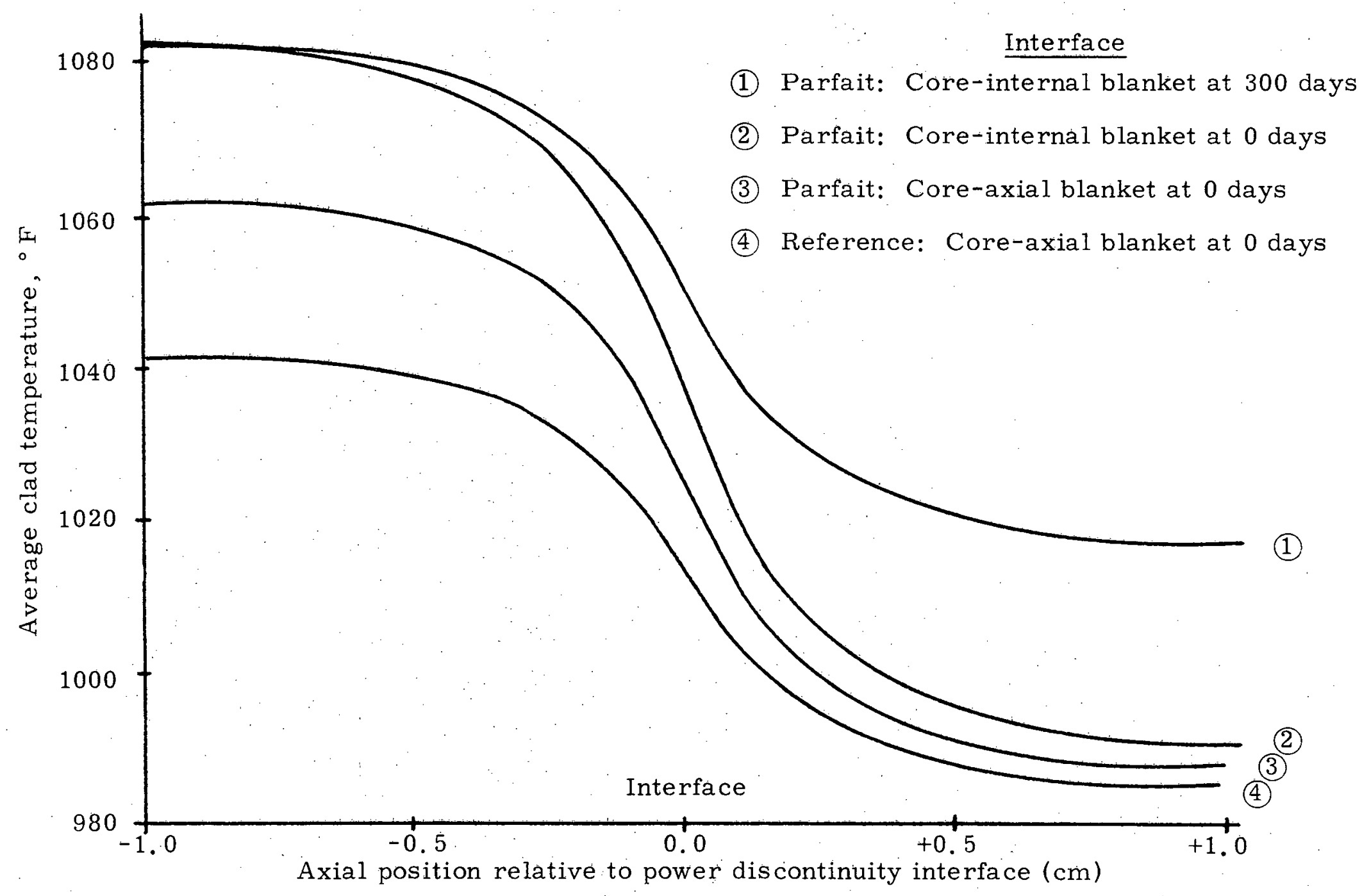

FIG. 3.20. Axial Temperature Profile in the Clad at the Power Discontinuity Interface 
compare the axial temperature profiles in the fuel and clad at the coreinternal blanket interface (as a function of exposure) to those at the core-axial blanket interface (BOC) for both the reference and parfait configurations. Although the temperature gradient at the fuel centerline is quite severe, axial conduction helps smear out this discontinuity so that in the clad, the peak axial temperature gradient is $120^{\circ} \mathrm{F} / \mathrm{cm}$. The maximum temperature difference in the clad of the parfait configuration across the core-internal blanket interface is $92^{\circ} \mathrm{F}$. This temperature difference results in a fractional increase in the clad diameter of only 0.00056 .

The linear power ratings used to obtain the interface temperature profiles were generated using the $2 \mathrm{DB}$ code. This code assumes a power profile which is proportional to the local fission rate and neglects the effects of gamma heating. It has been shown by Wood (W1), however, that gamma heating is comparable to fission heating in a depleted uranium blanket at the beginning of irradiation. Including the effects of gamma heating would therefore diminish the power discontinuity and reduce the associated temperature gradients.

\subsection{CONCLUSIONS}

The core engineering considerations evaluated in this chapter demonstrate a substantial advantage for the parfait concept over the reference configuration. The reduction of the peak fast neutron $(E>0.1 \mathrm{MeV})$ flux in the core greatly diminishes the detrimental effects of metal swelling. Dilation of the hexagonal wrapper tube due to swelling was estimated to be $37.5 \%$ smaller in the parfait 
configuration. The maximum fuel element elongation in the parfait configuration was also found to be $29 \%$ smaller than in the reference reactor. More importantly, the differential growth between opposite faces of the wrapper tube, which leads to fuel element bowing, was found to be substantially reduced in the inner core zone of the parfait configuration. Minimizing the effects of metal swelling is an advantage which could allow the parfait configuration to have a more compact core containing a higher fuel volume fraction.

Fuel swelling is also an area in which the parfait configuration offers an advantage relative to the reference design. The peak fuel burnup in the parfait configuration was estimated to be $7.6 \%$ smaller than that in the reference reactor. Reduced fuel swelling, which is a function of burnup, would allow the parfait configuration to employ higher density fuel in. its core and thus increase the effective fuel volume fraction of the configuration.

A thermal analysis of both configurations, in which the maximum coolant outlet temperature was assumed to be limiting, demonstrated that both cores are capable of operating to the same mixed-mean coolant outlet temperature. The materials in both cores operate at substantially the same temperatures with the parfait concept exhibiting a slight advantage in that the clad and structural components operate at a lower average temperature in the region of interest above the midplane. An analysis of the overpower capabilities of the two configurations revealed that the parfait core enjoys a $7 \%$ greater margin between the nominal operating power and an overpower condition corresponding to incipient fuel melting in the hottest fuel pin. 
This and the preceding chapter have described the normal operating characteristics of the reference and parfait systems. The next chapter describes the safety-related response of the two configurations to changes in core characteristics not encountered in normal full power operation. 


\section{Chapter 4}

\section{SAFETY CONSIDERATIONS}

\subsection{INTRODUCTION}

The previous two chapters have been devoted to a comparison of the parfait and reference systems under the normal full-power operating conditions of an equilibrium cycle. In this chapter the response of the two systems is compared for changes in the core characteristics which a re not encountered in normal full-power operation. Particular emphasis has been given to the calculation of those nuclear parameters which influence safety, including the delayed neutron fraction, the prompt neutron lifetime, the partial and complete coolant voiding coefficients, the isothermal Doppler coefficient and the power Doppler coefficient. As with all of the calculations in this report, it is the relative values of these parameters which are most relevant in assessing the potential for the parfait concept. This is particularly true for these safety-related parameters because of the calculational uncertainties in their absolute magnitudes indicated in Chapter 1, Table 1.2.

\section{2. DELAYED NEUTRON FRACTION AND PROMPT NEUTRON LIFETIME}

The effective delayed neutron fractions and the prompt neutron lifetimes for the parfait and reference designs were compared because of the importance of these parameters to the kinetic response of the reactors. The formulas used in this analysis are given below (H5): 


$$
\beta_{\text {eff }}=\frac{\int d V \sum_{i} \beta_{i} \nu_{i} \Sigma_{f i} \phi \phi^{*}}{\int d V \sum_{i} \nu_{\dot{i}} \Sigma_{f i} \phi \phi^{*}}
$$

where

$$
\begin{aligned}
\beta_{\mathrm{eff}} & =\text { effective delayed neutron fraction } \\
\int \mathrm{dV} & =\text { integral over the system volume } \\
v_{\mathrm{i} .} & =\text { fission yield for isotope } \mathrm{i} \\
\Sigma_{\mathrm{fi}} & =\text { macroscopic fission cross section of isotope } i \\
\phi^{*} & =\text { neutron flux } \\
\phi^{*} & =\text { adjoint flux } \\
\beta_{\mathrm{i}} & =\text { delayed neutron fraction for material } \mathrm{i} \\
& \Lambda=\frac{\int \mathrm{dV} \frac{\phi \phi^{*}}{\mathrm{v}}}{\int \mathrm{dV} \sum_{\mathrm{i}} v_{\mathrm{i}} \Sigma_{\mathrm{fii}} \phi \phi^{*}}
\end{aligned}
$$

where

$\Lambda=$ prompt neutron lifetime or, more properly, the neutron generation time

$\mathrm{v}=$ average neutron velocity.

Eluxes; adjoint fluxes and the macroscopic fission cross sections were generated using $2 \mathrm{DB}$, the fission neutron yields and delayed neutron fractions were obtained from reference (D2), and the average neutron velocities, in each region were obtained by flux and volume weighting: the average neutron group velocities. Calculations were performed for the reference reactor and a $30-\mathrm{cm}$ internal blanket parfait configuration. The results, presented in Table 4.1, show that the delayed neutron fractions and the prompt neutron lifetimes are very nearly equal for both configurations. 
TABLE 4.1

Comparison of the Effective Delayed Neutron

Fraction and Prompt Neutron Lifetime

\begin{tabular}{ccc}
\hline Parameter & Reference & $\begin{array}{c}30-\mathrm{cm} \text { IB } \\
\text { Parfait }\end{array}$ \\
\hline Delayed neutron fraction, $\beta_{\text {eff }}$ & 0.00416 & 0.00412 \\
Prompt neutron lifetime (sec) & $2.98 \times 10^{-7}$ & $2.90 \times 10^{-7}$ \\
\hline
\end{tabular}

\subsection{SODIUM DENSITY REACTIVITY EFFECTS}

The removal of some or all of the coolant from a large sodiumcooled fast reactor will result in reactivity changes due to three effects (D1): reduced neutron captures in sodium, spectrum hardening (which favors additional fertile material fissions and reduces the capture-to-fission ratio in the fissile materials) and increased neutron leakage from the core. The latter two considerations dominate, with spectrum hardening contributing a positive reactivity effect and neutron leakage contributing a negative effect. Because the probability of neutron leakage from the core is strongly position-dependent, the sodium density reactivity coefficient is also strongly position-dependent; that is, generally positive toward the center of the core and negative in the peripheral regions.

There are several mechanisms by which the sodium density in a region of the core may be reduced. A severe reduction of coolant flow to a fuel assembly operating at full power could cause the sodium to boil. 
The resulting sodium vapor generated in the fuel channels would, in turn, expel the remaining liquid sodium and thus void the element. The reactivity effect of the total removal of sodium from different regions of the core is evaluated in Section 4.3.1. A related mechanism for reducing the sodium density in a region of the core is the thermal expansion of the liquid metal coolant. The temperature dependence of the sodium density in the temperature range of interest in fast reactors is illustrated in Fig. 4.1. Temperature changes in, the core, therefore, affect the sodium atom density in the core, which in turn causes a reactivity change. Such temperature changes are experienced, for example, in taking the reactor from the cold startup condition to full power operation or when flow is varied in the primary and secondary sodium loops. Another mechanism by which the average sodium density in the core may be reduced is by the entrainment of gas (fission gas or cover gas, for example) in the primary coolant. The reactivity effect of this slight reduction in the average sodium density in the core is similar to that caused by thermal expansion. The reactivity effect of a partial reduction of the sodium density in both configurations is evaluated in Section 4.3.2.

\subsubsection{Regionwise Sodium Void Reactivity}

As stated in Section 1.2, the sodium void characteristics of fast reactor cores made up of alternating slabs of fissile and fertile material have been investigated in two earlier studies. In one study (L3) involving a 1500-lïter $\mathrm{Pu}-\mathrm{U}$ metal-fueled reactor, inserting a layer of blanket material at the core midplane was found to have a 


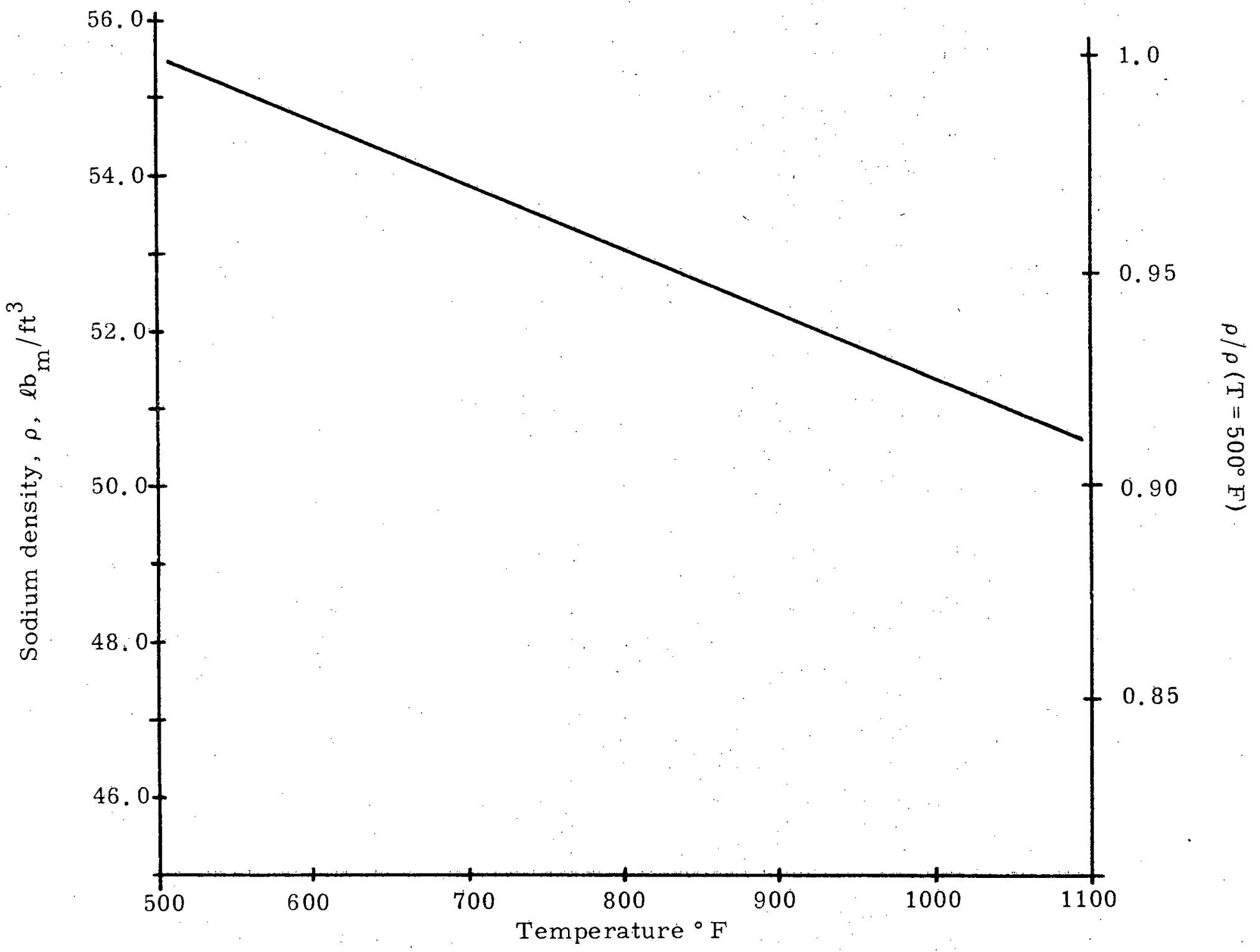

Fig. 4.1. Sodium Density as a Function of Temperature 
favorable effect on the sodium void coefficient; that is, it was made less positive or more negative. This characteristic was confirmed for several thicknesses and compositions of the internal blanket. In a Westinghouse study ( $\mathrm{H} 1)$, a concept employing stacks of pancake cores separated by blankets was investigated for carbide-fueled reactor systems. That study revealed that the parfait-type distribution of fissile and fertile material could diminish a positive sodium void coefficient.

The reactivity worth of sodium in the reference and parfait configurations of the present study was determined by comparing the $\mathrm{k}_{\text {eff }}$ predictions for each configuration with and without sodium totally removed from specific regions of the reactor. The cores compared in this analysis were the standard reference core (Chapter 1, Table 1.5) and a parfait configuration in which the internal blanket had a thickness of $40 \mathrm{~cm}$ and a radial extent of $90 \mathrm{~cm}$. (The radial extent of the inner core zone of both configurations was the same.) The core and blanket regions of both reactors were loaded with fissile concentrations representative of the beginning of an equilibrium cycle. The specific regions which were voided of sodium are defined in Fig. 4.2. Because axial symmetry was assumed in these calculations, voiding of a region shown in the figure was accompanied by voiding in a mirror image region in the lower half of the core. These calculations were performed with the 2DB code, employing the standard four-group cross section set, and the results are listed in Table 4.2. These results demonstrate the favorable sodium void characteristics of the parfait configuration. 


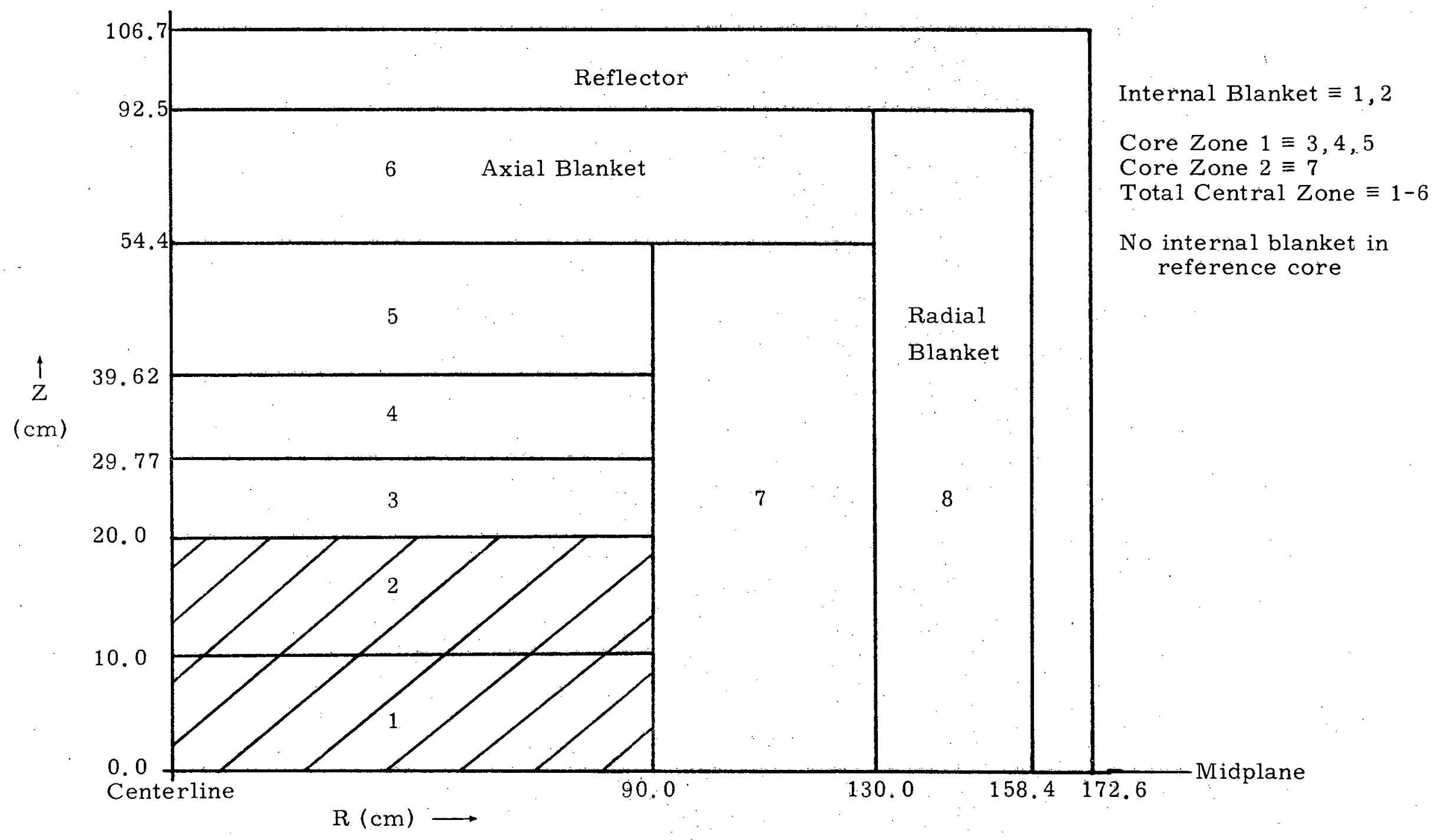

FIG. 4.2. Definition of the Reactor Regions Used in the Sodium Void Analysis 
TABLE 4.2

BOC Sodium Void Worth by Zone in the Reference and Parfait Reactors

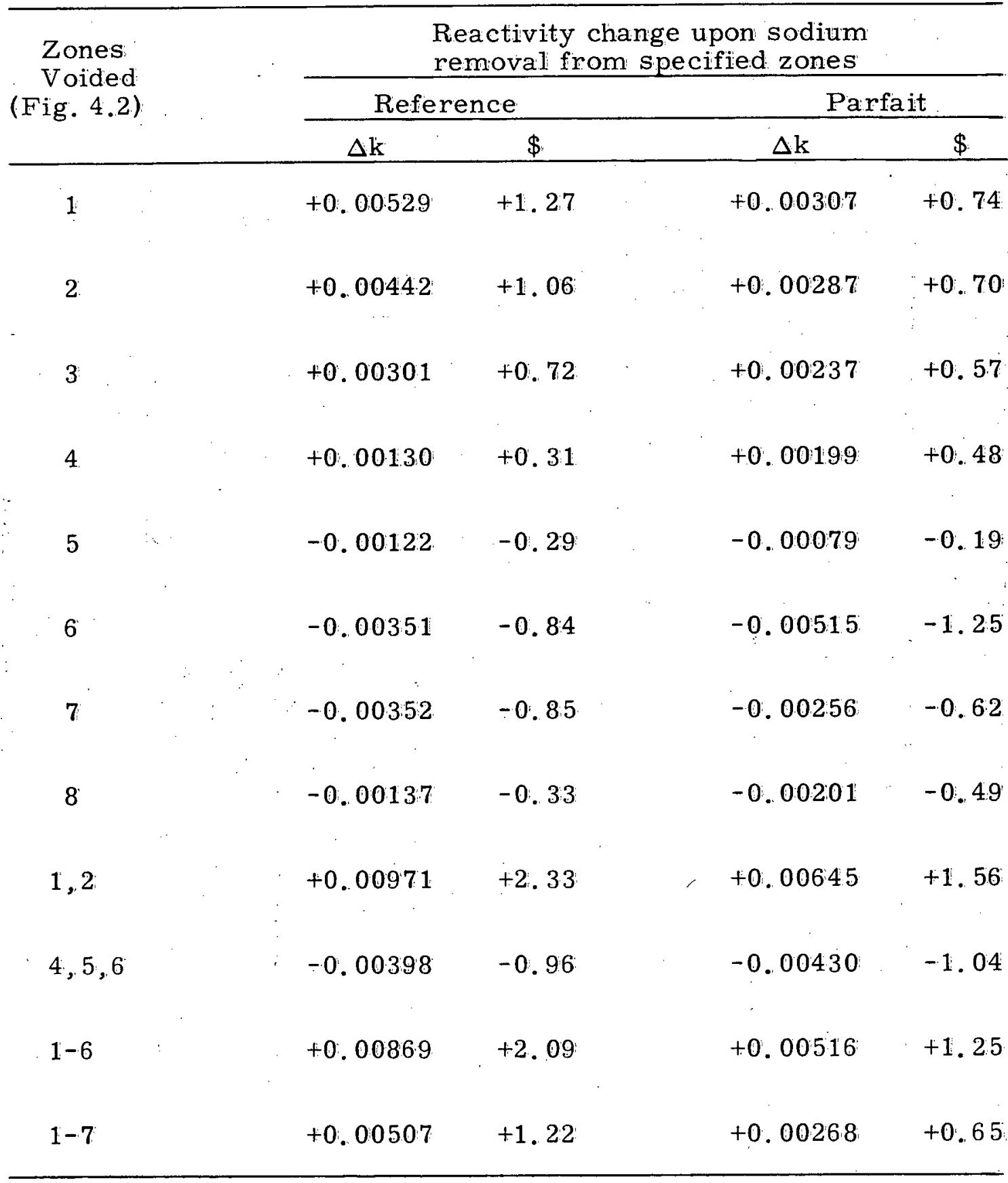


The removal of sodium from the parfait configuration results in a smaller increase or a larger decrease in $\mathrm{k}_{\text {eff }}$ than in the reference core for each of the zones voided except 4,5 and 7. From the point of view of safety, the change in the multiplication factor is primarily of interest when the change is positive. Therefore, since the removal of sodium from zones 5 and 7 results in a decrease in $k_{\text {eff }}$ for both configurations, it is only the slightly more positive reactivity contribution of zone 4 which is significant. A general conclusion from the results of Table 4.2 is that the parfait configuration has more favorable sodium void characteristics than the reference core. The most positive sodium void reactivity effect occurs when zones 1 through 4 as defined in Fig. 4.2 are voided. For this case, the positive reactivity effect in the parfait configuration is only $74 \%$ of that for the reference reactor. A more detailed calculation of the response of each configuration to a specific sequence of events in a voiding accident would be required to state that the parfait configuration would respond more favorably in every case.

Because of the significant buildup of plutonium in each of the blanket regions, calculations were also performed to determine the reactivity effect of removing sodium from reference and parfait configurations having a fissile concentration and distribution characteristic of the end of an equilibrium burnup cycle (EOC). The results are shown in Table 4.3 . 
TABLE 4.3

EOC Sodium Void Worth by Zone in the

Reference and Parfait Reactors

\begin{tabular}{ccccc}
\hline \multirow{2}{*}{$\begin{array}{c}\text { Zones } \\
\text { Voided } \\
\text { (Fig. 4.2) }\end{array}$} & \multicolumn{4}{c}{$\begin{array}{c}\text { Reactivity change upon removal of } \\
\text { sodium from specified zones }\end{array}$} \\
\cline { 2 - 5 } & \multicolumn{2}{c}{ Reference } & \multicolumn{2}{c}{ Parfait } \\
\cline { 2 - 5 } & $\Delta \mathrm{k}$ & $\$$ & $\Delta \mathrm{k}$ & $\$$ \\
\hline 1,2 & +0.01036 & +2.49 & +0.00837 & +2.03 \\
$1-6$ & +0.01060 & +2.55 & +0.00891 & +2.16 \\
$1-7$ & +0.00857 & +2.06 & +0.00770 & +1.87 \\
\hline
\end{tabular}

A comparison between these results (EOC) and those of Table 4.2 (BOC) reveals that both cores exhibit the characteristic increase in the positive sodium void reactivity effect with burnup. The parfait configuration still maintains an advantage in that the positive $\Delta \mathrm{k}$ increases are smaller than in the reference core throughout the burnup cycle, but this difference is diminished as the parfait core burns up and takes on a fissile distribution and flux shape more similar to the reference core.

Several variations in the method used to calculate the effect of sodium removal from the cores were carried out in order to gain further assurance that the conclusions derived from Table 4.2 were correct. In the above calculations, the internal blanket was assumed to contain a homogeneous smear of fissile material such that the total fissile inventory of the region was equivalent to that which would be built up in equilibrium operation. In order to determine the effect of a more realistic fissile material distribution, the internal blanket was divided 
into alternating annuli of clean blanket material, and blanket material which had been irradiated for one cycle. The resulting fissile distribution approximated that of a scatter reload scheme in the central zone. This, however, was found to have no effect on the sodium void predictions.

The calculations of Table 4.2 were also carried out without any control poison in the cores. Because sodium removal from a core results in spectral hardening, which in turn renders a control poison (boron-10) less effective, a series of calculations were also performed for reference and parfait configurations loaded with a homogeneous boron concentration sufficient to suppress one half of the BOC excess reactivity of each configuration. The results are shown in Table 4.4 along with the comparable results from Table 4.2 .

TABLE 4.4. BOC Sodium Void Worth With and Without Boron in the Core

\begin{tabular}{|c|c|c|c|c|c|}
\hline \multirow{3}{*}{ Case } & \multirow{3}{*}{$\begin{array}{c}\text { Zones } \\
\text { Voided } \\
\text { (Fig. 4.2) }\end{array}$} & \multicolumn{4}{|c|}{$\begin{array}{l}\text { Reactivity change upon sodium } \\
\text { removal from specified zones }\end{array}$} \\
\hline & & \multicolumn{2}{|c|}{ Reference } & \multicolumn{2}{|c|}{ Parfait } \\
\hline & & $\Delta \mathrm{k}$ & $\$$ & $\Delta \mathrm{k}$ & $\$$ \\
\hline \multirow{3}{*}{$\begin{array}{l}\text { Without boron } \\
\text { (from Table } 4.2 \text { ) }\end{array}$} & 1,2 & +0.00971 & +2.33 & +0.00645 & +1.56 \\
\hline & $1-6$ & +0.00869 & +2.08 & +0.00516 & +1.25 \\
\hline & $1-7$ & +0.00507 & +1.22 & +0.00268 & +0.65 \\
\hline \multirow{3}{*}{$\begin{array}{l}\text { With boron } \\
\text { (Boron concen- } \\
\text { tration sufficient } \\
\text { to suppress one } \\
\text { half BOC excess } \\
\text { reactivity) }\end{array}$} & 1,2 & +0.01051 & +2.52 & +0.00634 & +1.54 \\
\hline & $1-6$ & +0.01087 & +2.61 & +0.00611 & +1.48 \\
\hline & $1-7$ & +0.00923 & +2.21 & +0.00534 & +1.30 \\
\hline
\end{tabular}


This comparison shows that although the positive sodium void effect was, in each case, underpredicted by calculations which did not include control poison in the core, the parfait configuration still exhibited more favorable sodium void characteristics than the reference design.

The four-group cross section set used in the above calculations. was not recollapsed over the neutron spectrum of a core voided of sodium. In order to evaluate the effect of local spectrum hardening upon the sodium void calculations and to confirm the adequacy of the four-group predictions, a comparison was made between the sodium void predictions as calculated above and predictions using the original 26-group cross section set. This comparison is shown in Table 4.5 for reference and parfait configurations which included boron in the cores.

TABLE 4.5

26-Group and Four-Group BOC Sodium Void Worth Predictions for the Reference and Parfait Systems

\begin{tabular}{ccccc}
\hline \multirow{2}{*}{$\begin{array}{c}\text { Number of } \\
\text { Neutron } \\
\begin{array}{c}\text { Energy } \\
\text { Groups }\end{array}\end{array}$} & \multicolumn{3}{c}{$\begin{array}{c}\text { Reactivity change upon sodium } \\
\text { removal from zones } 1-6\end{array}$} \\
\cline { 2 - 5 } & \multicolumn{2}{c}{ Reference } & \multicolumn{2}{c}{ Parfait } \\
\hline $\begin{array}{c}4 \mathrm{k} \\
\text { groups }\end{array}$ & +0.01087 & +2.61 & +0.00611 & +1.48 \\
(from Table 4.4) & +0.00756 & +1.82 & +0.00504 & +1.22 \\
\hline
\end{tabular}

This table demonstrates that the four-group calculations over-estimated the sodium void worth for both the reference and parfait cores. In this case, as with the previous comparisons, the variation in the 
calculational procedure yielded different absolute results, but did not alter the relative results; that is, the parfait configuration still exhibited favorable sodium void characteristics in comparison to the reference reactor.

The sodium void characteristics of an alternate parfait configuration in which the $40-\mathrm{cm}$ internal blanket was divided into two $20-\mathrm{cm}$ regions separated by $20 \mathrm{~cm}$ of core material were also determined. This split-parfait design was found to have inferior sodium void characteristics when compared to the conventional parfait configuration of this report. A more detailed description of the concept and the results are provided in Appendix $B$.

\section{3.2. Partial Sodium Density Reduction}

The calculations of the previous section involved the total removal of sodium from specific regions of the reactor. Such a condition might be part of a postulated accident sequence for the reactor. There are, however, mechanisms - including thermal expansion of the sodium and the passage of well-dispersed, micro-gas-bubbles through the coreby which a partial reduction in the sodium density in the reactor could be realized during relatively normal operation. Therefore, the response of both the reference and parfait configurations to a partial sodium density reduction was determined. A series of four-group $\mathrm{k}_{\text {eff }}$ calculations similar to those described in the previous section were performed for each configuration. The results for a $50 \%$ reduction in the sodium density throughout the reactor are listed in Table 4.6. An unrealistically large change in the sodium density was used to insure 
TABLE 4.6

Reactivity Effect of Reducing the Reactor Sodium Density by $50 \%$

\begin{tabular}{lcccc}
\hline Time & \multicolumn{2}{c}{ Reference } & \multicolumn{2}{c}{ Parfait } \\
\cline { 2 - 5 } $\begin{array}{l}\text { During } \\
\text { Irradiation }\end{array}$ & $\Delta \mathrm{k}^{*}$ & $\begin{array}{l}\text { \& } / \% \mathrm{Na} \\
\text { Removal }\end{array}$ & $\Delta \mathrm{k}^{* *}$ & $\begin{array}{l}\text { \& } \% \mathrm{Na} \\
\text { Removal }\end{array}$ \\
\hline BOC & +0.00228 & +1.096 & +0.00032 & +0.155 \\
EOC & +0.00401 & +1.928 & +0.00331 & +1.600 \\
\hline
\end{tabular}

* $\Delta \mathrm{k}$ upon removal of $50 \%$ of reactor sodium

*** Reactivity change per percent of sodium removal from reactor

computational accuracy, since a small difference between values of $\mathrm{k}_{\text {eff }}$ was being computed. Similar predictions of the sodium worth per fractional change in sodium density were also obtained in a calculation in which the sodium density was reduced by $10 \%$. A comparison of the results demonstrates that this change in the systems results in a substantially smaller increase in the system multiplication factor for the parfait configuration than for the reference design. Again, this difference diminished with burnup.

\subsection{DOPPLER COEFFICIENTS}

The primary mechanism for terminating an uncontrolled reactivity insertion in a fast reactor core is the prompt temperature coefficient associated with Doppler broadening of neutron absorption resonances in the fuel atoms. Heating the fuel causes a change in the relative. velocities between the neutrons and fissile and fertile atoms, and this change increases the resonance absorption reactions, particularly below about $10 \mathrm{keV}$. The net reactivity effect of Doppler broadening 
is dominated by the negative contribution due to enhanced $\mathrm{U}-238$ capture.

There are three Doppler-related coefficients of interest in fast reactors. The first is the isothermal Doppler coefficient. It is defined as the change in $\mathrm{k}_{\text {eff }}$ per degree change in the system temperature, $\left(\frac{1}{\mathrm{k}} \frac{\mathrm{dk}}{\mathrm{d} T}\right)$, and contributes a substantial part of the reactivity swing associated with taking the reactor from cold startup to hot operating conditions. The second coefficient is the power coefficient of reactivity. It is defined as the change in the system reactivity for a given change in the system power $\left(\frac{1}{\mathrm{k}} \frac{\mathrm{dk}}{\mathrm{dP}_{\text {total }}}\right)$. The ... primary contribution to this reactivity effect is the Doppler broadening associated with the temperature change in the fuel as the power of the reactor is changed. The third Doppler-related coefficient is the adiabatic power coefficient which is defined as the fractional change in $\mathrm{k}_{\text {eff }}$ for a given change in the reactor power under the condition of adiabatic heat-up of the fuel pins. In his analysis, Wood (W1) has shown that the power coefficient of reactivity and the adiabatic power coefficient are proportional.

The isothermal Doppler coefficient and the power coefficient of reactivity for the reference and parfait cores are evaluated in the next two subsections. The cross section set used in these calculations was the FTR Set \#200 (N1) described in Section A.1.2. For use in evaluating the Doppler broadening effect, these cross sections were evaluated at various temperatures using the $1 \mathrm{DX}$ code $(\mathrm{H} 6)$ to adjust resonance self-shielding. 


\subsubsection{Isothermal Doppler Coefficient}

The isothermal Doppler coefficient. was evaluated for the reference and parfait configurations at the beginning and end of the equilibrium cycle by performing $\mathrm{k}_{\mathrm{eff}}$ calculations using the $2 \mathrm{DB}$ code and cross sections evaluated at $300^{\circ} \mathrm{K}$ and $1000^{\circ} \mathrm{K}$. The results are presented in Table 4.7.

TABLE 4.7

Isothermal Doppler Coefficient Comparison

\begin{tabular}{cccc}
\hline $\begin{array}{c}\text { Time } \\
\text { During } \\
\text { Cycle }\end{array}$ & $\frac{1}{\mathrm{k}} \frac{\Delta \mathrm{k}}{\Delta \mathrm{T}},{ }^{\circ} \mathrm{K}^{-1}$ & $\begin{array}{c}\text { Ratio } \\
\text { Parfait }\end{array}$ \\
\cline { 2 - 4 } Reference & 30 -cm IB Parfait & & $\left(\frac{\text { Reference }}{\text { Refer }}\right)$ \\
BOC & $-2.188 \times 10^{-5}$ & $-2.267 \times 10^{-5}$ & 1.036 \\
\hline
\end{tabular}

The difference in the predicted isothermal Doppler coefficients for the two configurations is less than the $\pm 15 \%$ calculational uncertainty currently estimated for this parameter (Chapter 1, Table 1.2).

\subsubsection{Power Coefficient of Reactivity}

The power coefficient, which depends upon the Doppler characteristics of the configuration and upon the power distribution in the system, may be expressed in the form:

$$
\frac{1}{\mathrm{k}} \frac{\mathrm{dk}}{\mathrm{dP}_{\text {TOTAL }}}=\left(\frac{1}{\mathrm{k}} \frac{\mathrm{dk}}{\mathrm{dT}}\right)\left(\frac{\mathrm{dT}_{\text {LOCAL }}}{\mathrm{dP}_{\text {TOTAL }}}\right)
$$


The Doppler constant of each configuration was determined and then this constant was multiplied by the estimated temperature change in the fuel per unit change in system power, $\frac{d T}{d P}$, to determine the power coefficient. In this calculation, the power coefficient contribution of the external blankets was neglected. This is equivalent to assuming that as the reactor power is changed, the temperature change in the fuel of the external blankets is negligible. The reactivity effect of a temperature increase in the blanket.region would be negative in both the reference and parfait configurations (because the predominant fuel component is $\mathrm{U}-238$ ) but, because of the low power generation rates in these regions as compared to the core regions, neglecting the effect of the external blankets is justifiable for present purposes. This approximation was confirmed by Wood (W1) who found that the power coefficient contribution of the external blankets was less than $1 \%$ of the total. The power coefficient of reactivity calculated in this section is therefore that due to the core alone.

The Doppler constant defined by Equation 4.4, was determined for each of the configurations by performing two 26-group $\mathrm{k}_{\mathrm{eff}}$ calculations which differed only in the temperature at which the cross sections used in the calculation were evaluated.

$$
\mathrm{C} \equiv-\frac{\overline{\mathrm{T}}}{\mathrm{k}} \frac{\mathrm{dk}}{\mathrm{dT}}
$$

In this equation, $\overline{\mathrm{T}}$ is the average of the two temperatures used in the calculation of the Doppler constant. These two temperatures were also comparable to the average temperatures in the fuel before and after the power change $\left(\Delta \mathrm{P}_{\text {TOTAL }}\right)$ for which the local temperature changes 
$\left(\Delta \mathrm{T}_{\text {LOCAL }}\right)$ were evaluated. Because of the distinctly different composition of the internal blanket (as compared to core material) and the different temperature change it experiences, two Doppler constants were determined for the parfait configuration: one for the core regions and one for the internal blanket region. The results of the Doppler constant calculations are listed in Table 4.8.

TABLE 4.8

Doppler. Constants for the Reference and Parfait Configurations

$$
\mathrm{C} \equiv-\frac{\overline{\mathrm{T}} \mathrm{dk}}{\mathrm{k} \mathrm{dT}}
$$

\begin{tabular}{lcc}
\hline & \multicolumn{2}{c}{$C$ (Doppler constant) } \\
\cline { 2 - 3 } & Reference & 30-cm IB Parfait \\
\hline Core zones & 0.00938 & 0.00680 \\
Internal blanket & -- & 0.00268 \\
\hline
\end{tabular}

These results are somewhat larger than those which have been reported for large fast reactors, 0.0077 (K2); however, it is the relative value of these parameters which is the focus of this study.

The local fuel temperature changes ( $\mathrm{dT}_{\mathrm{LOCAL}} / \mathrm{dP}_{\mathrm{TOTAL}}$ ) were calculated for two steady-state conditions representing a factor of two difference in system power. In this case, the average power density in each of the regions of the reactor, which may be translated into a linear power rating, doubles. The increase in the centerline fuel temperature due to this increase in the average linear power rating is given by: 


$$
\Delta \mathrm{T}_{\mathrm{C}_{l}}=\Delta \mathrm{q}^{\prime} / 4 \pi \mathrm{k}_{\mathrm{f}}
$$

where

$$
\begin{aligned}
& \Delta \mathrm{T}_{\mathrm{C}_{l}}=\text { Change in the centerline fuel temperature } \\
& \Delta \mathrm{q}^{\prime}=\text { Change in the average linear power rating } \\
& \mathrm{k}_{\mathrm{f}} \quad=\text { Thermal conductivity of the fuel. }
\end{aligned}
$$

(This analysis neglects the effects of structural changes in the fuel material, assumes a constant fuel thermal conductivity and assumes a fuel surface temperature independent of the linear power rating.) For the parabolic temperature distribution which exists in the fuel pins, the average increase in the fuel temperature is equal to one half of the fuel centerline temperature increase. The average changes in the fuel temperature corresponding to the given change in the system power were combined with the Doppler constants derived above to yield the power coefficients given in Table 4.9 .

TABLE 4.9

Power Coefficients of Reactivity (External blanket contribution excluded)

\begin{tabular}{lcc}
\hline \multirow{2}{*}{ Case } & \multicolumn{2}{c}{ Power Coefficient } \\
\cline { 2 - 3 } & $\frac{1}{\mathrm{k}} \frac{\Delta \mathrm{k}}{\Delta \mathrm{P}}, \mathrm{MW}_{\mathrm{t}}^{-1}$ & $\mathrm{c} / \mathrm{MW}_{\mathrm{t}}$ \\
\hline Reference (BOC) & $-1.638 \times 10^{-6}$ & -0.039 \\
$30-\mathrm{cm}$ IB Parfait (BOC) & $-1.470 \times 10^{-6}$ & -0.036 \\
\hline \hline Ratio $\left(\frac{\text { Parfait }}{\text { Reference }}\right)$ & & 0.92 \\
\hline
\end{tabular}


Table 4.9 demonstrates that in spite of the larger change in the average fuel temperature of the parfait configuration (because the additional system power is generated in a smaller fissile-loaded core volume), the power coefficient of the parfait configuration is still $8 \%$ smaller than that of the reference core. Toward the end of life, when a greater fraction of the system power is generated in the internal blanket, the power coefficients become more nearly equal. The smaller magnitude of the power coefficient represents a disadvantage for the parfait configuration, but the difference between the two estimates is still within the current margin of calculational uncertainty, $\pm 15 \%$, as reported in Table 1.2 of Chapter 1 .

\subsection{NET REACTIVITY EFFECTS FROM STARTUP TO FULL POWER OPERATION}

The net reactivity effect of taking the reactors from the cold startup to hot, full power operation was estimated by making use of the reactivity coefficients calculated in the previous sections. The reference and parfait reactors were assumed to be at an initial, isothermal temperature of $300^{\circ} \mathrm{F}$. Each configuration was first raised to an isothermal temperature of $875^{\circ} \mathrm{F}$. The isothermal Doppler coefficients calculated for each configuration were used to estimate the reactivity effect of this system change. During this heatup, the sodium density in the core decreases by about $6 \%$ and the reactivity effect of this change was calculated using the sodium density coefficient. The power coefficients were then used to calculate the reactivity effect of taking the zero power, heated systems to full power $\left(2500 \mathrm{MW}_{\mathrm{t}}\right)$ 
conditions. These reactivity effects are summarized in Table 4.10. This table demonstrates that the net reactivity effect in going from cold startup to hot, full power operation is nearly identical for the two configurations. Note, however, that the reactivity effects of axial and radial thermal expansion of the cores in both configurations have been neglected in this analysis.

TABLE 4.10

Reactivity Effects from Startup to Full Power Operation

\begin{tabular}{|c|c|c|c|c|}
\hline \multirow{3}{*}{$\begin{array}{l}\text { System } \\
\text { Change }\end{array}$} & \multicolumn{4}{|c|}{ Reactivity Change } \\
\hline & \multicolumn{2}{|c|}{ Reference } & \multicolumn{2}{|c|}{$30-\mathrm{cm}$ IB Parfait } \\
\hline & $\Delta \mathrm{k}$ & $\$$ & $\Delta \mathrm{k}$ & $\$$ \\
\hline $\begin{array}{l}\text { Isothermal } \\
\text { heatup }\end{array}$ & -0.00700 & $'-1.683$ & -0.00725 & -1.760 \\
\hline $\begin{array}{l}\text { Sodium density } \\
\text { reduction }\end{array}$ & +0.000274 & +0.066 & +0.000038 & +0.009 \\
\hline $\begin{array}{l}\text { Zero power to } \\
\text { full power }\end{array}$ & -0.00410 & -0.986 & -0.00367 & -0.891 \\
\hline $\begin{array}{l}\text { Total: } \\
\text { Cold startup to } \\
\text { full power }\end{array}$ & -0.01083 & -2.603 & -0.01088 & -2.642 \\
\hline
\end{tabular}




\subsection{FUEL MOVEMENT WITHIN THE REACTOR}

A detailed evaluation of the mechanisms for and the effects of fuel movement within the reference and parfait configurations was beyond the scope of this work. However, an indication of the effects of small movements of fuel material in the cores may be obtained by noting the shape of the function $\phi \phi^{*}$, the product of the flux and the adjoint flux. An axial plot of this function was given in Chapter 2, Figs. 2. 31 and 2. 32 , and radial plots at three different planes of the cores are given in Figs. 4.3, 4.4 and 4.5. The axial curves indicate that the slumping of fuel from a substantial portion of the core zone above the midplane (the zone in which the fuel is the hottest and therefore the most likely to experience slumping) toward the internal blanket would yield a negative reactivity effect. By comparison, fuel slumping in the entire core zone above the midplane of the reference reactor would yield a positive reactivity effect. Figures $4.3,4.4$ and 4.5 indicate that the radial movement of core material in the inner zone of the parfait configuration should result in a substantially smaller reactivity effect because of the flatter $\phi \phi^{*}$ profiles. At the outer edge of the parfait configuration, however, where the $\phi \phi^{*}$ gradient is steeper than that of the reference core, fuel movement would contribute to larger reactivity effects for the parfait core - more negative if the movement is outward and more positive if the movement is inward. 


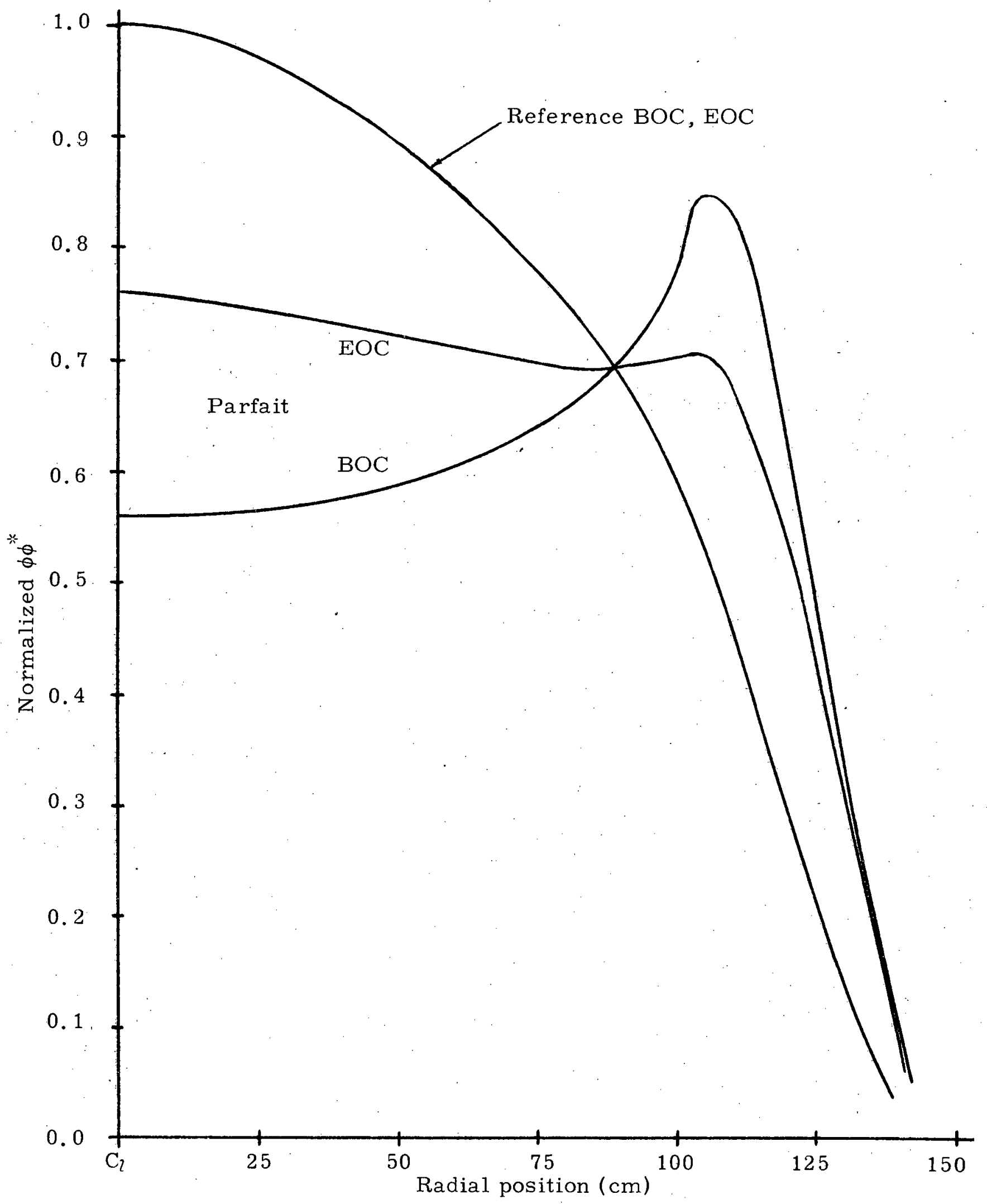

FIG. 4. 3. Normalized $\phi \phi^{*}$ vs. $\mathrm{R}$ at the Core Midplane 


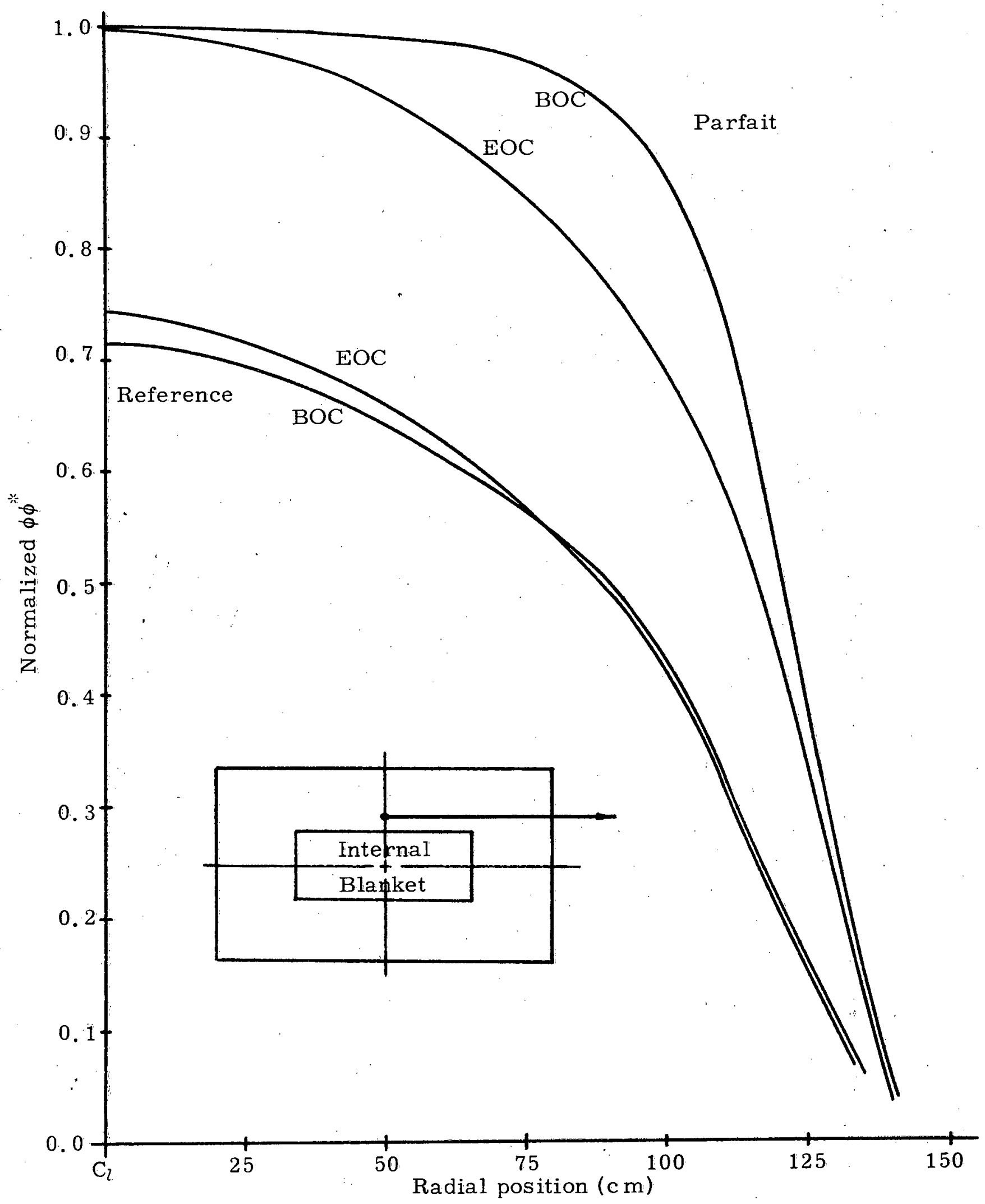

FIG. 4.4. Normalized $\phi \phi^{* *}$ vs. $R$ at $Z=27.3 \mathrm{~cm}$ Above Midplane 


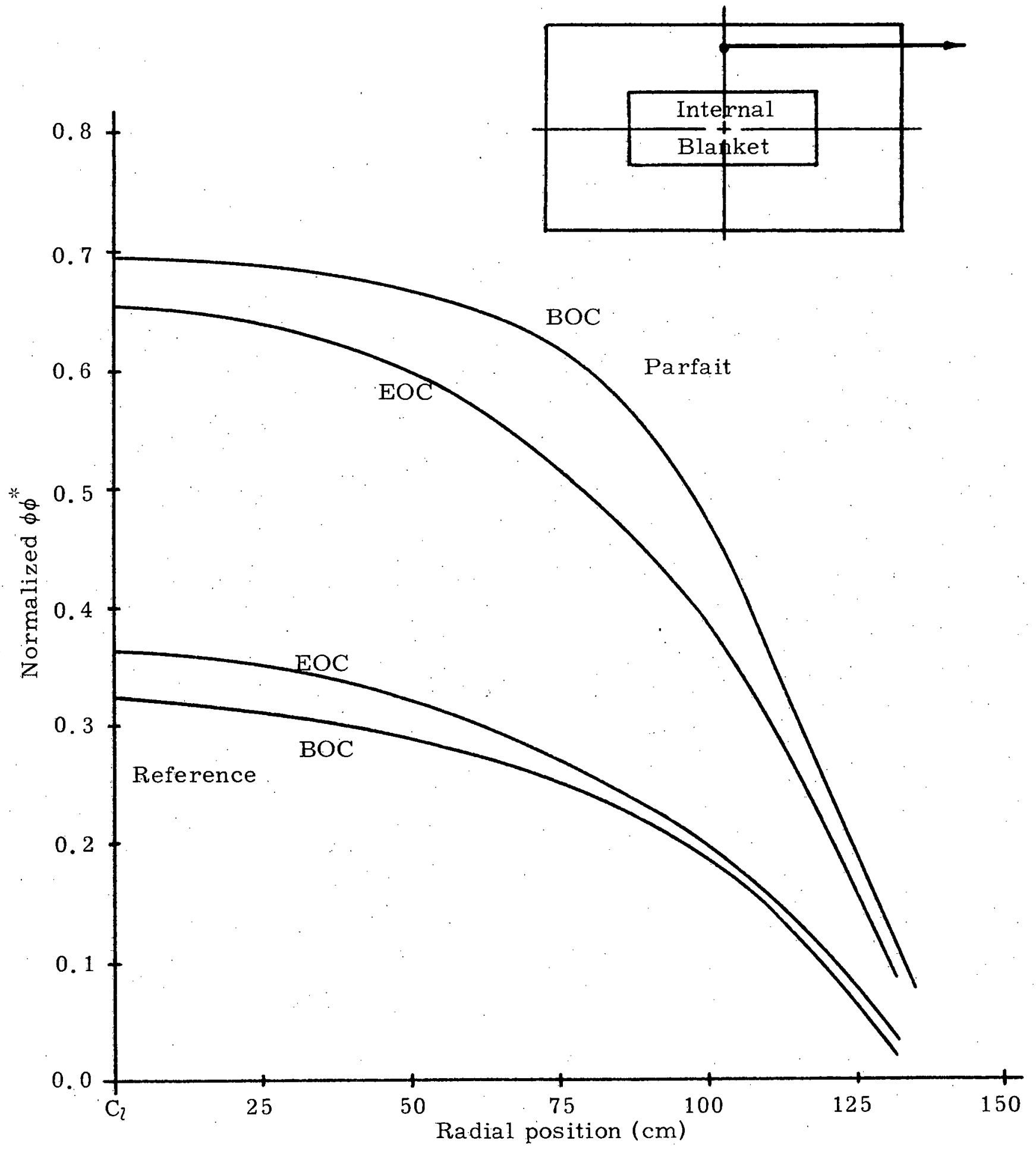

FIG. 4.5. Normalized $\phi \phi^{* *}$ vs. $R$ at $Z=42.08 \mathrm{~cm}$ Above Midplane 


\section{7. CONCLUSIONS}

With regard to the sodium void characteristics calculated in this chapter, the parfait configuration demonstrated substantial advantages over the reference design. Voiding of sodium from the internal blanket of the parfait configuration was found to contribute a smaller positive reactivity than voiding of a comparable region in the reference core. The complete and partial voiding of the core zones (and internal blanket) of each configuration was found to result in a positive reactivity effect that was, on the average, about $25 \%$ smaller in the parfait configuration. Another important safety parameter, the power Doppler coefficient, was also calculated. The results of those calculations indicate that the negative reactivity effect of an increase in the total system power is $8 \%$ smaller in the parfait configuration at the beginning of a burnup cycle and nearly equal to that of the reference core at the end of the cycle.

A calculation of the effective delayed neutron fraction and the prompt neutron lifetimes demonstrated that these parameters were substantially the same for both configurations. Finally, an estimate of the response of both configurations to small local melting and slumping of fuel in the hottest part of the core indicated that the parfait configuration would respond more favorably, that is, with a smaller reactivity change. 


\section{Chapter 5 \\ FEASIBILITY AND ECONOMICS}

\section{1. INTRODUCTION}

The previous three chapters have been devoted to a discussion of the operational characteristic of the parfait configuration relative to the reference reactor. Constraints were imposed to guarantee the operational feasibility of the concept and in each of the areas investigated, neutronics, core engineering and safety, substantial advantages have been identified for the parfait configuration.

This chapter deals with a number of the nonoperational characteristics of the parfait core which, nevertheless, have a bearing upon its feasibility. In addition, the relative economic performance of the reference and parfait cores operating in an equilibrium fuel cycle are compared. The economic environment for the evaluation and the equilibrium fuel cycle are defined. Simulation of the burnup physics of this cycle is described and finally, the fuel cycle costs are compared for a variety of economic conditions and design characteristics.

\subsection{FEASIBILITY}

\subsubsection{Fabrication}

One of the biggest unknowns surrounding the ultimate economic performance of the commercial breeder reactor relates to the cost of fabricating reliable fuel elements. Because of the low facility throughput and their first-of-a-kind nature, the current test facilities and 
demonstration reactors will experience core fabrication costs several times that which would afford a commercial system economic viability. Therefore, for the purpose of evaluating the potential application of the parfait concept, the fabrication costs estimated for a mature fast reactor economy have been assumed in this report.

The parfait configuration makes use of a fuel design which is essentially the same as that of the reference core and therefore most of the steps in the fabrication process will be the same. In fact, the design of the fuel assemblies for loading in the outer core zones of both reactor configurations are identical except for the actual plutonium enrichment of the core zone pellets. The internal structure of the fuel pins of the inner core zone is different, however, as illustrated in Fig. 5.1. The effect of these differences on the fabrication costs of the inner core zone fuel elements was estimated by drawing upon industrial experience from the fabrication of fuel for light water reactors. Figure 5.2 (A4) illustrates the major steps in the fabrication of BWR fuel. Although there will be significant differences in the fabrication of fast reactor fuel including, for example, the reduced pin diameters, different spacer designs and the requirement for remote handling of plutonium fuels, this flow chart is illustrative of the large number of actual operations and inspections performed in the fabrication of nuclear fuel. In evaluating the effect on the fabrication cost of adding an internal blanket region to the fuel pins of the inner core zone, it is important to note that the only steps in this elaborate process which are affected are the rod-load step and the rod enrichment scan. A study by the Battelle Northwest Laboratories indicates 


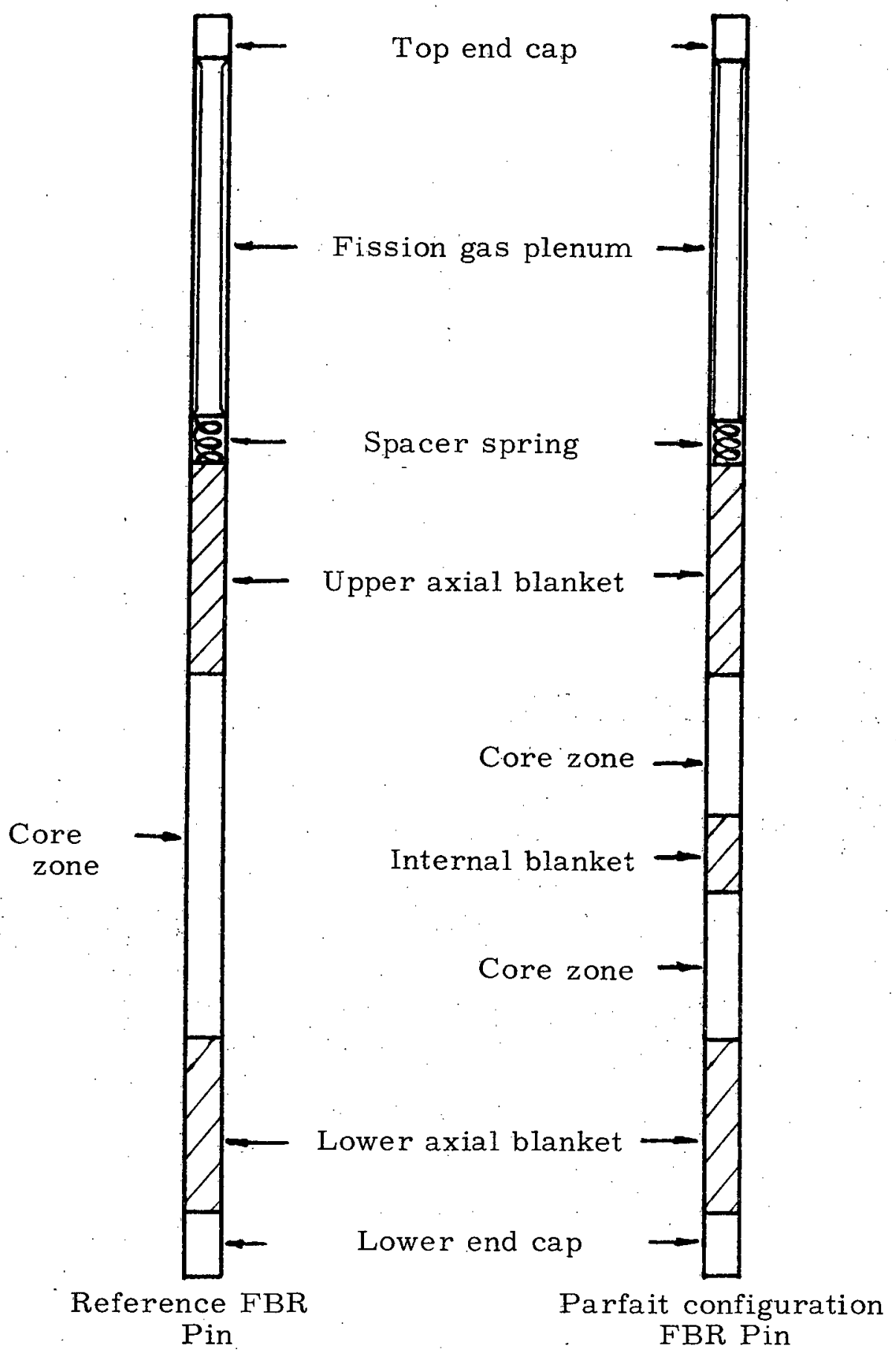

FIG. 5.1. Internal Components of the Inner Core Zone Fuel Pins of the Reference and Parfait Designs 


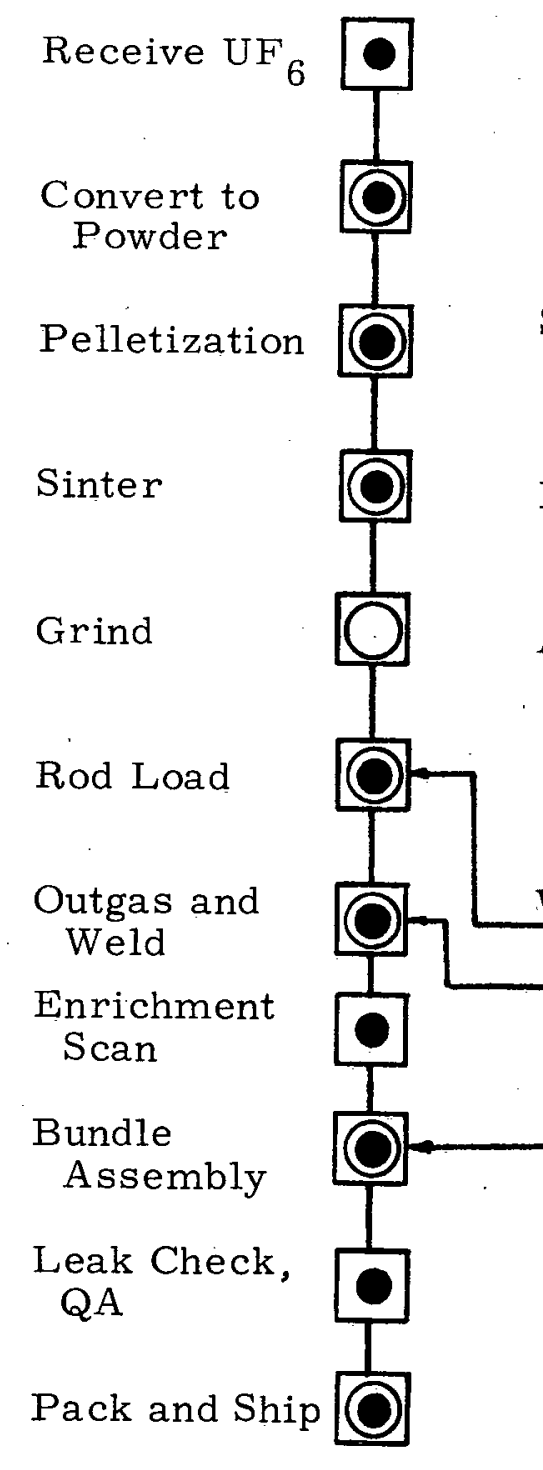

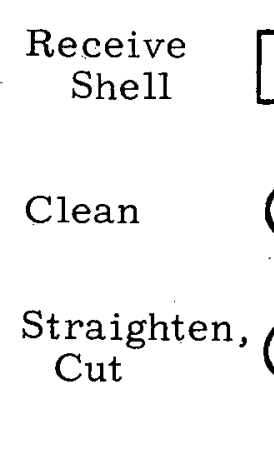
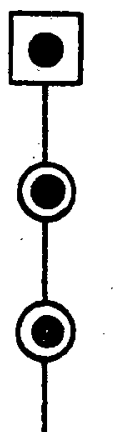

Inspect

Autoclave

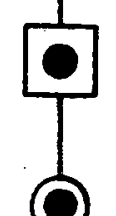

\section{Inspect}

Stock

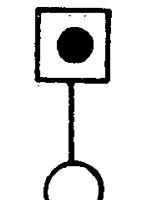

Clean

Machine

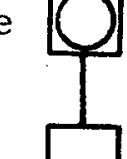

Pack

QA

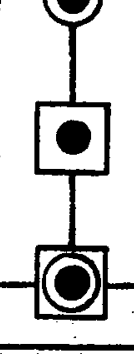

Plug

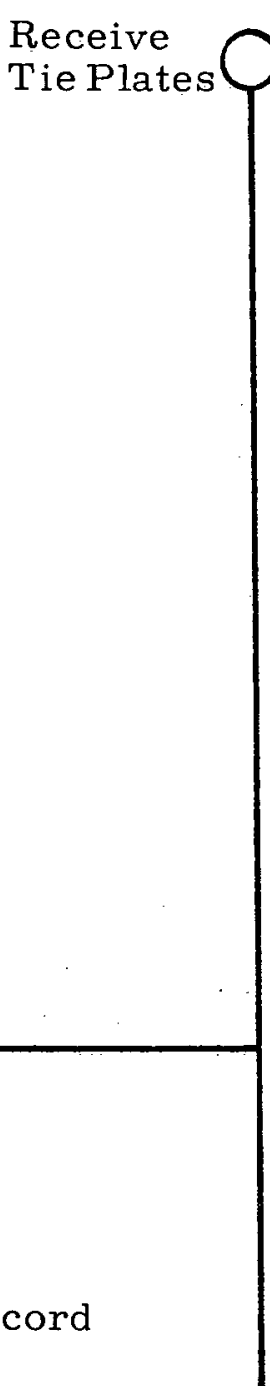

Operation

$\square$ QA Inspection

- Permanent Record Generated

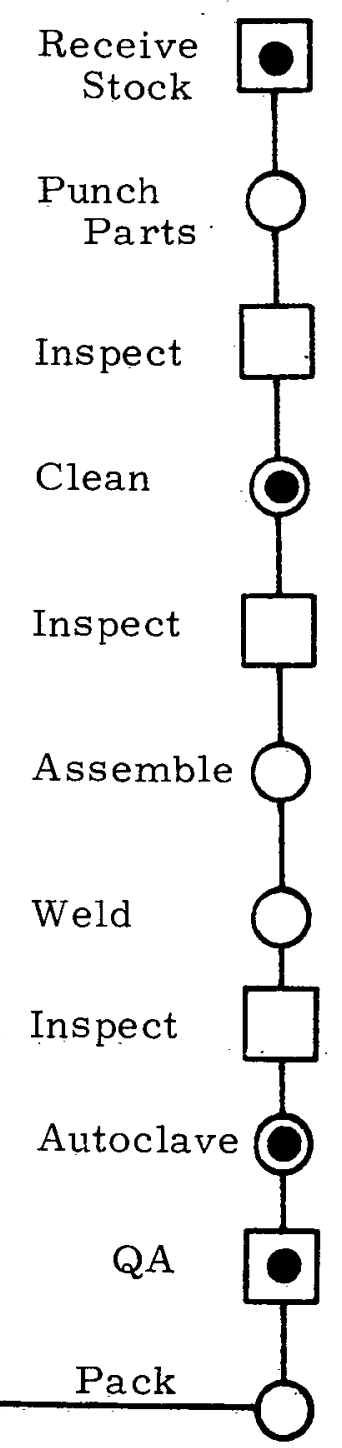

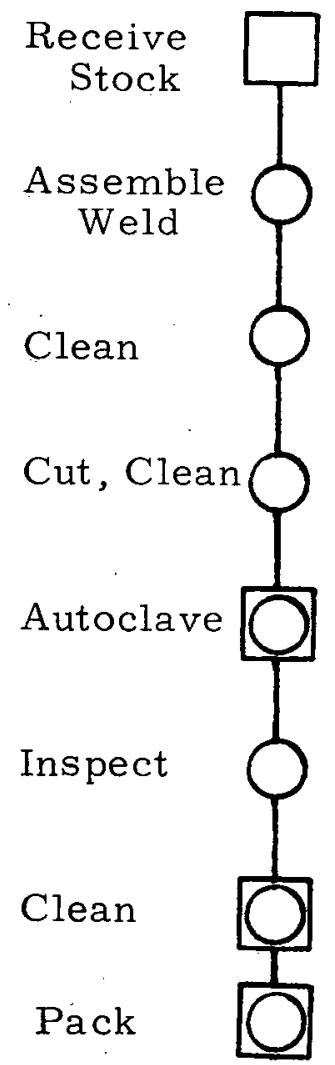

FIG. 5.2. Process Flow Chart for the Fabrication of BWR Fuel (A4) 
that the rod-load step contributes only insignificantly to the total fabrication costs. In this study (B4, B5), the time and cost components of each of the steps in the fabrication of a LWR fuel element loaded with mixed oxide pellets containing high exposure recycled plutonium were evaluated. A condensed version of the results of that study are shown in Table 5. 1.

TABLE 5.1

Fuel Element Fabrication Cost Components

\begin{tabular}{|c|c|}
\hline Operation & $\begin{array}{l}\text { Percent of Total } \\
\text { Fuel Element Fabrication Costs }\end{array}$ \\
\hline Rod-load & 2.5 \\
\hline $\begin{array}{l}\text { Pelletization and preparation } \\
\text { of nuclear materials }\end{array}$ & 33.0 \\
\hline $\begin{array}{l}\text { Fabrication, inspection and } \\
\text { of cladding tubes }\end{array}$ & 33.0 \\
\hline $\begin{array}{l}\text { Assembly of fuel pins into a } \\
\text { complete fuel element }\end{array}$ & 12.0 \\
\hline All other steps & 19.5 \\
\hline Total & $\quad 100.0$ \\
\hline
\end{tabular}

In terms of time-per-process-step, the rod-load step was estimated to consume four hours per fuel element as compared to 891 hours for the pelletization of the nuclear materials. As previously indicated, these estimates were developed for the fabrication of plutonium-bearing 
EWR fuel, but because of the close similarity in the overall process, it can be assumed that the rod-load step would be only a minor contributor to the total fast reactor fuel fabrication costs as well. Under this assumption and because the core fuel elements of the parfait and reference designs are both made up of two types of fissile-loaded pellets and one type of blanket pellet, it was concluded that the fabrication costs for the core zone of the parfait configuration and the reference reactor would be the same. It should be noted, however, that the fissile-loaded core volume of the parfait configuration is smaller than that of the reference reactor, and since plutonium-bearing fuel pellets a re more expensive to fabricate than depleted uranium axial blanket pellets, the parfait configuration may actually have a reduced core fabrication cost.

One of the parfait-configurations discussed in Chapter 2 exhibited a design characteristic which would have a significant impact upon the core fabrication costs. The parfait core having a $50-\mathrm{cm}$ internal blanket required only one plutonium enrichment for both the inner and outer core zones. Therefore, because the process of pelletization and preparation of the nuclear material for rod loading represents a significant component of the fabrication process, having only one type of plutonium-loaded pellet in the core is a simplification which could lead to a substantial reduction of the total fabrication costs for this configuration. Parfait cores having internal blanket thicknesses of $50 \mathrm{~cm}$ and $30 \mathrm{~cm}$ are compared to the reference core in a later section of this chapter. 


\subsubsection{Quality Assurance}

Assuring strict adherence to design specifications is one of the major challenges in the fabrication of nuclear fuel as evidenced by the large number of quality assurance inspections indicated in Fig. 5. 2 . One of the nondestructive testing techniques developed for application to both LWR fuels and fast reactor fuels to aid in quality assurance programs is the gamma scan of individual fuel rods to evaluate their local fissile content. This technique, which has been applied to BWR fuel (A2) and will be used to examine fuel pins for the Fast Flux Test Facility (N2), could prove to be particularly useful in assuring the quality of fuel fabricated for use in a parfait configuration. The assay system makes use of a Californium-252 source to interrogate the fuel rods, and gamma-ray detectors to record the response (F2). The local fissile content and pellet-to-pellet uniformity is determined by moving the fuel pin past the source and counting the high energy $(>1200 \mathrm{keV})$ and low energy ( $100 \mathrm{keV}$ to $500 \mathrm{keV}$ ) delayed gamma rays resulting from the induced fission reactions. The accuracy of the assay system in determining the position-dependent fissile content of a specially loaded fuel pin is indicated in Fig. 5.3. The capability of the system to detect a change of only a few percent in plutonium enrichment is clearly demonstrated and is far more than would be required to differentiate between core pellets and internal blanket pellets in the scan of a parfait configuration fuel pin. The sensitive position-dependent gamma scan could be most useful in assuring the exact dimensional extent of the material regions within a fuel pin containing an internal blanket loading. 


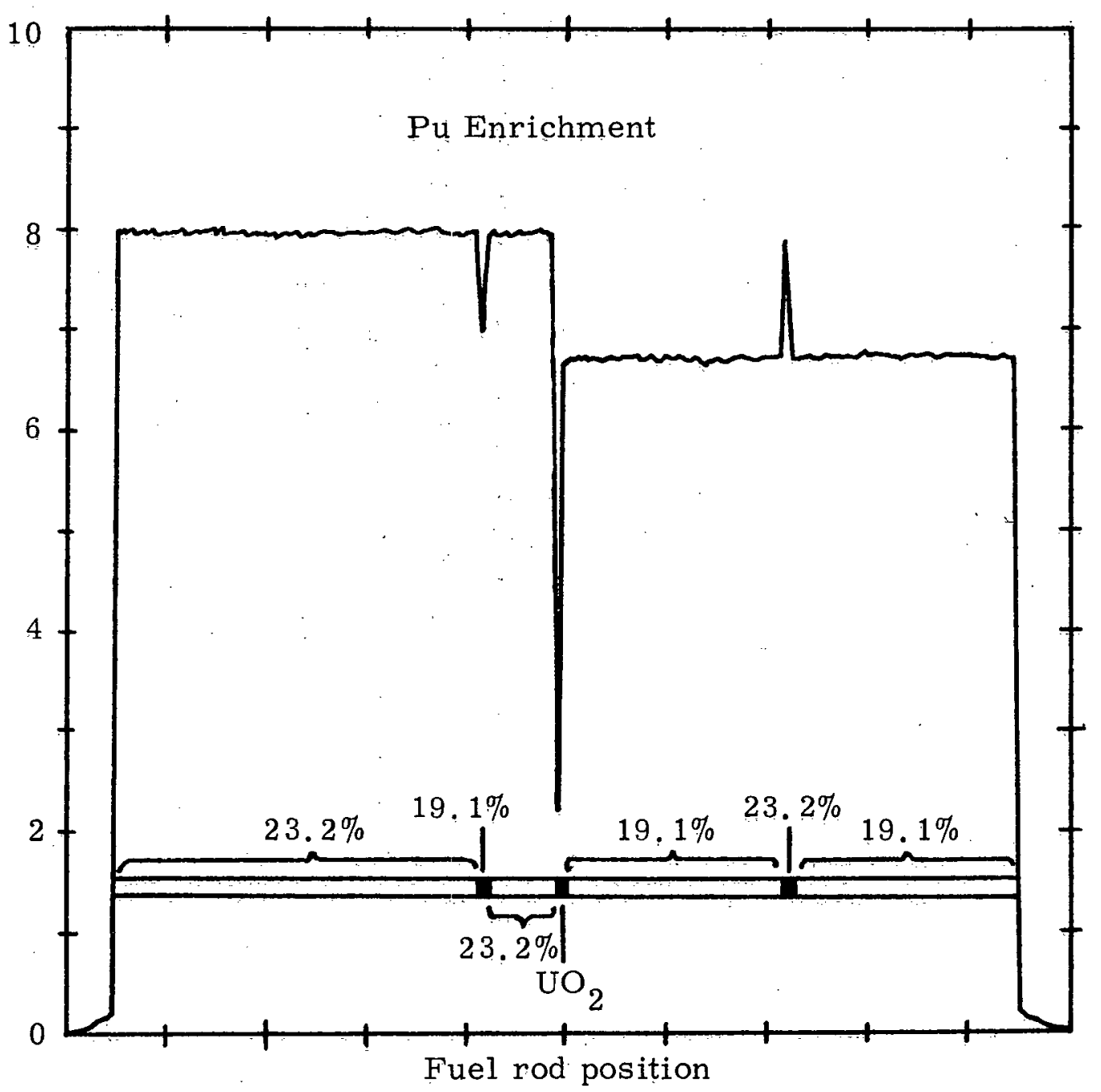

FIG. 5.3. Gamma Scan of an FFTF Fuel Pin with Various 
Even though the gamma scan technique offers positive assurance of a fuel pin's internal contents, it should be noted that even if a pin that was supposed to contain an internal blanket region were accidentally loaded with all core zone pellets, such a pin could be operated in a parfait configuration without exceeding the maximum allowable linear power rating. This favorable circumstance is a result of the flux dip in the internal blanket throughout the equilibrium cycle (Fig. 2. 10). For both the reference and parfait configurations, the accidental loading of a fuel pin from the outer core zone into an assembly of the inner core zone would result in an operating condition for which the maximum design value of the linear power was exceeded, and is therefore an occurrence which both configurations must be protected against.

Even in this unlikely circumstance, the parfait configuration would exceed its maximum design value by an amount less than that of the reference core because the fissile enrichments for the inner and outer core zones are more nearly equal for each of the parfait configurations.

\section{2. 3. Fuel Management Patterns}

Because of power peaking considerations, the primary constraint imposed upon fuel management schemes for reference FBR reactors is that, unlike light water reactors, fuel assemblies from the outer core zone may not be reloaded into the inner core zone. Within this constraint, the most often mentioned fuel management scheme for fast reactors is scatter reloading, which may or may not be accompanied by fuel assembly shuffling within a core zone and/or rotation of the fuel assemblies. The merits of the various refueling schemes will be best 
evaluated as operational experience is gained, but for the purposes of this report, it is sufficient to note that fuel management schemes available to the parfait configuration a re equally as restrictive or flexible as those for the reference core. The constraint is still imposed that fuel from the outer core zone may not be reloaded into the inner core zone, but within a core zone assemblies may be shuffled or rotated, as in the reference core. In fact, because of the flatter flux and power profiles in the inner core zone, and therefore; flatter burnup profile, the parfait configuration at the very least, offers greater flexibility in shuffling patterns and even diminishes those burnup differences which lead to the consideration of shuffling and fuel rotation schemes in the first place.

\subsubsection{Reprocessing}

The initial distribution of the fissile and fertile materials in the fuel elements of the inner core zone is a consideration, which, as discussed above, may have a small effect on the fabrication of the fuel, but will have no effect on the reprocessing of the irradiated fuel. The core and cladding materials of both configurations are the same and the steps in the recovery of valuable fissile material are the same. In both cases, the fuel bundle must be disassembled, the pins must be broken down mechanically and the oxide must be processed chemically. The axial blanket material and the core material will be reprocessed as a mixed batch (M1) and therefore the inner core zone fuel of the parfait concept will not require a special step for the separation of the internal blanket region from the core material prior to chemical processing. 
In short, the operation of a fast reactor with fuel containing an integral internal blanket region will introduce no unique fuel reprocessing problems.

\subsection{ECONOMICS}

\subsubsection{Definition of the Economic Environment}

The standard economic environment used in this study is the same as that used by Wood (W1) and was originally developed from an extensive review of the relevant literature by Brewer (B2). This environment is defined in Table 5.2. In addition to the unit processing costs displayed in the table, the effect of increasing the core fabrication costs to $\$ 400 / \mathrm{kg}$ HM was also evaluated.

For this comparison, both the refereñce core and parfait configuration were assumed to operate at a thermal efficiency of $40 \%$. A load factor of $82 \%$, which is equivalent to 300 full power days of operation per calendar year, was also assumed.

\subsubsection{Equilibrium Fuel Cycle}

The reference and parfait cores were evaluated on the basis of equilibrium fuel cycle cost because it is this parameter which is most indicative of the long term economic performance of the two systems. In the approach years, prior to achieving the equilibrium cycle, the operation of the two reactor configurations would be very similar. Each would experience the buildup of plutonium in all of the blanket regions and some core fuel assemblies would have to be removed from the reactor after just one year of irradiation so that new fuel could be 
TABLE 5.2

Standard Economic Environment

Financial Parameter

$\therefore-$

Income Tax Rate

Capital Structure

Bond fraction (debt) $f_{b}$
Stock fraction (equity) $f_{s}$

Rates of Return
Bonds $r_{b}$
Stocks $r_{s}$

Discount Rate, ${ }^{*}$

Isotope

$\mathrm{U}-238$

$\mathrm{Pu}-239$

$\mathrm{Pu}-240$

$\mathrm{Pu}-241$

$\mathrm{Pu}-242$
0.07

0.125

0.08

0.50

0.50 Base Case $\begin{aligned} & \text { High Cost of } \\ & \text { Money }\end{aligned}$
0.50

$\begin{array}{ll}0.50 & 0.50 \\ 0.50 & 0.50\end{array}$


loaded. If for any reason, it was necessary to accelerate the approach to equilibrium for the parfait configuration, the internal blanket could be loaded with natural or slightly enriched uranium to more closely match the equilibrium buildup of fissile material in the region. However, no unique difficulties in the approach to equilibrium have been identified for the parfait configuration.

For this comparison, core fuel elements were assumed to have a two-year residence time in the core, with one half of the elements in each of the core zones removed and replaced with fresh fuel on an annual refueling schedule.

The material and cash flows representative of an equilibrium fuel cycle are sketched in Fig. 5.4. Prior to the beginning of each irradiation cycle, the fissile material which will be loaded into the fresh fuel assemblies must be purchased and the fuel assemblies fabricated. The expenditures for both of these transactions were assumed to take place 0.5 years before the beginning of the irradiation cycle. Revenues from the sale of electricity were assumed to be received at the middle of the irradiation cycle which is the point in time to which all expenditures are referenced using present worth factors. After irradiation, spent fuel discharged from the reactor must be reprocessed for recovery of the valuable fissile isotopes. The expenditure for this activity and the realization of the fissile material credit were both assumed to take place 0.5 years after the end of the irradiation period. The physics and cash flow simulations of this equilibrium cycle are described in the next two sections of this chapter. 


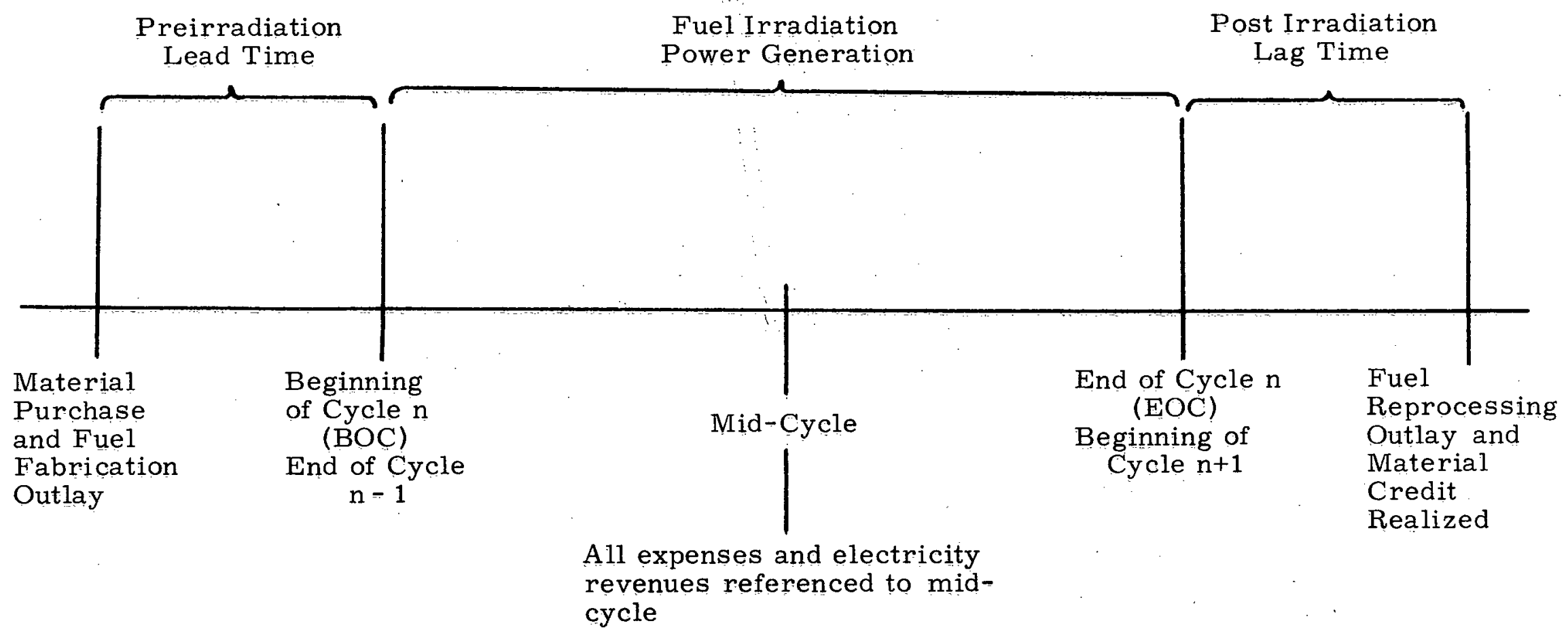

FIG. 5.4. Material and Cash Flow for an Equilibrium Fuel Cycle 


\subsubsection{Physics Simulation of the Equilibrium Fuel Cycle}

As with the neutronic and thermal-hydraulic calculations described in earlier chapters, preliminary burnup calculations were performed using a limited number of material zones to describe the reactor configuration to determine the approximate core fissile loadings. For the purpose of determining the fissile material inventories required for fuel cycle cost calculations, considerably greater detail was added to the description of the material regions of the reactor in the 2DB burnup calculations. In this way, the unrealistic movement of fissile material within the reactor, which results from the region-by-region material homogenization following each burnup time step in $2 \mathrm{DB}$, was minimized. The inner and outer core zones were each represented by four material regions, the radial blanket by nine regions and the axial blanket by eight regions. Azimuthal symmetry and axial symmetry about the core midplane were assumed.

The first step in the process of simulating the physics of an equilibrium fuel cycle was to determine the beginning-of-cycle (BOC) fissile content in each of the blanket regions. In the case of the axial blankets and the internal blanket, this was easily accomplished by performing burnup calculations for both reactor types which were initially loaded with clean blanket regions. The fissile and fertile material concentrations obtained after a burnup of 300 full power days were used in subsequent calculations as the $\mathrm{BOC}$ heavy metal concentrations in annular regions comprising one half of each of the blanket regions. The other half of each of the blanket regions was loaded with clean blanket material, i.e., depleted uranium oxide. This method of estimating the fissile loading of the axial and internal blanket regions 
simulates what would actually take place in an equilibrium cycle since the fresh fuel (comprising one half of the fuel assemblies in the core) would in fact contain clean blanket material and the other half of the fuel assemblies, which had already been in the reactor for one cycle, would contain blanket material which had been irradiated for 300 days.

The BOC fissile content of the radial blanket is not as easily estimated as that of the axial and internal blankets because the radial blanket assemblies may be managed independently of the core. Brewer's study (B2) demonstrated that on the basis of economic performance, the optimum irradiation time for batch-loaded blanket assemblies varied between two and eight years depending upon their location with respect to the core and Wood's study (W1) has demonstrated that the management of the radial blanket has little effect on the amount of fissile material bred in the region. Another study (E5), focusing on the engineering design of the blanket, has compared different blanket management schemes including in-out, out-in and element rotation, but considerable uncertainty still surrounds the question of how to best manage the radial blanket. Although it was unnecessary to actually specify an external management scheme for the purpose of evaluating the ultimate potential of the parfait configuration, the BOC fissile distribution in the radial blanket which was adopted for this study is similar to that which would be obtained in a modified in-out management pattern where the blanket assemblies had an average residence time in the reactor of four years. For these equilibrium fuel cycle calculations, the radial blanket regions were uniformly loaded (BOC) with the fissile and fertile material concentrations 
characteristic of the innermost radial blanket assembly row after one year of irradiation.

In spite of the inherent simplicity of the above models for estimating the equilibrium fuel cycle fissile concentrations in the blanket regions, a comparison between the reference core of this study and a core from the LMFBR Follow-On Studies (A1) having the same gross dimensional characteristics revealed that the two were nearly identical in terms of the fraction of the total reactor power generated in each of the major regions. Table 2.5 showed that the percent of the total reactor power generated in the core, axial blanket and radial blanket regions of the reference core at mid-equilibrium cycle were $90.55 \%, 3.76 \%$ and $5.69 \%$, respectively. The corresponding contributions for the reactor of the LMFBR Follow-On Studies were $91.7 \%, 3.1 \%$ and $5.2 \%$. Since the power generated in each of the regions of the reactor is proportional, at least in an average sense, to the fissile content in each of the regions, the remarkable agreement cited above lends credibility to the method described above for estimating the equilibrium fissile content of the blankets and to the results of those calculations.

The next step in the simulation of the physics of the equilibrium fuel cycle was the addition of fission product poisons to both the reference and parfait cores. The concentration of fission product poisons in each of the regions of the core was specified on the basis of local power generation rates and the total $\mathrm{BOC}$ fission product inventory was adjusted to be equivalent to that which would exist in a core in which half of the fuel had already been irradiated for one cycle. 
The fissile loading in the inner and outer core zones: was then adjusted to flatten the radial power profile and to provide the system with enough excess reactivity to achieve a reactivity-limited core cycle lifetime of 300 full power days as shown in Fig. 5.5. Particular care was taken in determining the required core fissile loading because of the sensitivity of the reactor performance to this parameter. Overestimating the required fissile loading of the core, for example, forces the overall system flux to be depressed, which in turn reduces the conversion rate throughout the reactor. An empirical relationship, $\Delta \mathrm{k} / \mathrm{k}=(\mathrm{kon}) \Delta \mathrm{M} / \mathrm{M}$ (D1), relating small changes in the effective multiplication factor of a fast reactor to changes in the fissile loading of the system, proved to be particularly useful in estimating the required. fissile loading. From a series of criticality calculations, the value of the constant. kon, was determined to be 0.550 for the reference core and 0.551 for the parfait core.

The effect of control poisons on the equilibrium fuel cycle was simulated by loading the core and axial blanket regions of the reactor systems with a uniform concentration of boron equal to the timeaveraged concentration of boron required to hold down the system excess reactivity during the burnup cycle. This boron concentration was held constant throughout the burnup cycle for each core and Fig. 5.6 gives a schematic representation of the resulting multiplication factor during the equilibrium cycle. By loading the reactor with a uniform, time-invariant poison concentration as described above, the total losses of neutrons to control poisons during the equilibrium cycle is closely approximated. 


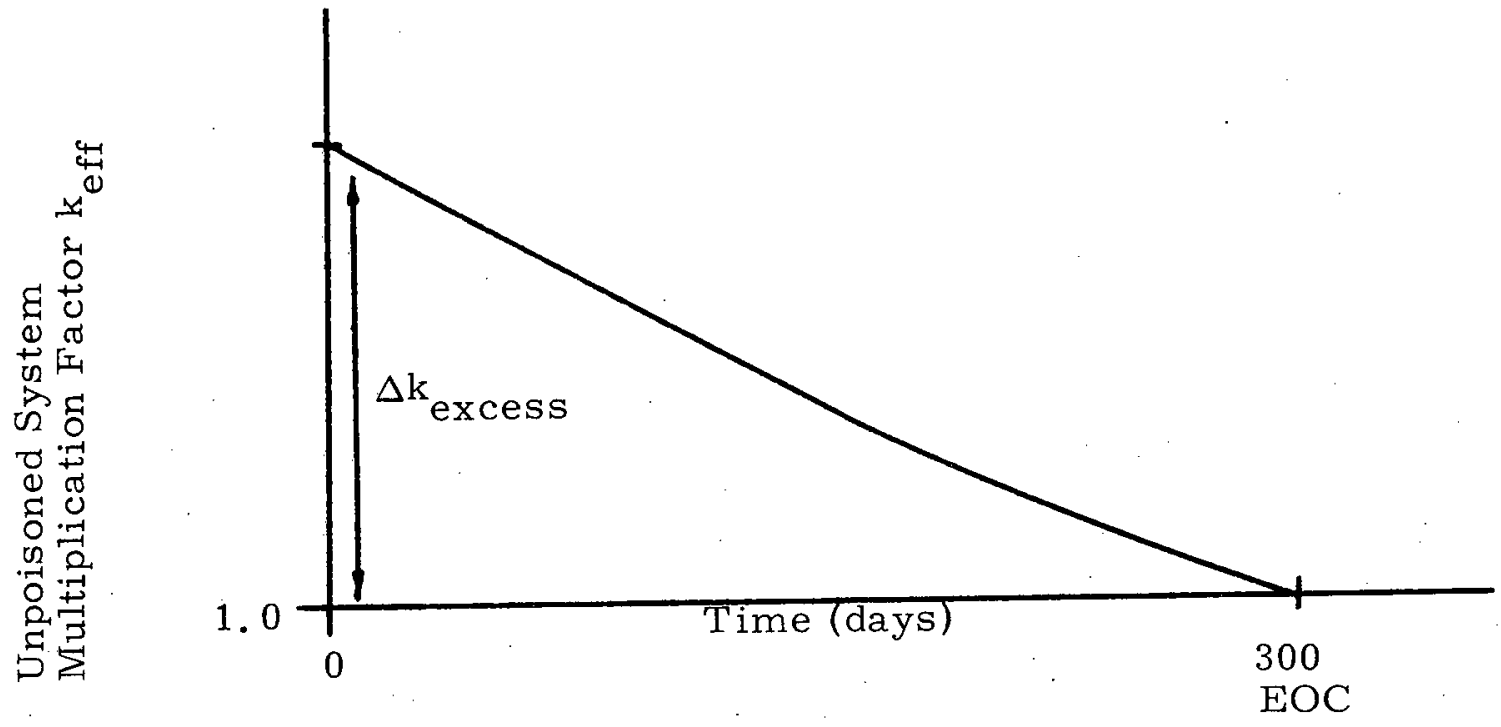

Fig. 5.5. Unpoisoned System Multiplication Factor During the Equilibrium Cycle

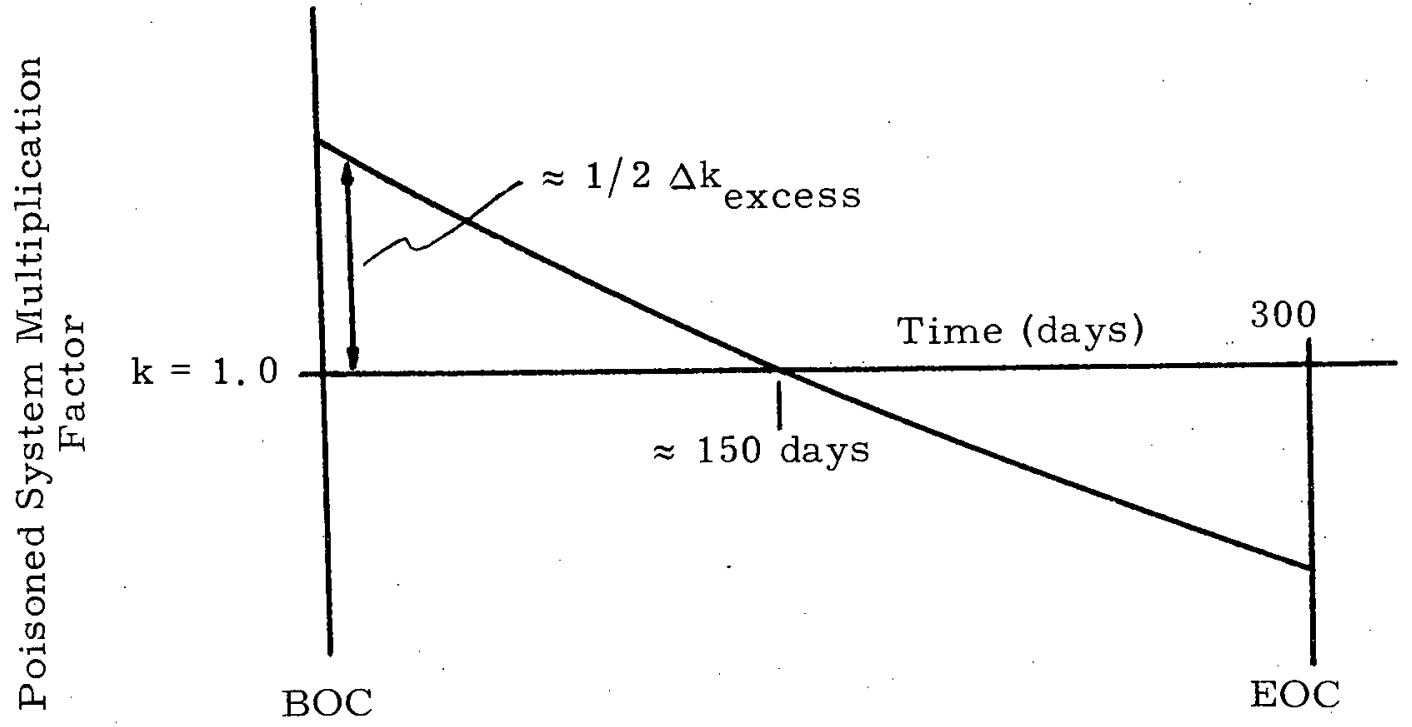

FIG. 5.6. Multiplication Factor for a System Poisoned Uniformly with the Time-Averaged Boron Concentration of the Equilibrium Cycle 
Once the BOC characteristics of the cores were established by the series of calculations described above, the $2 \mathrm{DB}$ code was used to burn up the reactors of interest in time steps of 100 days for the total cycle length of 300 days. The final product of the physics simulation of the equilibrium fuel cycle was the beginning-of-cycle and end-ofcycle inventories of the important heavy metal isotopes. A description of how these inventories were used in the determination of the fuel cycle costs is described in the following section.

\subsubsection{Fuel Cycle Cost Evaluation}

The primary calculational tool used in the economic comparison of the parfait and reference cores was the fast reactor fuel cycle cost code written by Brewer (B2) and modified by Wood (W1), hereafter referred to as BRECON. This code employs the cash flow method for calculating fuel cycle costs; a unit energy cost (mills $/ \mathrm{kwhr}_{\mathrm{e}}$ ) is determined such that revenues from the sale of electricity generated in a cycle offset all net, direct and indirect fuel cycle expenses incurred in that cycle. The effect of net income taxes is included in the code, and for tax accounting purposes in this study, the two post-irradiation transactions, reprocessing outlays and material credits, were treated as noncapitalized items, that is, a simple expense and a taxable income. A complete listing of the BRECON code and a development of its equations are contained in the above-mentioned references (B2, W1).

The equilibrium fuel cycle costs for the reference and parfait cores were developed by using the BRECON code to determine the fuel cycle cost contributions from each of the major physically distinct 
regions of the reactors; the core, the axial blankets, the internal blanket and the radial blanket. As described below, the material flows and related financial transactions of the actual equilibrium cycle were similated by manipulating the fissile and fertile inventories required as input to the BRECON code.

Only one half of the total volume of the fissile-loaded core zones, the internal blanket and the axial blanket, are reloaded at the beginning of each cycle, and therefore the direct fabrication cost for the core fuel assemblies was determined by summing up the product of the unit fabrication cost for each region (Table 5.2) times one half of the region's total heavy metal inventory. The fabrication charges associated with the remainder of the core which was loaded at the beginning of the previous cycle take the form of additional carrying charges on the fabrication expenditure for that fuel.

The direct radial blanket fabrication charges and the additional fabrication carrying charges for that fraction of the radial blanket fabricated and loaded in a previous cycle were handled in the same manner as the core regions, except that the fraction of the blanket fabricated and reloaded at the beginning of each equilibrium cycle was different. As described in Section 5.3.3, the average residence time for blanket assemblies in the reactor was assumed to be four years. Therefore, the fraction of the radial blanket fabricated for loading into the reactor at the beginning of each cycle was one-quarter. The additional carrying charges on fabrication expenditures made in preceding cycles for the remaining three-quarters of the radial blanket assemblies were three times the carrying charges on the 
direct radial blanket fabrication costs charged against the current cycle.

The equilibrium fuel cycle cost also includes carrying charges on the total expenditure for the fissile material loaded into the core. The plutonium in the blankets is not purchased; it is bred in-place. Therefore, there is no carrying charge associated with it. When fissile material is recovered from the blankets, the value of this material is present worthed to the mid-cycle as are all other charges and credits.

Reprocessing charges also make up part of the fuel cycle costs, but, as with the direct fabrication costs; they were only incurred for a fraction of the total material in each of the regions since only a fraction of the fuel is actually reprocessed after every cycle.

The final item in the fuel cycle cost is the credit for the gain in the fissile material bred during the cycle. In an operating reactor, the most highly burned core and blanket assemblies would be discharged and this material credit would be determined by their plutonium loading. In the equilibrium cycle simulated in this study, this material credit was determined by subtracting the total BOC fissile inventory in all of the regions of the reactor from the total EOC fissile inventory.

The relative economic performance of the reference and parfait cores is compared on the basis of equilibrium fuel cycle costs as developed above in the next section of this chapter. It is useful, however, to condense the fuel cycle cost equations to their simplest form to focus on the differences between the reference and parfait systems. 
For this simplest case, the effect of taxes has been neglected and the unit fabrication costs for the core and internal blanket of the parfait concept are assumed to be the same as those of the core zone of the reference reactor. With this latter condition, it is clear that both cores experience the same charges for fabrication services because the same number of core and radial blanket assemblies are required in each configuration. Similarly, the reprocessing charges for both reactor types are the same. Therefore, with these two components being equal, the differences in the fuel cycle costs for the two concepts lie in the two remaining components, the fissile inventory carrying charges and the fissile material credit. As noted in Chapter 2, the initial inventory of the parfait concept was greater than that of the reference core and therefore, this difference represents an economic penalty for the parfait core. The breeding ratio of the parfait core was, however, greater than that of the reference core, which leads to an economic advantage for the parfait core in the fissile credit component of the fuel cycle costs. These two fuel cycle cost differences for the reference and parfait cores tend to offset one another. The net fuel cycle cost advantage $(\$ / y r)$ for the parfait concept using this simple model is expressed in Equation 5.1. The symbol " $\Delta$ " in this equation stands for the difference between the parfait and reference cores in the quantity it precedes.

$$
\begin{aligned}
& {\left[\begin{array}{l}
\text { Annual fuel cycle } \\
\text { cost advantage for } \\
\text { the parfait core }
\end{array}\right]=C_{F}\left[\Delta\left[\begin{array}{l}
\text { Net fissile } \\
\text { material gain } \\
\text { in one cycle }
\end{array}\right]-\Delta\left[\begin{array}{l}
\text { BOC core } \\
\text { fissile } \\
\text { inventory }
\end{array}\right][x]\right.} \\
& \qquad(\$ / y r) \quad=(\$ / \mathrm{kg})[(\mathrm{kg} / \mathrm{yr})-(\mathrm{kg})(1 / \mathrm{yr})] \\
& \mathrm{C}_{\mathrm{p}} ; \text { unit cost of fissile material, } \$ / \mathrm{kg} \\
& \mathrm{x} ; \text { discount rate (cost of money) }
\end{aligned}
$$


A preview of the results from the more precise economic comparison given in the next section is provided by evaluating Equation 5.1 for a parfait configuration with a $30-\mathrm{cm}$ internal blanket and the reference core, both with a fuel volume fraction of 0.30 in the core. For this case, the difference in the net fissile gain per cycle was $13.52 \mathrm{~kg} / \mathrm{yr}$ and the difference in the $\mathrm{BOC}$ core fissile inventories was $80.11 \mathrm{~kg}$. In the economic environment defined in Table 5.2, the market value of fissile material $\left(\mathrm{C}_{\mathrm{p}}\right)$ was set at $\$ 10,000 / \mathrm{kg}$ and the discount rate $(x)$ at $8.0 \%$. For these parameters, Equation 5.1 predicts a total yearly cost advantage for the parfait core of $\$ 71,000 / y r$. This amount, although not totally insignificant, is equivalent to less than one percent of the total fuel cycle expenses incurred by the reactors during one year of equilibrium operation. The conclusion then is that the two most significant components of the fuel cycle costs which are different for the two reactor configurations very nearly offset one another, and thus the total fuel cycle costs for each may therefore be expected to be very nearly equal. Results confirming this simple model are presented in the next section.

\subsubsection{Case Studies}

Based on the results of the neutronic calculations in Chapter 2, a comparison of the equilibrium fuel cycle costs was performed for three cores: the reference reactor, a parfait configuration with a $30-\mathrm{cm}$ internal blanket and a parfait configuration with a $50-\mathrm{cm}$ internal blanket. The results of Chapter 2 also demonstrated a strong dependence of reactor performance on the fuel volume fraction in the core. Therefore, in addition to evaluating the effects of the internal 
blanket thickness, the economic performance of the same three reactors was also compared at three different core fuel-volume-fractions, namely $0.27,0.30$ (the base case) and 0.33 .

The net result of these calculations was the intercomparison of what amounts to nine "different" reactors under a variety of economic conditions. The fuel cycle costs quoted in these comparisons were developed by performing equilibrium cycle burnup calculations as described in Section 5.3.3. The fuel cycle material flows derived from these calculations were then used in the economics model described in Section 5.3.4 to determine the equilibrium fuel cycle costs.

In order to provide a meaningful and yet manageable representation of the effects of the different economic conditions for each of the different reactors, a few selected comparisons are discussed in the following pages and near the end of this section, the fuel cycle costs for one example are tabulated by cost component item for each of the regions of the reactor. Each of the graphs presented includes the results for the nine "different" reactor configurations.

In the pages which follow, comparisons of fuel cycle costs evaluated under different economic conditions demonstrate the sensitivity of each of the reactor systems to a specific economic parameter. For this study, the two most significant economic parameters which were varied are the fabrication costs and the cost of money. As indicated in Equation 5.1, however, the primary fuel cycle cost differences between the reference and parfait systems are in the fissile inventory use charge and the material credit (bred plutonium) component. 
In each of the comparisons which follow, for which a given set of economic parameters has been specified, it is these two components, arising from the differences in the neutronic characteristics of the cores which contribute to the fuel cycle cost differences between the systems.

In the first comparison, shown in Fig. 5.7, three different variations relating to fabrication charges have been compared. In one of these variations, the standard economic environment (base case), as defined in Table 5.2, was employed. The assumption in this case, Case \#2, is that the unit cost $(\$ / \mathrm{kg})$ of fabricating the internal blanket is the same as the unit cost of fabricating the core regions. Case \#3 is the same as Case \#2 except that the unit charge for fabrication of the core and internal blanket zones was increased to $\$ 400 / \mathrm{kg}$. Case \#1 allows for the possibility that the charges related to the fabrication of the internal blanket region may be less than those for the core regions. Note that the base case economic environment calls for core fabrication charges of $\$ 314 / \mathrm{kg}$ whereas the axial blanket charges a re only $\$ 80 / \mathrm{kg}$. The difference reflects the fact that clean blanket material presents far fewer handling problems than does plutonium-bearing nuclear material. Therefore, all of the fabrication process steps up to the point of rod loading could be performed with less difficulty and presumably less cost. At best, the internal blanket unit fabrication charges could only be as low as those for the axial blanket, and this was taken as the condition for Case \#1.

A few general characteristics of the curves shown in Fig. 5. 7 are immediately evident. The curves for Cases \#2 and \#3 a re essentially 


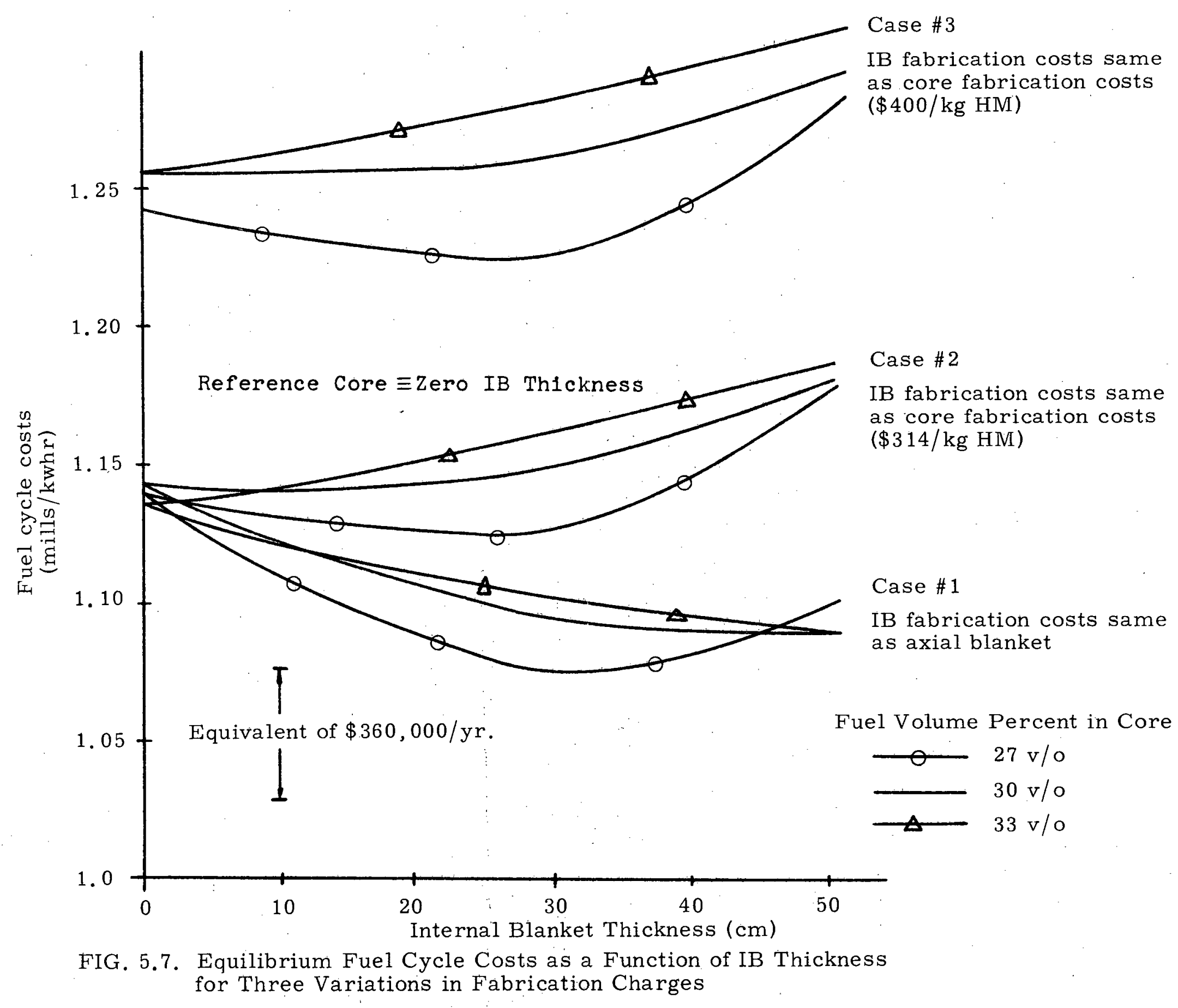


the same but displaced from one another by about $0.1 \mathrm{mills} / \mathrm{kwhr}$, or about $8.5 \%$ of the total fuel cycle costs; the result of an increase in the core fabrication costs from $\$ 314 / \mathrm{kg}$ to $\$ 400 / \mathrm{kg}$. Although this change in the absolute energy costs is quite substantial, the relative attractiveness of the parfait concept as compared to the reference core was not affected by the increased unit fabrication costs. The curves of Case \#1 exhibit an initially decreasing fuel cycle cost as the thickness of the internal blanket is increased. This characteristic is due to the overall reduction in the total expenditure for fuel fabrication as more and more of the core volume is made up of the internal blanket, for which the unit fabrication charges are smaller.

The most overriding conclusion which may be drawn from Fig. 5.7 is that for each of the cases, the differences in the fuel cycle costs predicted for the reference and parfait cores are very small. All of the differences are less than 0.05 mills $/ \mathrm{kwhr}$ and, as shown in the figure, a change in the fuel cycle costs of this amount is equivalent to an annual chà rge of about $\$ 360,000$.

The influence of the fuel cycle costs of the discount rate (which reflects the effective cost of money) is demonstrated in Fig. 5.8. For simplicity, the fuel cycle costs as a function of internal blanket thickness are plotted in this figure only for the reactors having 30 volume percent fuel in the core. In this comparison, an increase in the discount rate from $8.0 \% / \mathrm{yr}$ to $9.25 \% / \mathrm{yr}$ resulted in an increase in the fuel cycle costs of $0.133 \mathrm{mills} / \mathrm{kwhr}$, or about $11 \%$. As with the results of the previous comparison, the absolute change in the energy cost from the variation of this parameter was quite substantial, but the relative 


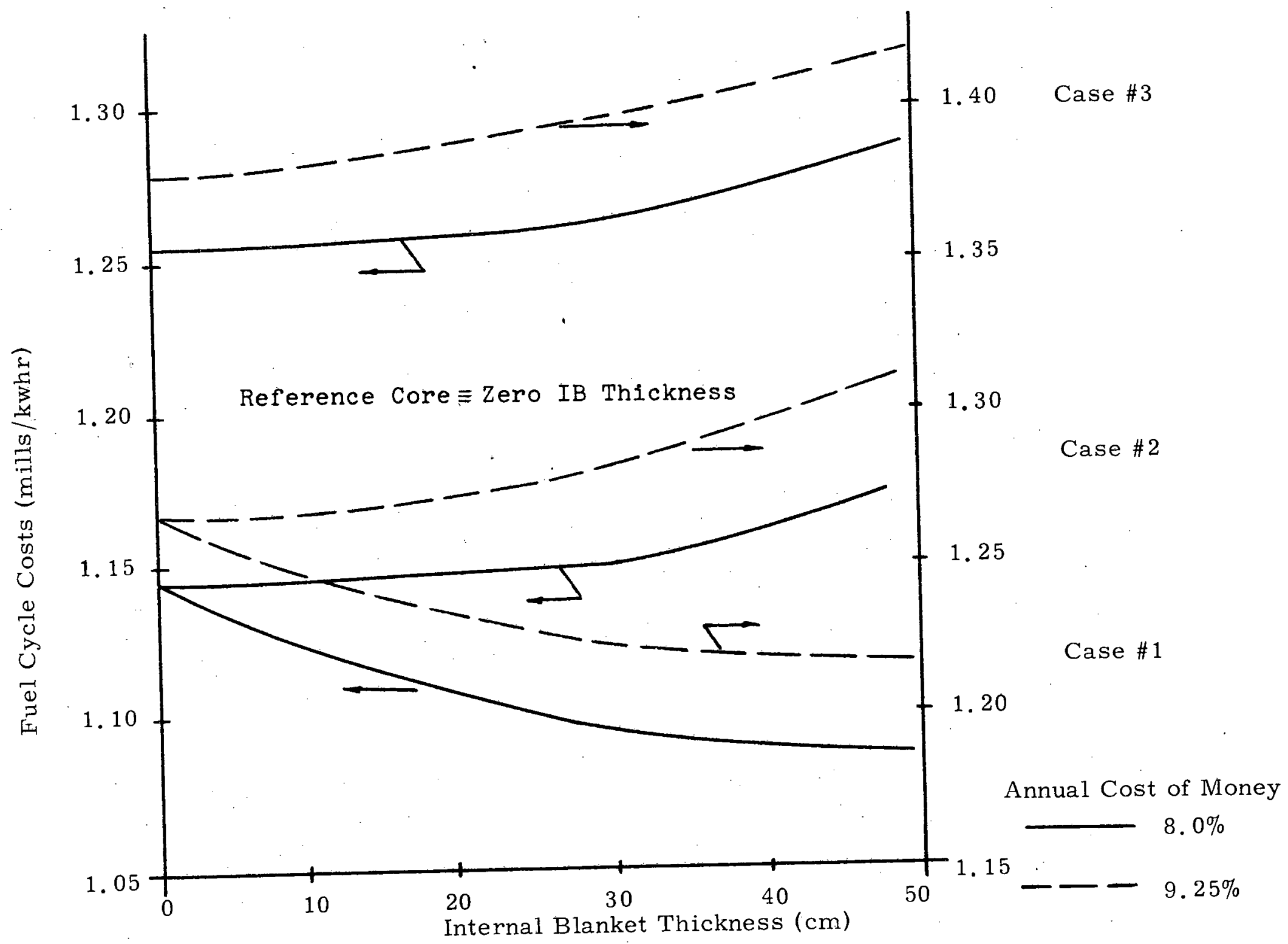

FIG. 5.8. Equilibrium Fuel Cycle Costs as a Function of IB Thickness for an Effective Cost of Money of $8.0 \% / \mathrm{yr}$ and $9.25 \% / \mathrm{yr}$ 
attractiveness of the parfait concept was again unaffected.

An examination of the curves shown in Fig. 5.7 reveals that for each of the cases, \#1, \#2 and \#3, the fuel cycle costs predicted for the reactors having the lowest fuel-volume-fraction in the core were the lowest. Because of the more favorable neutronic characteristics predicted in Chapter 2 for the cores having the higher core fuel-volumefractions (Fig. 2.24), this surprising result requires an explanation. This result is related to the method of assessing fuel fabrication charges on a cost per kilogram basis. The total heavy metal inventory in the cores having the lower fuel-volume-fractions was smaller than that of the cores with the higher fuel-volume-fractions. Therefore, since the number of kilograms of material fabricated for these cores was lower, the direct and indirect fabrication charges were also lower. This, however, is an unrealistic circumstance because the same fabrication services would be required for both the reference and parfait cores before each equilibrium cycle, regardless of the fuel-volumefraction of the core. That is, the same number of fresh fuel assemblies would be required and the cost of these elements, exclusive of the nuclear material costs, would be the same, regardless of the spacing of the fuel pins in the assembly or the spacing of the fuel elements in the core. Therefore, in order to allow a realistic intercomparison between configurations having different fuel-volumefractions in the core, the results of Case \#2 shown in Fig. 5. 7 were normalized so that each of the cores had the same fabrication charges as the reference core with 30 volume percent fuel in the core. This is, in essence, the same as assessing direct fabrication charges on the 
basis of cost per unit volume rather than cost per kilogram of heavy metal. The results are shown in Fig. 5.9 along with the original results of Fig. 5.7. Note that this modified and more realistic handling of the fabrication charges tends to separate the curves of Fig. 5.7, so that the cores having the higher fuel-volume-fractions achieve the lowest fuel cycle costs. In the case of the reference core, this modification allows the reactor to demonstrate a fuel cycle cost reduction of more than $0.21 \mathrm{mills} / \mathrm{kwhr}$ for an increase in the fuel volume percent in the core from $27 \mathrm{v} / 0$ to $33 \mathrm{v} / 0$. Similar advantages for the higher fuel-volume-fractions were also demonstrated for the parfait configurations.

A breakdown of the fuel cycle cost contributions from each of the major regions of the reference and parfait cores is provided in Table 5.3. Similar information is listed in Table 5.4 as the percent of the total fuel cycle costs exclusive of direct burnup in the core and material credits for fissile material bred in the blankets. (Since each of the configurations is a breeder, the net fuel cycle cost contribution of these two components is negative. Therefore, since the purpose of Table 5.4 is to provide a breakdown of the cash outlays of the fuel cycle, these components have been excluded from the table.) The comparison which is presented in these two tables is for the base case reactors, each having 30 volume percent fuel in core. The economic parameters are those of the standard economic environment defined in Table 5.2 with the modification in the handling of fabrication charges discussed above. These tables demonstrate that the most significant component of the fuel cycle cost for each of the reactor configurations 


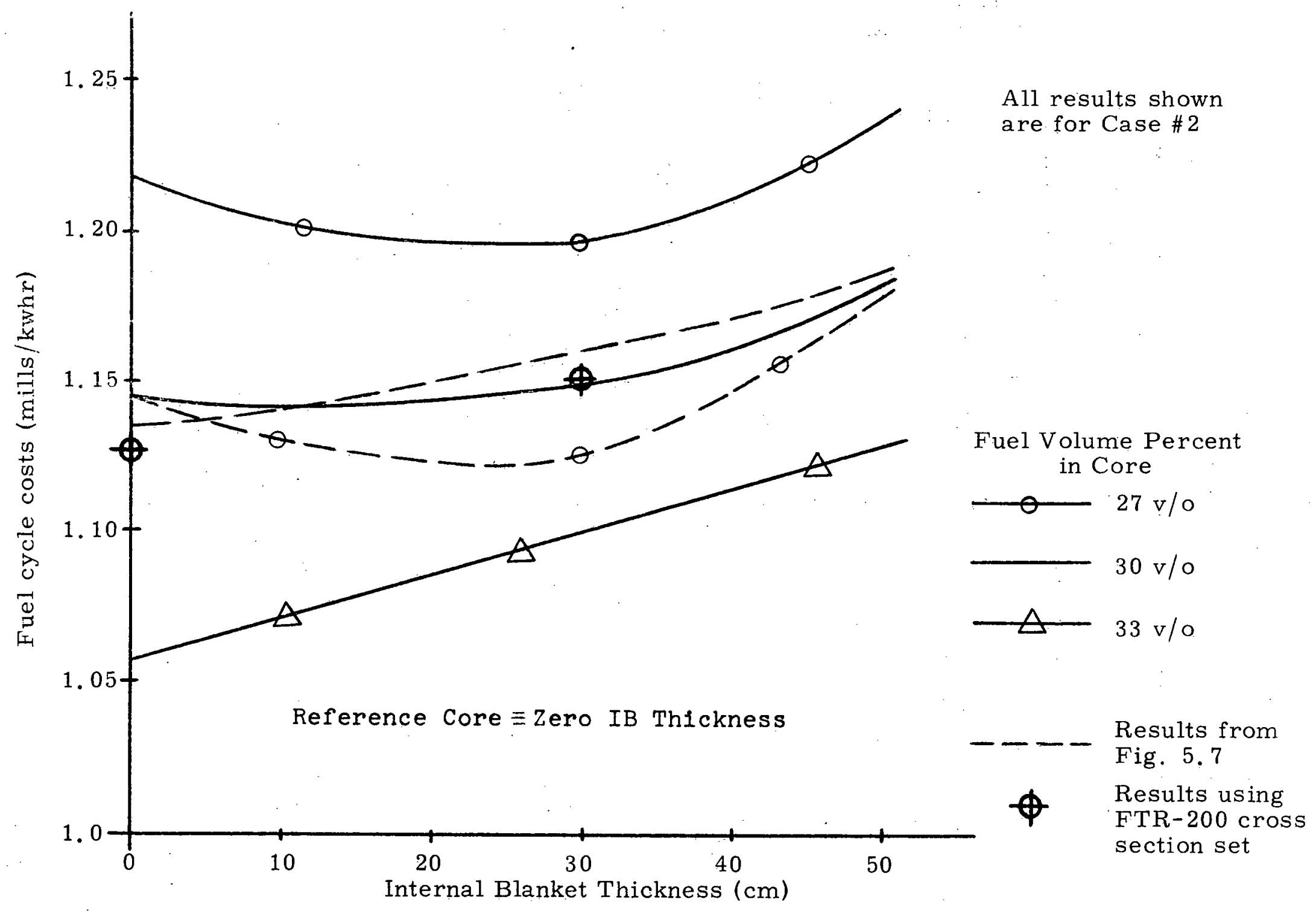

FIG. 5.9. Fuel Cycle Costs as a Function of IB Thickness with Fabrication Charges for all Cores Normalized to the Reference Core with $30 \mathrm{v} / 0$ Fuel in Core 
TABLE 5.3

Equilibrium Fuel Cycle Cost Contributions by Region

(Base Case: $30 \mathrm{v} / 0$ Fuel in Core)

\begin{tabular}{|c|c|c|c|}
\hline \multirow[b]{2}{*}{.} & \multicolumn{3}{|c|}{ Cost Contribution, mills/kwhr } \\
\hline & Reference & $\begin{array}{c}30-\mathrm{cm} \text { IB } \\
\text { Parfait }\end{array}$ & $\begin{array}{c}50-\mathrm{cm} \text { IB } \\
\text { Parfait }\end{array}$ \\
\hline \multicolumn{4}{|l|}{ Core } \\
\hline $\begin{array}{l}\text { Direct burnup } \\
\text { Inventory carrying charges } \\
\text { Direct fabrication } \\
\text { Fabrication carrying charges } \\
\text { Net reprocessing charges }\end{array}$ & $\begin{array}{l}0.1964 \\
0.6568 \\
0.3093 \\
0.0990 \\
0.0456 \\
\end{array}$ & $\begin{array}{l}0.3385 \\
0.6687 \\
0.2533 \\
0.0810 \\
0.0373 \\
\end{array}$ & $\begin{array}{l}0.4144 \\
0.6804 \\
0.2210 \\
0.0706 \\
0.0326 \\
\end{array}$ \\
\hline Subtotal & 1.3071 & 1.3788 & 1.4190 \\
\hline \multicolumn{4}{|l|}{ Internal Blanket } \\
\hline $\begin{array}{l}\text { Net material credit } \\
\text { Net reprocessing charges } \\
\text { Direct fabrication } \\
\text { Fabrication carrying charges }\end{array}$ & $\begin{array}{l}- \\
- \\
-\end{array}$ & $\begin{array}{r}-0.1092 \\
0.0083 \\
0.0560 \\
0.0180 \\
\end{array}$ & $\begin{array}{r}-0.1556 \\
0.0130 \\
0.0883 \\
0.0284 \\
\end{array}$ \\
\hline Subtotal & & -0.0269 & -0.0259 \\
\hline \multicolumn{4}{|l|}{ Axial Blanket } \\
\hline $\begin{array}{l}\text { Net material credit } \\
\text { Net reprocessing charges } \\
\text { Direct fabrication } \\
\text { Fabrication carrying charges } \\
\quad \text { Subtotal }\end{array}$ & $\begin{array}{r}-0.1873 \\
0.0356 \\
0.0616 \\
0.0196 \\
-0.0705\end{array}$ & $\begin{array}{r}-0.2052 \\
0.0356 \\
0.0616 \\
0.0196 \\
-0.0884\end{array}$ & $\begin{array}{r}-0.2113 \\
0.0356 \\
0.0616 \\
0.0196 \\
-0.0945\end{array}$ \\
\hline \multicolumn{4}{|l|}{ Radial Blanket } \\
\hline $\begin{array}{l}\text { Net material credit } \\
\text { Net reprocessing charges } \\
\text { Direct fabrication } \\
\text { Fabrication carrying charges }\end{array}$ & $\begin{array}{r}-0.2120 \\
0.0349 \\
0.0520 \\
0.0333 \\
\end{array}$ & $\begin{array}{r}-0.2338 \\
0.0349 \\
0.0520 \\
0.0333 \\
\end{array}$ & $\begin{array}{r}-0.2420 \\
0.0349 \\
0.0520 \\
0.0333 \\
\end{array}$ \\
\hline Subtotal & -0.0918 & -0.1136 & -0.1218 \\
\hline $\begin{array}{l}\text { Total Expenses } \\
\text { Total Material Credits }\end{array}$ & $\begin{array}{r}1.5441 \\
-0.3993\end{array}$ & $\begin{array}{r}1.6981 \\
-0.5482\end{array}$ & $\begin{array}{r}1.7857 \\
-0.6089\end{array}$ \\
\hline TOTAL FUEL CYCLE COSTS & 1.1448 & 1.1499 & 1.1768 \\
\hline
\end{tabular}


TABLE 5.4

Percent of Equilibrium Fuel Cycle Costs

by Item and by Region

\begin{tabular}{ccc}
\hline & Percent Cost Contribution \\
& $30-\mathrm{cm}$ IB & $50-$ cm IB \\
Reference & Parfait & Parfait \\
\hline
\end{tabular}

Core

Inventory carrying charges

Direct fabrication

Fabrication carrying charges

Net reprocessing charges

$\begin{array}{rrr}48.73 & 49.19 & 49.62 \\ 22.95 & 18.63 & 16.11 \\ 7.35 & 5.96 & 5.15 \\ 3.35 & 2.74 & 2.38\end{array}$

Internal Blanket

Direct fabrication

Fabrication carrying charges

Net reprocessing charges

$\begin{array}{lll}- & 4.12 & 6.44 \\ - & 1.32 & 2.07 \\ - & 0.61 & 0.95\end{array}$

Axial Blanket

Direct fabrication

Fabrication carrying charges

Net reprocessing charges

$\begin{array}{lll}4.60 & 4.53 & 4.49 \\ 1.45 & 1.44 & 1.43 \\ 2.64 & 2.62 & 2.60\end{array}$

Radial Blanket

Direct fabrication

Fabrication carrying charges

Net reprocessing charges

3.86

3.82

2.45

3.79

2.47

2. 57

2.43

2.60

2. 54

TOT AL

100.0

100.0

100.0

* Percent of all expenses exclusive of direct fissile burnup in the core and all material credits for fissile bred in the blankets. 
is the carrying charge on the expenditure associated with the core fissile inventory. Because the fissile inventory increases with the thickness of the internal blanket, this component is larger for the two parfait configurations than for the reference core. The next most significant cash outlay of the fuel cycle is the direct expenditure for the fabrication of the core zone of the reactor. (The sums of the direct fabrication costs for the core and internal blanket regions of the parfait designs are equivalent to those of the reference core, which was required by the method of assessing the fabrication charges discussed earlier.)

Table 5.3 also demonstrates that the material credits (fissile material gain) from the axial and radial blankets of the parfait configuration are greater than those of the reference core. This characteristic indicates that on the basis of economic performance the optimum external blanket thicknesses for the parfait configuration would be greater than for the reference reactor. This, however, is a design variation which was excluded in defining the scope of this work.

It is interesting to note that the $30-\mathrm{cm}$ internal blanket parfait configuration exhibits an advantage over the reference core in the net amount of fissile material gained (which is proportional to the sum of the direct burnup component in the core and the material credit components of each of the blanket regions). The $50-\mathrm{cm}$ internal blanket configuration, however, exhibits a disadvantage in this respect. Therefore, it would appear as though the internal blanket thickness of this configuration is beyond the economic optimum - especially in light 
of the fact that this configuration also has higher core inventory carrying charges than the reference reactor. As indicated in Table 5. 3, the fuel cycle cost for this parfait concept is greater than that of the reference core by 0.032 mills/kwhr. This analysis, however, has not taken into account the potential reduction in the core fabrication costs which this configuration may be able to claim because, as discussed in Section 5.2.1, only one fissile enrichment. is required for the core zones. A simple calculation indicates that an $11 \%$ reduction in the core fabrication costs would be sufficient to offset the $0.032 \mathrm{mills} / \mathrm{kwhr}$ fuel cycle cost differential which separates the reference core and this 50$\mathrm{cm}$ internal blanket parfait configuration. Based on the breakdown of the fabrication costs indicated in Table 5.1 (for which the pelletization process accounts for $33 \%$ of the total fuel element fabrication costs), an $11 \%$ reduction in fabrication costs would appear to be attainable.

A comparison between the fuel cycle costs for the reference core and a parfait configuration with a $30-\mathrm{cm}$ internal blanket was also performed using the alternate cross section set described in Appendix A.1.2. The same procedures as those already described in this chapter were employed and the results for the base case cores containing $30 \mathrm{v} / 0$ fuel are plotted in Fig. 5.9 with the symbol " $"$ ". The results using the two different cross section sets for the burnup calculations are seen to agree quite well.

The results of Fig. 5.9 are replotted in Fig. 5. 10 to re-emphasize the importance of the fuel-volume-fraction in the core as a parameter which has a major effect on the economic performance of the system. 


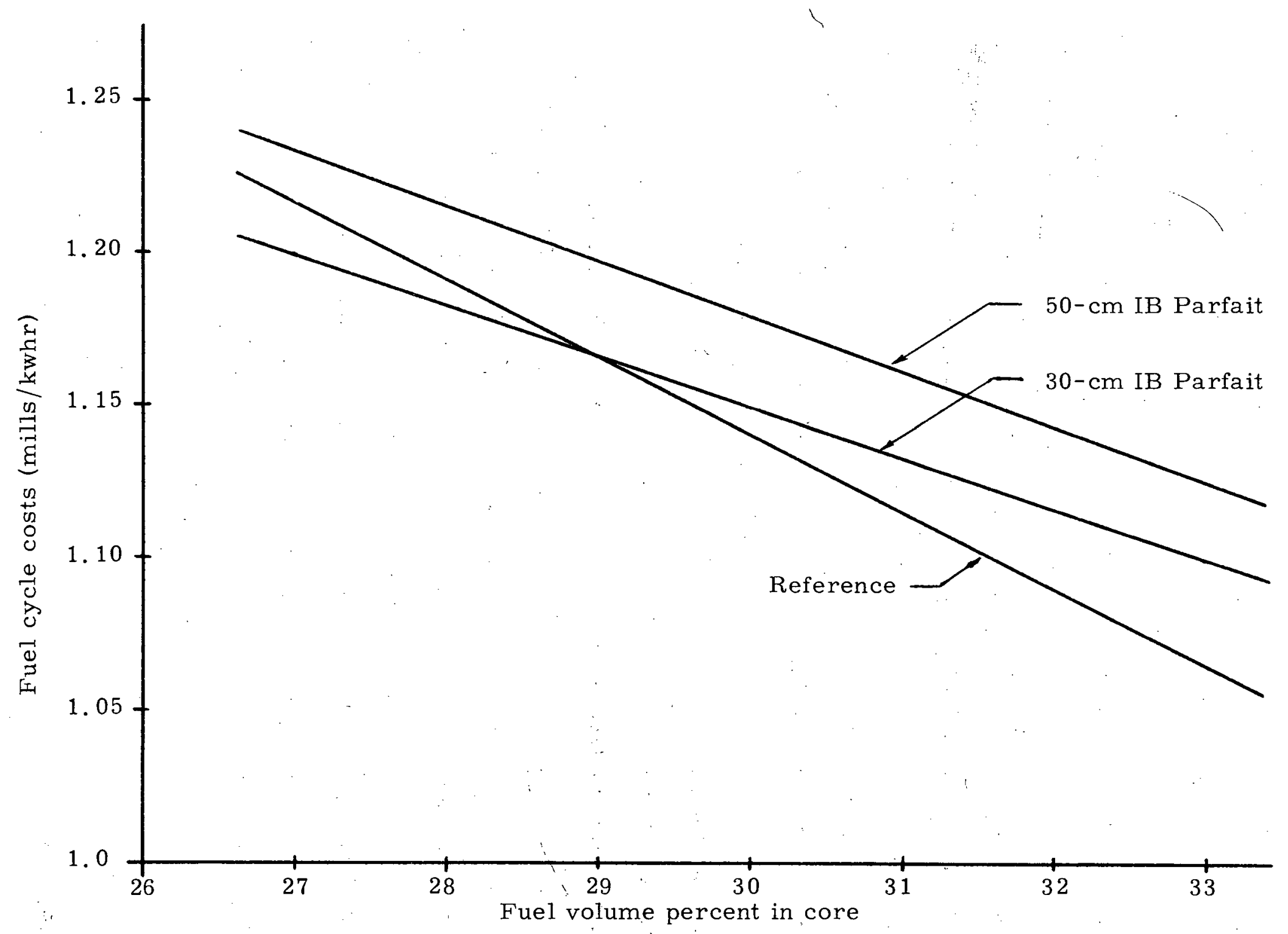

FIG. 5. 10. Fuel Cycle Costs as a Function of Fuel Volume Percent with Fabrication Charges for All Cores Normalized to the Reference Core with $30 \mathrm{v} / \mathrm{o}$

Fuel in Core 
To repeat, the results shown in. Fig. 5.10 were derived from calculations using the "base case" economic environment of Table 5.1 and for which the fabrication charge for each of the reactors was the same as that of the reference core having a fuel-volume-fraction of 0.30 . In this figure, the fuel cycle cost reductions for the higher fuel-volumefractions are indicative of the superior neutronic behavior of these configurations as described in Chapter 2. The results for the $50-\mathrm{cm}$ internal blanket parfait configuration do not incorporate the potential reduction in core fabrication costs discussed previously.

At any given fuel volume percent, each of the cores display very nearly the same fuel cycle costs. According to Fig. 5.10, in the range of fuel volume percent from $27 \mathrm{v} / 0$ to $29 \mathrm{v} / 0$ the parfait configuration would have a slight cost advantage and in the range from $29 \mathrm{v} / 0$ to $33 \mathrm{v} / \mathrm{o}$ the reference core exhibits a slight advantage. In either case, the fuel cycle costs differ by less than 0.05 mills/kwhr which, as previously stated, is equivalent to an annual expenditure of about $\$ 360,000$ for the $1000-\mathrm{MW}_{\mathrm{e}}$ reactors of this study. In Chapters 2 and 3 , however, the possibility of achieving a higher fuel-volume-fraction in a parfait core was discussed. This possibility a rose because of the reduced number of control rods required for the parfait core and the reduced effects of material swelling in the stainless steel structural components as the result of the reduced peak fluences in the core. The maximum potential gain in core fuel volume percent for the parfait configuration as a result of these considerations may be on the order of several percent, which would give certain parfait configurations a fuel cycle cost advantage over the reference core of about 0.05 mills $/ \mathrm{kwhr}$. 
A precise determination of the fuel cycle cost advantage that could be realized by taking into account an increase in the fuel volume fraction of the core would require a complete and detailed design of an actual parfait core and was beyond the scope of this work, but Fig. 5.10 does demonstrate the potential advantage to be gained in this respect.

One of the characteristics of a fast reactor which is often used as a figure of merit as to its breeding capabilities is the system doubling time. A simple estimate of the relative doubling times was made for the reference reactor and a parfait configuration having a $30-\mathrm{cm}$ internal blanket, each with a core fuel-volume-fraction of 0.30. For this comparison, the doubling time was defined as the number of equilibrium fuel cycles required to breed an amount of extra fissile material equivalent to the equilibrium core fissile loading. As indicated in Fig. 2.2, the fissile inventory of the parfait core was $3.2 \%$ greater than that of the reference core, but the annual yield of fissile material was $15 \%$ greater. The net result of these two counteracting influences is that the calculated doubling time of the parfait core is only $90 \%$ as long as that of the reference reactor.

\subsection{CONCLUSIONS}

The characteristics of the parfait configuration discussed in this chapter were found to have no adverse effect upon the feasibility of the concept. Including an internal blanket as an integral part of the inner core zone fuel assemblies would appear to introduce no unique problems for the parfait configuration in the areas of fuel fabrication, fuel management and reprocessing. 
A method for simulating the physics of an equilibrium fuel cycle and a method for evaluating the equilibrium fuel cycle costs were described in this chapter and a comparison of the economic performance of the reference and parfait cores was performed using these methods. The fuel cycle costs for the two reactor types were found to be very similar with the parfait configuration exhibiting the potential for a slight advantage over the reference core as a result of the possibility of utilizing an increased fuel-volume-fraction in these cores. 
Chapter 6

SUMMARY AND CONCLUSIONS

\subsection{INTRODUCTION}

The purpose of the research summarized here has been to evaluate the neutronic, thermal-hydraulic, mechanical and economic characteristics of the advanced liquid-metal cooled fast breeder reactor configuration shown in Fig. 6.1. This configuration, called the parfait blanket concept, consists of conventional axial and radial external blankets surrounding a short cylindrical core into which a thin horizontal layer of blanket material has been inserted at the core midplane. This internal blanket region is limited in radial extent to the inner core zone, is an integral part of the core fuel assemblies, as are the upper and lower axial blanket regions, and is made up of standard axial blanket pellets. This study has yielded results which indicate a substantial advantage for the parfait configuration over more conventional designs. In particular, the parfait configuration has demonstrated a reduced burnup reactivity swing, an increased breeding ratio and a substantially reduced peak flux. This latter characteristic, together with a flatter radial power profile in the inner core enrichment zone, results in reduced wrapper tube dilation due to swelling and reduced unrestrained fuel element bowing due to radial flux and power gradients. The parfait configuration also exhibits substantially improved sodium void characteristics. The groundrules employed in the evaluation of the parfait concept are discussed below and the performance 


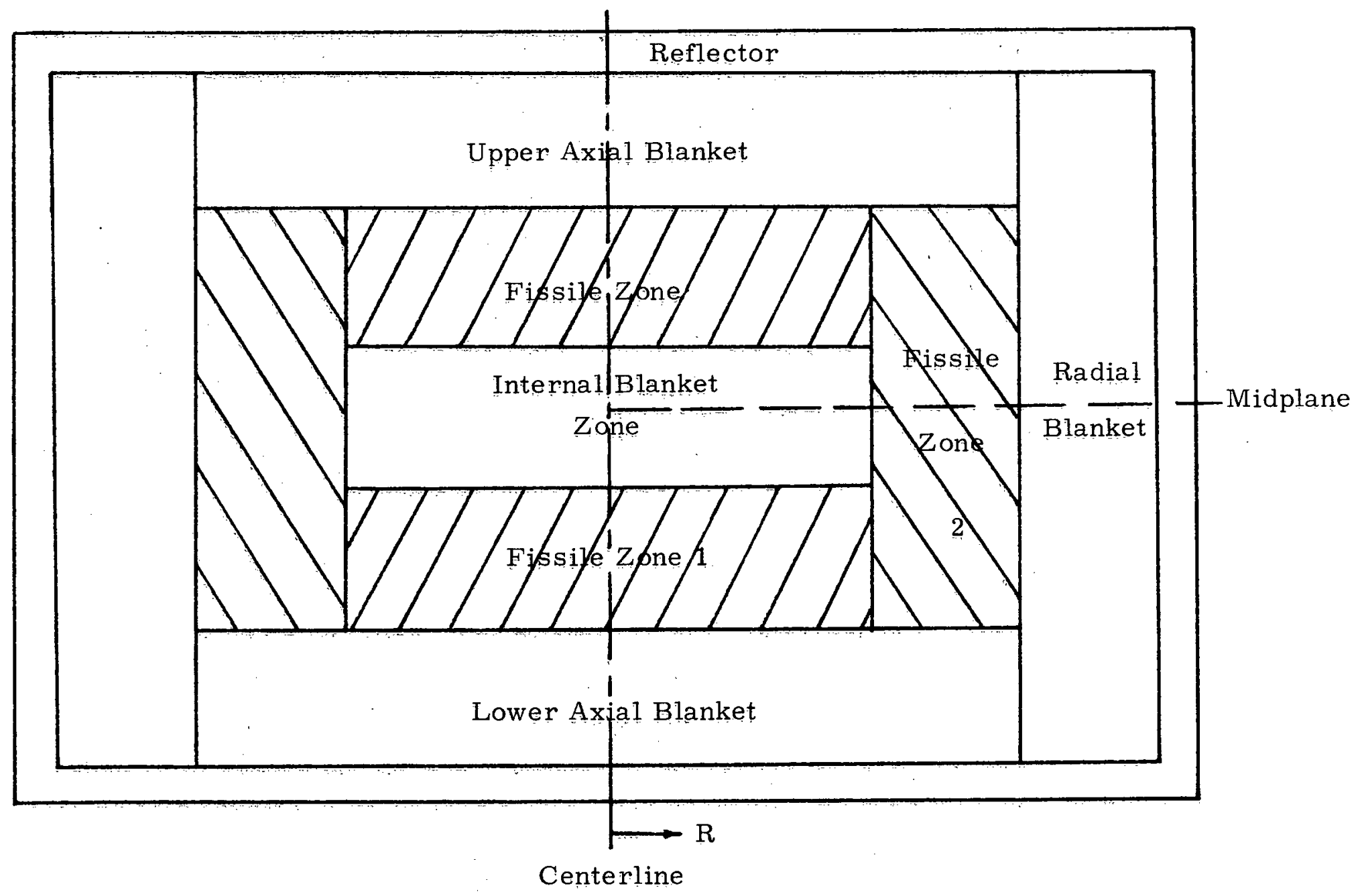

FIG. 6.1. The Parfait Blanket Concept 
characteristics mentioned above are discussed in more detail in subsequent sections.

Although a large number of internal blanket concepts, including annular and modular designs have been investigated in the past, these early studies appear to have optimized a fast reactor design for a single performance characteristic (e.g., to minimize sodium void effects) and were carried out at a time when many of the difficult fast reactor design problems, such as swelling, were, as yet, not fully appreciated. None of these earlier internal blanket concepts is currently the reference design for large fast power reactors.

The product of the present study is a comparative evaluation of the merits and demerits of the parfait blanket concept. It was performed for the purpose of assessing the potential for the application of this configuration to large fast breeder power reactors. The method of evaluation has been to perform a series of parallel calculations employing the same methods and basic data to compare the equilibrium cycle performance of a parfait system with that of a conventional two-zone 1000-MW $\mathrm{e}$ LMFBR. Every effort has been made to identify the major differences between the parfait and the conventional design and to focus on a quantitative evaluation of the major items of concern.

Since there are currently no firm designs for a large LMFBR, the conventional, or reference, reactor characteristics were chosen from the final round designs of the AEC-sponsored $1000-\mathrm{MW}_{\mathrm{e}} \mathrm{LMFBR}$ Follow-On Studies (A1). The overall characteristics of the reference and parfait designs of this study are given in Table 6.1. 
TABLE 6.1. Dimensional and Material Characteristics of the Reference and Parfait Systems

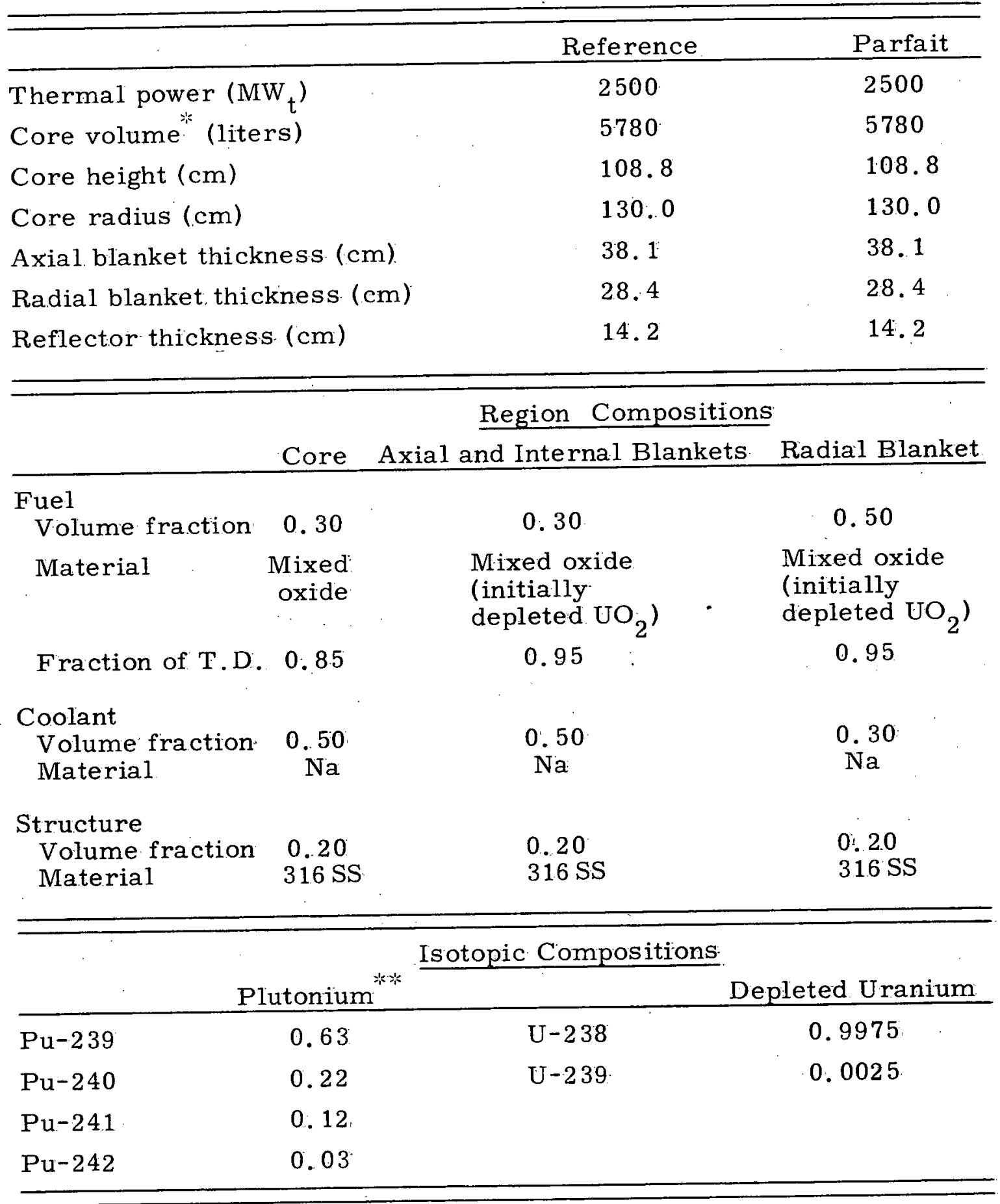

* The core volume of the parfait design includes the internal blanket region.

*** LWR discharge at $\sim 30,000 \mathrm{MWd} / \mathrm{T}$ (B1). 
The characteristics of the reference design are similar to those of the Atomics International $1000-\mathrm{MW}_{\mathrm{e}} \mathrm{LMFBR}$ design in reference (A1), except that the fuel volume fraction in the core has been decreased to conform with current practice as reflected in the FFTF and demonstration plant designs.

Many of the characteristics of the reference and parfait configuration were required to be the same so that the two concepts could be readily compared. Both configurations were required to generate the same total thermal power, use the same materials and have external blankets of the same dimensions and initial composition. With the exception of the fissile enrichments and the internal blanket region, the characteristics of the fuel assemblies in both cores were required to be the same. The requirement was also imposed that the core of the parfait configuration consist of only two types of fuel assemblies as is the case in the reference design. Imposing these constraints allowed this study to focus solely on the effects of the internal blanket.

\subsection{NEUTRONICS}

The primary calculational tool used in comparing the reference and parfait configurations was the two-dimensional, diffusion theory code, 2DB (L5). The cross section set used in these calculations was a four-group set, collapsed from a 26 -group, modified Bondarenko set using the ANISN code (E4). The neutron energy group structure is shown in Table 6.2. 
TABLE 6.2

Neutron Energy Group Structure

\begin{tabular}{ccc}
\hline Group & $\begin{array}{c}\text { Upper Energy Limit } \\
(\mathrm{MeV})\end{array}$ & $\begin{array}{c}\text { Fraction of Fissile Neutrons } \\
\text { Born in Group }\end{array}$ \\
\hline 1 & 10.0 & 0.5894 \\
2 & 1.35 & 0.3948 \\
3 & 0.111 & 0.0141 \\
4 & 0.0248 & 0.0017 \\
\hline
\end{tabular}

The primary design variables in the evaluation of the parfait concept included the axial and radial extent $8 \mathrm{f}$ the internal blanket and its initial composition. In this study, the axial blankets and the internal blanket were both initially composed of depleted uranium oxide. The practical consideration of minimizing the number of different types of fuel pellets loaded in the core fuel assemblies dictates that the internal blanket pellets be identical to those of the axial blanket. It was also shown that the selection of depleted uranium oxide as the internal blanket material is consistent with the aim of maximizing the yield of bred fissile material.

The primary criterion used in defining the axial and radial dimensions of the internal blanket was that the peak power density in the parfait configuration not exceed that in the reference reactor. This limit was imposed because of the strong influence of the power density (or equivalently, the linear power rating) upon the fuel pin centerline temperature. A configuration in which the internal blanket extended across both the inner and outer enrichment zones was 
investigated; however, it was found that the maximum power density of this design exceeded that of the reference reactor for a wide range of internal blanket thicknesses. The radial extent of the internal blanket was, therefore, required to be the same as that of the inner enrichment zone. This requirement meant that varying the radial extent of the internal blanket was accompanied by moving the boundary between the inner and outer core zone - a procedure which has a substantial effect on the flux and power distributions in the core. The most favorable radially-flattened power profiles for the parfait configuration were obtained when the inner core zone had roughly the same dimension as in the reference reactor. A small advantage in radial flux flattening and in the breeding ratio were realized by extending the inner zone of the parfait configuration to $100 \mathrm{~cm}$ as compared to $90 \mathrm{~cm}$ in the reference core. It should be noted that the radial extent of the inner core zone and the internal blanket is only discontinuously variable; it may only be increased or decreased by integral numbers of fuel assembly rows. The parfait configuration, however, offers considerable design flexibility because the axial and radial dimensions of the internal blanket may be varied simultaneously to achieve the desired power profile.

The axial extent, or thickness, of the internal blanket was treated as a continuously variable parameter because oxide pellets may be fabricated and assembled into any specified length. The effects of varying the thickness of the internal blanket were evaluated by comparing the cores shown in Fig. 6.2. The blankets of each configuration were loaded with a fissile content representative of the 


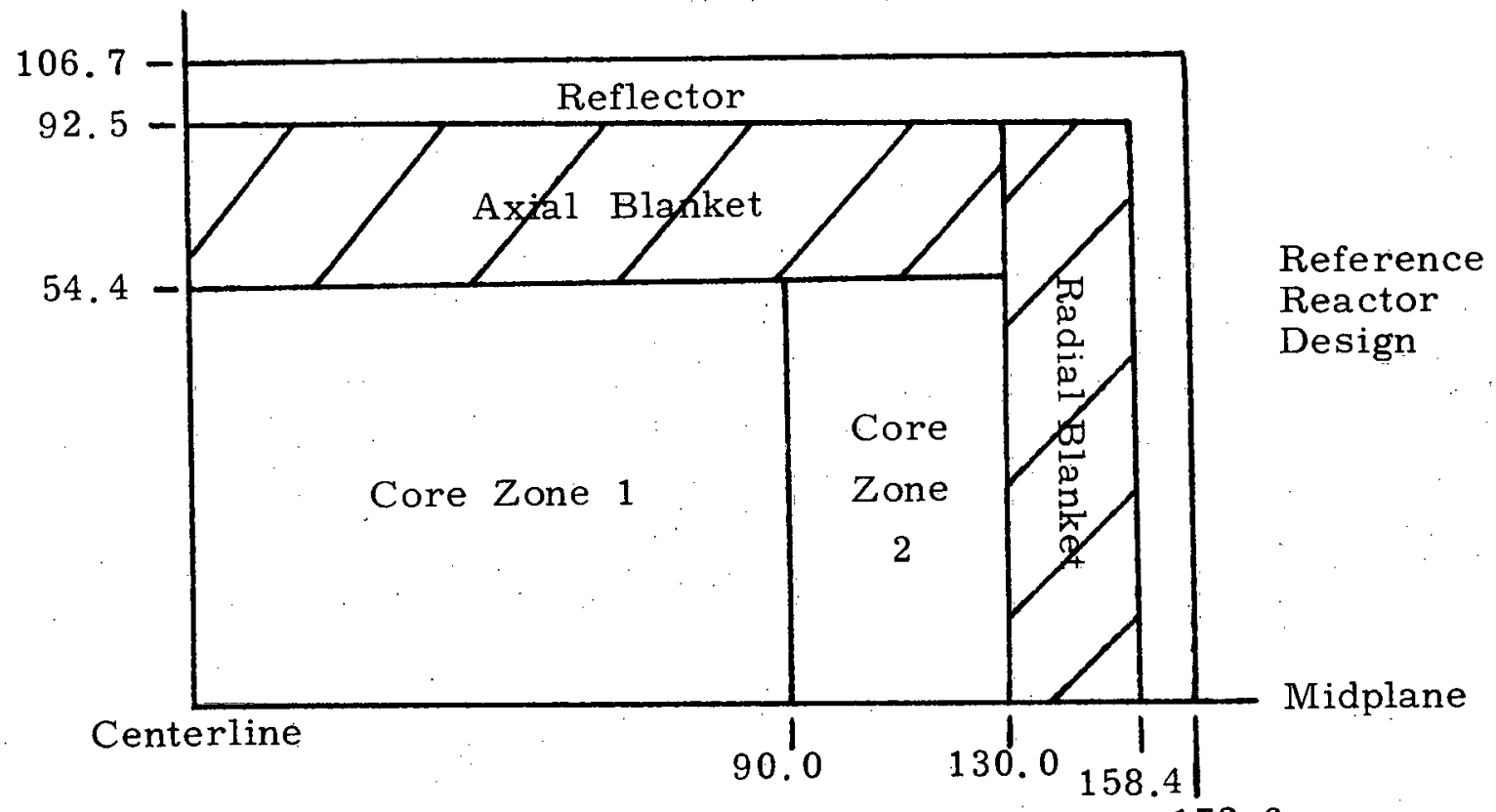

172.6

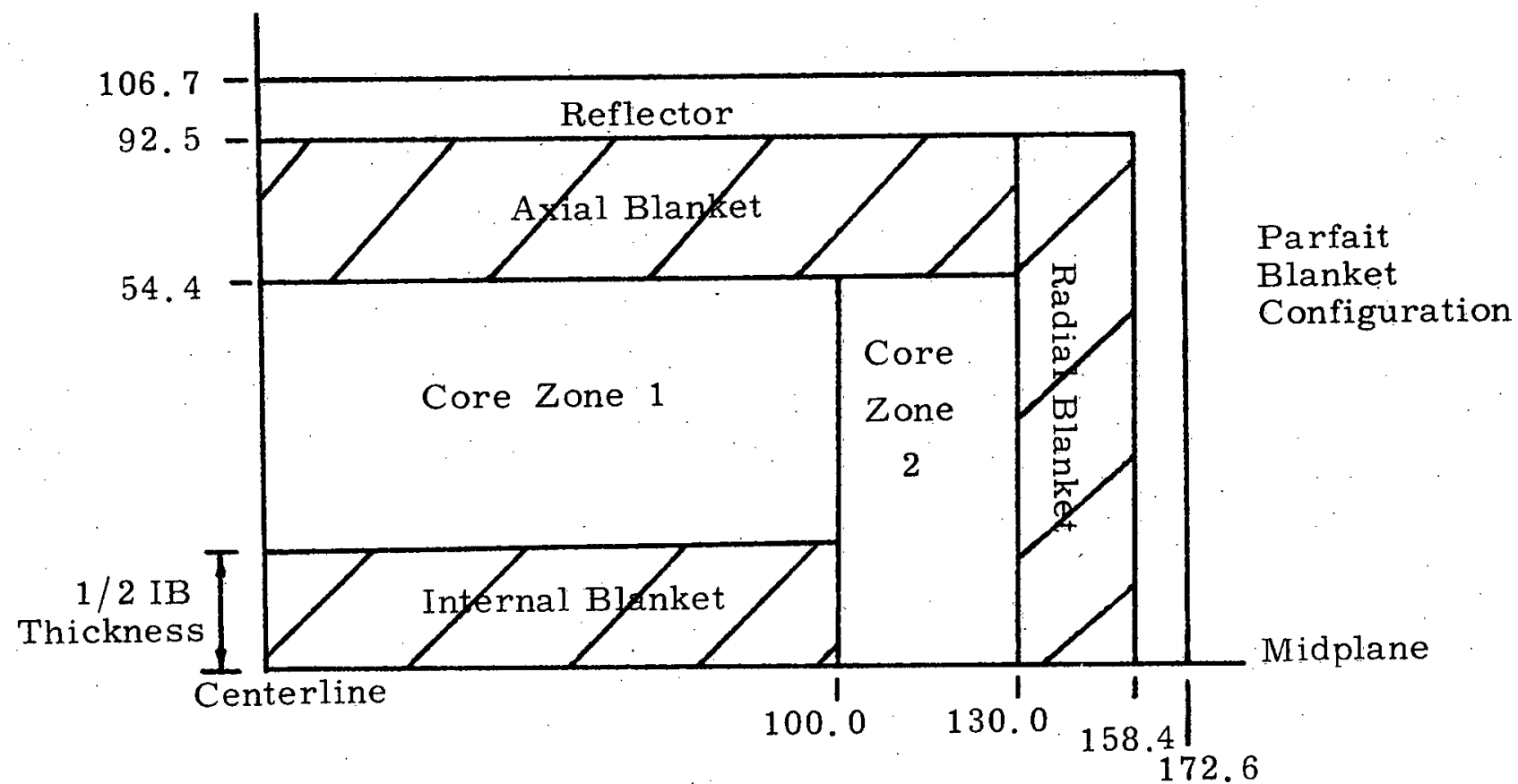

FIG. 6.2. Core Configurations for Evaluating the Effects of Internal Blanket Thickness 
beginning of a cycle of equilibrium operation. The enrichments in the core zones were adjusted to obtain the minimum peak power density throughout the burnup cycle and allow a reactivity-limited core lifetime of 300 full power days. The performance and design parameters of the parfait configuration are summarized in Table 6.3 as a function of internal blanket thickness.

The performance of the parfait configuration relative to the reference reactor is presented in Fig. 6.3, where the results are plotted as the ratio of the parameter for the parfait design to that of the reference system. Very briefly, this figure demonstrates the following characteristics of the parfait configuration:

1) The initial core fissile inventory increases monotonically as a function of internal blanket thickness

2) The breeding ratio of the parfait configuration is slightly improved over that of the reference core. The maximum improvement of about $2 \%$ is diminished, however, as the internal blanket is made so thick that the fertile material at its center becomes less efficient at breeding.

3) The peak power density is reduced compared to the reference reactor. This is a result of axial and radial flux (and power) flattening which, in the case of the $50-\mathrm{cm}$ internal blanket, is so dramatic that even though $27 \%$ of the fissile-loaded volume of the core is replaced by blanket material, the parfait configuration is able to generate as much power as the reference reactor while operating within the same power density limit. The beginning of cycle (BOC) and end of cycle (EOC) axial and radial flux profiles of the reference reactor and a $30-\mathrm{cm}$ internal blanket parfait configuration are shown in Figs. 6.4 and 6.5. During irradiation the flux profiles of the parfait configuration become progressively more similar to those of the reference reactor. 
TABLE 6. 3. Parfait System Performance as a Function of Internal Blanket Thickness

\begin{tabular}{|c|c|c|c|c|c|c|c|c|}
\hline $\begin{array}{l}\text { Internal } \\
\text { Blanket } \\
\text { Thickness } \\
\quad(\mathrm{cm})\end{array}$ & $\begin{array}{l}\text { BOC } \\
\text { Core } \\
\text { Fissile } \\
\text { Inventory } \\
\quad(\mathrm{kg})\end{array}$ & $\frac{\Delta \mathrm{k}}{300 \text { days }}$ & $\begin{array}{c}\mathrm{BR} \\
(\mathrm{BOC})\end{array}$ & $\begin{array}{l}\text { Peak } \\
\text { Power } \\
\text { Density } \\
(\text { BOC) } \\
(\mathrm{MW} / \ell)\end{array}$ & $\begin{array}{l}\text { Peak } \\
\text { Flux }\left(\times 10^{-16}\right) \\
(\mathrm{BOC}) \\
\left(\mathrm{n} / \mathrm{cm}^{2} \mathrm{sec}\right)\end{array}$ & $\begin{array}{l}\text { Peak } \\
\text { Power } \\
\text { Density } \\
(150 \text { days }) \\
(\mathrm{MW} / \ell)\end{array}$ & $\begin{array}{l}\text { Peak } \\
\text { Flux }\left(\times 10^{-16}\right) \\
(150 \text { days }) \\
\left(\mathrm{n} / \mathrm{cm}^{2} \mathrm{sec}\right)\end{array}$ & $\epsilon_{2} / \epsilon_{1}{ }^{*}$ \\
\hline 0 & 2065.02 & 0.052 & 1. 2291 & 0.600 & 0.929 & 0.573 & 0.946 & 1.327 \\
\hline 20 & $* *$ & 0.040 & 1.2500 & 0.560 & 0.740 & 0.544 & 0.766 & 1.216 \\
\hline 30 & 2146.12 & 0.040 & 1.2500 & 0.570 & 0.676 & 0.536 & 0.696 & 1. 150 \\
\hline 40 & $* * *$ & 0.040 & 1.2500 & 0.573 & 0.626 & 0.537 & 0.648 & 1.074 \\
\hline 50 & 2187.30 & 0.044 & 1.2430 & 0.593 & 0.599 & 0.551 & 0.608 & 1.000 \\
\hline
\end{tabular}




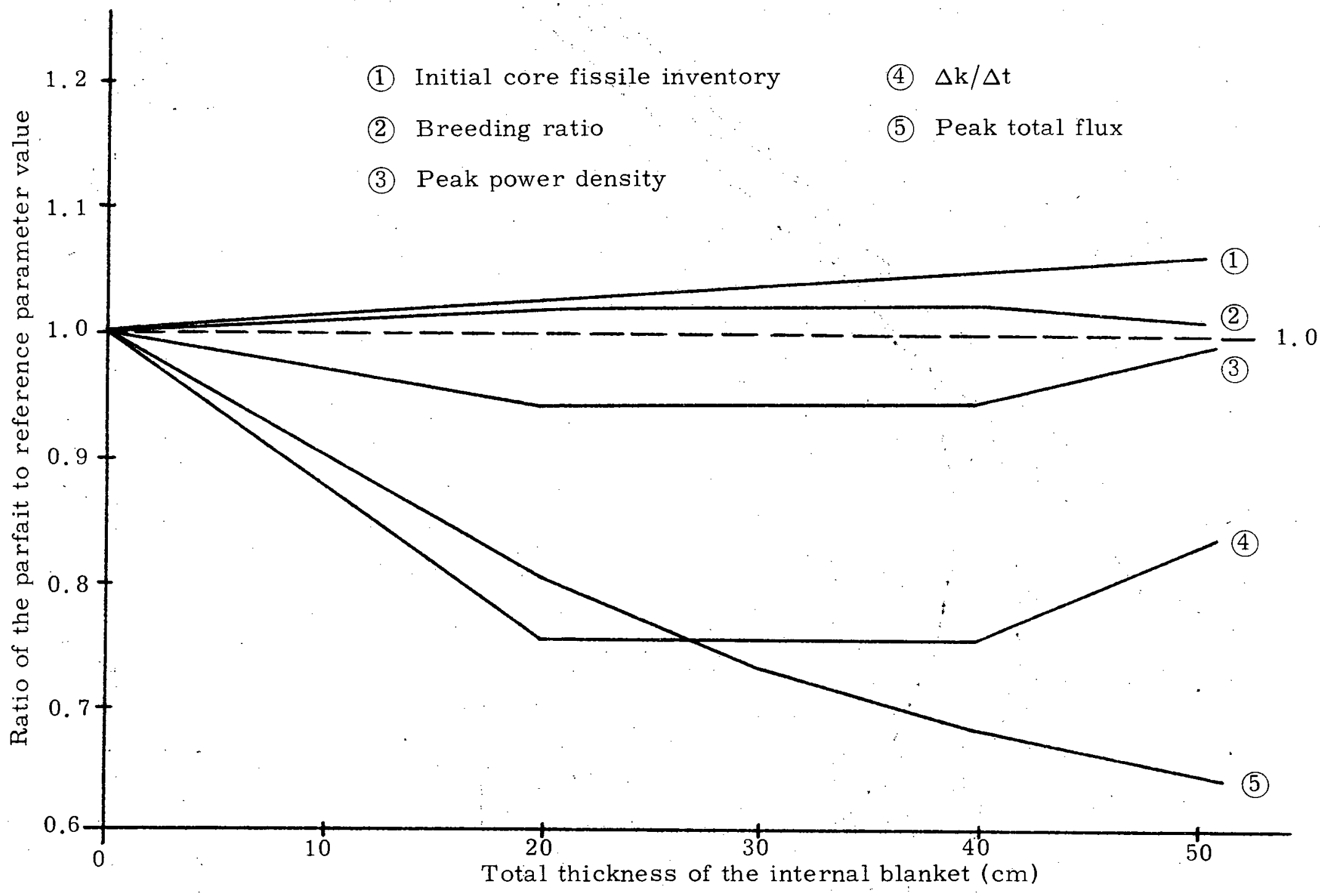

FIG. 6. 3. Parfait Performance Relative to the Reference Core as a Function of Internal Blanket Thickness 


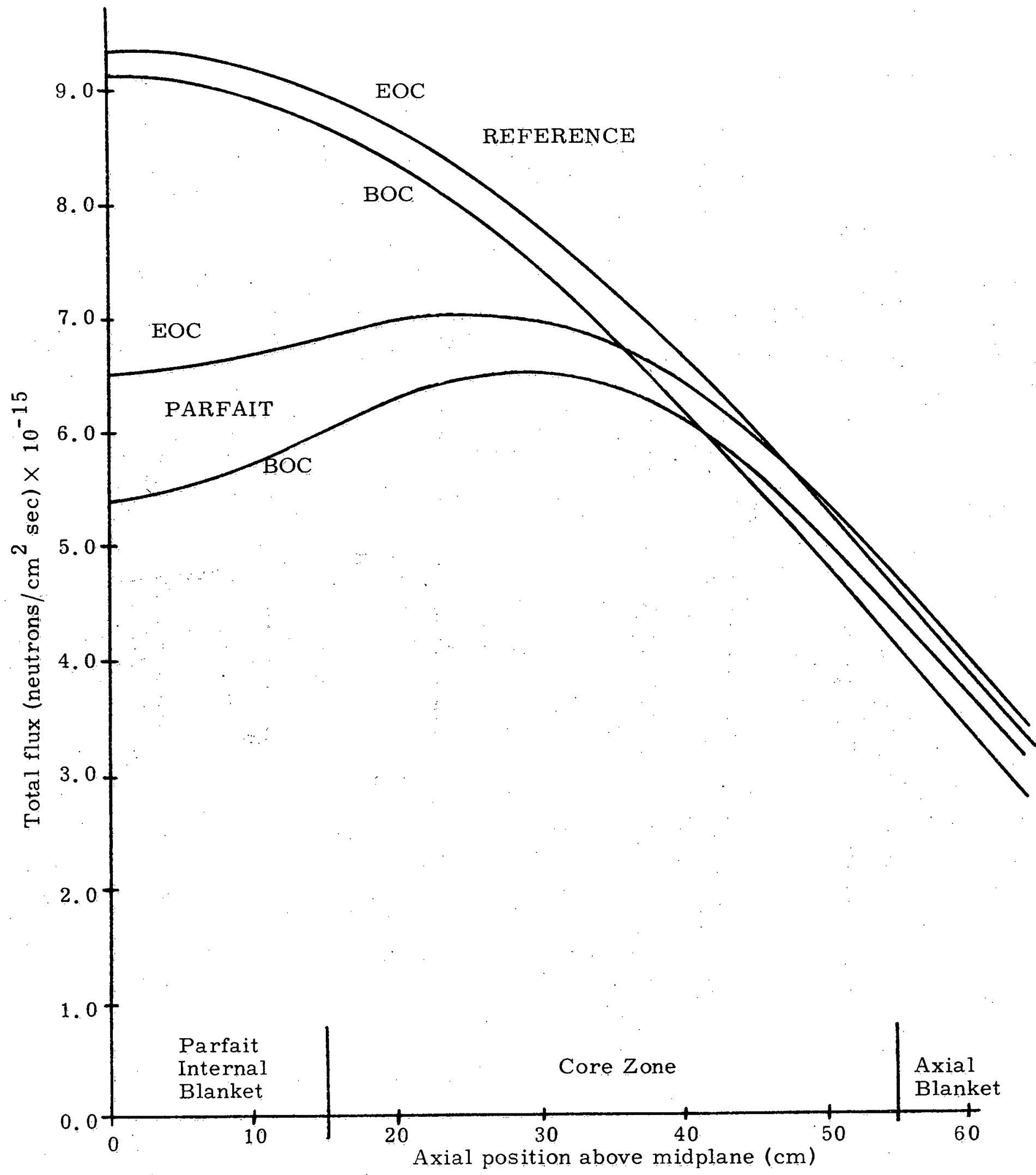

FIG. 6.4. Total Flux Along Core Centerline for Reference Core and $30-\mathrm{cm}$ IB Parfait 


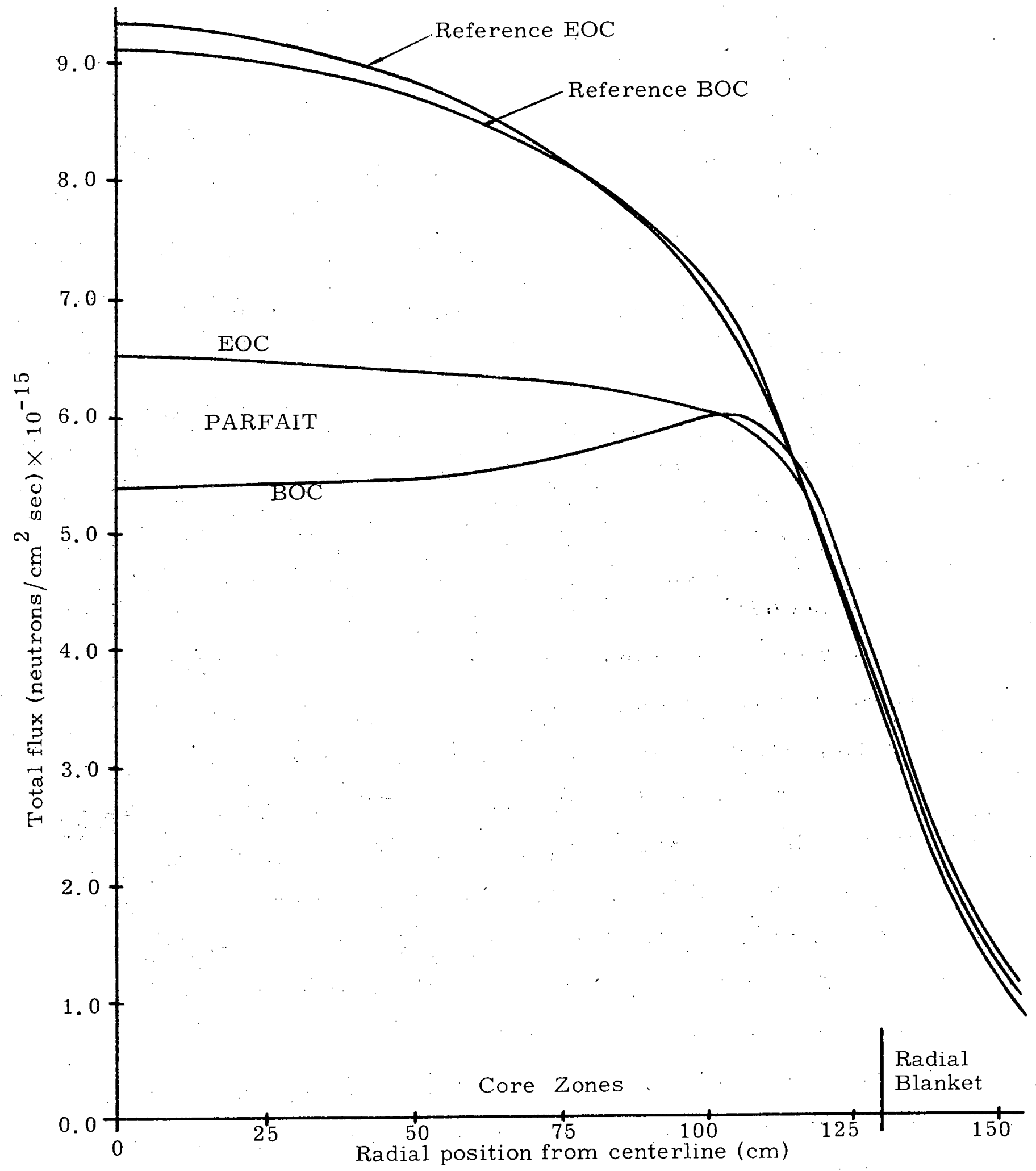

FIG. 6.5. Total Flux at Core Midplane for Reference Core and $30-\mathrm{cm}$ IB Parfait 
4) The burnup reactivity loss of the best parfait configuration is $25 \%$ smaller than that of the reference reactor. This characteristic is a consequence of the enhanced breeding of fissile material in the high-worth central region of the reactor.

5) The ratio of the fissile enrichment in the outer core zone to that of the inner core zone decreases as the internal blanket thickness is increased. As indicated in Table 6.3, the enrichment for the two core zones was equal for the $50-\mathrm{cm}$ internal blanket parfait configuration.

6) The peak flux in the core decreases substantially with an increase in the internal blanket thickness. For a $30-\mathrm{cm}$ internal blanket, the peak flux is reduced by $27 \%$. A commercial LMFBR of the parfait design could thus be introduced which would experience a substantially reduced peak fluence and therefore require less of an extrapolation with regard to fluence effects than for the reference design.

Figure 6.3 also demonstrates that the attractive performance characteristics of the parfait configuration exhibit broad maxima and minima, thus affording the reactor designer considerable flexibility in varying the internal blanket thickness to achieve a specific core characteristic without sacrificing overall system performance.

Characteristics and advantages similar to those described above were also confirmed for parfait configurations of a demonstration size LMFBR (2510 liter core volume), a gas-cooled 1000-MW reactor and a $1000-\mathrm{MW}_{\mathrm{e}}$ carbide-fueled LMFBR.

The fuel volume fraction in the core is a design parameter which was identified as having a significant impact upon the performance of both the reference and parfait designs. Figure 6.6 illustrates this effect for two major performance characteristics, the breeding ratio 


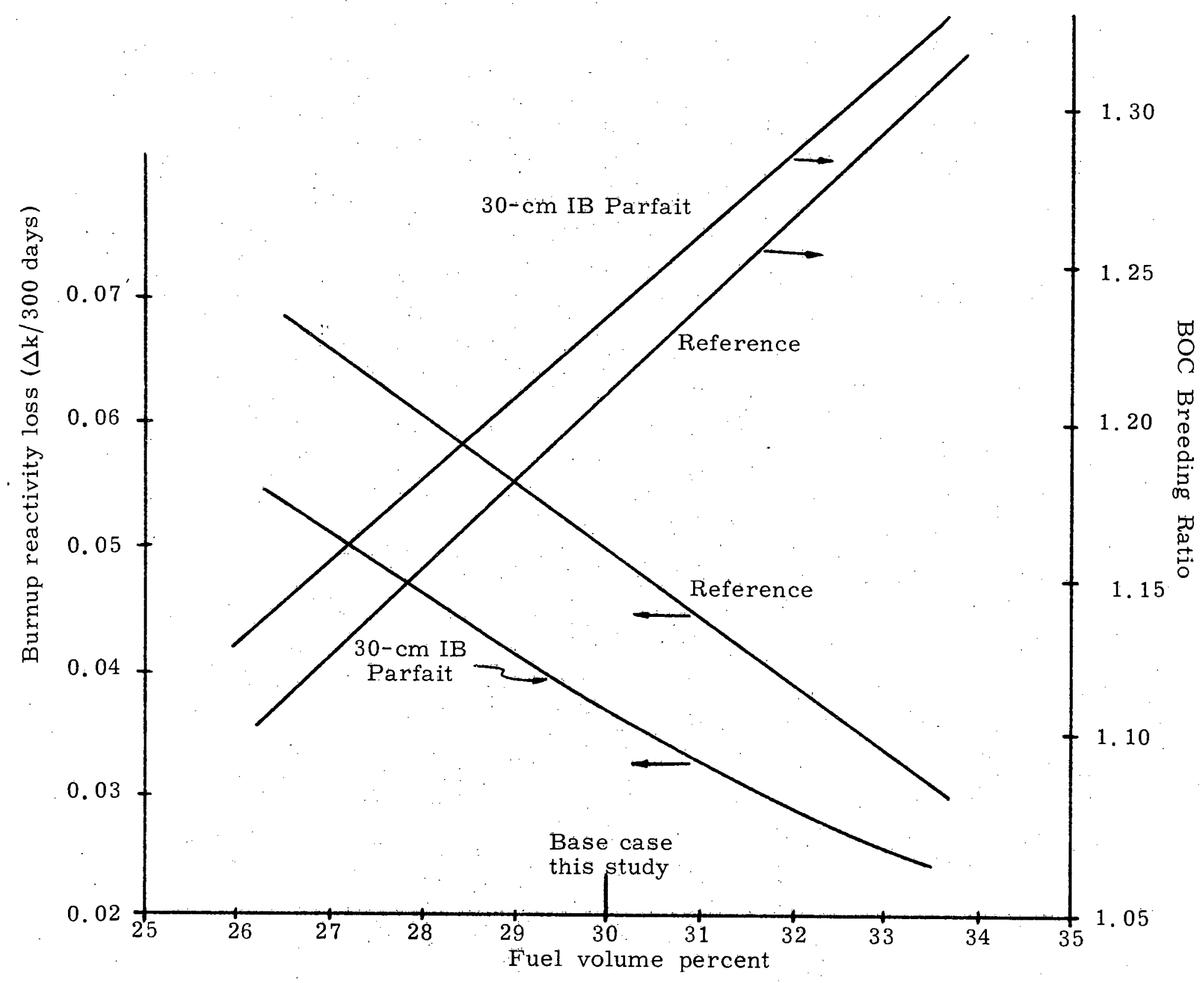

FIG. 6.6. Performance Sensitivity to Fuel Volume Percent in Core 
and the burnup reactivity loss. This comparison was made for cores of equal volume and equal reactivity-limited lifetimes. Figure 6.6 demonstrates that the performance of both configurations improves as the fuel volume fraction increases and that the advantage enjoyed by the parfait configuration in both of these parameters is slightly diminished at the higher fuel volume fractions. A key point, however, as will be illustrated in later sections, is that the parfait configuration is more suited to a higher fuel volume fraction because of reduced fuel and metal swelling and reduced control rod requirements.

A comparison of the control requirements for both the reference and parfait configurations demonstrated that including an internal blanket in a fast reactor core introduces no unique control problems. The average worth per unit mass of control poison in both configurations is nearly equal. The only major difference between the control systems of the two designs is that the parfait configuration, with its reduced burnup reactivity swing, would require fewer and/or lower worth burnup control rods than the reference reactor. This would allow more fuel assemblies to be included in the parfait configuration, resulting in a further decrease in the average linear power rating in the core and an increase in the core fuel volume fraction. Both changes enhance the performance of the parfait configuration relative to the reference core.

It was also shown in the evaluation of the control requirements for the parfait configuration that the interaction of the internal blanket and a control rod bank could cause a small axial flux tilt such that the local power density in the lower core volume could, at times during 
the burnup cycle, be as much as $4.5 \%$ higher than if the effect of the control rods had been neglected. In this calculation, the control rod bank was simulated as an annulus of control material. Since this distribution of control poison would spatially isolate the inner core zone more effectively than discrete control rods, it is believed that the magnitude of the power shift has been overestimated. In any event, the magnitude of the power shift could be reduced by employing. appropriate control rod withdrawal patterns.

\section{3. CORE ENGINEERING}

The reference and parfait configurations were compared in the areas of thermal performance, materials' performance and core mechanical design. The parfait configuration evaluated had an internal blanket thickness of 30 centimeters. This configuration, as illustrated in Fig. 6. 3, exhibited the most favorable performance characteristics. identified for the parfait concept, including a significantly reduced peak total flux.

The thermal analysis of the reference and parfait cores included a calculation of the mixed-mean core coolant outlet temperature. Fuel elements were treated as annular core and blanket regions and two different.fixed coolant orificing schemes were employed. In one scheme, coolant flow was supplied such that the maximum coolant outlet temperature from each channel during irradiation was $1050^{\circ} \mathrm{F}$. In the other scheme, one coolant flow rate was supplied to each of the fuel annuli in an enrichment zone based on the coolant requirements of the highest powered assembly within the zone. The maximum 
coolant outlet temperature during the irradiation cycle was again fixed at $1050^{\circ} \mathrm{F}$. The mixed-mean core coolant outlet temperatures calculated using both orificing schemes demonstrated that the reference and parfait configurations perform very similarly and that for a realistic orificing scheme, the mixed-mean core coolant outlet temperatures for the two systems would be nearly identical.

The axial temperature profiles in the coolant, clad and fuel were also determined in this analysis. The maximum fuel centerline temperature in the reference configuration was slightly greater than that in the parfait core because of the slightly higher power density in the reference configuration as illustrated in Fig. 6.3. The fuel centerline temperature in the parfait configuration exhibits step changes in the core at the interfaces between the fissile-loaded region and the internal blanket. These power discontinuities produce axial temperature gradients that are very similar to those at the core-external axial blanket interface, and are not expected to lead to any fuel performance limitations. The parfait configuration actually exhibits a slight advantage over the reference configuration in that the average clad and coolant temperatures are lower in the important region above the core midplane.

Throughout this evaluation, the reference and parfait configurations have been compared on the basis of equal thermal output. The two configurations, however, operate at different peak power densities and therefore with different margins between normal full power operation and the overpower condition for which the hottest pins achieve centerline melting. This characteristic of the parfait concept's 
capabilities relative to the reference system was assessed by comparing the fraction of the core volume of each configuration in which fuel centerline melting occurs as a function of the overpower ratio. This analysis assumed a coolant flow such that each fuel annulus operated with a maximum coolant outlet temperature of $1050^{\circ} \mathrm{F}$. The results revealed that the reference reactor first experiences fuel melting for a $15 \%$ overpower condition. Fuel melting does not occur in the parfait configuration until $22 \%$ overpower is reached. The parfait configuration therefore enjoys a $7 \%$ greater overpower operating margin than the reference reactor. Or conversely, for equal operating margins, the parfait configuration is capable of generating $7 \%$ more power than the reference system.

The primary factor contributing to the greater operating margin for the parfait configuration is its reduced peak power density. This characteristic is also one of the factors contributing to a $7.6 \%$ smaller peak burnup in the parfait configuration. Since burnup has been found to correlate with fuel swelling (B8), the parfait configuration also enjoys an added operating margin in this respect. Fuel swelling has been accommodated in fast reactor designs by reducing the asfabricated fuel density, and therefore the reduced fuel swelling in the parfait configuration may be viewed as a means of allowing a slight increase in the effective core fuel volume fraction. Alternatively, this characteristic could allow the parfait configuration the economic advantage of higher average fuel burnups.

The effects of metal swelling (20\% cold-worked, type 316 stainless steel) in the parfait configuration are also diminished because of the 
reduced fast flux $(\mathrm{E}>0.1 \mathrm{MeV})$ in the core. An estimate of the endof-cycle (EOC) wrapper tube dilation due to metal swelling as a function of axial and radial position is presented in Fig. 6.7. (This analysis neglected the effects of axial temperature variations along the wrapper tube which, if considered, would have the effect of moving the location of peak dilation slightly above the core midplane.) The peak wrapper tube dilation in the parfait configuration is $37 \%$ smaller than in the reference system. The parfait core may therefore be made more compact and have a higher fuel volume fraction.

Elongation of the wrapper tubes is another manifestation of metal swelling which is reduced in the parfait configuration because of the reduced fast flux. Figure 6.8 presents an estimate of the EOC wrapper tube elongation in the reference and parfait configurations. This figure clearly demonstrates the reduced peak elongation in the parfait core. In addition, this figure illustrates that the radial gradient in the wrapper tube elongation, the cause of fuel element bowing, is significantly reduced in the inner core zone of the parfait configuration. The analysis which produced these results neglected the effect of temperature differences between opposite faces of the wrapper tube. These temperature differences arise from radial power gradients in the core and including their effect would improve the relative advantage for the parfait configuration. 


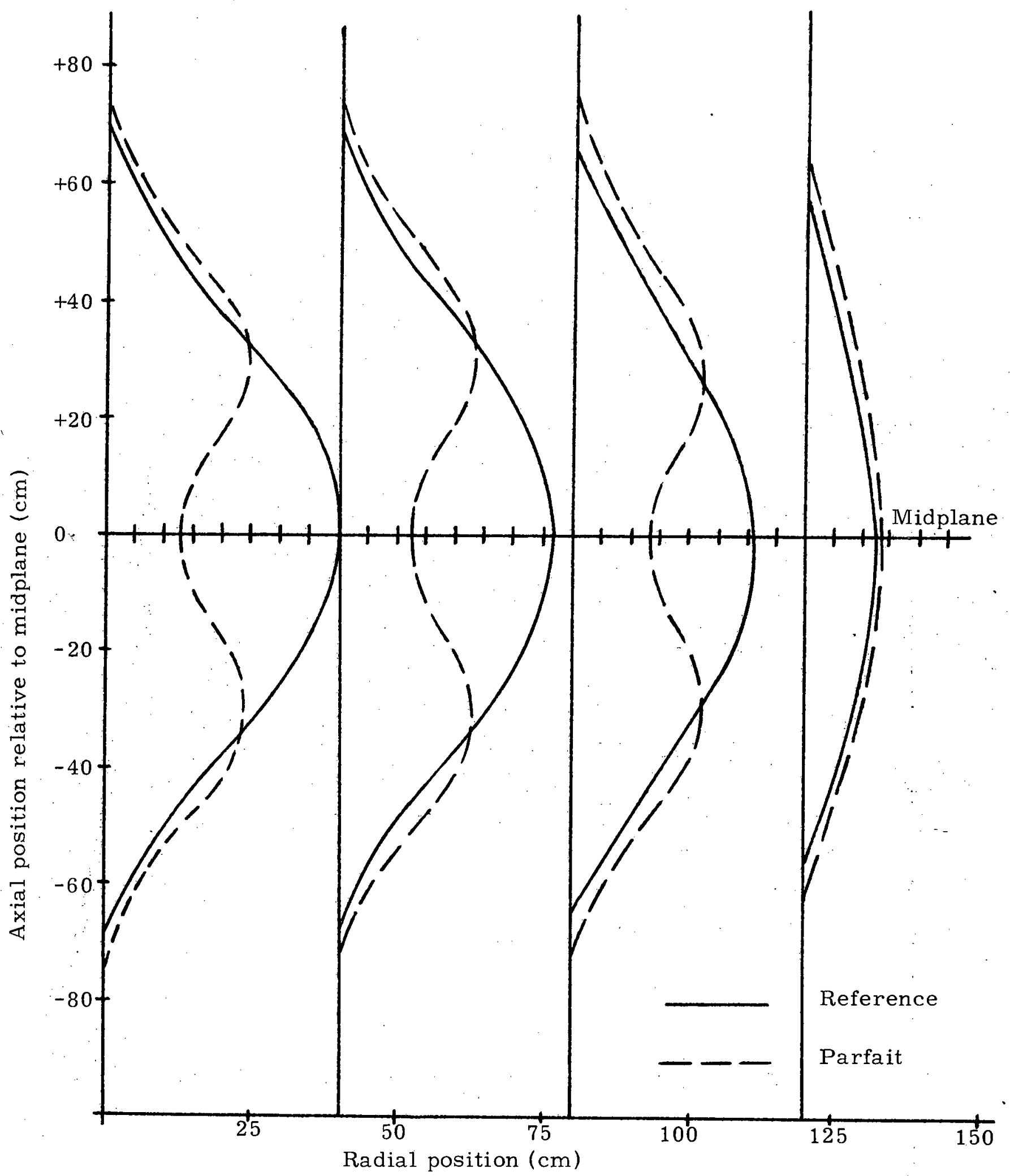

[Distance between vertical lines at midplane equal $0.05 \mathrm{~cm}$. Maximum dilation $=0.4 \mathrm{~cm}$.]

FIG. 6.7. EOC Wrapper Tube Dilation Due to Swelling 


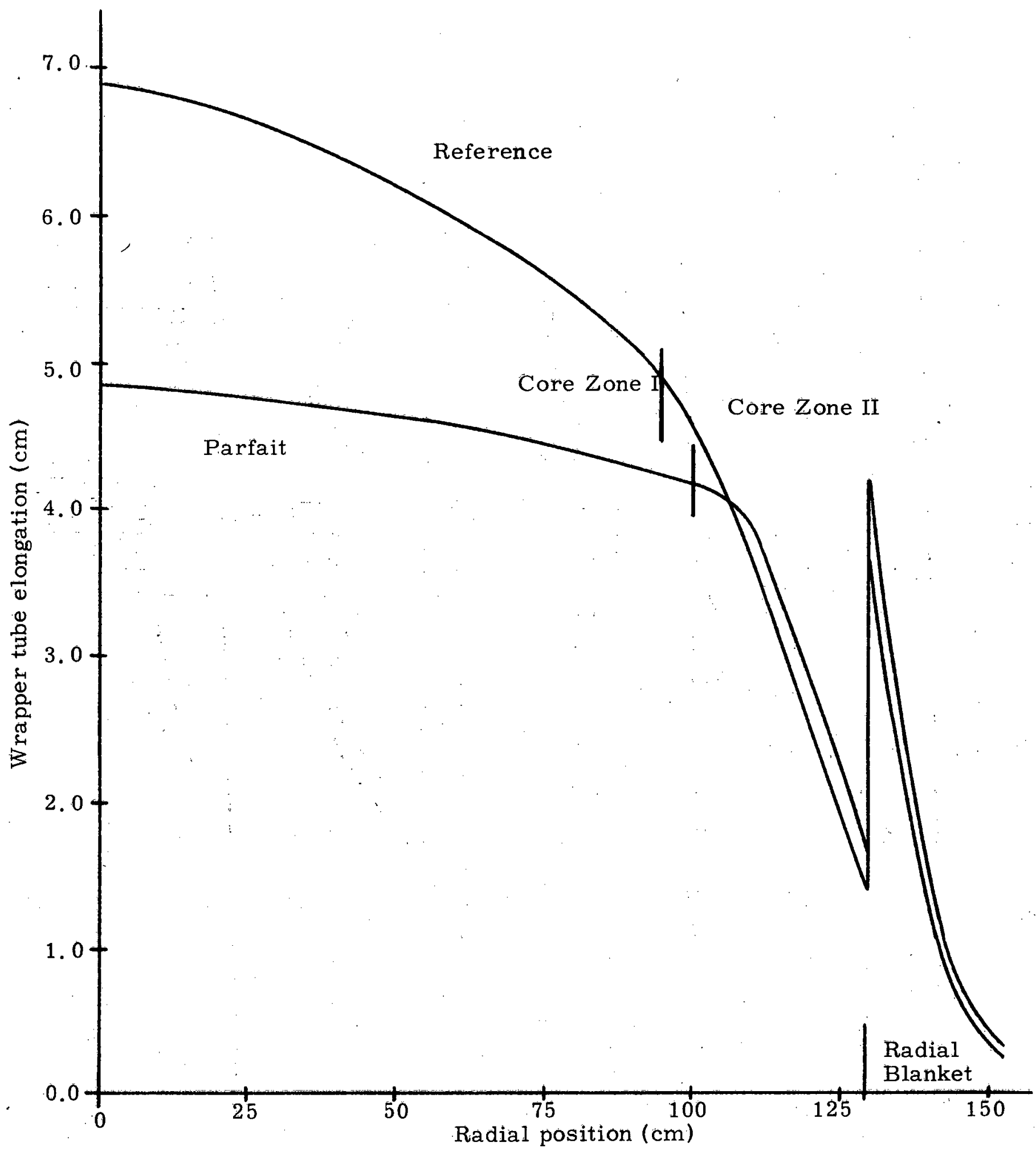

FIG. 6. 8. EOC Wrapper Tube Elongation Due to Swelling 


\subsection{SAFETY CONSIDERATIONS}

The response of the reference and parfait configurations to changes in core characteristics which are not encountered in normal full-power operation were calculated with particular emphasis given to those nuclear parameters which influence safety, including the delayed neutron fraction, the prompt neutron lifetime, the partial and complete coolant voiding coefficients, the isothermal Doppler coefficient and the power Doppler coefficient. In the analysis described here, as with all of the other calculations of this evaluation, it is the consistently calculated relative values of these parameters which are of most interest in assessing the potential of the parfait concept. This is particularly true of these safety-related parameters. For example, the calculational uncertainty on an absolute basis has been estimated to be $\pm 15 \%$ in the Doppler coefficient and $\pm 1.5 \$$ in the sodium void reactivity (G1): discrepancies which are sufficiently large to mask the small differences calculated here.

Table 6.4 summarizes the results of these calculations for the reference and parfait configurations.

The power Doppler coefficient, reflecting the reactivity effect of a change in the system power, is the primary mechanism for terminating a power excursion in fast reactors. The magnitude of this coefficient is $8 \%$ smaller in the parfait configuration; however, this apparently unfavorable characteristic is, in some sense, offset by a substantially reduced sodium void reactivity effect. Voiding of sodium from the internal blanket of the parfait configuration was found to contribute a smaller positive reactivity increment than 
TABLE 6.4

Comparison of Safety-Related Nuclear Parameters of the Reference and Parfait Configurations

\begin{tabular}{|c|c|c|c|}
\hline Parameter & Reference & Parfait & $\begin{array}{c}\text { Ratio } \\
\text { Parfait/Reference }\end{array}$ \\
\hline Delayed neutron fraction & 0.00416 & 0.00412 & 0.990 \\
\hline Prompt neutron lifetime (sec) & $2.98 \times 10^{-7}$ & $2.90 \times 10^{-7}$ & 0.973 \\
\hline $\begin{array}{l}\text { Inner core zone sodium void } \\
\text { reactivity effect }(\$)\end{array}$ & +1.82 & +1.22 & 0.670 \\
\hline $\begin{array}{l}\text { Isothermal Doppler coefficient, } \\
\qquad \frac{1}{\mathrm{k}} \frac{\Delta \mathrm{k}}{\Delta \mathrm{T}}\left({ }^{\circ} \mathrm{K}^{-1}\right) \\
\text { (Between } 300^{\circ} \mathrm{K} \text { and } 1000^{\circ} \mathrm{K} \text { ) }\end{array}$ & $-2.19 \times 10^{-5}$ & $-2.27 \times 10^{-5}$ & 1.036 \\
\hline $\begin{array}{l}\text { Power Doppler coefficient } \\
\text { (c/MWt) } \\
\text { (At ful1 power) }\end{array}$ & -0.039 & -0.036 & 0.923 \\
\hline
\end{tabular}


voiding a comparable region in the reference core. The complete and partial voiding of the core zones (and internal blanket) of each configuration was found to result in a positive reactivity insertion that was, on the average, about $25 \%$ smaller in the parfait configuration.

A calculation of the reactivity losses during reactor startup was performed by making use of the reactivity coefficients mentioned above. The calculation revealed that the reference and parfait configurations experience equal reactivity losses in going from cold startup to hotfull-power conditions.

\subsection{FEASIBILITY AND ECONOMICS}

In addition to allowing a ready comparison between the reference and parfait configurations, the constraints imposed in defining the scope of this evaluation guaranteed the technical feasibility of the parfait concept. The parfait concept uses the same core materials and the same basic fuel element design as the reference reactor. As related in the previous sections, there are no apparent obstacles to the operation of a fast reactor with an internal blanket. The same appears to be true for the preirradiation and postirradiation steps in the fuel cycle. A detailed evaluation of the fuel fabrication process was carried out based on reference (B4) which indicated that including an internal blanket region in one half of the fuel assemblies of a core would have a negligible effect on the core fabrication costs. It was also found that enrichment scanning techniques already exist (F2) which may be used to quality-assure the distribution of fissile material in individual fuel rods. The parfait configuration may also 
make use of all of the fuel management schemes applicable to the reference reactor including intra-zone fuel element shuffling and/or rotation. The flatter radial power profile in the inner core zone of the parfait configuration, however, lessens the need to employ such schemes. And finally, the current plans call for the reprocessing of axial blanket material and core material as a mixed batch (M1), and the refore the operation of a fast reactor with fuel containing an internal blanket introduces no unique fuel reprocessing problems.

The economic performance of the reference and parfait configurations were compared on the basis of equilibrium fuel cycle costs for several variations in financing charges, fabrication costs and fuel volume fractions. The fast reactor fuel cycle cost code, BRECON $(\mathrm{B} 2, \mathrm{~W} 1)$, was used in this analysis. This code employs the cash flow method for calculating fuel cycle costs; a unit energy cost (mills/kwhr $\mathrm{e}_{\mathrm{e}}$ ) is determined such that revenues from the sale of electricity generated in a cycle offset all net, direct and indirect fuel cycle expenses incurred in the cycle. Beginning and end-of-cycle fissile and fertile material inventories required in BRECON were generated in burnup calculations using the $2 \mathrm{DB}$ code. Core fuel elements were assumed to have a two-year (two-cycle) residence time in the core and radial blanket assemblies a four-year residence time, and all blanket regions were loaded with fissile concentrations characteristic of equilibrium operation. The fuel cycle costs by region and by item are presented in Table 6.5 for the base case $(30 \mathrm{v} / 0$ fuel in core) for the reference reactor and two parfait configurations. Total fuel cycle costs as a function of core fuel volume percent for these configurations are shown in Fig. 6.9. 
TABLE 6.5

Equilibrium Fuel Cycle Cost Contributions by Region

(Base Case: $30 \mathrm{v} / 0$ Fuel in Core)

\begin{tabular}{|c|c|c|c|}
\hline & \multicolumn{3}{|c|}{ Cost Contribution, mills/kwhr } \\
\hline & Reference & $\begin{array}{c}30-\mathrm{cm} \text { IB } \\
\text { Parfait }\end{array}$ & $\begin{array}{c}50-\mathrm{cm} \text { IB } \\
\text { Parfait }\end{array}$ \\
\hline \multicolumn{4}{|l|}{ Core } \\
\hline $\begin{array}{l}\text { Direct burnup } \\
\text { Inventory carrying charges } \\
\text { Direct fabrication } \\
\text { Fabrication carrying charges } \\
\text { Net reprocessing charges }\end{array}$ & $\begin{array}{l}0.1964 \\
0.6568 \\
0.3093 \\
0.0990 \\
0.0456 \\
\end{array}$ & $\begin{array}{l}0.3385 \\
0.6687 \\
0.2533 \\
0.0810 \\
0.0373 \\
\end{array}$ & $\begin{array}{l}0.4144 \\
0.6804 \\
0.2210 \\
0.0706 \\
0.0326 \\
\end{array}$ \\
\hline Subtotal & 1.3071 & 1. 3788 & 1.4190 \\
\hline Internal Blanket & & & \\
\hline $\begin{array}{l}\text { Net material credit } \\
\text { Net reprocessing charges } \\
\text { Direct fabrication } \\
\text { Fabrication carrying charges }\end{array}$ & $\begin{array}{l}- \\
- \\
-\end{array}$ & $\begin{array}{r}-0.1092 \\
0.0083 \\
0.0560 \\
0.0180 \\
\end{array}$ & $\begin{array}{r}-0.1556 \\
0.0130 \\
0.0883 \\
0.0284 \\
\end{array}$ \\
\hline Subtotal & & -0.0269 & -0.0259 \\
\hline \multicolumn{4}{|l|}{ Axial Blanket } \\
\hline $\begin{array}{l}\text { Net material credit } \\
\text { Net reprocessing charges } \\
\text { Direct fabrication } \\
\text { Fabrication carrying charges }\end{array}$ & $\begin{array}{r}-0.1873 \\
0.0356 \\
0.0616 \\
0.0196 \\
\end{array}$ & $\begin{array}{r}-0.2052 \\
0.0356 \\
0.0616 \\
0.0196 \\
\end{array}$ & $\begin{array}{r}-0.2113 \\
0.0356 \\
0.0616 \\
0.0196 \\
\end{array}$ \\
\hline Subtotal & -0.0705 & -0.0884 & -0.0945 \\
\hline \multicolumn{4}{|l|}{$\underline{\text { Radial Blanket }}$} \\
\hline $\begin{array}{l}\text { Net material credit } \\
\text { Net reprocessing charges } \\
\text { Direct fabrication } \\
\text { Fabrication carrying charges }\end{array}$ & $\begin{array}{r}-0.2120 \\
0.0349 \\
0.0520 \\
0.0333 \\
\end{array}$ & $\begin{array}{r}-0.2338 \\
0.0349 \\
0.0520 \\
0.0333 \\
\end{array}$ & $\begin{array}{r}-0.2420 \\
0.0349 \\
0.0520 \\
0.0333 \\
\end{array}$ \\
\hline Subtotal & -0.0918 & -0.1136 & -0.1218 \\
\hline Total Expenses & 1.5441 & 1.6981 & 1. 7857 \\
\hline Total Material Credits & -0.3993 & -0.5482 & -0.6089 \\
\hline TOTAL FUEL CYCLE COSTS & 1. 1448 & 1.1499 & 1. 1768 \\
\hline
\end{tabular}




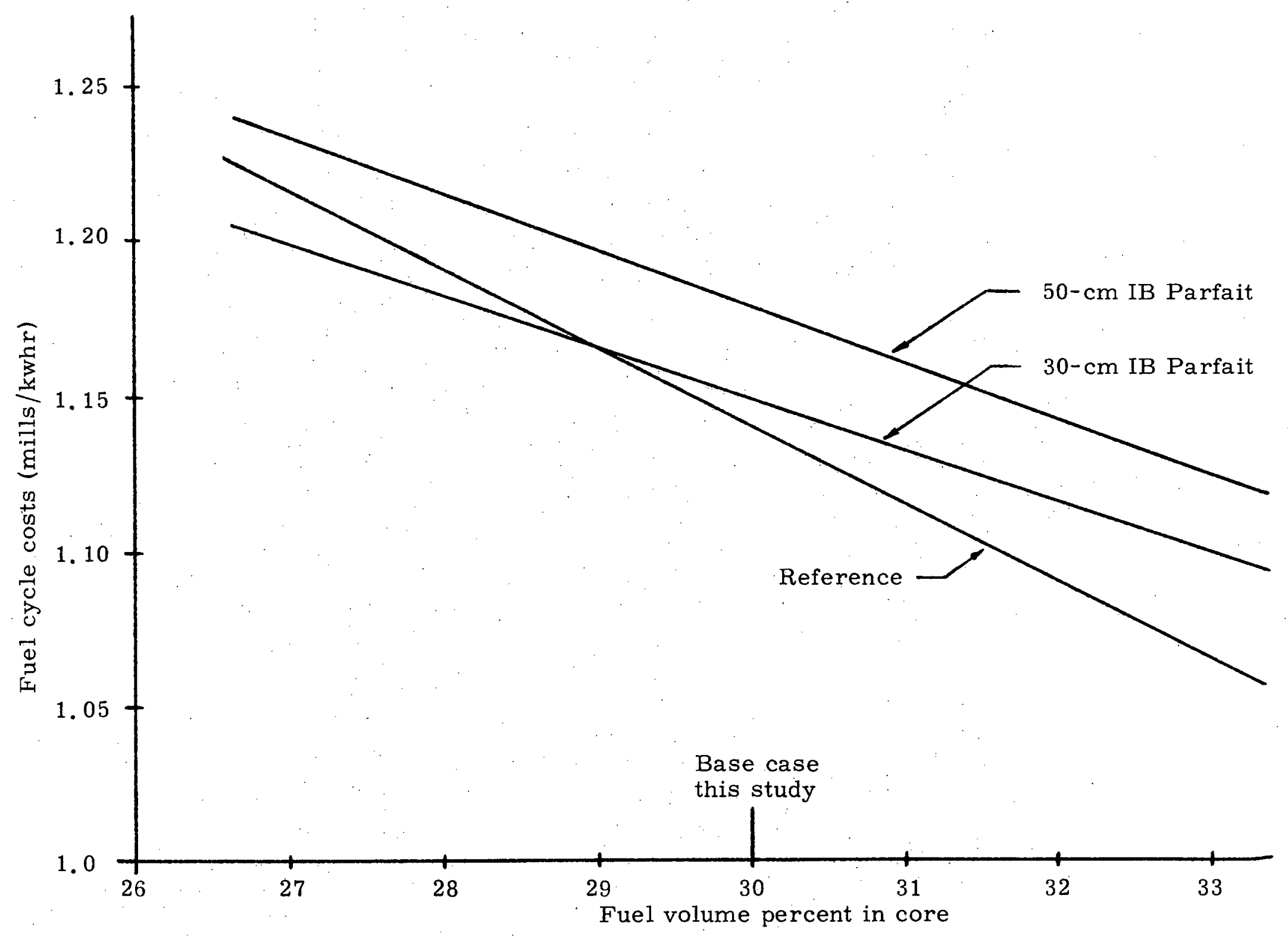

FIG. 6.9. Fuel Cycle Costs as a Function of Fuel Volume Percent (Fabrication Charges for All Cores Normalized to the Reference Core with $30 \mathrm{v} / \mathrm{o}$ Fuel in Core) 
These curves demonstrate that the reference reactor and the 30 $\mathrm{cm}$ internal blanket configuration have essentially equal fuel cycle costs for the base case. Throughout the range of fuel volume fractions investigated, the fuel cycle costs differ by at most $0.05 \mathrm{mills} / \mathrm{kwhr}$, or the equivalent of $\$ 360,000 / y r$. There are, however, several characteristics of the parfait configuration which will enhance its economic performance relative to the reference reactor. The analysis which produced the above results assumed equal unit fabrication costs $(\$ 314 / \mathrm{kgHM})$ for the core regions and the internal blanket. If, on the other hand, fabrication costs for the internal blanket are equal to those estimated for the axial blanket, $\$ 80 / \mathrm{kgHM}$, the curve for the $30-\mathrm{cm}$ IB parfait configuration in Fig. 6.9 is displaced downward by $0.055 \mathrm{mills} / \mathrm{kwhr}$ and the curve for the $50-\mathrm{cm}$ IB parfait configuration is displaced downward by 0.075 mills $/ \mathrm{kwhr}_{\mathrm{e}}$. In addition, the capability of employing higher core fuel volume fractions in the parfait designs as the result of reduced fuel swelling, reduced metal swelling and reduced control rod requirements would further enhance the economic performance of the parfait concepts.

\subsection{CONCLUSIONS AND RECOMMENDATIONS}

The design and performance characteristics of the parfait blanket concept are summarized in Table 6:6. The advantageous characteristics of the parfait blanket concept may be exploited in a variety of ways. For example, the decreased peak power density relative to the reference reactor may be viewed as a means of providing an extra overpower operating margin, a means of obtaining a higher thermal 
TABLE 6.6

Summary Evaluation of the $30-\mathrm{cm}$ IB

Parfait Blanket Configuration Relative

to the Reference Reactor

\section{Advantages}

Increased breeding ratio $(2 \%)$

Decreased doubling time $(10 \%)$

Decreased peak fast flux (25.5\%)

Decreased wrapper tube elongation (29\%)

Decreased wrapper tube dilation (37.5\%)

Decreased burnup reactivity swing (25\%)

Fewer control rods in core

More fuel assemblies in core

Reduced losses of neutrons to control poisons

Decreased peak power density ( $5 \%$ )

Decreased peak fuel burnup (7.6\%)

Decreased fuel swelling

Increased overpower operating margin

Flatter radial flux and power profiles in the inner core zone

Decreased thermal bowing

Decreased fluence-induced bowing

More favorable sodium void characteristics.

Potential for higher core fuel volume fraction

\section{Disadvantages}

Increased core fissile inventory (3.9\%)

Reduced power Doppler coefficient ( $8 \%$ )

Higher peak clad temperature $\left(17^{\circ} \mathrm{F}\right)$ 
power output or a means of reducing the fissile-loaded core volume. Such changes, however, affect the design of the entire reactor. In the present work, the evaluation of the parfait system was carried out under a strict set of conditions which, in effect, assured that the parfait design could be employed as a replacement core in a system designed to accommodate a conventional core. Although indicating that the parfait concept is a superior replacement, the present results do not fully exploit the advantages of the concept. Therefore, the principal recommendation of this report is that the parfait blanket concept be subjected to a complete core design in which the arbitrary constraints on parameters such as the dimensions of the core and external blankets are removed. Particular attention should be given to full exploitation of the reduced fuel and metal swelling potential of the parfait concept. In addition to this major effort, a number of minor refinements should be incorporated: the effect of gamma heating in the internal blanket should be included, and the radiation dose to core externals should be evaluated. The parfait concept should also be examined to determine its susceptibility to and behavior during hypo- -.... thetical core dis ruptive accidents relative to conventional core designs:

In conclusion, the parfait blanket concept offers sufficient prospects for improved fast breeder reactor performance and reduced power costs to merit its consideration as the reference design for future liquid-metal cooled fast breeder reactors. 
Appendix A

\section{CROSS SECTIONS AND CODES}

\section{A. 1. CROSS SECTION SETS AND GROUP COLLAPSES}

\section{A.1.1. Cross Section Collapse to Four Groups}

The twenty-six group, constant lethargy width cross section set obtained in May of 1970 by Brewer (B2) from the Battelle Northwest Laboratory was collapsed to the four energy group structure given in Chapter 2 using the one-dimensional transport code ANISN (E4). The collapsing procedure uses linear flux weighting over region-dependent flux spectra.

A $1000-M \mathrm{e}^{- \text {size }}$ LMFBR was mocked up in one dimension as four concentric material regions: an inner core zone, an outer core zone, a radial blanket and a reflector. The cross sections of the reactor materials were collapsed over the flux spectra characteristic of each of the four reactor regions. Figure. A. 1 shows the relative group fluxes in each of the 26-energy groups for the core regions of the reactor and Fig. A. 2 gives the four-group representation of the core region spectra.

\section{A. 1.2. FTR-200 Cross Section Set}

An alternate cross section set designated FTR Set \#200 (N1), presently being used in FFTF design calculation, was obtained and used to perform a limited number of calculations for comparison with the cross section set described above. This set is essentially the 


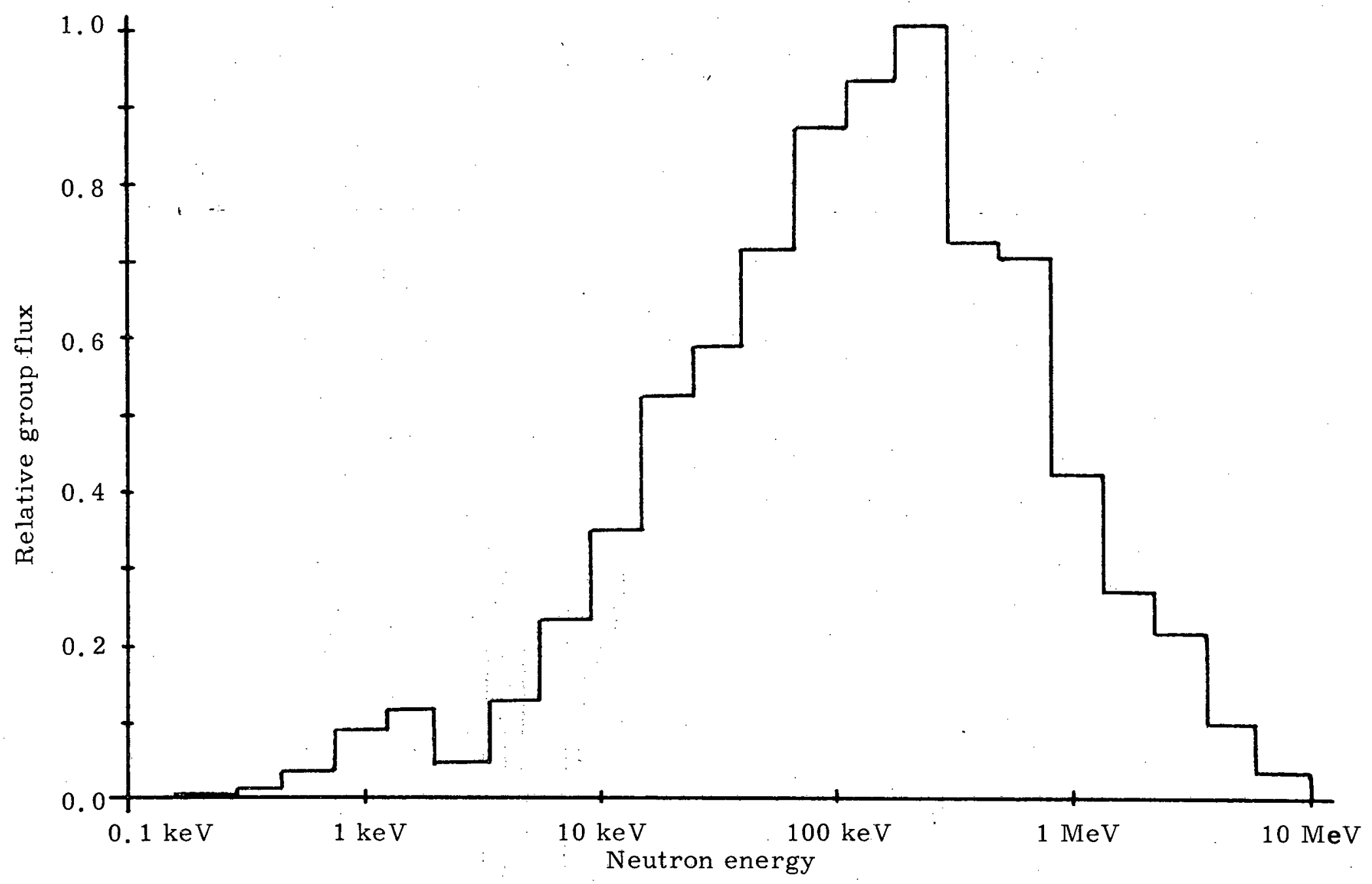

FIG. A. 1: 26-Group Neutron Spectrum in Core 


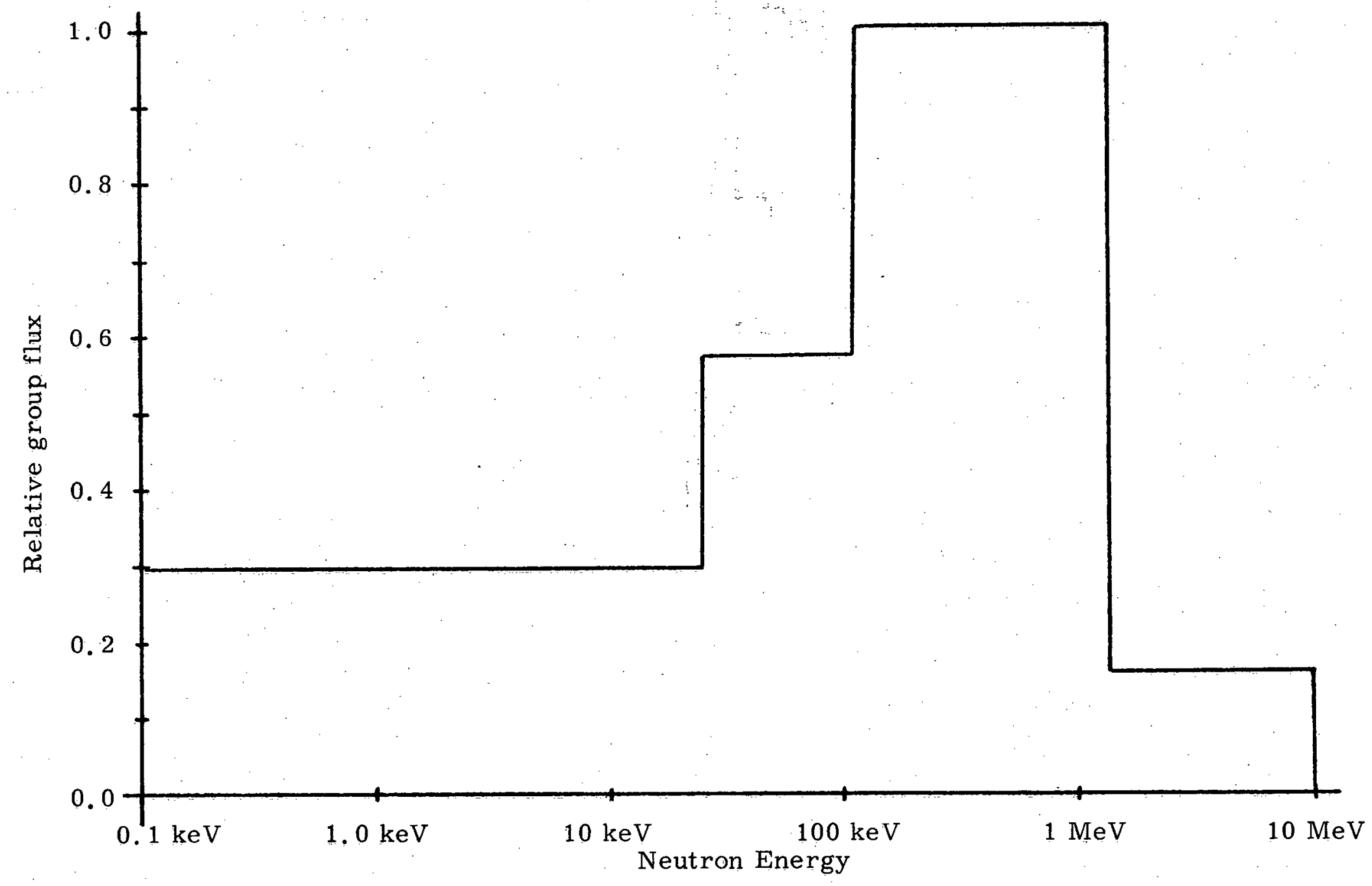

FIG. A.2. Four-Group Neutron Spectrum in Core 
same as the 26-group Bondarenko set (B3), except for some modifications in the primary heavy metal isotopes. This set was collapsed to the four-group structure shown in Table A. 1, also by means of the ANISN transport theory code.

TABLE A. 1

FTR Set \#200 Energy Group Structure

\begin{tabular}{ccc}
\hline Group & Upper Energy Limit & Emission Spectrum \\
\hline 1 & $10.5 \mathrm{MeV}$ & 0.771 \\
2 & $0.8 \mathrm{MeV}$ & 0.226 \\
3 & $46.5 \mathrm{keV}$ & 0.004 \\
4 & $1.0 \mathrm{keV}$ & 0.0 \\
\hline
\end{tabular}

\section{A. 2. METHODS SUPPORT AND VERIFICATION}

\section{A. 2.1. Transport Theory vs. Diffusion Theory - Four-Group Flux Predictions}

In order to verify that the flux predictions using diffusion theory would be comparable to those predicted using transport theory, two cases, each employing four neutron energy groups, were compared. The group fluxes predicted by the diffusion theory code, 2DB, and those of the transport theory code, ANISN, using an $\mathrm{S}_{8}$ approximation are plotted in Figs. A. 3 and A.4. The 2DB calculations were performed for the parfait configuration defined in Section 1.4, having a $30-\mathrm{cm}$ internal blanket. In the one-dimensional ANISN code, this configuration was approximated as a slab reactor having the same axial dimensions and the same material compositions. The results of these calculations demonstrate a very close agreement in each of 


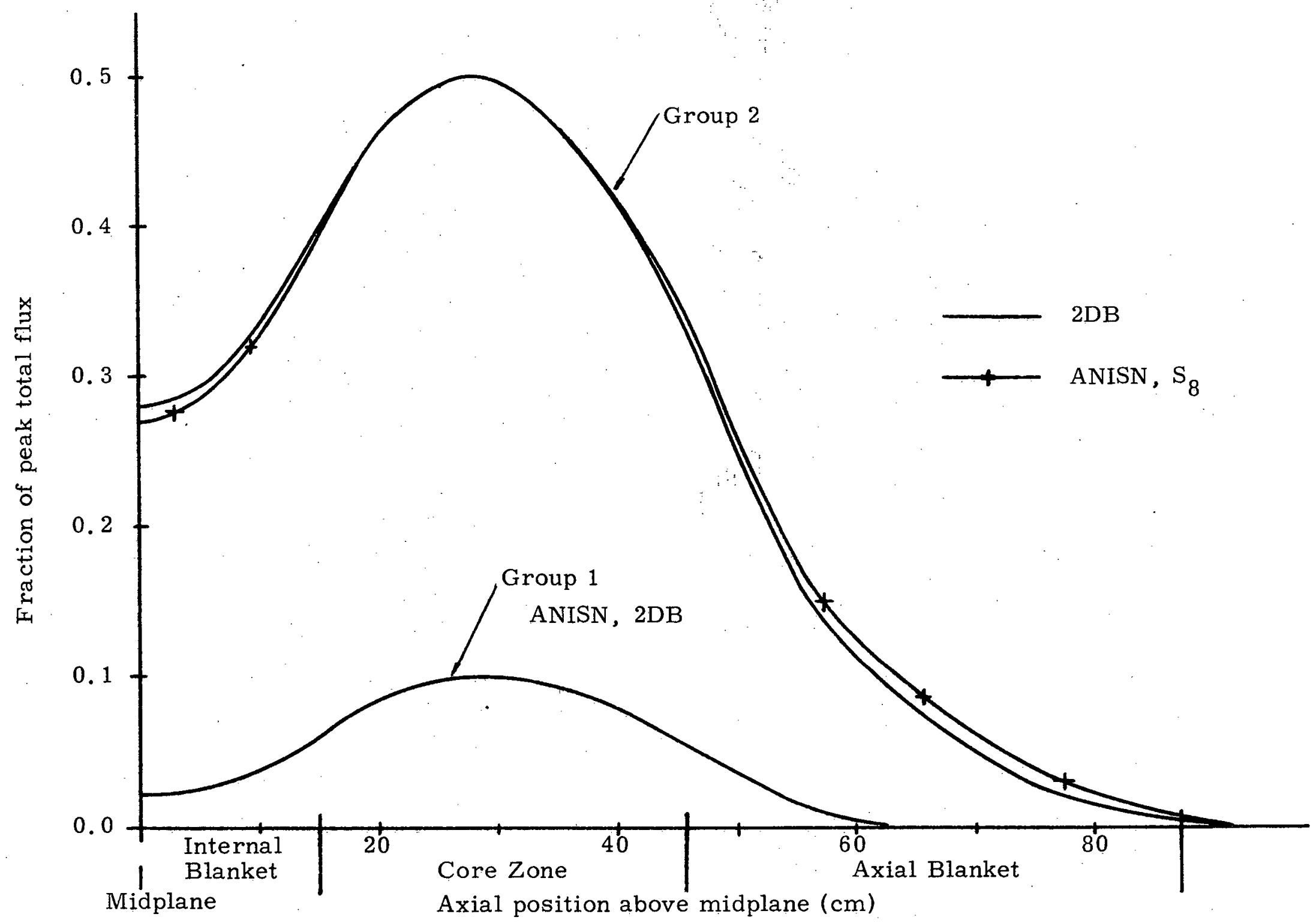

FIG. A. 3. Transport Theory vs. Diffusion Theory, Group Fluxes 1 and 2 


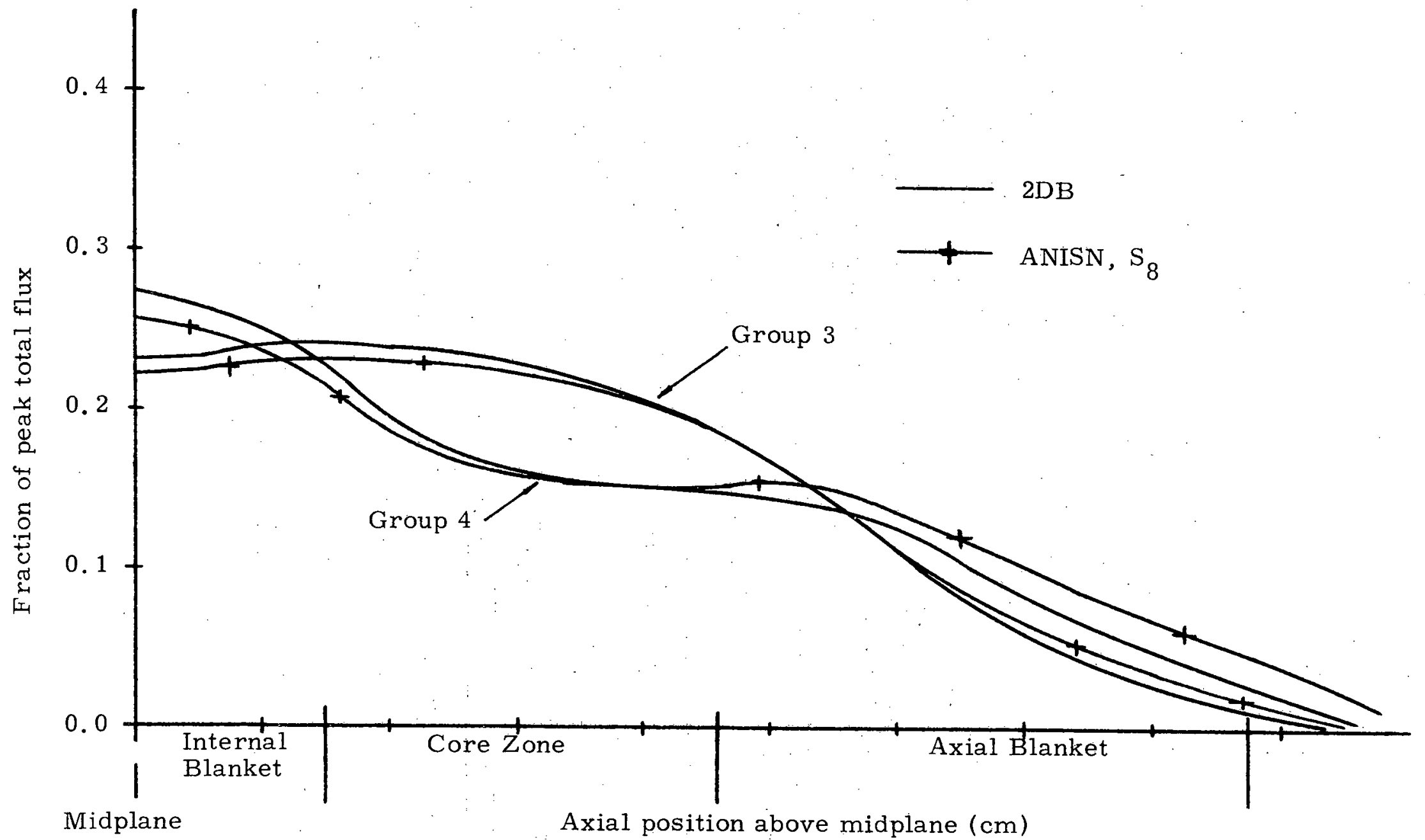

FIG. A.4. Transport Theory vs. Diffusion Theory, Group Fluxes 3 and 4 
the group fluxes, particularly in the important fissile-loaded regions of the core. In the blanket regions, the group fluxes each compare to within about $2 \%$. In the internal blanket region, the diffusion theory predictions were consistently higher than transport theory predictions.

\section{A. 2. 2. Comparison with Critical Experiments}

Loading number 21 of ZPPR Assembly 2 (K1) was simulated using the $2 \mathrm{DB}$ code and the two four-group cross section sets described in Section A.1. The idealized geometry of the experiment is shown in Fig. A. 5 and the region-average material compositions are shown in Table A.2. The results of these calculations are tabulated in two different ways in Table A.3. First, the $\mathrm{k}_{\text {eff }}$ predictions are listed for calculations which used the material number densities of the actual experiment and second, the fissile concentrations were adjusted to achieve a critical configuration.

Both calculations underestimated the required fissile inventory to achieve criticality, which is characteristic of calculations which homogenize the material compositions within regions as does $2 \mathrm{DB}$. The percentage error in predicting the critical inventory for both calculations is within the typical $2 \%$ to $8 \%$ underpredictions attributed to the effects of critical assembly heterogeneity (D1) which were not accounted for in the present calculations. 


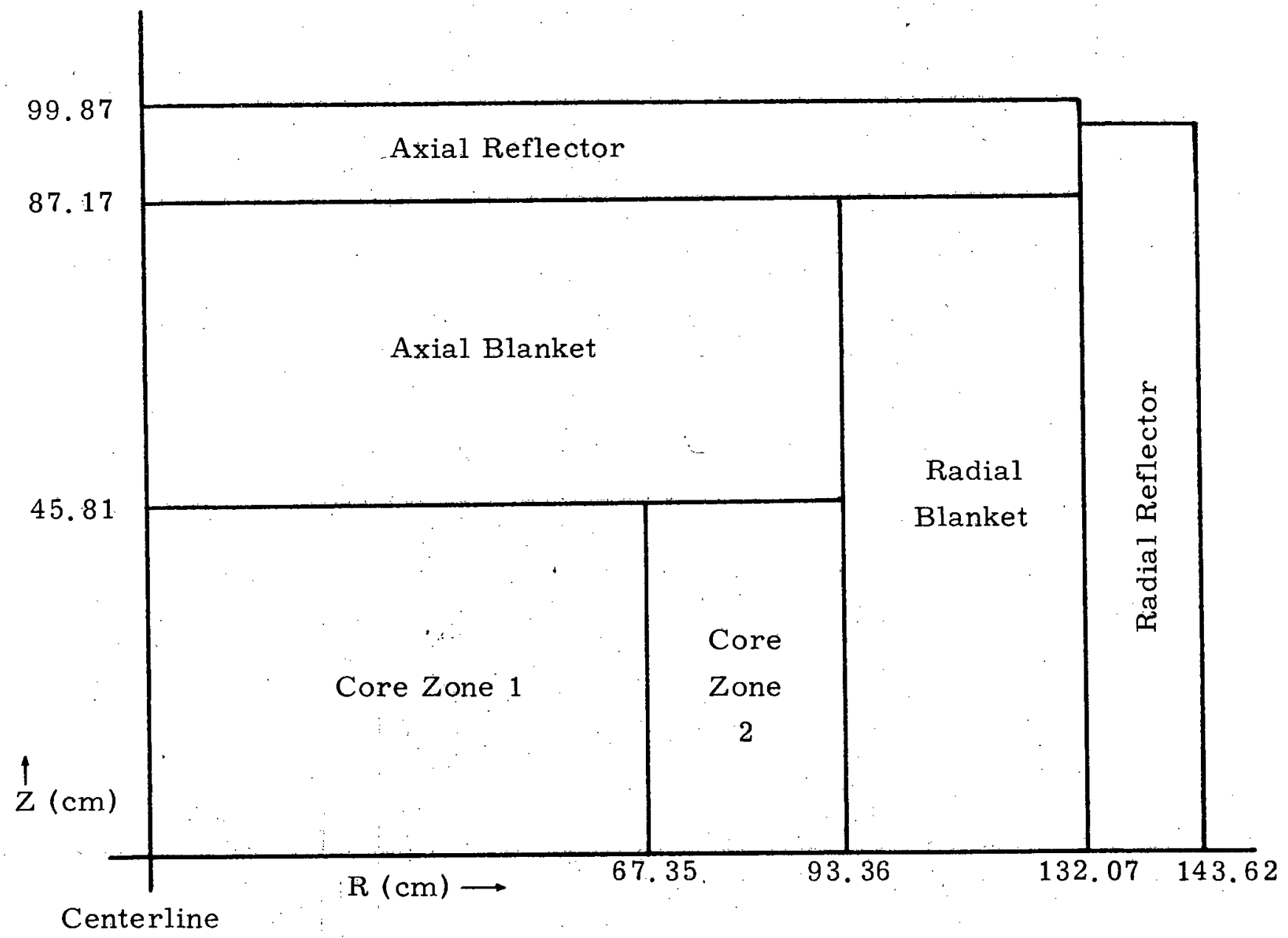

FIG. A. 5. ZPPR-2 Critical Experiment Idealized Geometry 
TABLE A.2. ZPPR Assembly 2 (Loading No. 21) Region-Averaged Compositions

\begin{tabular}{|c|c|c|c|c|c|c|}
\hline \multirow[b]{2}{*}{ Material } & \multicolumn{6}{|c|}{ Region-Averaged Compositions, atoms $/ \mathrm{cm}^{3} \times 10^{-24}$} \\
\hline & $\begin{array}{l}\text { Inner } \\
\text { Core } \\
\text { Zone } \\
\end{array}$ & $\begin{array}{l}\text { Outer } \\
\text { Core } \\
\text { Zone } \\
\end{array}$ & $\begin{array}{l}\text { Radial } \\
\text { Blanket }\end{array}$ & $\begin{array}{l}\text { Radial } \\
\text { Reflector }\end{array}$ & $\begin{array}{c}\text { Axial } \\
\text { Blankets } \\
\end{array}$ & $\begin{array}{c}\text { Steel } \\
\text { Axial } \\
\text { Reflector } \\
\end{array}$ \\
\hline $\mathrm{Pu}-239$ & 0.0008433 & 0.0012762 & -- & $-\div$ & -- & -- \\
\hline $\mathrm{Pu}-240$ & 0.0001117 & 0.0001690 & -- & -- & -- & -- \\
\hline$P u-241$ & 0.0000159 & 0.0000239 & -- & -- & -- & -- \\
\hline $\mathrm{Pu}-242$ & 0.0000018 & 0.0000028 & -- & -- & -- & -- \\
\hline $\mathrm{U}-235$ & 0.0000123 & 0.0000115 & 0.0000245 & -- & 0.0000156 & -- \\
\hline $\mathrm{U}-238$ & 0.0055503 & 0.0051974 & 0.0110854 & -- & 0.0070416 & -- \\
\hline $\mathrm{Na}$ & 0.0081100 & 0.0093938 & 0.0063640 & - & 0.0087224 & -- \\
\hline $\mathrm{O}$ & 0.0131059 & 0.0117749 & 0.0201326 & -- & 0.0139466 & -- \\
\hline $\mathrm{Fe}$ & 0.0120738 & 0.0143994 & 0.0069750 & 0.0715610 & 0.0094411 & 0.0723132 \\
\hline $\mathrm{Cr}$ & 0.0025591 & 0.0026796 & 0.0020066 & 0.0012051 & 0.0024489 & 0.0015396 \\
\hline $\mathrm{Ni}$ & 0.0011771 & 0.0012381 & 0.0009053 & 0.0005133 & 0.0011103 & 0.0006627 \\
\hline Mn & 0.0002042 & 0.0002132 & 0.0001605 & 0.0005981 & 0.0002077 & 0.0006196 \\
\hline Mo & 0.0002312 & 0.0003419 & 0.0000143 & 0.0000118 & 0.0000144 & 0.0000129 \\
\hline $\mathrm{C}$ & 0.0000235 & 0.0000233 & 0.0010130 & 0.0005575 & 0.0000297 & 0.0005587 \\
\hline $\mathrm{Al}$ & 0.0000042 & 0.0000049 & 0.0000021 & -- & 0.0000025 & -- \\
\hline
\end{tabular}


TABLE A. 3

Comparison with Critical Experiment

\begin{tabular}{|c|c|c|c|c|c|c|}
\hline & $\begin{array}{c}\text { Cross } \\
\text { Section } \\
\text { Set }\end{array}$ & $\underset{\text { Prediction }}{\mathrm{k}_{\text {eff }}}$ & $\begin{array}{l}\text { Fissile } \\
\text { Inventory } \\
\quad(\mathrm{kg})\end{array}$ & $\begin{array}{c}\text { Corrected } \\
\mathrm{k}_{\mathrm{eff}}^{\text {(b) }}\end{array}$ & $\begin{array}{c}\text { Corrected } \\
\text { Fissile } \\
\text { Inventory } \\
(\mathrm{kg})\end{array}$ & $\begin{array}{l}\% \text { Error } \\
\text { in Fissile } \\
\text { Inventory } \\
\text { Prediction }\end{array}$ \\
\hline $\begin{array}{l}\text { Experiment } \\
(\mathrm{ZPPR}-2)\end{array}$ & -- & 1.0 & 2134.6 & 1.0 & 2134.6 & -- \\
\hline Calculation & A. 1.1 & 0.973 & 2132.6 & 1.0 & 2239.8 & $4.8 \%$ \\
\hline Calculation & A. 1.2 & 0.991 & 2132.6 & 1.0 & 2168.4 & $1.65 \%$ \\
\hline
\end{tabular}

(a) Calculation using the material concentrations of the actual critical experiment.

(b) Fissile concentrations adjusted to achieve a critical configuration. 


\section{A. 2.3. One-, Two- and Four-Group Burnup Comparisons}

Although the use of four neutron energy groups has been demonstrated to be sufficiently accurate for calculations of power distributions and fuel cycle cost parameters (H3), the possibility of employing fewer energy groups was investigated. The burnup behavior of a given reactor system using cross sections collapsed from 26 groups down to one, two and four groups using the ANISN code as shown in Figs. A. 6 and A. 7. Although the burnup reactivity loss $(\Delta k / \Delta t)$ for each of the cases was found to be similar, the absolute predictions of $\mathrm{k}_{\mathrm{eff}}$ and the breeding ratio were found to vary over a significant range. Based on the favorable results obtained using the four-group set to calculate the results of the critical experiment (A.2.2), it was concluded that four groups would be the minimum required to perform acceptable neutronic calculations.

\section{A. 2.4. Comparison of Twenty-Six Group and Four-Group Predictions}

Although the bulk of the neutronic calculations were performed using four neutron energy groups, one set of burnup calculations for a reference and a parfait configuration were performed using the original 26-group cross section set to discover any bias which may have been introduced into the evaluation of the parfait configuration by the cross section collapse described in Section A.1.1. A comparison between the results of the four-group and 26-group calculations revealed that each predicted the same peak power density to within less than $0.7 \%$ and the same burnup reactivity loss within the convergence limits on $\mathrm{k}_{\text {eff }}$ in the code for both the reference and parfait cores. 


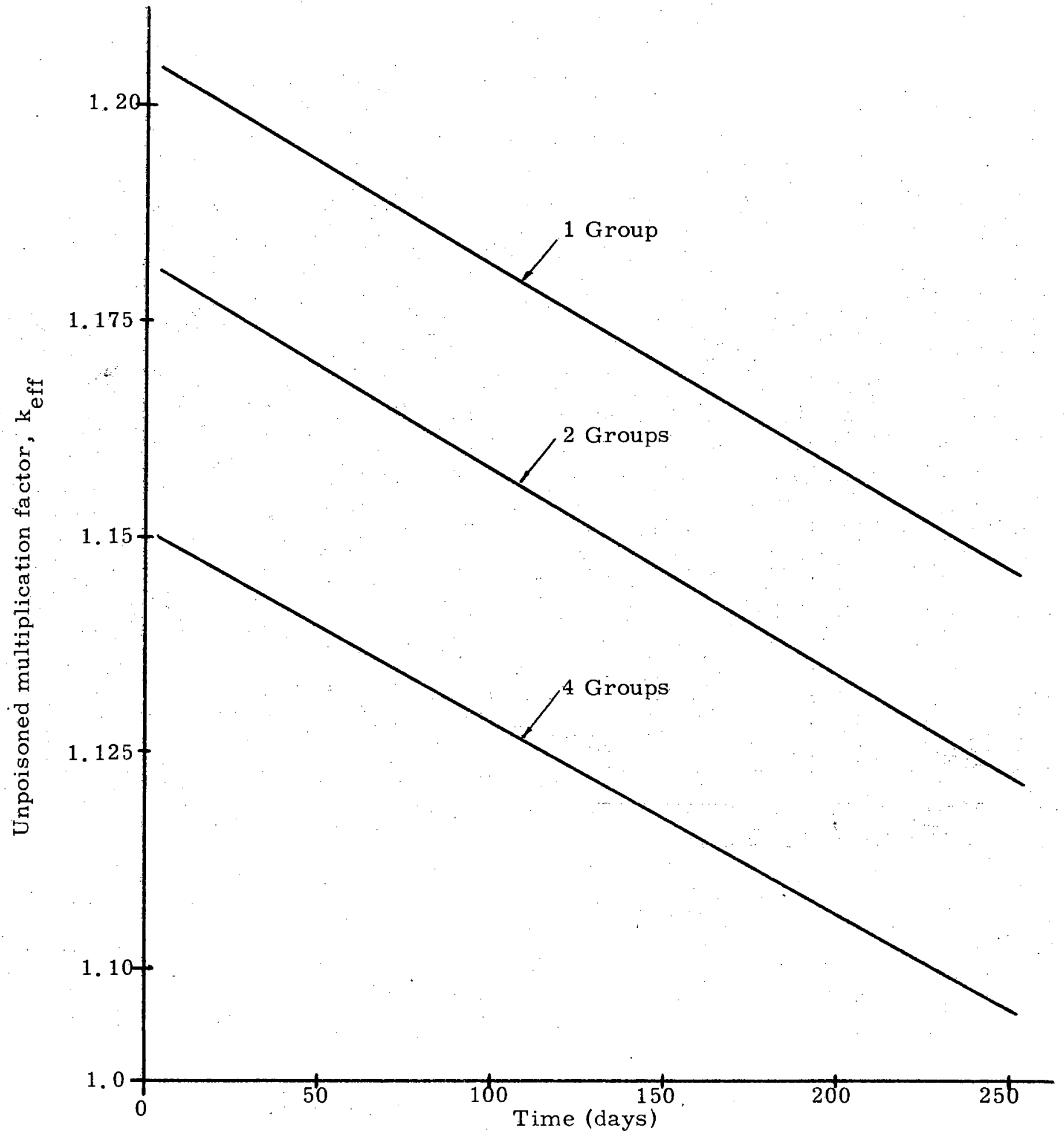

FIG. A.6. One-, Two- and Four-Group Burnup Behavior, keff vs. Time 


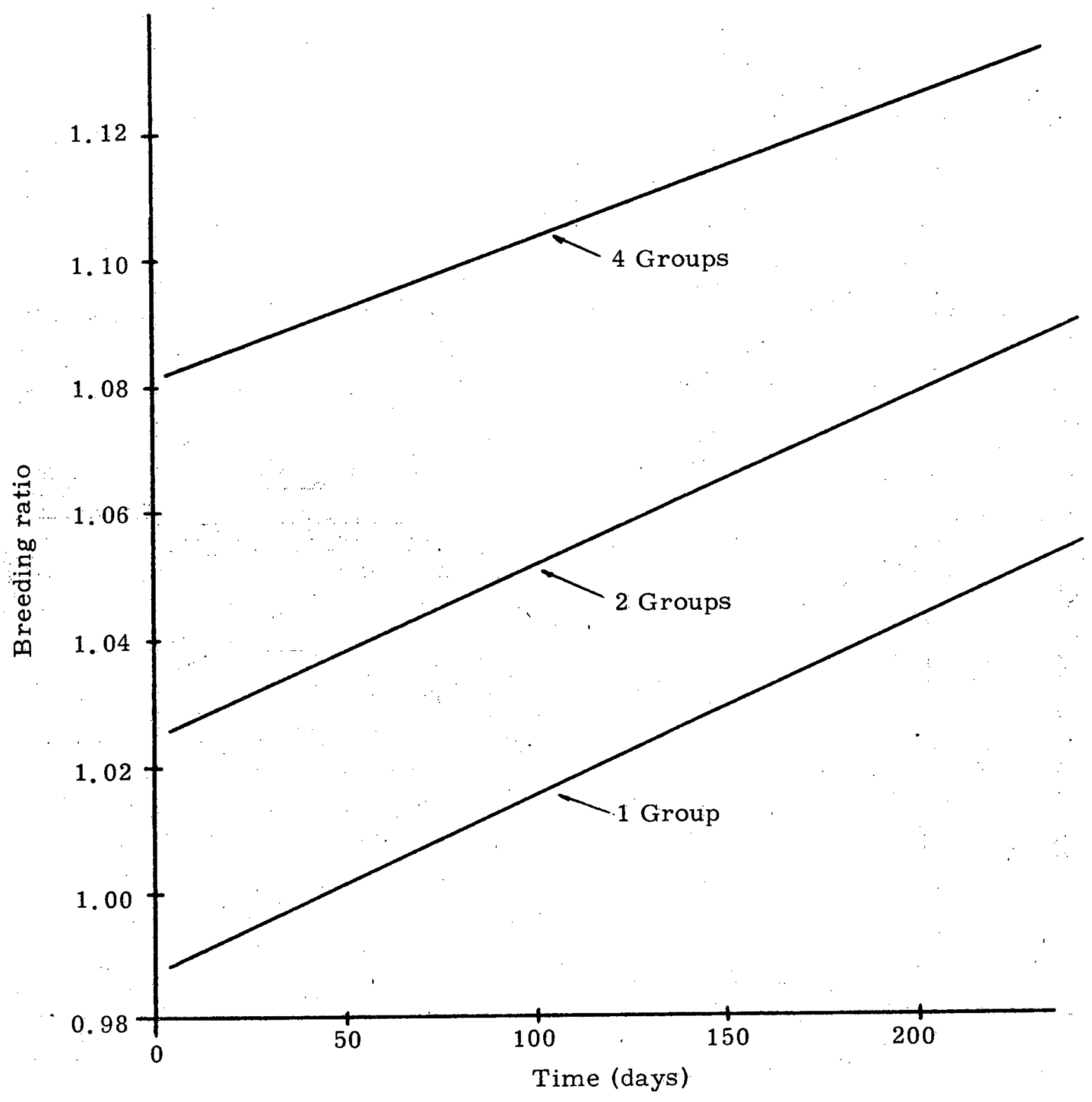

FIG. A. 7. One-, Two- and Four-Group Group Burnup Behavior, Breeding Ratio vs. Time 
The four-group calculation slightly underpredicted the breeding ratio for both reactor configurations, but the amount by which it was underpredicted for the parfait configuration was significantly greater than for the reference reactor. Therefore, if the 26-group predictions are considered "truth," the calculations performed in this study are conservative in their prediction of the breeding ratio advantage for the parfait core. A comparison performed by Brown (B6) between the four-group cross section set most extensively used in this study with other few group sets (four and 26 groups) demonstrated that this set tends to underpredict captures in uranium-238 which provides an explanation for the results described above. 


\section{Appendix B \\ OTHER PARFAIT BLANKET CONFIGURATIONS}

In this appendix, a number of other applications of the parfait blanket concept in fast breeder reactor design are briefly considered: gas-cooled fast reactors (GCFR), demonstration plant LMFBR's, a split-parfait blanket design and a carbide-fueled reactor.

\section{B. 1 GAS-COOLED PARFAIT CONFIGURATION}

A limited comparison was performed to evaluate the potential for the parfait concept as an alternative core and blanket configuration for gas-cooled fast breeder reactors. The gas-cooled reference and parfait designs of this study were simply approximated as the standard LMFBR configurations defined in Chapter 1, Table 1.5, with the exception that the sodium number density was set to zero. The fourgroup cross section set used in this analysis was the same as that described in Section 2.1; that is, the cross sections were not recollapsed over the spectrum of a gas-cooled configuration. The results of a comparison between the two-zone reference design and a $30-\mathrm{cm}$ internal blanket parfait configuration are presented in Table B. 1. The results of this table are similar to those of Table 2.3 (Chapter 2) in which the performance characteristics of the liquid-metal cooled designs are compared. The gas-cooled parfait concept exhibits the advantage of a reduced reactivity swing, an increased breeding ratio and a reduced peak flux when compared to the gas-cooled reference 
design. The parfait. configuration also displays the disadvantage of an increased core fissile inventory.

\section{TABLE B. 1}

Comparison of Gas-Cooled Reference and $30-\mathrm{cm}$ IB Parfait Configurations

\begin{tabular}{lc}
\hline \multicolumn{1}{c}{ Parameter } & $(\text { Parameter })_{\text {Parfait }} /$ (Parameter $_{\text {Reference }}$ \\
\hline $\begin{array}{c}\text { Core fissile inventory } \\
\text { Burnup reactivity loss, } \\
\Delta \mathrm{k} / \Delta \mathrm{t}\end{array}$ & 1.06 \\
Breeding ratio (BOC) & 0.74 \\
Peak power density & 1.025 \\
Peak flux & 0.97 \\
\hline
\end{tabular}

Although the peak total fluxes in the gas-cooled designs are comparable to those of the LMFBR's, the harder neutron spectrum in the gas-cooled concepts may enhance the advantages of the reduced peak flux in the parfait designs.

Comparison of the gas-cooled parfait and the liquid-metal cooled parfait also indicates that the flux dip in the internal blanket is less pronounced in the gas-cooled configuration. Whereas the total flux along the core centerline at the beginning of the equilibrium cycle dips about $17.5 \%$ from the peak flux in the liquid-metal cooled configuration, the total flux dips only $9.0 \%$ in the gas-cooled design. The power generation in the internal blanket is also about $20 \%$ greater at the beginning of the burnup cycle in the gas-cooled design. 
The most significant advantage for the parfait design as a gascooled concept may be in an area not covered in Table B. 1. In this comparison, the gas-cooled reference design had two fissile enrichment zones, whereas the most recent gas-cooled designs (demo plant) have included as many as four fissile enrichment zones to promote radial power flattening. With its characteristicly flatter radial flux profile (Chapter 2, Figs. 2.20 and 2.21), the parfait configuration may be able to reduce the number of enrichment zones, thus allowing the gas-cooled parfait concept to claim a fabrication advantage over the conventional gas-cooled designs. In addition, the current Gulf GCFR designs use vented fuel. This helps alleviate fuel burnup effects on fuel lifetime and therefore focuses more attention on fluence effects. Since the parfait configuration has a $28 \%$ lower total flux, a potentially longer fuel lifetime and higher fuel reliability is implied.

\section{B. 2. DEMONSTRATION PLANT LMFBR PARFAIT CONFIGURATION}

A comparison was made between demonstration plant LMFBR reference and parfait configurations. The basic core geometry of the reference demonstration plant was taken to be that of the ZPPR Assembly 2 critical experiment shown in Fig. A. 5. As with the comparison of the larger $2500-\mathrm{MW}_{\mathrm{t}}$ reactors of this report, the internal blanket of the demonstration plant parfait configuration was required to have the same radial extent as the inner enrichment zone, the external blankets of the two configurations were required to have the same dimensions and initial composition, and both the reference and 
parfait configurations were required to produce the same power, $1000 \mathrm{MW}_{\mathrm{t}}$. The core volume (including the internal blanket) inside the external blankets was 2,510 liters.

A comparison of the demonstration plant reference reactor and the parfait configuration as a function of internal blanket thickness yielded results similar to those displayed in Fig. 2.2 (Chapter 2). The comparison given in Table B. 2 is for a parfait configuration having a $30-\mathrm{cm}$-thick internal blanket. This table illustrates that the demonstration plant parfait concept exhibits the same advantages and disadvantages compared to the reference design that were identified in the comparison of the larger $1000-\mathrm{MW}_{\mathrm{e}}$ reactors.

TABLE B. 2

Comparison of Demonstration Plant LMFBR Reference and Parfait Configurations

\begin{tabular}{lc}
\hline \multicolumn{1}{c}{ Parameter } & $\left(\right.$ Parameter) ${ }_{\text {Parfait }} /\left(\right.$ Parameter $_{\text {Reference }}$ \\
\hline Core fissile inventory & 1.04 \\
Burnup reactivity loss, & 0.76 \\
$\Delta \mathrm{k} / \Delta \mathrm{t}$ & 1.023 \\
Breeding ratio (BOC) & 0.98 \\
Peak power density & 0.71 \\
Peak flux & \\
\hline
\end{tabular}

\section{B. 3. SPLIT-PARFAIT BLANKET CONFIGURATION}

The sodium void characteristics of the split-parfait blanket configuration shown in Fig. B. 1 were determined and compared to those of the conventional parfait configuration. This study was motivated in part by previous Westinghouse studies which examined multi-layer 

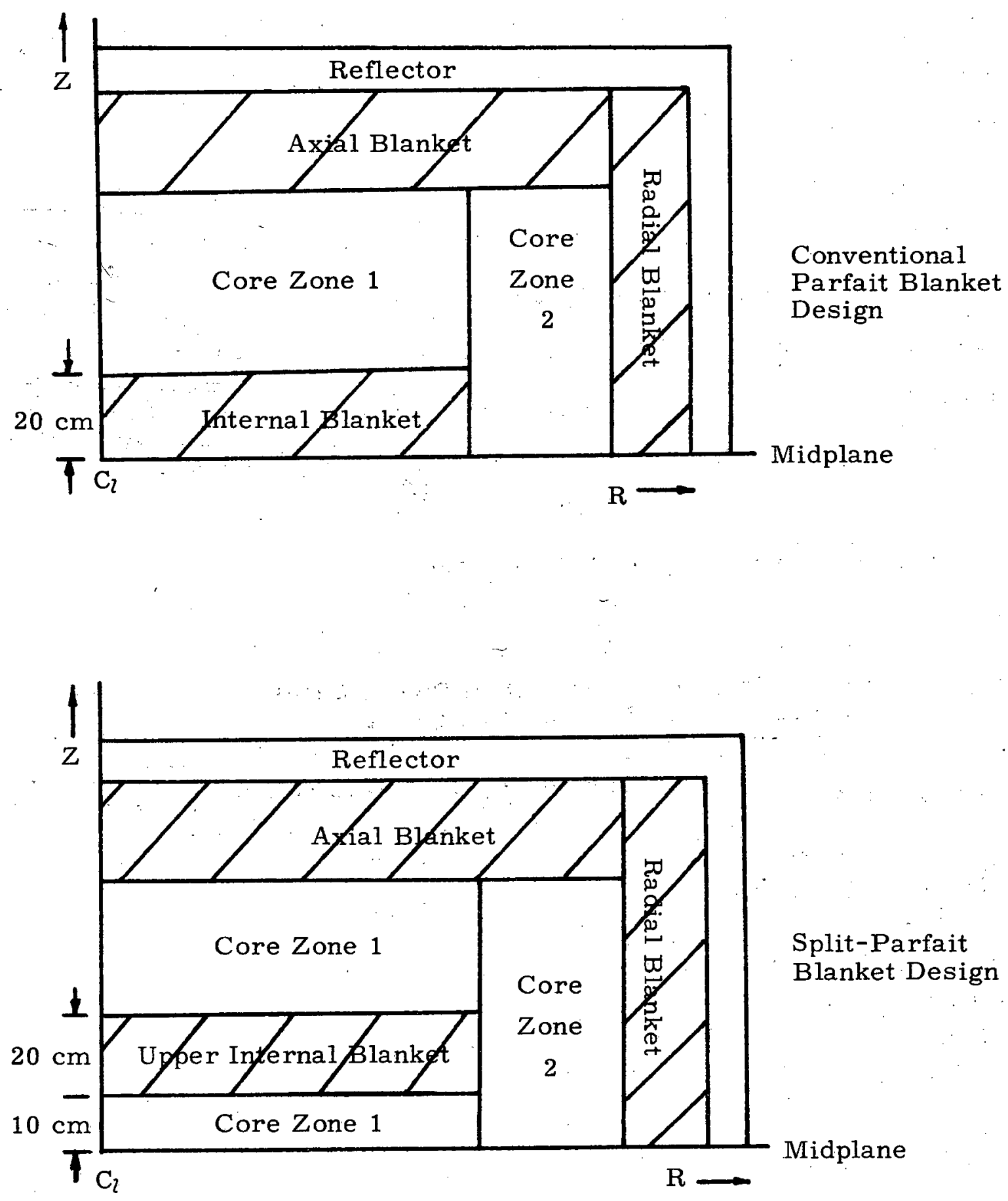

FIG. B. 1. Conventional.and Split-Parfait Configurations 
cores in an attempt to mitigate sodium void reactivity effects (H1). The split-parfait design contained two $20-\mathrm{cm}$-thick internal blanket regions separated by $20 \mathrm{~cm}$ of core material at the reactor midplane, and the conventional parfait design contained one $40-\mathrm{cm}$-thick internal blanket region. A comparison of the sodium void characteristics of these two designs and the reference reactor is given in Table B.3. This table reveals that the sodium void characteristics of the split-parfait configuration are more favorable than those of the reference reactor, but less favorable than those of the conventional parfait design. On the basis of sodium void characteristics, therefore, there appeared to be no incentive for further investigation of the more complicated split-parfait configuration.

TABLE B. 3

Comparison of the Sodium Void Characteristics of the Conventional Parfait and Split-Parfait Configurations

\begin{tabular}{cccc}
\hline $\begin{array}{c}\text { Voided Zones } \\
\text { (Chap. 4, Fig. 4.2) }\end{array}$ & $\begin{array}{c}\Delta \mathrm{k} \text {, upon sodium removal from zones indicated } \\
\text { Reference } \\
\text { (from Table 4.4) }\end{array}$ & $\begin{array}{c}\text { Conventional } \\
40-\mathrm{cm} \text { IB } \\
\text { Parfait }\end{array}$ & $\begin{array}{c}\text { Split } \\
\text { Parfait }\end{array}$ \\
\hline 1,2 & +0.01051 & +0.00634 & +0.00754 \\
$1-2$ & +0.01087 & +0.00611 & +0.00926 \\
$1-7$ & +0.00923 & +0.00534 & +0.00805 \\
$50 \%$ all zones & +0.00228 & +0.00032 & +0.00202 \\
\hline
\end{tabular}

\section{B.4. CARBIDE-FUELED PARFAIT CONFIGURATION}

The analysis contained in the main body of this report has been limited to oxide-fueled reactors. The AEC, however, has recently announced that a more active program for the development of advanced 
fast reactor fuel will be pursued (N3). One of the fuels which will be developed is carbide fuel, which has been considered for fast reactors because of its higher thermal conductivity and higher heavy-metal atom density compared to oxide fuel. Selected properties of these fuels are compared in Table B. 4 (E6, E7). The advantages of the carbide fuels have been long understood and a number of early design studies were based on the postulated availability of carbide fuel (A1). More recently, however, the emphasis has been on the more highly developed oxide fuel, which is currently accumulating valuable in-service experience in light water reactors.

TABLE B. 4

Comparison of Uranium Carbide and Uranium Oxide

\begin{tabular}{lcc}
\hline \multirow{2}{*}{ Property } & \multicolumn{2}{c}{ Fuel } \\
\cline { 2 - 3 } & Uranium Oxide, $\mathrm{UO}_{2}$ & Uranium Carbide, UC \\
\hline Density, $\mathrm{g} / \mathrm{cm}^{3}$ & 10.97 & 13.63 \\
Uranium content $\left(\mathrm{g} / \mathrm{cm}^{3}\right)$ & 9.67 & 12.97 \\
Melting point, ${ }^{\circ} \mathrm{C}$ & $2790 \pm 20$ & $2350 \pm 50$ \\
Thermal conductivity & 0.044 & $0.23-0.25$ \\
(at $\left.500^{\circ} \mathrm{C}\right)$, watt $\left./ \mathrm{cm}^{\circ} \mathrm{C}\right)$ & 1.0 & 6.0 \\
Power quotient & &
\end{tabular}

* Linear power rating relative to $\mathrm{UO}_{2}$ for a cylindrical fuel rod each operating with the centerline temperature at the melting point.

Because of the interest in advanced fuel cycles, the performance characteristics of a carbide-fueled parfait configuration were computed and compared to those of a carbide-fueled reference design. The overall characteristics of the reactors compared in this analysis were 
the same as those of the oxide cores (Chapter 1, Table 1.5), except that oxide fuel was replaced by carbide fuel. The same procedures used in the comparison of the oxide cores were employed in this evaluation. The blanket regions were loaded with fissile concentrations representative of equilibrium operation, the inner and outer core zone enrichments were adjusted to achieve radial power flattening, and the core zones of both configurations were loaded for a reactivity limited core lifetime of 300 full power days. The results of a comparison between the reference reactor and a parfait configuration having a $30-\mathrm{cm}$ internal blanket, both loaded with carbide fuel, are presented in Table B. 5. A comparison between these results and those given in Tables 2.2 and 2.3 (Chapter 2) for the oxidefueled reactors illustrates part of the incentive for developing carbide fuels. The substantially reduced burnup reactivity swing and the increased breeding ratio are two performance characteristics which make this advanced fuel concept particularly attractive.

A comparison between the carbide configurations illustrates that two of the attractive characteristics previously identified for the oxide-fueled parfait configuration have been lost. Although the burnup reactivity loss of the parfait configuration is $14 \%$ smaller than that of the reference reactor, both configurations exhibit such a small burnup reactivity loss (only about one seventh of that for the oxide cores) that this advantage is of little more than academic interest. In addition, the breeding ratio advantage of the parfait configuration has also been lost. In the oxide-fueled parfait configuration, the higher breeding ratio, resulting in a greater yield of bred fissile material, helped 
TABLE B. 5

Comparison of the Reference and Parfait Configurations Employing Carbide Fuel

\begin{tabular}{|c|c|c|c|}
\hline Quantity & Reference & $\begin{array}{l}30-\mathrm{cm} \mathrm{IB} \\
\text { Parfait }\end{array}$ & $\begin{array}{c}\text { Ratio } \\
\text { (Parfait/Reference) }\end{array}$ \\
\hline Core fissile inventory $(\mathrm{kg})$ & 2193.2 & 2309.8 & 1.053 \\
\hline Burnup reactivity loss, $\Delta \mathrm{k} / 300$ days & 0.007 & 0.006 & 0.86 \\
\hline Peak flux (BOC) $\left(\mathrm{n} / \mathrm{cm}^{2} \mathrm{sec}\right)$ & $0.856 \times 10^{16}$ & $0.579 \times 10^{16}$ & 0.677 \\
\hline Peak power density $(B O C)\left(M_{t} / \ell\right)$ & 0.619 & 0.578 & 0.90 \\
\hline Breeding ratio (BOC) & 1.446 & 1.440 & $\sim 1.0$ \\
\hline Peak flux $(\mathrm{EOC})\left(\mathrm{n} / \mathrm{cm}^{2} \mathrm{sec}\right)$ & $0.874 \times 10^{16}$ & $0.627 \times 10^{16}$ & 0.717 \\
\hline Peak power density (EOC) $\left(\mathrm{MW}_{\mathrm{t}} / \ell\right)$ & 0,620 & 0.534 & 0.86 \\
\hline Breeding ratio (EOC) & 1.366 & 1.363 & $\sim 1.0$ \\
\hline$\left(\frac{\text { Outer zone enrichment }}{\text { Inner zone enrichment }}\right)$ & 1.291 & 1.153 & 0.894 \\
\hline
\end{tabular}


offset the economic penalty of the greater core fissile inventory. In the carbide-fueled reactors, both the reference and parfait configurations have nearly equal breeding ratios.

The parfait configuration does, however, exhibit two characteristics which may help offset the economic penalty of a higher core fissile inventory. Table B. 5 illustrates that the peak power density in the parfait configuration is substantially below that of the reference reactor throughout the burnup cycle. If the parfait configuration were allowed to operate to the same peak power density as the reference reactor, this configuration would be capable of producing $10 \%$ more power. Or, alternatively, this peak power density margin could allow the fissile-loaded core volume (and therefore the fissile inventory) of the parfait configuration to be reduced, making the two configurations more competitive.

The other major advantage of the parfait configuration is the substantial reduction in the peak flux in the core. This means that the parfait configuration will exhibit reduced swelling and bowing effects, as discussed in Chapter 3 , and thereby possibly allow higher burnup in the fuel. This advantage may be particularly important in reactors operating with an advanced fuel, like carbide, because the higher thermal conductivity of the fuel may allow higher linear power ratings. The fuel in these reactors will therefore experience higher fluences and higher burnups per unit time.

In short, the parfait concept may offer some performance advantages in carbide-fueled reactor systems. Similar advantages 
would be expected for nitride fuel, another advanced fuel concept. The significance of these advantages may be better assessed as more experience with the advanced fuels is gained. 


\section{Appendix C}

\section{REFERENCES}

A1 Argonne National Laboratory, Evaluation Report - 1000-MW LMFBR Follow-On Studies, Volume I - Summary, Volume II - Plant Design Part I, (Draft) January 16, 1970.

A2 "Assuring the Quality of BWR Nuclear Fuel," General Electric Technical Information Release, acquired June 1973.

A3 Argonne National Laboratory, Reactor Physics Constants, ANL-5800, Second Edition, July 1963.

B1 Benedict, M., Course Notes for MIT Summer Course, Principles and Methods of Nuclear Fuel and Power Management, 22.98S, Summer 1972.

B2 Brewer, S.T., et al., "The Economics of Fuel Depletion in Fast Breeder Reactor Blankets," MITNE-123, COO-3060-4, November 1972 .

B3 Bondarenko, I.I., ed., Group Constants for Nuclear Reactor Calculations, Consultants Bureau, New York, 1964.

B4 Burnham, J.B. and Merker, L.G., "Comparative Costs of Oxide Fuel Elements, Volume I," BNWL-273 Volume 1, Battelle Northwest Laboratory, July 1966.

B5 Burnham, J.B., et al., "Comparative Costs of Oxide Fuel Elements, Appendix," BNWL-273 APP, Battelle Northwest Laboratory, July 1966.

B6 Brown, G.J., et al., "Evaluation of High Performance LMFBR Blanket Configurations," MITNE-150, COO-2250-4, forthcoming.

B7 Brown, G.J., "A Study of High-Albedo Reflectors for LMFBR's,"... Nucl. E./S.M. Thesis, Nuclear Engineering Department; MIT, March 1972.

B8 Boltax, A., et al., "Mixed-Oxide Fuel Pin Performance Analysis Using the OLYMPUS Computer Code," Conference on Fast Reactor Fuel Element Technology, ANS Proceedings, 1971.

B9 Brunell, R.D., "Heating and Heating 2," AI-64-Memo-177, Atomics International. 
C1 Carajilescov, P. and Todreas, N.E., "Expansion of the Method of Correlated Temperatures to Clad and Fuel Design Analyses," Technical Article, Draft, MIT, 1973.

C2 Craig, C.N., et al., "Steady State Performance of $\mathrm{PuO}_{2}-\mathrm{UO}_{2}$ Fast Reactor Fúels," Conference on Fast Reactor Fuel Element Technology, ANS Proceedings, 1971.

D1 Davey, W. G. and Redman, W.C., Techniques in Fast Reactor Critical Experiments, AEC Monograph, Gordon and Breach Science Publishers, New York, 1970.

D2 Driscoll, M.J., "The Physics of Fast Reactors," Notes for MIT Special Summer Session Course 22.94S, MIT, 1969.

E1 Edison Electric Institute, "Fast Breeder Reactor Report," April 1968.

E2 Epel, L. G., et al., (eds.), The Ordered-Bed Fast Reactor

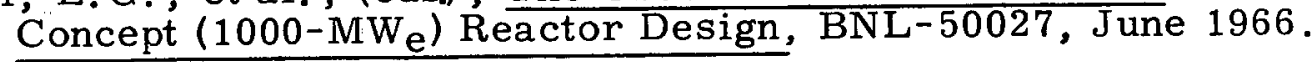

E3 Ebizuka, Y., Mizuta, H., "Consideration on the Design of the Fast Power Reactor with a Central Blanket," Bulletin of the Tokyo Institute of Technology, Ser. B, 54, 1963.

E4 Engle, W.W., Jr., "A User's Manual for ANISN, a OneDimensional Discrete Ordinates Transport Code with Anisotropic Scattering," K-1693, March 1967.

E5 Engel, F.C. , et al., "Design Analysis of the LMFBR Blanket," WARD-3045T2B-9, March 1973.

E6 Etherington, H., ed., Nuclear Engineering Handbook, McGrawHill Book Company, Inc., 1958.

E7 El-Wakil, M. M. , Nuclear Power Engineering, McGraw-Hill Book Company, Inc., 1962 .

F1 Fuller, E.L., "Reactivity Effects of Core Slumping in Fast Reactors: A Case Study," FRA-TM-35, Argonne National Laboratory, June 5, 1972.

F2 Forster, R.A., et al., " ${ }^{252}$ Cf Assay System for FBR Fuel Pins: Description and Óperating Procedures Manual," LA-5071-M, October 1972.

G1 Greebler, P., Hutchins, B.A., "Significance of Integral Parameters in the Design and Performance of Fast Breeder Reactors," National Topical Meeting on New Developments in Reactor Physics and Shielding, CONF-720901, Kiamesha Lake, New York, 1972. 
G2 Goldsmith, M.W. "Evaluation of a Gas-Cooled Fast Breeder Reactor for Ship Propulsion," Nucl. E. Thesis, MIT Nuclear Engineering Department, August 1972.

G3 General Electric Company, "Sodium-Cooled Reactors Core Engineering Program, Forty-Fifth Quarterly Report," GEAP-10028-45, March 1973.

H1 Heck, F.M., et al. "Liquid Metal Fast Breeder Reactor Design Study, "WCAP-3251-1, Westinghouse Electric Corporation, January 1964.

H2 Hinkelmann, B., "Evaluation of Neutron Nuclear Data for Several Actinides in the Energy Range from Thermal to $10 \mathrm{MeV}$," IAEA, Nuclear Data for Reactors, Helsinki, June, 1970.

H3 Hoover, J., and Menley, D.A., "Alternative Neutron Energy Group Collapsing Schemes Applied to Fuel Cycle Calculations," Applied Physics Division Annual Report July 1, 1969June 30, 1970, ANL-7710, January 1971.

H4 Hardie, R.W. and Little, W.W., Jr., 3DB, A Three-Dimensional Diffusion Theory Burnup Code, BNWL-1264, March 1970.

H5 Hardie, R.W. and Little, W.W., Jr., PERT-V, A TwoDimensional Perturbation Code for Fast Reactor Analysis, BNWL-1162, September 1969.

H6 Hardie, R.W. and Little, W.W., Jr., 1DX, A One-Dimensional Diffusion Code for Generating Effective Nuclear Cross Sections, BNWL-954, March 1969.

H7 Huebotter, P.R., et al., Design, Research and Development Implications of Metal Swelling in Fast Reactors, ANL-7786, Argonne National Laboratory, April 1971.

J 1 Joest, K.H., "Studies on the SNR Control Rod System," The Physics of Fast Reactor Operation and Design, British Nuclear Energy Society, London, 1969.

K1 Kaiser, R.E., et al., "Experimental Evaluation of the Critical Mass for ZPPR Assembly 2," ZPR-TM-47, Argonne National Laboratory, January 20, 1971.

K2 Kidman, R.B., et al., "The Shielding Factor Method of Generating Multigroup Cross Section Sets for Fast Reactor Analysis," Nucl. Sci. Eng. , 48, 1972.

L5 Little, W.W., Jr. and Hardie, R.W., 2DB User's Manual Revision 1, BNWL-831 Rev. 1, August 1969. 
L6 Lamarsh, J.R. , Introduction to Nuclear Reactor Theory, Addison-Wesley Publishing Company, Inc., New York, 1966.

L7 Leggett, R.D., et al., "Linear Heat Rating for Incipient Fuel Melting in $\mathrm{UO}_{2}-\mathrm{PuO}_{2}$ Fuel," Trans. Am. Nucl. Soc., 15, 2, November 1972 .

M1 McVey, W.H., personal communication, December 14, 1973.

N1. Nelson, J.V., "Cross Section Set for Preliminary Design of FTR, FTR Set No. 200," HEDL-TME-71-65, 1971.

N2 Nuclear News, "Fuel," Vol. 16, No. 1, p. 49, January 1973.

N3 NucleonicsWeek, news item, p. 2, AIF/ANS San Francisco Special, November 15, 1973 .

P1 Pluta, P.R., et a1., "Safety and Reliability. Considerations in Core Design," MITNE IAP Fast. Reactor Design Seminar Notes, January 22, 1973.

P2 Pluta, P.R., personal communication, January 22, 1973.

S1 Sofer, G. A., et al., "Selected Optimization Studies in the Use of Carbide Fuel in Large Fast Breeder Reactors," Proceedings of the Conference on Safety, Fuels and Core Design in Large Fast Power Reactors, AN.L-7120, 1965.

W1 Wood, P.J. and Driscoll, M.J., "Assessment of Thorium Blankets for Fast Breeder Reactors," COO-2250-2, MITNE-148, July 1.973 . 